\title{
Regulation of and by pharmacists in the Netherlands and Belgium: an economic approach
}

Citation for published version (APA):

Philipsen, N. J. (2003). Regulation of and by pharmacists in the Netherlands and Belgium: an economic approach. [Doctoral Thesis, Maastricht University]. Universiteit Maastricht. https://doi.org/10.26481/dis.20031211np

Document status and date:

Published: 01/01/2003

DOI:

10.26481/dis.20031211np

Document Version:

Publisher's PDF, also known as Version of record

\section{Please check the document version of this publication:}

- A submitted manuscript is the version of the article upon submission and before peer-review. There can be important differences between the submitted version and the official published version of record.

People interested in the research are advised to contact the author for the final version of the publication, or visit the DOI to the publisher's website.

- The final author version and the galley proof are versions of the publication after peer review.

- The final published version features the final layout of the paper including the volume, issue and page numbers.

Link to publication

\footnotetext{
General rights rights.

- You may freely distribute the URL identifying the publication in the public portal. please follow below link for the End User Agreement:

www.umlib.nl/taverne-license

Take down policy

If you believe that this document breaches copyright please contact us at:

repository@maastrichtuniversity.nl

providing details and we will investigate your claim.
}

Copyright and moral rights for the publications made accessible in the public portal are retained by the authors and/or other copyright owners and it is a condition of accessing publications that users recognise and abide by the legal requirements associated with these

- Users may download and print one copy of any publication from the public portal for the purpose of private study or research.

- You may not further distribute the material or use it for any profit-making activity or commercial gain

If the publication is distributed under the terms of Article $25 \mathrm{fa}$ of the Dutch Copyright Act, indicated by the "Taverne" license above, 


\section{Regulation of and by Pharmacists in the Netherlands and Belgium}

An Economic Approach 



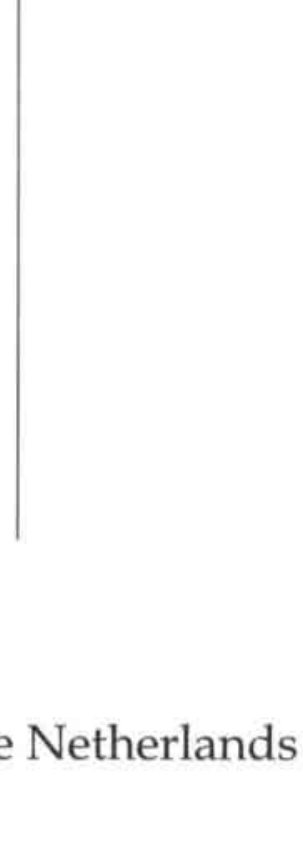

\author{
An Economic Approach \\ PROEFSCHRIFT \\ Ter verkrijging van de graad van doctor \\ aan de Universiteit Maastricht \\ op gezag van de Rector Magnificus, \\ Prof.dr. A.C. Nieuwenhuijzen Kruseman \\ volgens het besluit van het College van Decanen, \\ in het openbaar te verdedigen \\ op donderdag 11 december 2003 om 12:00 uur
}

door

Niels Philipsen 


\section{Promotores:}

Prof.dr. M.G. Faure

Prof.dr. J.A.H. Maks

\section{Beoordelingscommissie:}

Prof.mr. F.C.B. van Wijmen (voorzitter)

Prof.dr. E.E.C. van Damme (Universiteit van Tilburg)

Prof.dr. A.I. Ogus (University of Manchester/Universiteit Maastricht) 


\section{ACKNOWLEDGEMENTS}

At first sight, writing a thesis seems to be a fairly lonely process. In fact, I remember very well that at my appointment, now five and half years ago, my supervisor Michael Faure especially warned me for that. And partly he was right. However, experience has taught me that writing a thesis also involves making many new contacts: via academic conferences home and abroad, via meetings and workshops, via correspondence and conversations with people 'in the field' and of course also within the new working environment. There are many persons who I would like to thank for their general support, for their interest in my research or for their comments on previous drafts of my thesis. Although I cannot mention everyone who in some role contributed to the writing of this book, there are a few persons I would like to mention.

First and foremost I am grateful to my supervisors Michael Faure and Hans Maks. Cooperation with the both of them has always been a pleasure. I thank Michael for having encouraged me (especially in the early years) to take part in the conferences organised by the European Association of Law and Economics (EALE) and the American Law and Economics Association. Thanks to the EALE conferences I have established research contacts all over Europe. I am also grateful to Michael for the many discussions we had about my thesis. Whether these discussions took place during lunch, in a bar, abroad or in the METRO building, they were always very useful. I thank Hans for the (academic) support he has given me, already since I was a student at the faculty of economics. Hans always watched carefully that I, working at an institute for legal research, would not forget my background as an economist. Therefore I not only feel attached to METRO, but also to Eurecom. Without Michael and Hans this book would not look as it does today.

Furthermore I would like to thank the members of the reading committee, for useful comments on an earlier version of the manuscript. Frans van Wijmen, Eric van Damme and Anthony Ogus had already commented on previous papers, for which I am still very grateful. Also Roger van den Bergh, Herman Nys and Harry Struij- 
ker-Boudier offered valuable comments on drafts of this thesis. I am also indebted to Mr. F. Moss of the KNMP, who provided me with valuable practical information.

Moreover, I would like to mention my colleagues at METRO. During the five years of my research METRO has turned out to be a really pleasant environment. I am grateful to all of my (ex-) colleagues for having created this working environment, that is, for the many interesting discussions we had, and for the many activitities outside work, ranging from dinners, movies and concerts to playing squash. In particular I would like to mention David Grimeaud, Ida Wendt and my paranimf and current room mate Marianne Gijzen. I am also indebted to Marjo Mullers for making the book camera-ready and to Lisa Waddington and Catharine Sevenster for commenting upon my English writing skills.

Beyond academic life, I wish to thank my parents for their constant and generous support, without which it would never have been possible to even begin with this thesis. I also wish to express my thanks to my brother Rens and to my grandparents for their concern. Finally I have to mention my friends: my paranimf Nicolai, my fellow musicians in Thuss (for me there is no life without music), the Veldwezelt club and the Lowlanders. Thanks to all of them those five and a half years seemed almost like five and a half months.

Maastricht, October 2003

Niels Philipsen

My work was supported by NWO grant 510010502 . 


\section{TABLE OF CONTENTS}

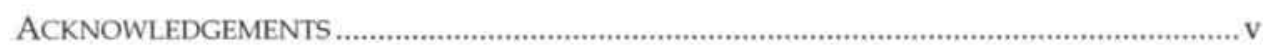

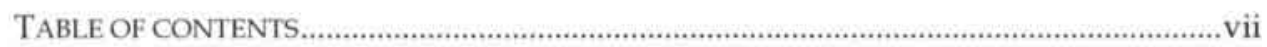

LIST OF ABBREVIATIONS ...............................................................................................ii

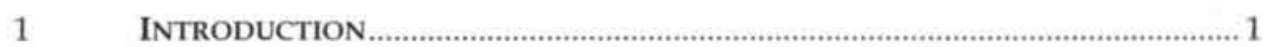

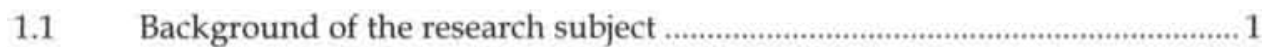

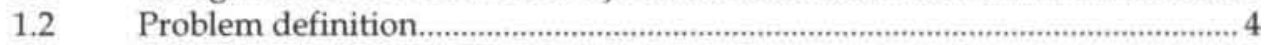

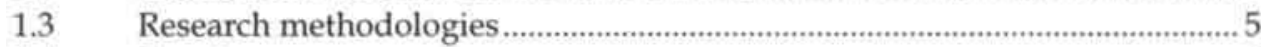

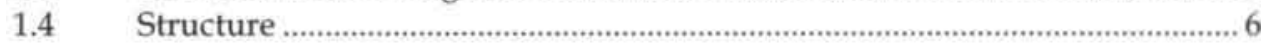

2 AN ECONOMIC ANALYSIS OF THE REGULATION OF PROFESSIONS .......................9

2.1 An introduction to the problems of (self-)regulation in the professions .......9

2.2 Regulation as a correction for market failure: the public interest

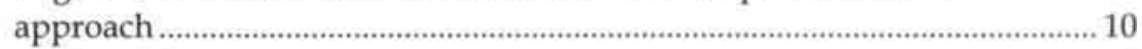

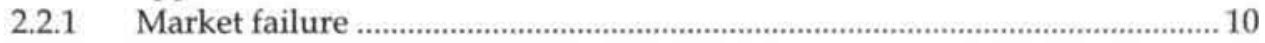

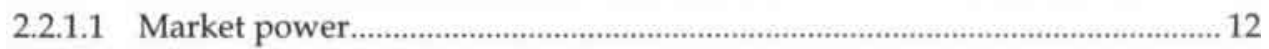

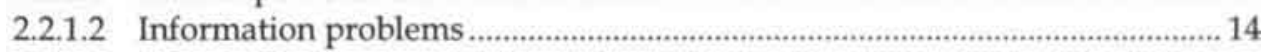

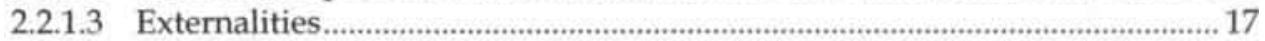

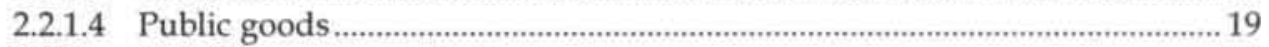

2.2.2 Liability versus regulation .........................................................................20

2.2.2.1 Shavell's criteria for liability and regulation ................................................2 20

2.2.2.2 Liability versus regulation in the professions ...............................................22

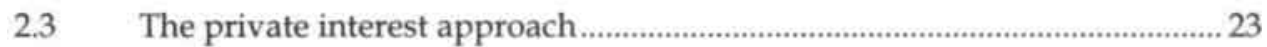




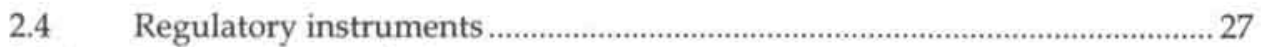

2.4.1 Information regulation ............................................................................2

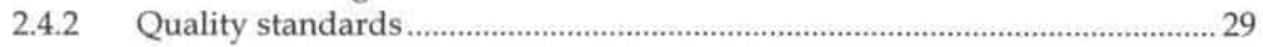

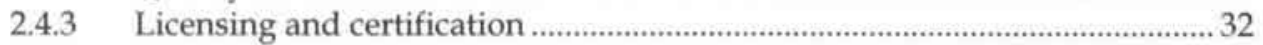

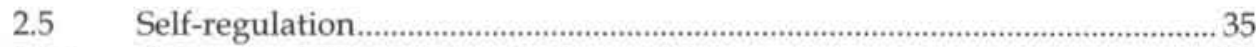

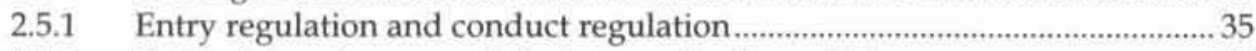

2.5.2 Public interest arguments in favour of self-regulation.....................................37

2.5.3 Private interest arguments against self-regulation ..........................................38

2.5.4 Self-regulation: a summary of the literature....................................................39

2.6 An evaluation of the economic theory ....................................................... 42

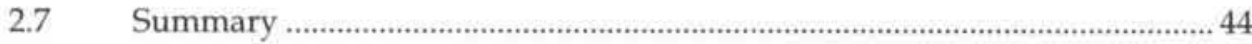

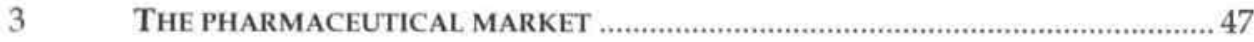

3.1 Production, distribution and consumption of drugs.....................................4

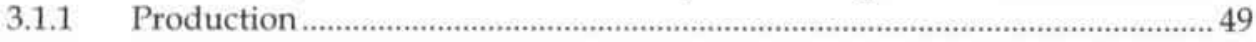

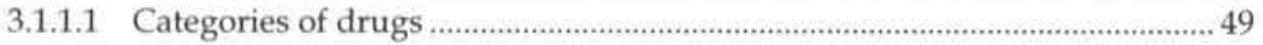

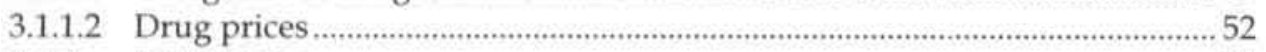

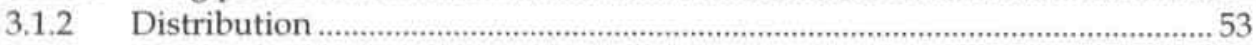

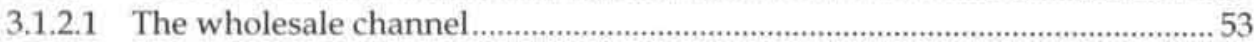

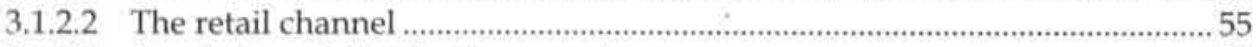

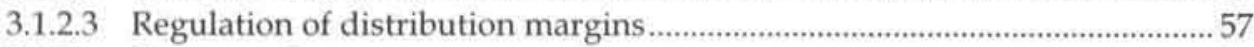

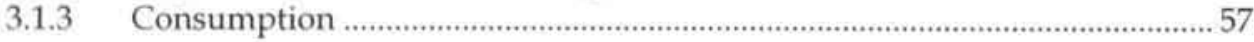

3.2 The profession of pharmacist in the Netherlands and Belgium.....................59

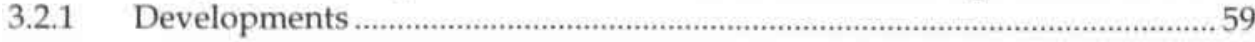

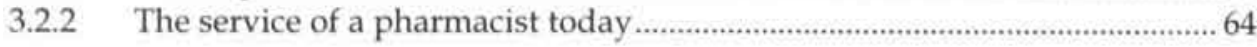

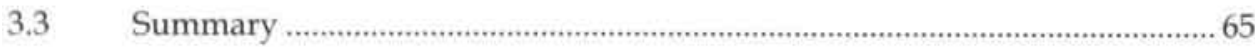

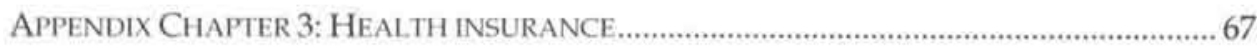

A.3.1 Health insurance for pharmaceuticals in the Netherlands: an overview ....67

A.3.2 Financing and benefits under the Dutch health care system..........................69

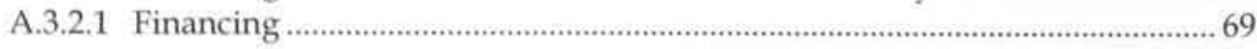

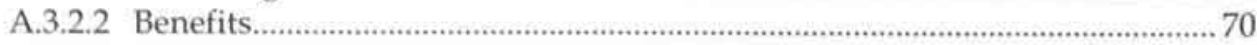

A.3.2.3 Drug Reimbursement System (GVS) ……….............................................70

A.3.3 Health insurance for pharmaceuticals in Belgium: an overview ...................71

A.3.4 Financing and benefits under the Belgian health care system .......................72

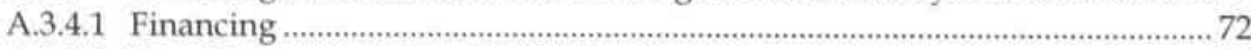

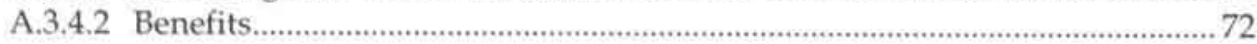




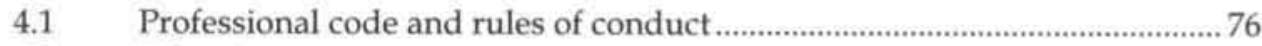

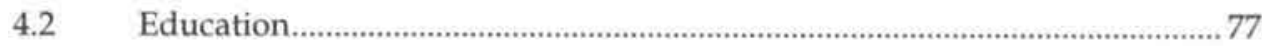

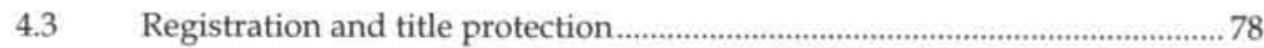

4.3.1 The professional monopoly of a pharmacist ..................................................78

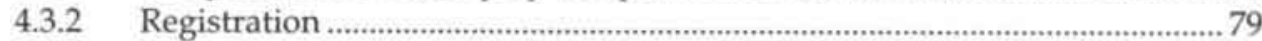

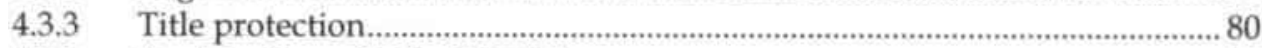

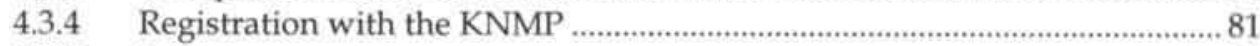

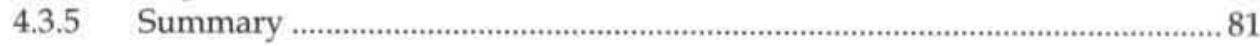

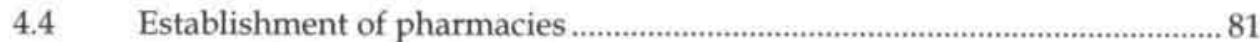

4.4.1 The establishment policy of the KNMP ........................................................... 81

4.4.2 Contracts between pharmacists and health insurers ….................................. 83

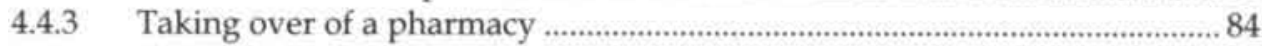

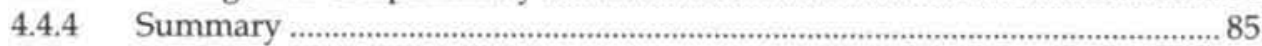

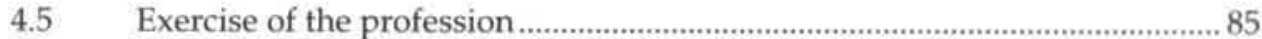

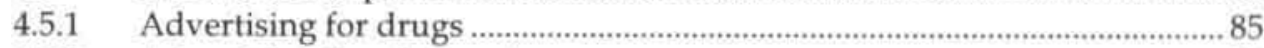

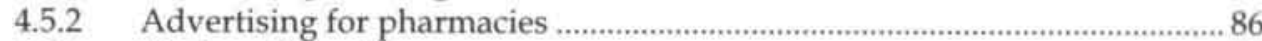

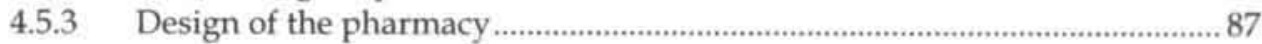

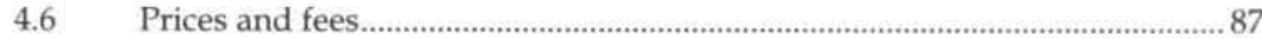

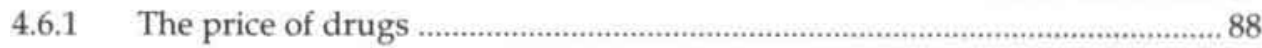

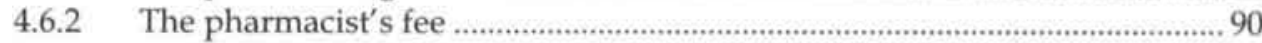

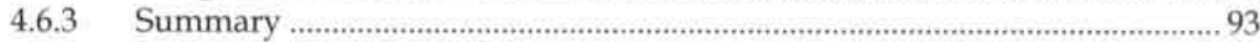

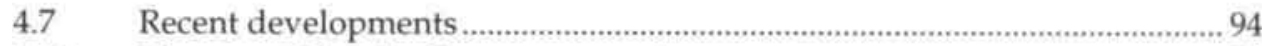

4.7.1 Measures taken by the government ..........................................................94

4.7.2 The impact of the Competition Act on the pharmaceutical market .............95

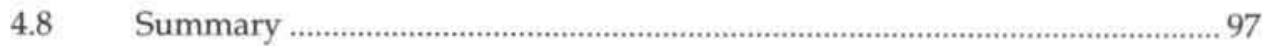

5 THE REGULATION OF PHARMACISTS IN BELGIUM ……....................................99

5.1 Professional code and rules of conduct .........................................................99

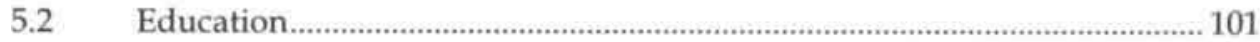

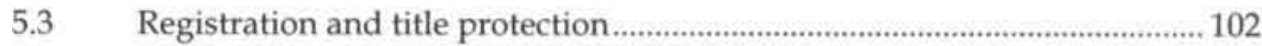

5.3.1 The professional monopoly of the pharmacist ...............................................102

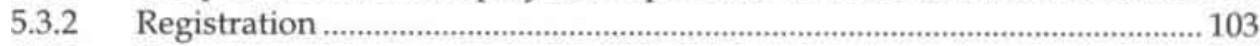

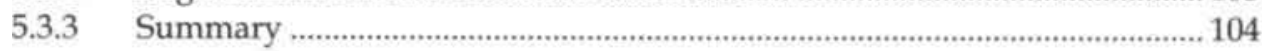


5.4 Establishment of pharmacies ....................................................................... 104

5.4.1 Supervision over the establishment of pharmacies ........................................104

5.4.2 Supervision over the takeover price of pharmacies........................................105

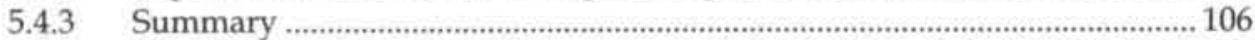

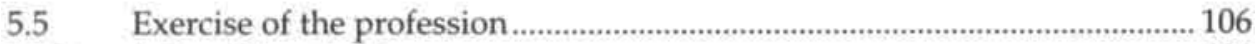

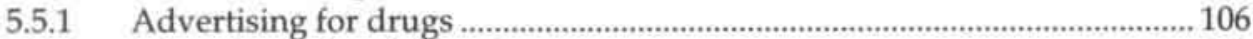

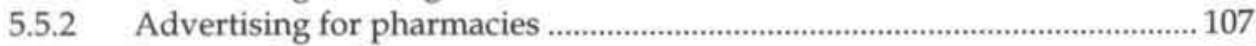

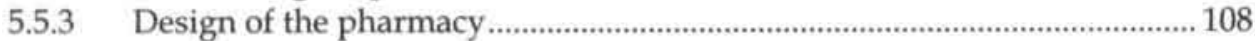

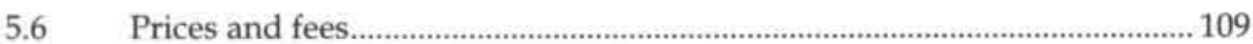

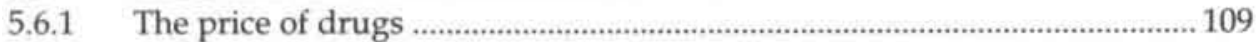

5.6.2 Reimbursement for the pharmacist...............................................................111

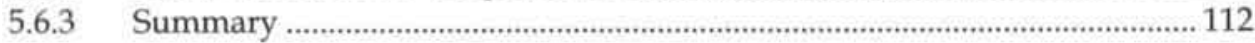

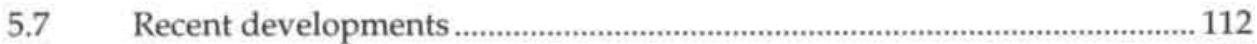

5.8 Summary ….................................................................................................... 113

6 AN ECONOMIC ANALYSIS OF THE REGULATION IN THE NETHERLANDS

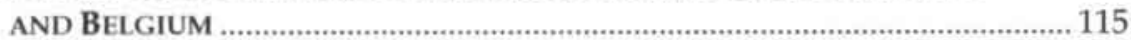

6.1 Differences and similarities in regulation ..................................................115

6.2 A public interest analysis of the regulation on the pharmaceutical market

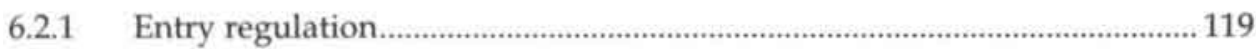

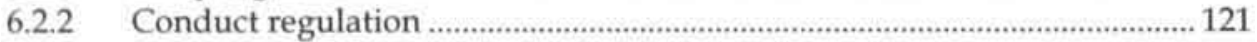

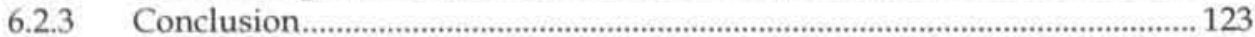

6.3 A private interest analysis of the regulation on the pharmaceutical

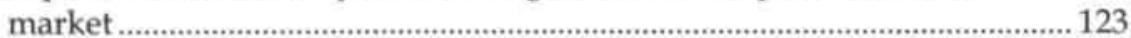

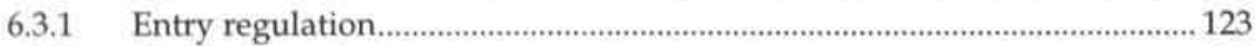

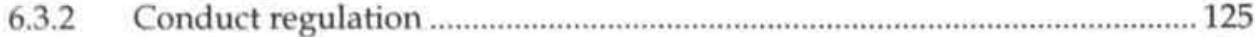

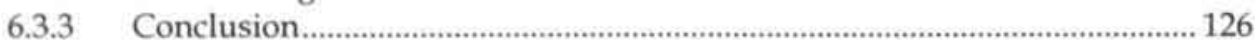

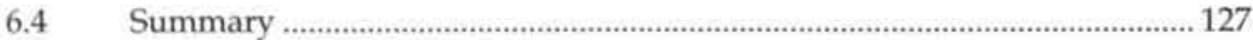

$7 \quad$ AN EMPIRICAL AND COMPARATIVE ANALYSIS .............................................129

7.1 How to measure rent seeking on the pharmaceutical market.....................130

$7.2 \quad$ The number of pharmacists ...................................................................... 131

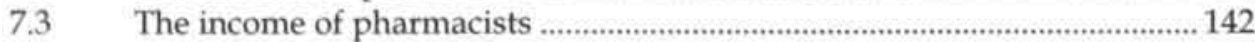

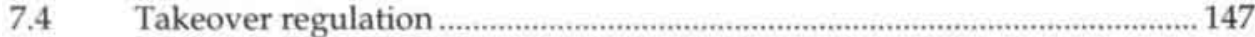

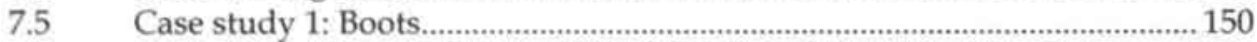

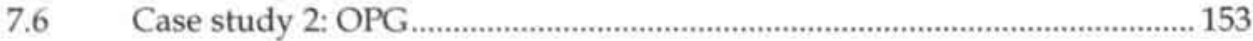




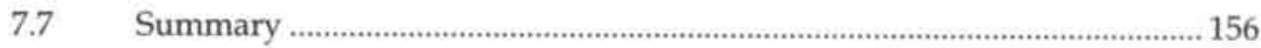

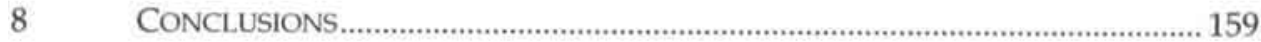

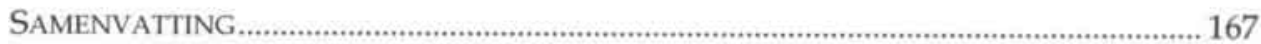

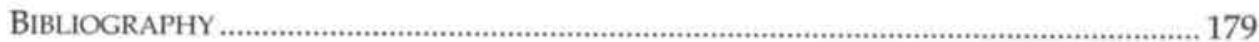

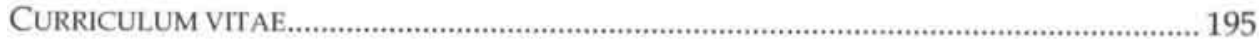





\section{LIST OF ABBREVIATIONS}

\begin{tabular}{|c|c|}
\hline \multirow[t]{3}{*}{ APB } & Algemene Pharmaceutische Bond \\
\hline & Association Pharmaceutique Belge (APB) \\
\hline & Belgian Pharmacists Association \\
\hline \multirow[t]{3}{*}{ AVGI } & Algemene Vereniging van de Geneesmiddelenindustrie \\
\hline & Association Générale de l'Industrie du Médicament (AGIM) \\
\hline & Belgian Pharmaceutical Industry Association \\
\hline \multirow[t]{2}{*}{ BEF } & Belgische frank \\
\hline & Belgian francs \\
\hline B.S. & Belgisch Staatsblad \\
\hline \multirow[t]{2}{*}{ BIG } & Beroepen in de Individuele Gezondheidszorg \\
\hline & Individual Health Care Professions \\
\hline \multirow[t]{3}{*}{ BIGE } & Belgisch Instituut voor Gezondheidseconomie \\
\hline & L'Institut Belge de L'Economie de la Santé (IBES) \\
\hline & Belgian Institute of Health Economics \\
\hline \multirow[t]{2}{*}{ CTG } & College Tarieven Gezondheidszorg \\
\hline & Health Charges Board \\
\hline \multirow[t]{2}{*}{$\mathrm{CVZ}$} & College voor zorgverzekeringen \\
\hline & Health Insurance Board \\
\hline \multirow[t]{2}{*}{$\mathrm{FT}(\mathrm{T}) \mathrm{O}$} & farmacotherapeutisch (transmuraal) overleg \\
\hline & pharmacotherapeutic (transmural) consultations \\
\hline \multirow[t]{2}{*}{ GVS } & Geneesmiddelenvergoedingssysteem \\
\hline & Drug Reimbursement System \\
\hline \multirow[t]{2}{*}{ HIA } & Ziekenfondswet (ZFW) \\
\hline & Health Insurance Act \\
\hline \multirow[t]{3}{*}{ KNMP } & Koninklijke Nederlandse Maatschappij ter bevordering der \\
\hline & Pharmacie \\
\hline & Royal Dutch Association for the advancement of Pharmacy \\
\hline \multirow[t]{2}{*}{ MDW } & Marktwerking, Deregulering en Wetgevingskwaliteit \\
\hline & Functioning of Markets, Deregulation and Legislative Quality \\
\hline
\end{tabular}




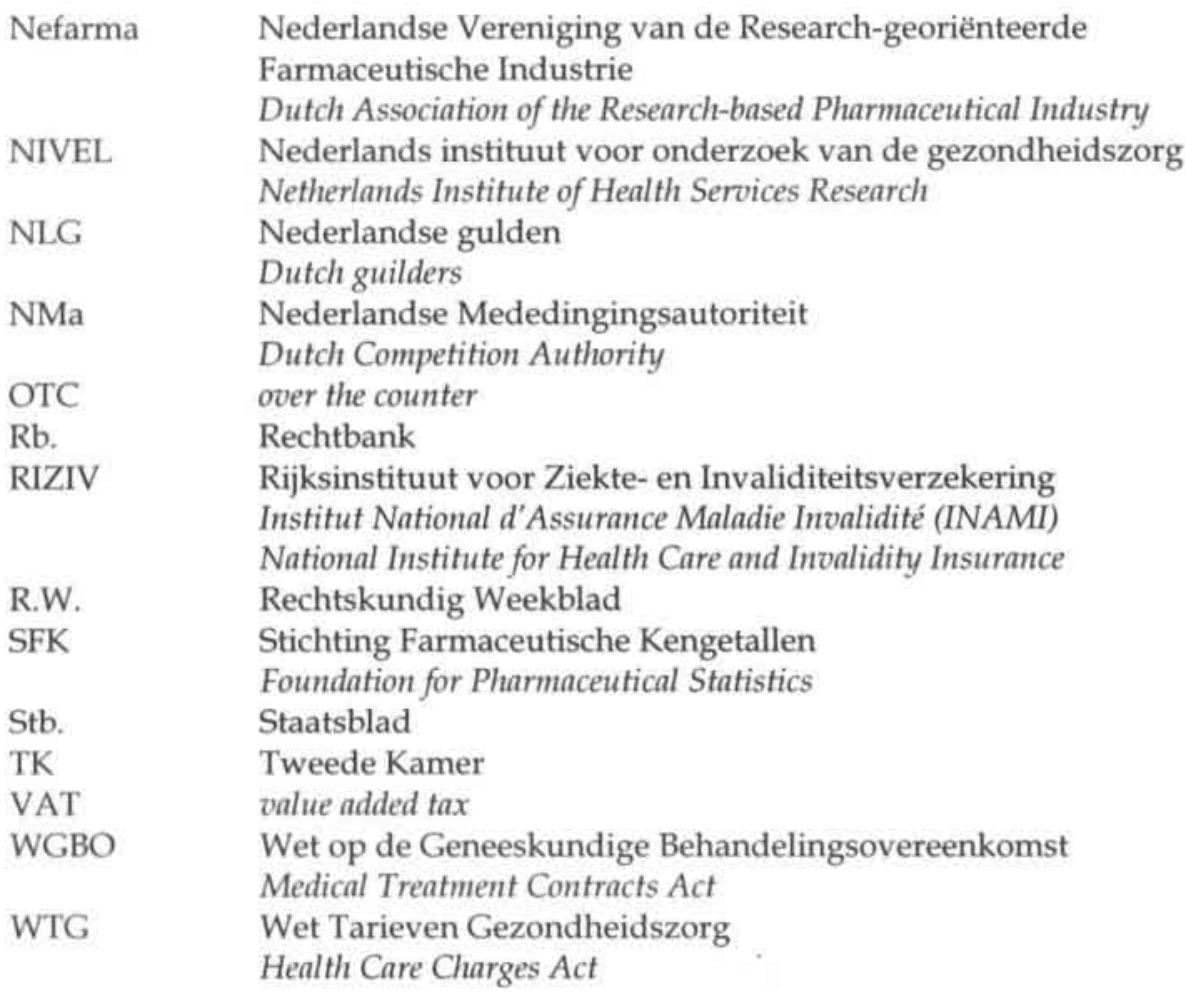



will to some extent apply to other professions and other countries as well. I will come back to this in more detail below.

As far as the entry into a profession is concerned, one can generally note two types of entry barriers. Entry may be regulated either directly, e.g. through the fixing of a numerus clausus (that is, if only a pre-determined number of practitioners is permitted per territory) or indirectly, e.g. through obligatory apprenticeships with particularly heavy duties and a lack of appropriate remuneration. In addition, often the regulator awards a professional monopoly, such as the monopoly to plead for attorneys or the duty to contact an architect when a building is constructed. The professions may achieve a limitation of external competition by a large definition of this professional monopoly. Furthermore, self-regulation may also contain restrictions on competition within a profession. Examples are a prohibition on advertising and a prohibition of partnerships and cooperation with other professions. Such 'rules of conduct' aim at protecting professional integrity and dignity, but often at the expense of consumers. Also, competition within a profession may be restricted by the direct regulation of fees, either by the government or by self-regulating bodies.

In recent years the (public and self-) regulation of professions has received more and more attention from politics, i.e. regulators and competition authorities, and as a result also from judges and the media. In addition to the European Commission, which asked the Institute for Advanced Studies in Vienna (IHS) to do an extensive investigation into the regulation of several professions in the EU Member States, reports on the regulation of professions have been published by, e.g. the Office of Fair Trading in England (on accountants, architects, lawyers and pharmacists), and by the economic consultancy bureaus Indecon and London Economics with respect to several professions in Ireland (for the Irish Competition Authority). ${ }^{2}$ In the Netherlands the professions have received special attention from the government within the framework of the so-called 'MDW' projects: since the mid-1990s inquiries have been made into, among others, accountants, lawyers, brokers, and health care professions (dentistry and physiotherapy). ${ }^{3}$ The Dutch Competition Authority NMa has played an important part as well in recent years, and it still does, as I will show later on in this thesis. The basic question in all these reports and competition cases is always if, and how, more competition can be introduced into the markets of the professions. about these reports: infra, $\$ 2.5 .1$. (Marktwerking, Deregulering en Wetgevingskwaliteit). These projects are usually carried out jointly by the Ministry of Economic Affairs and the Ministry of Law. Website: <http://www.minez.nl>. 
One of the professions that is characterised by a high level of self-regulation is the pharmaceutical profession. There seems to be a clear informational asymmetry, ${ }^{4}$ since most consumers of pharmaceutical products and other services provided by a pharmacist cannot be assumed to have adequate information on the quality of the services provided. Some form of regulation may then be used to guarantee a minimum quality. However, other parties in the pharmaceutical market (such as the government, health insurers, physicians, organisations of patients, etc.) may already have some information on the quality of pharmaceutical products and services. It needs to be examined whether there are indeed information problems in this market. ${ }^{5}$ In addition, the extent to which the pharmaceutical market is regulated needs to be examined more carefully: is all this regulation necessary in order to solve the information problems, or are the negative effects on social welfare larger than the positive effects? In the pharmaceutical sector self-regulation co-exists with governmental regulation. It is essential to both analyse the instruments of governmental regulation and the rules enacted by the profession itself.

In this thesis I will examine the regulation of pharmacists in two countries: the Netherlands and Belgium. Some of the results of this 'case study' have previously been published - in an amended version - in papers in acadamic journals. ${ }^{6}$ The reason I have chosen these countries for the analysis is that, although it concerns two neighbouring countries, the regulation and the number of pharmacists are very different. Hence, it is particularly interesting to compare these two regimes and to examine whether the difference in the market structure of pharmacies in the two countries is related to the varying scope of the regulation. Moreover, it is interesting to focus on these two - rather different - legal regimes since similar approaches towards the regulation of pharmacies can be found in other European legal systems as well. Hence, I expect that the findings have some relevance also outside the DutchBelgian context.

It should be made clear from the outset that the analysis in this thesis is necessarily limited to certain aspects of the regulation of pharmacists. I will deal in particular with those regulations that limit the entry into the pharmaceutical profession and those that restrict the competition between pharmacists. To this end, however, the main tasks of a pharmacist today and his/her place in the pharmaceutical market need to be defined. In connection with that also the way in which those tasks are regulated needs to be analysed. I strive to keep the analysis of the regulatory framework as concise and to-the-point as is necessary for the economic analysis, of course without omitting any important aspects. It should be stressed that, this being a thesis in law and economics, my intention is that it should be comprehensible both for economists and lawyers who are interested in the field of law and economics, as well as for profession members and politicians interested in the topic of regulation

The concept 'information asymmetry' will be discussed in chapter 2

Or other problems, such as externalities. Infra, $\$ 2.2$.

6 Maks, Philipsen and Faure (2001); Philipsen and Faure (2002a); Philipsen and Faure (2002b). 
of professions. In some places I will have to refer to other sources for details regarding the economic or legal background, although I tried to keep this to a minimum.

\subsection{Problem definition}

In the light of the diverse arguments pro and contra (self-)regulation, the question arises whether the positive effects of regulation on social welfare - following, for example, from quality improvements and information provision - or its negative effects - following from restrictions on competition - dominate. The problem statement in this thesis is therefore as follows: do there exist forms of (self-)regulation in the pharmaceutical profession that increase social welfare in the economy, or is this regulation merely a result of rent-seeking behaviour? In order to answer this main question four other questions will have to be answered first.

The first of these questions concerns an economic analysis of (self-)regulation: what does economic theory teach us about (self-)regulation in the professions? The arguments of the so-called public interest approach and the private interest approach to regulation will be examined in this respect. While the former approach looks at regulation as a correction for market failure and assumes that governments and other public agencies are able to ameliorate identified market failures at low cost, the latter approach stresses the role of interest groups in the formation of regulation and points to the danger of government failure as a result of lobbying by interest groups.

The second question is: what national regulations and self-regulatory measures issued by professional bodies exist in the Netherlands and in Belgium with respect to the pharmaceutical profession? Naturally, it is impossible to examine the effects of self-regulation on social welfare without having analysed first the current state of this regulation. Moreover, since there is a lot of government intervention in the pharmaceutical market, obviously an analysis of self-regulation only will not be sufficient: one needs to consider both self-regulation and public regulation.

Next, the regulations that restrict competition in the pharmaceutical market will have to be examined more closely, following the line of reasoning of the economic theory presented earlier. Hence the third question: does the (self-)regulation of the pharmaceutical profession promote social welfare, or should it (to a lesser or greater extent) be considered as a tool in the hands of private interest groups? The outcome of this qualitative analysis might be that (a part of the) self-regulation is merely used to seek rents from a limitation of competition, instead of it being used to ensure an optimal quality or the continuity of pharmaceutical services.

Finally, it is necessary to carry out a quantitative analysis of the rent-seeking behaviour by pharmacists if one wants to draw any firm conclusions. Empirical data with respect to, inter alia, the number of pharmacies and the incomes of pharmacists need to be acquired, both for the Netherlands and for Belgium. The fourth question is therefore as follows: is there any empirical evidence of rent-seeking behaviour by phar- 
macists? This part of the analysis is a practical complement to the theoretical analysis based on the economic literature presented earlier.

On the basis of these four questions an answer to the central problem statement will be formulated. From a policy point of view it will be suggested which parts of the current regulatory system are economically efficient and which parts decrease rather than improve social welfare in the economy.

\subsection{Research methodologies}

The research methodologies used in this research are on the one hand an economic analysis of (self-)regulation with an application to the specific case of the pharmaceutical market, and on the other hand a comparative law and economics approach to the self-regulation of pharmacists in the Netherlands and in Belgium.

The first part of the book focuses upon the economic literature in the field of regulation, in particular with respect to the liberal professions. The arguments for (self-) regulation that follow from the public interest approach (and which are based on welfare economics and the concept of market failure), and against it, as identified via the private interest approach (based upon the capture theory, public choice theory and the economic theory of regulation), are investigated there. Furthermore, I will, from an economic point of view, consider some regulatory instruments and compare regulation to liability rules.

The second part of the book consists of a presentation and examination of the pharmaceutical market, more specifically the regulation of and by pharmacists. After a brief introduction to the pharmaceutical market in general, a positive-legal analysis of the regulation of the pharmaceutical market in the Netherlands and in Belgium is carried out. Next, these legal rules will be analysed from a qualitativeeconomic point of view in order to estimate the effects of the intense regulation on the amount of rents. The differences between the two legal systems will be explained, as far as the intensity of regulation of the pharmacists is concerned, using $a$ comparative law and economics approach. The rent-seeking hypothesis will be applied to the pharmaceutical profession and the particular legal tools in the Netherlands and Belgium will be reviewed in the light of the economic literature. In addition, I will present a quantitative (empirical) analysis of the rent-seeking behaviour by Dutch and Belgian pharmacists, by means of a presentation and analysis of acquired empirical data. The word 'acquired' should be stressed here: obtaining exact data on some of the indicators, e.g. the incomes of pharmacists and take-over prices of pharmacy buildings, was impossible. Some data were either unavailable or were not released for the purpose of academic research because of non-disclosure policies. Other data were not available as a time-series, which excludes the use of statistic methods such as regression equations. The latter was also the case when sources contradicted each other, which occurred as well. Therefore, the empirical analysis consists in some places necessarily of circumstantial evidence based on own compu- 
tations and in other places of comparative and time-series analyses. Two case studies are included as well, which, next to providing some (tentative) evidence of rentseeking behaviour, give some insights into the developments that are taking place in the pharmaceutical market in the Netherlands.

\subsection{Structure}

The structure of the book follows directly from the research questions defined above. In chapter 2 an economic analysis of the regulation of the liberal professions will be presented. The main argument of the public interest approach to regulation appears to be that professional services are experience goods in markets characterised by asymmetric information and adverse selection; and regulation may be needed in order to improve on this situation. Self-regulation may in some cases be the most effective kind of regulation, instead of e.g. information remedies and quality standards enforced by the government, or liability rules. The private interest approach to regulation, however, claims that the behaviour of self-regulating professions can often be characterised as rent-seeking. Professional bodies are considered to be interest groups pursuing private goals instead of public goals. The private interest approach to regulation predicts that interest groups are most successful in appropriating rents if they are small, single-issue oriented and well organised. At least two of these three criteria often apply to professional bodies.

Chapter 3 provides an overview of several important aspects of the market for drugs. The production, distribution and consumption of drugs will be discussed briefly, as well as the evolution of the pharmacists' profession. Chapter 4 and chapter 5 deal with the regulation of pharmacists in the Netherlands and in Belgium respectively. Together, the chapters 2-5 constitute the framework for the economic analysis in the following chapters.

This framework will be reviewed in the light of the economic literature in chapter 6 . The particular regulations will be evaluated according to the public and the private interest approach to regulation. Then a 'theoretical' answer to the problem statement can be given, based on the insights of economic theory. The strengths and weaknesses of the Dutch and the Belgian regulatory systems regarding pharmacists will hereby come to the fore.

In addition to this qualitative analysis, chapter 7 provides for an empirical, i.e. quantitative, research of self-regulation in the pharmaceutical profession. This empirical analysis is supplemented by two case studies with respect to the Dutch pharmaceutical market, dealing with the chemist's chain Boots and the wholesale chain OPG respectively. A conclusion can then be formulated, finally, in chapter 8 . There I will provide an answer to the central problem statement defined above based on my findings. Also an assessment will be made as to which particular legal or professional rules are effective in enhancing social welfare, and which are not. 
Chapter 1

This thesis describes the situation as of 1 July 2003. Developments after that date could only be taken into account to a limited extent. 



\section{AN ECONOMIC ANALYSIS OF THE REGULATION OF PROFESSIONS}

\subsection{An introduction to the problems of (self-)regulation in the professions}

Many liberal professions such as lawyers, architects, physicians and pharmacists are subject to self-regulation by public professional bodies. These professional bodies are often drawn exclusively or predominantly from members of the profession itself. Thus, while public regulatory bodies are usually independent of the interests they regulate or at least should be, this independence is totally absent in the professions. This makes it interesting and useful to investigate the effects of this selfregulation on social welfare. On the one hand, self-regulation may restrict entry into the profession and limit competition within the profession, while on the other hand it may improve the quality of professional services. In this chapter an economic analysis of self-regulation is presented. The first question defined in the introduction will therefore be answered: what does economic theory teach us about selfregulation in the professions? Of course, this question cannot be answered without a thorough analysis of the problems concerning the public regulation of professions.

There exist different instruments that could be used to regulate the economic activities of professionals, such as mandatory information disclosure, regulation of advertising, quality standards, licensing, and certification. These regulatory instruments can be used by self-regulatory agencies as well as by public (or: government) bodies. Moreover, in practice one often sees a mixture of public and private regulations. In order to analyse self-regulation it will therefore have to be compared to public regulation. Naturally, the question whether government intervention of any kind is necessary at all will have to be answered first. In addition the question should be addressed whether the regulatory measure chosen is an appropriate remedy for the problem that it is supposed to solve.

The economic analysis in this chapter is based on two different approaches towards regulation. The public interest approach will be discussed first (\$2.2). Some arguments for regulation will thereby come to the fore. These arguments have in com- 
mon that they consider regulation as a correction for market failure. Section 3 presents the private interest approach to regulation. This approach, which stresses the role of interest groups in the formation of regulation, presents arguments against (self-)regulation. After this rather general discussion of the economic theory with respect to the coming about of regulation, I will analyse some regulatory instruments (\$2.4). More specifically, the relative benefits and costs of information regulation, quality standards and prior approval (licensing and certification) will be presented. The topic of section 5 is self-regulation by professional bodies. There I will present an overview of the pros and cons of self-regulation as suggested by the public and private interest approach respectively, as well as a survey of some articles on self-regulation from the economic literature. In the section after that the economic theories will be evaluated (\$ 2.6). The resulting framework will be used for the subsequent research in later chapters. Section 7 closes the chapter with a short summary.

\subsection{Regulation as a correction for market failure: the public interest approach}

The approach of the 'public interest' gives a number of grounds for regulation. Of course, what exactly constitutes the public interest is not a constant, but will vary according to time, place and the specific values held by a particular society. ${ }^{7}$ For the purposes of this research, I will only look at public interest in the sense of social welfare as defined in the economic science, especially in welfare economics. The grounds for regulation presented in this section have in common that they are derived from the perceived shortcomings of the market system itself to deal with certain problems leading to less social welfare. I leave out other possible justifications for regulation, such as those resulting from distributive purposes or paternalistic arguments.

\subsubsection{Market failure}

Welfare economics teaches us that, if we have a general equilibrium in an economy with perfect competition on all markets, the resulting allocation will be Paretoefficient. A Pareto-efficient situation is a situation wherein it is impossible to enlarge someone's utility (or: welfare) without making someone else worse off. ${ }^{8}$ This situation requires a number of conditions:

7 Ogus(1994, p. 29).

8 The Pareto criterion is very strict in the sense that even potential changes that would increase the utility of many people and that would only slightly decrease the utility of one person, would not be approved by it. According to the so-called Kaldor-Hicks criterion, a welfare improvement requires that the gainers from a change are (theoretically) able to compensate the losers. In other words: the gainers have to gain more than the losers lose. See e.g. Ogus (1994, 
(1) on every market there should be many small and identical producers, who cannot significantly influence the price level and who sell homogeneous products in their respective markets; ${ }^{9}$

(2) there should be perfect information in that economy, meaning that all market participants are informed about all (equilibrium) prices and characteristics of goods;

(3) there are no externalities; and

(4) the products are private goods.

In practice these conditions will never be completely satisfied. In other words: there is - some degree of - market failure (or: there are market distortions). ${ }^{10}$ The regulation as a remedy for market failure aims to lead to an increase in social welfare. This does not mean that the regulation of a market should attempt to realise perfect competition. ${ }^{11}$ Were the government to have at its disposal all information on all markets and their distortions, it could compute and pursue a so-called 'second best' Pareto-optimum. Such omniscience does not exist in practice. ${ }^{12}$ However, the regulation of a market can be focussed on the partial realisation of welfare improvements. ${ }^{13}$ In order to be able to show the effects of regulation on the level of social welfare in a partial market, one has to analyse the changes in consumer surplus, producer surplus, and the deadweight welfare loss that result from this regulation. ${ }^{14}$

pp. 24-25), Cooter and Ulen (2000, pp. 43-44) and Van Velthoven and Van Wijck (2001, pp. 24 $25 ; 29-30)$.

9 In addition, there must be a large number of consumers, who cannot significantly influence the price level. However, I do not deal with this condition here, nor with the related market failure called monopsony that occurs when this condition is not fulfilled, i.e. when there is market power on the demand side of the market. For an introduction to monopsony, see e.g. Carlton and Perloff (2000, pp. 105-107).

10 For a more elaborate discussion on Pareto-optimality and market failure see e.g. Varian (1984, pp. 190-209; 253-262), Scherer and Ross (1990, pp. 66-95), Mamuth (1992, pp. 119-128; 181 190), Tirole (1992, pp. 6-7; 106-114), Cooter and Ulen (2000, pp. 12; 40-44) and Van Velthoven and Van Wijck (2001, pp. 51-63).

11 Lipsey and Lancaster (1957) prove the existence of this so-called second best problem.

12 Despite that it is, according to $\mathrm{Ng}$ (1983, pp. 231-233), still the best strategy for a government to pursue first best optimum conditions in case of information poverty on a market, if it wants to maximise welfare. However, if the government does have some information on the average divergences between price and marginal costs in an economy (information scarcity) it should according to $\mathrm{Ng}$ not pursue first best conditions, but the so-called 'third best' rules, whereby the ratio price/marginal cost on a certain market is made equal to the average ratio in the economy, See $\mathrm{Ng}$ (1983, pp, 233-242). For a more formal treatment see Green (1961), Boadway and Harris (1977), Hatta (1977) and Ng (1977).

13 Here one has to make sure that the regulatory intervention does not go too far. To partially intervene in a certain market will after all affect other markets in the economy as well.

14 Economists disagree on the question whether only the consumer surplus should be taken as a decisive criterion for regulation, or the total surplus. Aiginger et al (1998, p. 804) present the results of a survey of industrial economists, in which (among other questions) this question was put to 114 experts. $63 \%$ of the interviewees thought that the total surplus should be re- 
If one of the above mentioned four conditions for perfect competition is not met there is, hence, a form of market failure. In the law and economics literature one finds a discussion of regulation as a remedy for these forms of market failure, directed towards an improvement in social welfare. The assumption is made that the government and other public agencies predominantly act in the public interest (or at least try to do so). As stated above, this approach to regulation is generally known as the public interest approach, to make the contrast with the private interest approach explicit. ${ }^{15} \mathrm{It}$ is important to remember that the public interest approach only tells us when there is a prima facie case for regulation: that is, market failure always has to be compared with (possible) regulatory failure. Regulation may fail if the efficiency gains to which it does give rise are outweighed by increased transaction costs or misallocations in other sections of the economy. ${ }^{16}$

Obviously, the four forms of market failure to be discussed in this section are the following: market power, imperfect information, externalities and perfect goods.

\subsubsection{Market power}

In economic theory many market structures have been analysed that do not satisfy the first condition mentioned above: that of many small and identical producers who cannot significantly influence the price level and who sell homogeneous products. ${ }^{17}$ At the other end of perfect competition there is pure monopoly. Compared to firms under perfect competition, who sell their products at the level where price equals marginal costs (which in turn are equal to the minimum average costs), a monopolist will sell its (smaller) output at a higher price level: where its marginal costs of producing equal its marginal benefits. ${ }^{18}$ While the firms in a setting of per-

garded, $26 \%$ was of the opinion that only the consumer surplus should be the final yardstick and $11 \%$ was indifferent.

Posner (1974, pp. 336-341). See also Van den Bergh (1993, pp. 33-42), Ogus (1994, pp. 29-75), De Bijl and Van Damme (1996, pp. 10-21) and Den Hertog (2000, pp 25-231). Hägg (1997, p. 356) points out that to some extent the distinction between the public and the private interest approach has lost validity due to the entry of game theory and institutional research during the last decades of the 20th century. He concludes that 'the public interest approach and the special interest approach are better viewed to mirror two distinct historical phases in the economic research, emphasising the corrective and the redistributive impact of public regulation respectively'. Hantke-Domas (2003) argues that a public interest theory as such does not exist because it does not have any known origin. He states that Posner's characterisation of the public interest theory has indeed similarities with the welfare rationale for regulation, but that 'further research is needed to prove or deny a connection between both the concepts of public interest and the welfare economics rationale for regulation' (p. 190).

Ogus (1994, p. 30). Lazzarini and Carvalho de Mello (2001) analyse regulatory failure for the specific case of derivative markets, where they make a distinction between regulatory failure in governmental regulation and in self-regulation.

Supra, note 9 .

18. For an introduction to the efficiency consequences of monopoly in the law and economics literature, see Posner (1998, Ch. 9), Van den Bergh (1997, Ch. 2), Cooter and Ulen (2000, pp. 
fect competition are price takers, a monopolist is a profit maximiser. As a result, a monopolist always operates in a Pareto inefficient manner. ${ }^{19}$ Other market structures that have been analysed in economic theory include oligopoly, duopoly and monopolistic competition. ${ }^{20}$ On such markets there is a risk of cartel formation or abuse of a dominant market position by undertakings ${ }^{21}$ Regulation in the form of competition law may be used to offer a solution for this. The markets of the liberal professions are characterised by product heterogeneity and all kinds of cooperations. In the practice of Belgian and Dutch competition policy since the late 1990s it has already been shown that professionals are subject to the supervision of the competition authorities.22

It is important to keep in mind that the public interest argument here is not that regulation has to be used to create as much competition as possible, but only that it may be in the public interest to regulate cartels and abuse of dominance. Indeed, there are also cases where it will be better to have only one or a few producers in the market rather than many small firms. Such cases, which result from economies of scale and economies of scope in production, are called natural monopolies or natural oligopolies. Theoretically, a natural monopoly exists when there is sub-additivity of costs, meaning that the costs of producing certain goods together are smaller than the costs of producing these goods separately. ${ }^{23}$ Formally this means that the following must hold for $n$ goods:

$$
C\left(q_{1}, q_{2}, \ldots, q_{n}\right)<C_{1}\left(q_{1}\right)+C_{2}\left(q_{2}\right)+\ldots+C_{n}\left(q_{n}\right)
$$

In practice it is often difficult to determine whether there is really sub-additivity of costs. Therefore usually a monopoly is already called 'natural' when its average and marginal cost functions are both decreasing. ${ }^{24}$ However, even in these situations

26-33), Van den Bergh and Camesasca (2002, pp. 78-88) and Van Velthoven and Van Wijck (2001, pp. 250-261). An elaborate microeconomic analysis can be found in many standard textbooks; see e.g. Mamuth (1992, Ch. 7), Tirole (1992, pp. 66-75) and Carlton and Perloff (2000, pp. 87-105).

19 Varian (1984, pp. 79-85).

20 See e.g. Mamuth (1992, Chs, 7-8) and Varian (1984, Ch. 2).

21 Carlton and Perloff (2000, Chs. 4-5) analyse both the behaviour of an undertaking with a dominant market position and the conditions under which a cartel could arise. See also Viscusi et al (2000, Chs. 5-9) for a discussion on oligopoly, collusion and monopoly power.

See for the Netherlands e.g. the decisions of the Dutch Competition Authority NMa in cases concerning veterinary surgeons (Decision $n$ r. 397/1998), notaries ( $n$ r. 952/1999), general practitioners (nr. 537/2001) and pharmacists (nr. 912/2001). For a general article on the Belgian situation, see De Juristenkrant, Vrije beroepen en concurrentierecht: de strijd gaat verder, 16, 2000. An overview of the approach of the EC in applying competition law to the professions, including a brief overview of the most important cases in this area, is provided in Andrews (2002). That article also deals with the US approach. Bos (1995, p. 23). See also Ogus (1994, pp. 30-31) and Viscusi et al (2000, Ch. 11). 
regulation may be needed to control the behaviour of the natural monopolist: every unregulated monopolist may after all be inclined to abuse its dominant position. The regulation of natural monopolies is a very difficult but important topic. The central question in the economic literature that discusses this topic ${ }^{25}$ - as well as in the enforcement of the competition rules by national competition authorities and the European Commission ${ }^{26}$ - is whether or not a certain facility or infrastructure is a so-called essential facility (like telecom networks: one needs access to the network to be able to provide the telecom service) and if so, how access to the essential facility should be regulated. Moreover, for a public authority it often appears to be difficult to regulate (i.e. supervise) the tariffs to use the natural monopoly, because a government normally does not have at its disposal the very specific information on e.g. costs needed to effectively regulate an undertaking that owns an essential facility. ${ }^{27}$

\subsubsection{Information problems}

A second possible reason for regulation according to the public interest approach to regulation is the existence of information problems on a market. This argument is of particular importance for the topic of this thesis, being the regulation of the professional services offered by a pharmacist. Here the public interest argument for regulation starts from the perspective that professional services are experience goods of which the quality cannot be immediately recognised by the consumer. The term experience goods has been introduced by Nelson to indicate the difference with search goods. ${ }^{28}$ In the case of search goods, consumers already know where they can obtain each of the options available to them, but they have to evaluate the utility of each option first on price and quality. According to Nelson this evaluation is subject to two restrictions: 1) the consumer must inspect the option; and 2) that inspection must occur prior to purchasing the brand. However, this search process will not work properly when the quality of a product can only be determined after having consumed or used it. If the properties of a product can only be determined after consumption the product is called an experience good. Professional services will often fit into this category, although some services, such as medical care and financial advice, would probably be more correctly classified under a third category: the

For a quite recent contribution to the essential facility concept see Temple Lang (2000) and for an overview of cost-based regulation methods see Knieps (2001, pp. 79-114). Viscusi et al (2000, Ch. 12) devote a whole chapter to the regulation of natural monopolies; they especially pay attention to the regulation of electric power in the United States.

Goyder (1998, pp. 346-350) and Van den Bergh and Camesasca (2002, pp. 272-277) provide a summary of the most important EC cases with respect to the access of essential facilities.

Of course this subsection just introduces the lack of competition problem and its social welfare consequences. For in depth analyses I refer to the advanced textbooks in industrial economics, such as Carlton and Perloff (2000) and Tirole (1992).

Nelson (1970, p. 312). 
so-called trust goods (or: credence goods). ${ }^{29}$ These are goods or services of which the properties can only be assessed with the help of highly technical standards and for which there is no learning through the repeat-purchase-mechanism. If consumers are not able to reliably judge the quality of a service before and after the transaction, then the only factor left to save on information costs becomes trust in the professional providing the service. ${ }^{30}$

Because professional services are often experience goods (or trust goods), this leads to information asymmetry on the market. After all, consumers do not have at their disposal all information with respect to the quality of the services rendered by professionals, while professionals themselves do have this information. Akerlof (1970) showed in his famous example of the market for used cars that, in an unregulated market, asymmetric information will lead to a deterioration of quality of the offered products. ${ }^{31}$ The process of quality deterioration is a result of adverse selection. In Akerlof's example there is asymmetric information because sellers of used cars know the properties of every car they are selling, but potential buyers do not. The potential buyers only know the average quality of cars in the market. Therefore, they cannot tell whether a particular car is a good buy or a bad buy (lemon). If the market is unregulated, this information asymmetry will not be eliminated. The market will attract sellers of low quality cars who will depress average quality, lower prices and drive good quality cars out of the market. This process is cumulative and may therefore eventually destroy the whole market. This argument can be explained in formal terms: if $\theta_{1}$ is the valuation by consumers of a lemon, $\theta_{2}$ is the valuation by consumers of a high quality car and $\pi$ is the chance of getting a lemon, the expected value of a second-hand car is:

$$
\theta_{\mathrm{E}}=\pi \cdot \theta_{1}+(1-\pi) \cdot \theta_{2}
$$

Because a buyer cannot inspect the quality of a car prior to the actual buy, he will pay (up to) the average price of a car, which equals the average valuation $\theta_{\mathrm{E}}$. The market price will then lie between the value of a lemon and the value of a high quality car. However, suppliers of high quality cars will not be satisfied with this price, in contrast to suppliers of lemons: in the end only lemons will be supplied.

This analysis can easily be extrapolated to the professions. If consumers of professional services cannot evaluate the quality of the services provided by a particular profession member, but can only discriminate on price, professionals have no incentives to provide high quality services. After all, as a result of this asymmetric information they cannot signal relative differences in the quality of their services. The

Darby and Karni (1973) first introduced this category.

For a description of the differences between search goods, experience goods and credence goods, see also Tirole (1992, p. 106) and Bos (1995, pp. 33-34).

See also Varian (1984, pp. 291-293), Tirole (1992, pp. 108-110) and Cariton and Perloff (2000, pp. 423-425). 
market price will reflect only the average quality level and will thus attract average quality professionals. A decrease in the average quality level perceived by consumers will be the result, which in turn will lead to a reduction of the market price, and so on. ${ }^{32}$ Good professionals will be driven out of the market by bad professionals (quacks). Regulation might be able to convert this 'equilibrium' of low quality and low price into a market outcome characterised by high quality and reasonable price.

In addition to the problem of adverse selection, information asymmetry on a market can also lead to the principal-agent problem of demand generation. Lack of information from the side of consumers (e.g. the patients of a general practitioner) may cause professionals (in the same example the general practitioner) to provide extra services, which consumers would not have wanted if they were fully informed. The provision of these kinds of services is of course welfare decreasing. In economics this kind of behaviour from professionals is called moral hazard behaviour. ${ }^{33} \mathrm{~A}$ moral hazard problem arises when agent and principal have different individual objectives and the principal cannot easily determine whether the agent's actions are being taken in pursuit of the principal's goals or are self-interested misbehaviour. ${ }^{34}$ Again, regulation may be needed to solve the information asymmetry between principal and agent that causes the problem. ${ }^{35}$

Besides asymmetric information another information problem may occur on markets for professional services: bounded rationality of consumers. In the neoclassical theory it is assumed that individuals can adapt unlimited knowledge and always use this knowledge in an efficient way. ${ }^{36}$ In reality, however, individuals can remember and readily recall only a limited amount of information. It is efficient for consumers to use simplified rules to process the information they obtain, so they rationally use only some of the information they have collected because it is costly to process it. Economic theory predicts that such a consumer processes information

Van den Bergh (1999, p. 126).

Demand generation is a moral hazard problem on the supply side. Moral hazard often occurs on the demand side as well. The usual example taken in economics is the insurance business. People who are insured against e.g. bike theft do not have incentives to optimally reduce the risk of their bike being stolen. A classic paper on moral hazard and insurance is Shavell (1979). Also in health insurance the problem of moral hazard exists: Arrow (1963) pointed out that the demand for health care increases as soon as full insurance cover is available.

Milgrom and Roberts (1992, p. 170).

For an introduction to the concept of moral hazard see e.g. Mamuth (1992, p. 189), Milgrom and Roberts (1992, pp. 167-170) and Carlton and Perloff (2000, p. 427). For a formal approach of moral hazard behaviour in a principal-agent relationship see Tirole (1992, pp. 51-55),

Related to this assumption - and to the whole concept of perfect information - Stiglitz (2002) wrote an interesting article that gives an extensive overview of the development of information economics. The author is very critical of the assumption of perfect information, on which most formal modelling in economics is based. Stiglitz criticises especially the way the neoclassical models and the Chicago school of economics deal with the information problem. He indicates that even economies with very small information problems may look totally different from perfect information economies. 
up to the point where the marginal benefit of the information equals the marginal cost of processing more information. This behaviour is called bounded rationality. ${ }^{37}$ Moreover, consumers may simply lack the education level, or even the intelligence, to process all available information on products and services in a correct way. Regulation could be justified here as well, if the government (or a self-regulatory body) has more information at its disposal than consumers have..$^{36}$

\subsubsection{Externalities}

Another possible public interest justification for regulation arises from the existence of externalities.$^{39}$ Externalities appear if the utility or profit of a subject A is directly influenced by the way of acting of a subject B, while this subject B does not take this effect into account in the determination of his behaviour. ${ }^{40}$ In other words: the cost (or benefit) of the activity undertaken by B is borne in part by subject A. In case of a negative externality B invests too much in the activity from a social point of view: B only takes into account his private costs, which are lower than the social costs. The social costs consist of both the private costs of subject B and the external costs imposed on subject A. A well-known example of a negative externality is that of a factory discharging waste material in a river, forcing downstream drinking water companies to incur costs of water purification. ${ }^{41}$ In case of a positive externality subject $B$ invests too little in the activity from a social point of view. This implies that the social benefits of the activity undertaken by subject $B$ are higher than his private benefits. A textbook example of a positive externality is the pollination provided by a beekeeper to his neighbour who runs an apple orchard. ${ }^{42}$

A theoretical answer to the problem caused by negative externalities would be to impose a tax on all activities that generate external costs, thereby reducing the incentives to take part in such activities. ${ }^{43}$ Optimally, for each harmful activity the marginal tax rate should be equal to the marginal costs caused by it. The resulting tax is usually referred to as a Pigouvian tax. However, Coase (1960) stressed the reciprocal nature of harm. According to Coase, the parties concerned often can solve a problem caused by externalities themselves by means of negotiations. The external costs can then be 'internalised' in a contract between the parties. ${ }^{44}$ The famous Coase

Carlton and Perloff (2000, p. 422).

De Bijl and Van Damme (1996, p. 11).

For an economic analysis of externalities see e.g. Varian (1984, pp. 259-263), Mamuth (1992, pp. 183-185), Skaggs and Carlson (1996, pp. 126-129), Cooter and Ulen (2000, pp. 40-42) and Van Velthoven and Van Wijck (2001, pp. 51-55). See also Ogus (1994, pp. 18-19; 35-38).

De Bijl and Van Damme (1996, p. 12).

Den Hertog (2000, p. 229).

Cooter and Ulen (2000, p. 40).

Likewise, one could subsidise activities that generate external benefits.

Coase (1960). Coase himself did not use the term 'externalities'. 
theorem holds that in the absence of transaction costs, ${ }^{45}$ the outcome of such negotiations will be economically efficient regardless of how the law allocates property rights, because the parties involved will choose transactions that maximise their joint utility and thus social welfare. ${ }^{46}$ The Coase theorem deals with economic efficiency only; it does not say anything about distributional aspects. Naturally, the final distribution depends to a large extent on the initial allocation of property rights. Furthermore the assumption of zero transaction costs is of course a very strong one, especially if many parties are involved. In case of externalities that affect many parties, Coasian bargaining will only take place if there is symmetrical information among the parties concerned and if the transaction costs of bargaining are smaller than the transaction costs of public intervention.

In cases where transaction costs are prohibitive there will be no Coasian bargaining. Some kind of legal intervention is needed to effectuate the internalisation of the external costs. In other words, there may be a public interest justification for government regulation, e.g. by prohibiting companies to undertake certain harmful activities, or by regulating the activity level. An example of the latter form of regulation are tradable permits, such as the so-called 'rights to pollute' in the context of environmental pollution. ${ }^{47}$ However, even if we would assume that the government is perfectly capable of curing the market failure problem caused by externalities, account must be taken of the administrative costs of regulation: an externality may give rise to a misallocation but the costs of correcting it may outweigh the social benefits arising from such action. ${ }^{48}$

In the professions externalities may appear if the quality of a rendered service is poor. The low quality of a professional service might affect third parties as well as the client. This means that considerable losses may be thrown upon society if poorly trained professionals were allowed to perform their services. ${ }^{49}$ An example would be that of a poorly designed or constructed building that collapses and causes casu-

These are the costs of information gathering, direct contracting costs, and monitoring costs. The Coase theorem is discussed inter alia in Milgrom and Roberts (1992, p. 38; 293-305), Skaggs and Carlson (1996, pp. 537-539), Posner (1998, pp. 8; 55-58), Cooter and Ulen (2000, pp. 82-87) and Van Velthoven and Van Wijck (2001, pp. 91-97).

The starting point for most of the literature on tradable permits is a 1968 publication by Dales (new print, 2002). Dales proposed that a market of tradable permits would be organised by the government whereby tradable pollution rights would be granted for a certain period. The government would act as broker for the trade and would monitor the system. An extensive overview of the existing literature that has been published as a reaction to Dales' proposal can be found on the internet: <http://www.colby.edu/economics/faculty/thtieten/research> (website of Prof. T.H. Tietenberg). A recent paper on emissions trading is Peeters (2003). She analyses emissions trading from a legal point of view, i.e. as part of the new regulatory approach in EU environmental law.

Ogus (1994, p. 38).

Van den Bergh (1999, p. 108). See also Cox and Foster (1990, p. 10). 
alties. ${ }^{50}$ Furthermore, especially in the medical professions, mistakes by e.g. a physician or a pharmacist might have dramatic results not only for the patient but also for his family (for example, in case of death of the patient) or for other persons (for example, in case an incompetent doctor fails to diagnose a contagious disease, thus contributing to an epidemic).

\subsubsection{Public goods}

The fourth form of market failure that may give rise to regulation is the existence of public goods. ${ }^{51} \mathrm{~A}$ public good has two characteristics: nonrivalrous consumption (or: non-rivalry) and non-excludability. Nonrivalrous consumption implies that consumption of the good by one person is not at the expense of another person. Nonexcludability means that it is either impossible or too expensive (for a private profitmaximising firm) to exclude people from consumption of the good..$^{52}$ Classic examples of public goods are national defence, lighthouses and dykes.

If the product in question is a public good the market sometimes does not - or not sufficiently - generate the product. This can be explained as follows. Since consumers cannot be excluded from consumption of the good, they might be tempted to take a free ride on the willingness to pay of others. On the one hand, this 'free-rider behaviour' creates problems in raising sufficient money for production of the good, while, on the other hand, it becomes very difficult to determine the exact demand for the good. After all, consumers do not have incentives to reveal their true willingness to pay. If indeed the market does not (sufficiently) generate the public good, the government can play a role by either subsidising the production or by producing the good itself. Contrary to private firms, the government of course has the ability to use tax money to finance the production of the public good.

Information has the same characteristics as a public good: when it is supplied to someone, it can be supplied to others at no extra cost. If one looks at the professions, the danger exists that professionals underprovide socially valuable information because it may cost them more to provide this information than it is worth to consumers. Some of the problems surrounding information as a public good will be dealt with in section 2.4.1, where I discuss mandatory information disclosure with respect to the quality of professional services.

Such accident actually occurred in Maastricht in April 2003: the balconies of a modern apartment block suddenly fell down, which resulted in two casualties. See e.g. De Volkskrant, Balkons storten in: twee doden, 25 April 2003, Dagblad De Limburger, Balkons storten in: twee doden, 25 April 2003. 


\subsubsection{Liability versus regulation}

Under certain conditions, a market failure may also be remedied through private law in the form of liability rules. This implies that regulatory intervention is not needed in those cases. In a classic paper Shavell (1984) examined the choice between regulation and liability rules by defining four determinants: information asymmetry between the government and private parties, insolvency risk, the threat of a liability suit and administrative costs. In this section I describe these four determinants briefly and after that I will show that, in the context of the regulation of professions, private law alone will not suffice.

\subsubsection{Shavell's criteria for liability and regulation}

Shavell poses the following question: what is the socially desirable (efficient) way to employ liability and safety regulation in situations where we want to alleviate risks, i.e. the risk of harm to others? ${ }^{53}$ Obviously, liability rules will only work effectively if there is a victim who can bring a lawsuit against an identifiable injurer, who is able to pay the compensation due. If not, the government may have to intervene. From an economic point of view, there is an important difference between liability and regulation. While liability works rather indirectly, through the deterrent effect of a tort suit in case of damage, regulation modifies the behaviour of parties directly. That is, contrary to liability, which is employed at the initiative of private parties, regulation is generally independent of the actual occurrence of harm. ${ }^{54} \mathrm{In}$ addition there is a difference in enforcement: liability is enforced by private law, while regulation is enforced by public law and criminal law. ${ }^{55}$

The first determinant is information asymmetry between the government and private parties. In $\S 2.2 .1 .2 \mathrm{I}$ indicated that information problems (such as adverse selection, moral hazard and bounded rationality) may provide a justification for government intervention through regulation. However, according to Shavell for every activity first the question must be asked whether either the government or the parties involved can acquire the information at the least costs. The parties in an accident setting may have better information on the accident risk than that possessed by the regulatory body, because they generally have the best information on the costs and benefits of the activity that they undertake, on the optimal way to prevent accidents, and on the magnitude of accidents. ${ }^{56}$ If this is indeed so, liability will be a more effi- 
cient instrument than regulation. ${ }^{57}$ But if it becomes clear that some risks are not readily appreciated by the parties in an accident setting, this argument does not hold. In that case, and of course in cases where the government has better information on the factors mentioned above, regulation is preferred to liability.

The second determinant proposed by Shavell is insolvency risk, or incapacity to pay for harm done. If the potential damages are so high that they will exceed the wealth of the individual injurer, liability rules will not provide sufficient incentives to take optimal care. Namely, costs of care are directly related to the magnitude of the expected damages, and these will under a liability system never be higher than the individual wealth of the injurer. ${ }^{58}$ If the efficient care is determined instead by $e x$ ante regulation (backed up by a non-monetary sanction such as imprisonment), the potential injurer is obliged to comply with this regulation, irrespective of the injurer's wealth. ${ }^{59}$

The third determinant is the threat of a liability suit (or: the chance of escaping suit). If the damage is thinly spread among a large number of victims, it is likely that an injurer will escape liability. The reason is that individual victims in this case do not have sufficient - if any - incentives to bring a suit; after all, their individual harm may be very small. This will occur especially if the damage is not caused to individuals but to a common property such as a lake or a forest. Furthermore, the threat of a liability suit is small if a long time has elapsed before the damage becomes apparent, or if it is difficult to determine a causal link between the activity of the injurer and the damage. This is the problem of lack of evidence. For all these reasons a suit may never be brought, which implies that in these cases a tort system will have no deterrent effect. Shavell therefore concludes that if there is no threat of a liability suit, safety regulation is necessary to ensure that efficient care is taken by the (potential) injurer. ${ }^{60}$

Finally, the administrative costs of both systems must be compared. The administrative costs of the tort system consist of the public expenses of the legal system itself (such as fees for the judges) and the private costs of time, effort and legal expenses

This argument always holds under strict liability (that is, if one assumes a unilateral accident setting where only one party is able to influence the accident risk). Under negligence, however, one has to assume that the court has better access to this information than the regulatory body.

I assume risk-neutrality here. Of course, if one takes account of risk-aversion, insurance may - at least to some extent - provide an answer to some insolvency problems, provided that one is not dealing with very widespread and large risks involving e.g. great losses of human lives. Moreover, one has to assume that the insurer is perfectly capable of monitoring the insured: here we are back to the information problem again. For a discussion on attitudes towards risk and the demand for insurance, see e.g. Varian (1984, pp. 158-162), Mamuth (1992, pp. 170-175) and Cooter and Ulen (2000, pp. 46-50). 
borne by private parties. If one considers regulation, the administrative costs include the public costs of passing and enforcing the regulation and the private costs of compliance. ${ }^{61}$ With respect to these costs the liability system seems to have an advantage, because the administrative costs of the court system are only incurred if an accident has actually happened. A lot of accidents will be prevented by the deterrent effect of being held liable and having to pay damages to the victim. In case of regulation the costs of passing and enforcing the regulation are always there, irrespective of the actual occurrence of an accident.

Concluding this discussion of Shavell's paper, two of the determinants generally favour liability: administrative costs and information asymmetry (provided that private parties have the better information). The other two determinants generally favour liability: incapacity to pay for harm done and the chance of escaping suit. Often a combination of the two instruments will be optimal, with the balance between them reflecting the importance of the determinants. ${ }^{62}$ An example is driving on the road: there is safety regulation (maximum speed, guard rails, rules on driving on either the left side or the right side of the road) and there is a traffic liability system in case of accidents.

\subsubsection{Liability versus regulation in the professions}

How does the above relate to the topic of this thesis, the regulation of professions? Following Shavell, the four criteria described in \$2.2.2.1 should be considered in order to determine whether we need regulation or liability to cure a problem caused by market failure. The criteria seem to apply especially to the cases of externalities and information asymmetry, while they do not seem to be applicable at all to cases involving market failure caused by market power or public goods.

If one looks at the first of Shavell's determinants (information asymmetry between the government and private parties), intuitively one might be inclined to say that the government has less information at its disposal than private parties, if the latter group is defined as consisting only of the professionals providing the service. However, also the consumers of professional services belong to the private parties. In fact, there may be, on the one hand, an information asymmetry between the government and private parties, while, on the other hand, there may also be an information asymmetry between the private parties themselves. ${ }^{63}$ The latter will not be solved by liability. The former is actually the problem of self-regulation versus public regulation, which will be discussed in section 5 infra. The first determinant thus clearly favours regulation in this case. 
With respect to the insolvency risk, the second determinant, the question should be posed whether professionals would be able to pay for possible harm done as a result of bad quality services causing externalities. I argued in $\$ 2.2 .1 .3$ that bad quality services, especially in the medical professions, may have disastrous effects. It is obvious that we want some ex ante regulation of professional services, next to professional liability in case of such accidents, to make sure that the optimal level of care is taken.

The chance of escaping a lawsuit, the third determinant, is linked again to the information asymmetry argument and the fact that professional services are often experience goods or trust goods. For consumers of professional services, such as patients looking for medical advice, it is difficult to assess the quality of such services. If externalities result from, e.g., a poor diagnosis or bad drug therapy (think of the earlier example of contagious diseases or even the death of a patient) it may therefore be difficult to trace what exactly caused the problem. This would imply that some regulation is needed to solve this problem. Generally, however, this determinant does not seem to have a strong influence on the choice between liability and regulation for the specific case of the liberal professions. The problem will especially be that victims of poor quality services by e.g. pharmacists may simply lack the incentive to bring a suit because they do not realise that the health problems they face are caused by poor service in the pharmacy. Hence, there is a serious enforcement problem.

The last determinant, administrative costs, slightly favours liability, as discussed in § 2.2.2.1. Summing up: if Shavell's criteria are applied, a liability system alone (although clearly required) will not suffice to deal with problems caused by market failure in the professions. Despite the higher costs, some (public or self-) regulation is required. In particular, regulation should take care of the information asymmetry problem between professionals and consumers (clients, patients), but it may also be needed to prevent externalities causing large losses, for which professionals may be insolvent or for which there is lack of evidence.

\subsection{The private interest approach}

The public interest approach to regulation does not explain how a public perception as to what kind of legislative policies or arrangements would maximise social welfare is translated into legislative action. ${ }^{64}$ In other words, it does not specify how or when a new regulation originates. It does, however, assume that regulation will be formulated by government agencies to serve the public interest. The private interest approach to regulation on the other hand stresses the role of interest groups in the formation of regulation. Actually the private interest view I will present in this section has originated from several economic theories: the capture theory, (elements from) public choice theory and the economic theory of regulation. These theories 
have in common that they all suggest that regulation is not only an answer to market failure (if at all), but also a result of lobbying and rent-seeking behaviour by interest groups. ${ }^{65}$

The capture theory emphasises the influence of interest groups in the formation (and failure) of regulation. It takes as an assumption that regulatory agencies are subject to pressure, influence and bribery of the very people who are the subjects of a particular regulation and who in this way want to protect their own interests. Eventually the private interests of the people subject to regulation may then be served more by the regulation than the public interest is. ${ }^{66}$

In the public choice literature ${ }^{67}$ regulatory failure has been discussed frequently. The public choice theory explains, positively, how individual preferences are reflected in the voting procedures adopted by public institutions. The assumption is made that behaviour in the political arena is, in its essence, the same as behaviour in the market. ${ }^{68}$ That is, in both contexts economic subjects act rationally by maximising their utility. Politicians are likely to strive for maximisation of votes, because they want to be re-elected, but they may also try to maximise their budgets or prestige. This may give rise to inefficient regulation, especially when lobbying is involved. The concept of rent seeking ${ }^{69}$ is a central feature of the so-called Virginia School of Public Choice. ${ }^{70}$ Moreover, Keenan and Rubin (1988) argue that rational politicians will not only respond to lobbying activities from the already existing interest groups, but will under certain circumstances also take into account the possible actions of potential lobby groups: the so-called shadow interest groups. These are groups that ries are in any other way related to each other. See further the discussion of the separate theories below.

The capture theory was already described by the political scientists Bentley (1908) and Truman (1951), but came up especially in the 1960s after a number of empirical studies dealing with the influence of lobbying on regulation in the United States. However, the capture theory lacked a theoretical foundation, according to Posner (1974, pp. 341-343). See also Hägg (1997, pp. 342-343) and Den Hertog (2000, pp. 235-236).

See Cullis and Jones (1998) and McNutt (2002). A summary of the public choice theory can be found in e.g. Ogus (1994, pp. 58-71), Skaggs and Carlson (1996, pp. 134-140) and Posner (1998, pp. 572-576).

See, especially, Buchanan and Tullock (1962) and Buchanan, Tollison and Tullock (1980). Hăgg (1997, pp. 344-345) argues that, according to the rent-seeking theorists of the Virginia School, 'the social waste associated with lobbying have [...] to be added to other forms of inefficiencies that regulatory measures may cause'. An introduction to the Virginia School is provided in Den Hertog (2000, pp. 243-244). 
have not yet organised but that would have members and come into being if an event occurred. ${ }^{71}$

In his classic paper on regulation Stigler (1971) assumes that the government is the supplier of regulation, while the demand side exists of interest groups looking for protective regulation (such as regulated prices or entry barriers to the market). The demand for regulation will especially be high when the potential benefits of restrictions to competition cannot be obtained by the interest groups themselves, e.g. by means of cartel formation. According to Stigler's theory, which came to be known as the economic theory of regulation, ${ }^{72}$ it is the industry itself that asks for regulation. ${ }^{73}$ Regulation originates where the benefits are concentrated (the industry) and the costs can be divided over a large group (the consumers). Stigler claimed that every branch of industry, which is powerful enough to do this, will lobby the government for the erecting of entry barriers such as obligatory training or apprenticeships, product requirements, taxes, import quotas, etc. After all, entry barriers keep the supply of new producers on a market artificially low, which of course is beneficial to the insiders on the market (viz. the original producers) because they will be able to sell their products at relatively high prices. The same line of reasoning goes for direct rules of conduct like a prohibition to advertise. Advertising bans lead to a less transparent market where the prices asked can and will be higher than in a market without advertising bans. ${ }^{74}$

Peltzman (1976) formalised and extended Stigler's model. His model supports Stigler's conclusion that the costs of using the political process limit the size of the dominant group. Also, it produces as a second important result that the gain obtained by the winning group through political action will not be as great as is within the power of the political process to grant it. ${ }^{75}$ In other words, the best organised cartel will yield less to the membership if the government organises it than if it were organised privately. Peltzman explains this by arguing that not only well organised industries are expected to win favours on the political market, but that other interest groups and voters will be influential as well. Politicians will distribute favours and disfavours among pressure groups and voters in order to maximise their chances of

Keenan and Rubin (1988, p. 22).

Alternatively, this theory has been called the Chicago theory of regulation (Hägg, 1997, p. 343; Den Hertog, 2000, p. 236; Hantke-Domas, 2003, p. 180), because it has been developed and worked out in particular by Chicago economists: notably Stigler (1971), Posner (1974), Peltzman (1976) and Becker (1983). Stripped of detail, the Chicago school of economics is characterised by its trust in the functioning of the free market (the 'invisible hand' of Adam Smith) to solve certain forms of market failure. Classic papers on the development of the Chicago school are Posner (1979) and Reder (1982). See also De Bijl and Van Damme (1996, pp. 13-15). Stigler (1971, p. 3).

Benham and Benham (1975), who examined the market for eyeglasses in the USA, found that in state markets with greater professional control on information, prices appeared to be significantly higher than in less regulated states.

Peltzman (1976, p. 221). 
being re-elected. This to some extent weakens the political power of interest groups. $^{76}$

Becker (1983) presents a model of competition among pressure groups for political influence, i.e. taxes, subsidies and other political favours such as protective regulation. He makes the assumption that politicians and bureaucrats carry out the political allocations resulting from this competition. ${ }^{7}$ His model then shows that political equilibrium depends on the efficiency of each pressure group in producing pressure, the effect of additional pressure (from other interest groups) on their influence, the number of persons in different groups and the deadweight costs of taxes and subsidies ${ }^{78}$ In the analysis Becker unifies the view that governments correct market failures with the view that they favour the politically powerful: in his model both are produced by the competition for political favours. He argues that pressure groups have an incentive to demand the most efficient regulation, since regulations that cause deadweight costs discourage their political power while they encourage the power of pressure groups whose welfare is harmed. The model suggests that it is not the existence of well-organised pressure groups that may be harmful to the economy, but the unequal distribution of political power across these groups. ${ }^{79}$

The hypothesis that results from the private interest approach to regulation is, as stated above, a combination of elements from the three theories just described. Adherents of this approach claim that interest groups are continually influencing political decisions in order to seek rents for themselves. ${ }^{80}$ This kind of behaviour is called rent-seeking behaviour and the corresponding hypothesis is called the rentseeking hypothesis. ${ }^{81}$ In microeconomic theory the concept of 'rent' refers to the difference between the revenue from producing a good and the cost of producing the good. If there is competition between producers such rents will (to a great extent) be eliminated. However, if regulation exists that protects producers this effect will be softened. As a result of the decrease in competition, wealth will be transferred from consumers to producers. This is unproductive from society's point of view, as re-

Viscusi et al (2000, pp. 319-323) present a summary and analysis of what they call the 'Stigler/Peltzman model'.

Becker (1983, p. 372) states that 'politicians, political parties and voters will receive little attention [in the model] because they are assumed mainly to transmit the pressure of actioe groups'.

Becker (1983, p. 395).

See also Hăgg (1997, p. 345). Viscusi et al (2000, pp. 323-327) describe the Becker model in greater detail.

Hahn (1989a and 1989b) even argues that policy instruments, i.e. regulatory instruments such as those to be discussed in section 4 of this chapter, are almost never used in the way suggested by economic theory, because of the large influence that interest groups have on the rule-making process. Buchanan and Tullock (1975) study in this respect the example of environmental regulation in the USA. See also Maloney and McCormick (1982).

For a survey paper on rent seeking, see Tollison (1982). Tollison and Tullock (1995) present a selection of the most important papers on rent seeking. 
sources are devoted to capturing a wealth transfer ${ }^{82}$ Besides this argument of waste of resources, rent-seeking behaviour may also be condemned on distributional grounds. This is, however, not a private interest argument from an economic perspective.

Rent seeking is according to Olson (1965) most successful if groups are small, singleissue oriented and well organised. ${ }^{83}$ Interest groups in the professions seem to satisfy at least two out of these three characteristics. They are generally very well organised and are concentrated on a clear subject: the domain of their profession. Concerning the third characteristic it is moreover clear that the number of professionals will be relatively small compared to their potential number of customers. ${ }^{84}$

\subsection{Regulatory instruments}

As explained above (section 2) the services offered by professionals are often experience or trust goods. If in an unregulated market there is information asymmetry between professionals and consumers, adverse selection will occur, as a result of which the quality of these services will eventually be lower than the social efficient level (that would arise in a market with transparent information). Moreover, low quality services may in certain cases also lead to negative externalities. In this section I describe - in increasing order of intervention into the market - a number of regulatory instruments that can be used to solve problems with respect to the quality of professional services. The instruments that will be discussed here are information regulation, quality standards, and licensing and certification. It should be emphasised that the discussed instruments may also be applied by self-regulating groups. However, the social welfare consequences might then differ, as will be illustrated in section 5 .

\subsubsection{Information regulation}

The least interventionist instrument that may be used to tackle information problems on a market for professional services is simply to directly supervise the level and content of information provided by professionals. This supervision can be executed at various levels. The government (or a professional body) may decide to prohibit false and misleading information, e.g. by regulating advertisements. However, the regulation of information may also go a bit further, namely by obliging professionals to provide information relating to price, identity, composition, quantity or qual-

Tullock (1967) first emphasised the importance of income transfers and the attempts by industry to capture these transfers.

Olson (1965, Chs. 1-3). Posner (1974, pp. 344-347) makes a link to the theory of cartels, in which the characteristics are defined that predispose an industry to successful cartelisation.

It is obvious that the suppliers of the rents will in general be relatively large groups, which are difficult to organise and which face information problems. See also Van den Bergh (1993, p. 41), 
ity. This is called mandatory disclosure of information..$^{85}$ The discussion of certification, which can also be considered a form of information regulation, follows in \$ 2.4.3, where it will be compared to licensing.

The most common method used by suppliers to provide information on goods and services is advertising. Two types of advertising can be distinguished: price advertising and quality advertising. Because information is a public good professionals may sometimes not be encouraged to provide it. Cave (1985) investigates how the voluntary disclosure of information on price and quality differs according to whether search goods or experience goods are involved. He also shows that price advertisements may in some cases even have negative effects on consumer welfare. In the case of search goods there is no ground for prohibiting price advertising, since these goods are homogeneous in all their characteristics. Advertising will therefore lead to lower search costs for consumers and will drive prices to the competitive equilibrium. In the limit advertising for search goods may even eliminate all price differences, so that search costs are minimised. ${ }^{86}$ This argument does, however, not apply to experience goods: goods or services that differ in quality (to which many professional services belong). When information about price is easier to obtain than information about quality, increasing the availability of the former might discourage quality competition and lead to a degradation of quality on the market. This argument is frequently used by professional organisations to justify self-regulation that prohibits price advertising ${ }^{87}$ On the other hand an advertising ban will of course lead to higher consumer search costs and higher prices of services. An obligation to provide information on the quality of the service would decrease this problem. But often this is not so easy to monitor.

The economic literature describes a mechanism that provides incentives to suppliers of experience goods to produce goods and services of above minimum quality, whereby information on quality is voluntarily disclosed: repeat buying by consumers. ${ }^{88}$ Consumers buy a product or service often more than once. ${ }^{89}$ Moreover, the effect of repeat buying becomes larger if consumers pass on information about the quality of the good or service to other consumers, such as relatives and friends. It may therefore be important for professionals to make their services known through advertising to persuade consumers to a first buy. The fact that the information value of advertisements for experience goods is generally low does not matter according to this analysis, because a positive relationship between quality and advertising expenditures is assumed. Advertising functions as a 'signal': the supplier wants con-

Ogus (1994, p. 121).

Cave (1985, p. 346). Tirole (1992, pp. 289-295) analyses the difference between advertising for search and experience goods.

In addition to which often the claim is made that price competition would also threaten the integrity and ethical responsibilities of the profession.

Cave (1985, p. 343).

Of course, this depends very much on the product or service concerned. 
sumers to know that the product or service exists. If it turns out to be of low quality after consumption, consumers will just go to a different supplier the next time. According to this analysis information regulation is therefore not needed for products and services that have to be purchased repeatedly. However, this outcome may change as the long term and the short term are discerned.

In the long term the reputation of a professional depends on the quality of his or her services. The previously described mechanism of repeat buying influences the choice of service quality. However, in the short term a professional may abuse this reputation by lowering quality (for example by quickly and casually handling patients) and in that way make extra profits at the expense of a decrease in reputation. Shapiro (1983) calls this a fly-by-night strategy. ${ }^{90}$ This effect is predicted to be larger, the slower consumers adjust their views of service quality and the larger the shortterm gains. The public interest approach argues that if quality degradation of this kind occurs regularly the government has to regulate the provision of information. In the case of products (as opposed to services), information problems of this kind can sometimes be overcome by an obligation for producers to use labels on their products. Labels are objective indicators of quality, because they only reproduce the composition of a product. However, labels do have two weaknesses: they are not always easy to understand for the average consumer and they obviously cannot be used for professional services such as a visit to a pharmacist or a general practitioner.

To sum up briefly, one can state that (with regard to information provision for professional services) it would not be favourable if an economy only has information on prices and no information on quality. However, to disclose information on the quality of professional services is a complicated matter since it concerns experience goods or trust goods. Labels cannot offer a solution for this problem. In the long term the repeat buying mechanism may incite professionals to provide services of a proper quality and to voluntarily disclose information, but supervision over short term profit seeking (fly-by-night strategy) and false and misleading information remains a prerequisite.

\subsubsection{Quality standards}

A second instrument to regulate the quality of products and professional services is the enforcement of minimum quality standards. There are three types of quality standards: target standards, performance standards and specification standards. ${ }^{91}$ The least restrictive standard as far as intervention in the production process of suppliers is concerned, is the target standard. This implies that a government imposes criminal liability for eventual harmful consequences arising from the output of a supplier. This standard only works after the product or service has been 
brought onto the market, in contrast with the other two types. ${ }^{92} \mathrm{~A}$ performance standard (also called output standard) is used to check the quality of the final product or service before it comes onto the market, without intervening in the production process of the supplier. This is different if a specification standard is enacted. That type of standard involves control on the supply side: it forces or prohibits suppliers to use certain production methods or materials. Therefore such a standard is also called an input standard. For some professional services a specification standard may be less suitable, since the government does not always have at its disposal the specific knowledge required to set a specification standard.

As a result of a legally prescribed quality standard, all products and services that do not meet the standard are excluded from the market. Thus, this regulatory instrument interferes more with the market than the simple regulation of information. While information regulation tends to discriminate against people with a relatively poor educational background or intelligence, this is not the case if minimum standards are used. ${ }^{93}$ On the other hand, it might be the case that because of minimum quality standards some (relatively low quality) products are excluded from the market, which some people would have wanted to buy in an unregulated market. It is important to understand that the existence of low quality products does not necessarily imply that there is a problem, as long as there is a demand for these products. Obviously this demand must be based on correct information about the product or service in question and consumption of it should not cause any serious negative externalities, e.g. with respect to safety or health of third parties. However, if the quality of a product or service is too low from a social welfare point of view, standards may help to solve the problem. ${ }^{94}$ Unfortunately it is far from easy to determine the optimal standard.

In an often cited paper, Leland (1979), building on the work by Akerlof, investigates which market types are most likely to benefit from minimum quality standards. In his model the market is characterised by information asymmetries between consumers and suppliers: consumers do not even have any partial information, such as information gathered from relatives and friends, own experience or signalling activities from suppliers. Consumers only learn the true quality of a good or service after consumption. A second important assumption in Leland's model is that the opportunity costs, ${ }^{95} \mathrm{R}$, of supplying a unit of service of quality level, $\mathrm{q}$, are increasing in $\mathrm{q}:{ }^{96}$

For the difference between liability and regulation, see $\$ 2.2 .2$.

Shapiro (1983, p. 678).

Shapiro (1983) derives an equilibrium price-quality schedule for markets of experience goods and then analyses the effects of minimum quality standards on this equilibrium outcome. Indeed, he concludes that it is optimal to exclude some products from the market.

The concept of opportunity cost refers to the economic cost of an alternative that has been foregone (Cooter and Ulen, 2002, p. 30). E.g. a profit-maximising supplier has to consider the 


$$
\mathrm{R}^{\prime}(\mathrm{q})=d \mathrm{R} / d \mathrm{q}>0
$$

In other words, the opportunity costs of entering the market increase with quality. Under these conditions minimum quality standards may be socially desirable according to Leland. The following four market types are most likely to benefit from quality standards according to his analysis: (1) markets with a relatively priceinsensitive demand; (2) markets with high demand sensitivity to average quality; (3) markets where the costs associated with providing quality are low; and (4) markets where the willingness to pay for low quality goods or services is low. When the assumption above is reversed, ${ }^{97}$ i.e. if $\mathrm{R}^{\prime}(\mathrm{q})<0$, a minimum quality standard will always be socially desirable according to Leland. However, Leland's model predicts that if professional groups set quality standards themselves it is likely that the standards will be set too high, that is, above the optimum level. He explains this result by stating that:

' in choosing the optimal minimum standard, a professional group or industry seeks to maximize its net gains. As with any monopoly, ${ }^{98}$ extra profits can be achieved by a lower level of total supply than is socially optimal, [...] motivating the profession to set the optimal standard too high'.99

The introduction of a quality standard involves a number of different costs for an economy. Ogus (1994) points to the distinction between direct and indirect costs. ${ }^{100}$ The direct costs consist of the administrative costs of defining, monitoring and enforcing the quality standard and of the so-called compliance costs, which suppliers have to make to fulfil the minimum quality standard, e.g. investments in new equipment (if necessary) and the costs of adapting the plant. Also possible new maintenance costs belong to this category, as well as any costs resulting from losses in productivity (opportunity costs). The indirect costs of a standard are the (often unintended) side effects of the regulation. For example, standards may lead to productive or allocative inefficiency or act as a brake on technical change. Unfortunately, estimations of these indirect costs are difficult to make. A cost-benefit analysis of minimum quality standards will therefore not be easy. The benefits of quality standards are even more difficult to quantify than the costs, since they are very dependent on the specific product or service that is regulated and thus often difficult to

opportunities foregone by committing his resources to the production of one good instead of another. Leland (1979, p. 1331). Also Akerlof (1970) made this assumption.

For example, if certain educational requirements must be satisfied to enter a market, 'smarter' individuals may find it easier (less expensive in terms of opportunity costs) to meet those requirements.

For a brief discussion of monopoly power, see \$2.2.1.1 above.

Leland (1979, p. 1338). Gehrig and Jost (1995) investigate under which circumstances selfregulating clubs will provide and enforce quality standards themselves. See also section $5 \mathrm{in}$ fra.

Ogus (1994, pp. 154-155). 
predict in advance. Moreover, the benefits are usually spread widely over time and space. Many positive effects of a standard are only realised long after the introduction of the standard, which means that one has to take into account some discounting method if one wants to compute the current value of the benefits. A complicating factor in the assessment of the benefits is that other factors besides the standard itself may influence the situation in the relevant product market as well. The causal relationship between the minimum standard and its positive effects is then unclear.

The private interest approach to regulation warns for yet another problem: firms and professionals who expect to be subject to a government prescribed quality standard will use lobbying to push through their own ideas about the required quality level. A standard can be an effective means to protect insiders on a market against new competitors. Indeed, the introduction of a minimum quality standard is favourable for those who already comply with the requirements defined in the standard. That is, they do not have any compliance costs. The public choice theory already predicted that those who formulate the regulation may succumb to such lobbying by incumbents, in the hope that by doing so they will win votes and will be re-elected. From a private interest point of view one therefore has to take care that minimum quality standards will not be set too high.

Because the computation of the optimal standard is not an easy task and because standards constitute a relatively heavy interference with the market process, it is important to investigate first whether a standard really is the best answer to an information problem. If the purchase of a product or service of low quality involves only small risks for third parties, private law in the form of liability rules may sometimes offer a solution to the problem. Naturally this depends very much upon the circumstances. ${ }^{101}$ However, when the damage resulting from such a purchase can be high, liability law does not seem to offer sufficient protection and then a more farreaching instrument like a quality standard or a licensing system will be necessary.

\subsubsection{Licensing and certification}

Regulation in the form of licences or certificates can be used to oblige suppliers to meet certain predetermined conditions of education or training qualification, in order to guarantee an adequate quality of goods and services. These requirements of education and training may be determined both by public bodies and by professional groups themselves. In the professions it often occurs that members of the profession regulate the required work experience in the form of mandatory internships (on the job training) and courses, while the government takes care of the issue of diplomas for higher education. Title protection belongs to this category of regulatory instruments as well: it can be regarded as a form of certification. 
In contrast with information regulation and quality standards, licenses and certificates are issued before the regulated activity has taken place and are therefore $e x$ ante measures of quality control. Licensing goes further than certification. If a profession is licensed, this means that the performance of certain services is reserved to only those professionals who have a license issued by the regulator. ${ }^{102}$ Entry into the profession is restricted, whereas in the case of certification this is not the case. If certification is used every individual may be active in the regulated profession, but those who do not have a certificate may not use the protected title. ${ }^{103}$ The private interest economists warn for the danger that interest groups may use licenses as an entry barrier. ${ }^{104}$ The more conditions potential market entrants have to fulfil to gain their license, the higher the entry costs.

The economic justification for licensing is that the average level of quality in a market will rise because of exclusion of lowly-educated suppliers. The information asymmetry problem between buyers and sellers is thereby alleviated. However, the validity of this argument depends upon the relationship between the educational level of a supplier and his or her marginal cost of providing high quality. If an individual's human capital increases because of increased license requirements, it seems at first sight plausible that his marginal cost of providing high quality decreases. But to determine how strong this relationship is will be very difficult, especially considering the fact that an individual's human capital may depreciate over time if there are no periodic re-examinations. ${ }^{105}$ Shapiro (1986) has proven formally that if the relationship between human capital and high quality is indeed positive and if suppliers can build reputations over time by providing high quality, consumer welfare can be enlarged by licensing or certification. However, his analysis also shows that this holds only if consumers value high quality significantly compared to the marginal cost of providing quality for suppliers. Moreover, licensing will never lead to a Pareto-improvement, because there will always be consumers who would rather have bought low quality goods or services at a lower price. ${ }^{106}$

The danger exists that as a result of licenses such consumers will substitute the relatively expensive licensed services by cheaper 'alternative' services. Suppose, for example, that in the pharmaceutical profession more stringent educational requirements are introduced, which lead to a higher mark-up on the cost price of medicines in a pharmacy. Such an increase in educational requirements may be the result of a policy that aims at improving the medical advice given to patients by pharmacists. The higher price level of medicines in a pharmacy may cause some

It will in certain cases still be very difficult to determine exactly what is a lawful or unlawful activity, if that activity is performed by someone without the license. Some key elements for which a license is required must be isolated. Curran (1993, p. 53).

104 See e.g. Stigler (1971, pp. 5-6). Also Moore (1961) points to this danger of licensing.

105 Curran (1993, p. 58).

106 Shapiro (1986, p. 856). 
consumers to refrain from buying any medicines in spite of the increased education level of pharmacists, or (if possible) they might decide to look for substitutes at the chemist, where they do not receive medical information about interactions of this medicine with other medicines, but where the price is lower. In such cases it is doubtful whether licensing will enhance the overall quality level of services, or reduce it because of this substitution effect.

The idea behind the introduction of certificates on a market is that these serve as a signal of good quality. After all, the certificate (or title) can only be obtained if certain educational or training requirements have been fulfilled. If consumer preferences are heterogeneous, the advantage of certification is that consumers still have a choice between certified (and often more expensive) and uncertified services, which will not be the case in a licensed market. If the consequences of performance failure of the service can be harmful (think e.g. of a wrong diagnosis by a general practitioner) certification seems a less suitable instrument than licensing. However, this argument applies only if consumers generally are risk-averse instead of risk-neutral. Shapiro (1986) points out the danger that suppliers may be inclined to 'overinvest' in education in order to signal high quality levels. ${ }^{107}$ According to Shapiro total consumer welfare may in these cases decrease if many consumers consider professionals overtrained and their services overpriced because of some license or certificate. ${ }^{108}$

Finally, it should be mentioned here that in practice the difference between licensing and certification is not always as clear-cut as described above. That is, certification can in practice come very close to licensing if there is insufficient demand for uncertified services and if there are little or no professionals left on the market without the certificate. Under these circumstances it will be almost impossible for recently graduated professionals to enter (or to be active on) the market without owning the certificate.

The overall effect of licensing and certification thus depends on the heterogeneity of consumer preferences for quality, even if educational level (human capital) and quality are positively related. Summarising one can say about the difference between the two regulatory instruments that licensing intervenes further in the market process than certification, but that risk-averse consumers are better insured by it against possible harmful consequences of bad services. Drawbacks of licenses are that they can be used as entry barriers by interest groups and that they may incite consumers to substitute licensed services by alternative services.

108 Kleiner and Kudrle (2000) use data on the dental health of incoming Air Force personnel to analyse the effects of varying licensing stringency among US states. They find that tougher licensing does raise prices (for consumers) and profits (hourly earnings per dentist), while it does not improve the market outcomes (in terms of overall dental health, as measured by complaints to dental licensing boards and malpractice premiums). 


\subsection{Self-regulation}

Self-regulation can be defined as rules formulated by a professional body to govern the activities of its members. Self-regulation exists in many forms, which differ in legal force and in the degree of autonomy from the government. Concerning the legal force, Ogus (2000) makes a distinction between four types. ${ }^{109}$ According to Ogus self-regulation can be:

'(1) formally binding, non-compliance leading to public law or private law sanctions; (2) codes of practice which presumptively apply unless an alleged offender can show that some alternative conduct was capable of satisfactorily meeting the regulatory goals; (3) norms the breach of which leads to non-legal sanctions, such as ostracism; or (4) standards compliance with which is purely voluntarily'.

Concerning the degree of autonomy from the government, this can range from total absence of government intervention in the rule-making process towards selfregulation that needs approval from the government or another public body.

Although the argument of professional groups themselves is that by means of selfregulation they aim for a higher quality of services, self-regulation also has as a negative side effect that it often restricts competition. The extent of restriction of competition depends largely on the kind of regulatory instruments used in the selfregulation. Therefore I will first present a short overview of some regulatory instruments that are generally used in the professions (\$ 2.5.1). I make a distinction between entry regulation and conduct regulation. After that I will offer some arguments for (\$ 2.5.2) and against (\$ 2.5.3) self-regulation as presented by the public and private interest approach respectively. Finally, subsection 5.4 will provide a short overview of some of the leading economic publications that use a formal (i.e. mathematic) approach to analyse self-regulation in the professions.

\subsubsection{Entry regulation and conduct regulation}

Entry regulation defines the conditions that have to be fulfilled by potential professionals in order for them to be allowed to practice in the profession. The best known type of entry regulation is the requirement of a specific diploma. Furthermore, entry into a profession may be regulated, e.g. by a mandatory registration procedure or by requirements of nationality. In some professions even a numerus clausus on the number of practitioners applies, which means that there is a quantitative restriction on the number of practitioners that is allowed on the market. All these kinds of rules are often determined by the legislator or are at least backed by the government. Thus one can notice that in many cases public regulation and self-regulation are combined. The profession itself often supplements these requirements with a 
mandatory traineeship and/or an establishment policy with regard to the distribution of professionals in a certain market.

Also licensing may be used to restrict the entry into a profession, as I explained in section 4.3 above. Certification on the other hand does not prohibit uncertified professionals from entering the market, but can on occasion have the same effect as licensing. That is, if there is insufficient demand for uncertified goods or services, uncertified professionals will eventually disappear from the market. Because both licensing and certification will have effects on the market structure I classify these types of regulation among entry regulation. ${ }^{110}$

It is obvious that conduct regulation covers all rules that directly regulate the conduct of professionals. Many forms of conduct regulation can be found in the professional code and rules of conduct formulated by professional bodies. In the professional code usually a description of the tasks and duties of profession members is given. Because it determines how profession members must perform their activities in an ethical way it is also referred to as 'professional ethics'. In reference to the rules of conduct, an often-occurring example is the prohibition of advertising. In some professions, individuals are not allowed to advertise their specific qualities, prices, or services, or make advertisements for the practice of their own; only promotion of the profession as a whole is allowed then. The argument often used by professional bodies to justify these kind of advertising rules is that they want to prevent 'commercialisation' of the profession. A second rule of conduct that is common in some professions is a restriction of cooperation with other professions. In the Netherlands, for example, a discussion took place in the 1990s regarding the question whether lawyers should be allowed to form partnerships with accountants and notaries. ${ }^{\mathrm{m}}$ Other well-known forms of conduct regulation are restrictions on incorporation, e.g. prohibitions on employment of professionals by non-professionals, and geographical restrictions on the exercise of the profession. The last form of conduct regulation that will be mentioned here is regulation of fees. The intensity of price regulation may range from advisory prices on one side to administrated prices on the other. In the last case all competition on the market is eliminated, except competition in service quality. In the case of advisory prices profession members are in theory still free to set their prices, although the chance of collective pricing behaviour is rather high.

De Bijl and Van Damme (1996) assign these types of regulation to a third category called order regulation. However, they come to the conclusion as well that entry regulation and order regulation can both be classified under 'structural measures', to make explicit the distinction with conduct regulation. 11 April 1994, and MDW (1995, pp. 45-47). In 2002, the European Court of Justice concluded in the landmark Wouters case (C-309-99) that a prohibition on multi-disciplinary partnerships between accountants and lawyers is necessary in order to ensure the proper practice of the Dutch legal profession. 
All these rules have in common that they impose restrictions on the internal competition, i.e. the competition between practitioners within the same professional group. In addition also the external competition with other - but comparable - professions may be restricted by means of a broad definition of the professional monopoly. ${ }^{112}$ Examples of a professional monopoly are the monopoly to plead for attorneys and the monopoly to dispense medicines for pharmacists. ${ }^{113}$

Having just discussed a number of possible restrictions that may result from selfregulation, the question arises how self-regulation is judged according to the public and private interest perspectives. Therefore I will now present the arguments used by both approaches.

\subsubsection{Public interest arguments in favour of self-regulation}

Three arguments in favour of self-regulation as opposed to government regulation can be found in a paper written by Miller (1985), in which he makes a case for more government reliance on self-regulation. ${ }^{114}$ His arguments refer to respectively the specific knowledge of professionals, the flexibility of self-regulating agencies compared to public bodies and the lower costs of self-regulation. The first argument brought forward by Miller, the specific knowledge argument, implies that suppliers of

112 In a recent study of liberal professions in the EU (IHS, 2003, Ch. 3), carried out by the Institute for Advanced Studies in Vienna at the request of the European Commission, the professional monopoly is considered part of entry regulation, i.e. the number of exclusive and shared exclusive tasks is regarded as a part of the licensing system. The authors define separate indices for market entry regulation and for conduct regulation. The market entry regulation index includes (weighted) indicators for licensing, requirements in education and quota's/economic needs tests. The conduct regulation index consists of the following (weighted) variables: regulations on prices and fees, regulations on advertising, regulations on location, regulations on diversification, and regulations on form of business and interprofessional co-operation. Naturally, these indicators are to a large extent subjective, because they 'are objective measures conditional upon the prior subjective definition of a higher or lower degree of regulation (as implemented by the choice and weighting of relevant categories of regulation)' (p. 33).

113 More examples of entry and conduct regulation can be found in a number of reports published in early 2003, which consider the regulation of several liberal professions in different countries. OFT (2003) investigates the regulation of pharmacists in the United Kingdom and also contains a brief comparison with the regulation of pharmacists in Canada, France, Germany, Ireiand, the Netherlands, Norway and the USA. IHS (2003) compares the regulations governing lawyers, notaries, accountants, architects, engineers and pharmacists in the $15 \mathrm{EU}$ Member States. Indecon - London Economics (2003) contains an overview and analysis of the regulation of eight distinct professions in Ireland: solicitors, barristers, engineers, architects, veterinary surgeons, medical practitioners, dentists and optometrists. See also OFT (2001), which identifies restrictions to competition in the professional rules of accountants, architects, solicitors and lawyers in the UK. The report challenges a number of those rules, saying that they should either be removed or justified. A progress report was published one year later, on 25 April 2002.

114 Miller (1985, pp. 897-898). Miller is called by some the 'leading advocate of self-regulation: see Curran (1993, p. 60) and Van den Bergh (1999, p. 110). 
services mostly have more knowledge on quality and risks than public authorities have. Miller adds to this that even if they do not have this knowledge, they can probably get this information at lower costs. Indeed, the fact that professional services are experience goods makes it very difficult for public authorities to assess the quality of these services or the risks attached to supplying low quality services. This information is needed, however, in order to effectively regulate the performance of professional services. Because of this lack of information from the side of public authorities, Miller concludes that self-regulating agencies can better regulate themselves, i.e. control the quality level provided by their members. ${ }^{115}$ Indeed, to regulate effectively the government would have to hire experts, which are usually members of the regulated profession. Self-regulation will in that case reduce costs because it combines the regulators' and the experts' roles into one. ${ }^{116}$

Secondly, Miller claims that self-regulating agencies are less formalised than public regulatory regimes and therefore more flexible. That is, public agencies often have to go through a long bureaucratic and costly process before an old rule can be changed or a new one enacted. The greater flexibility of self-regulating agencies will especially be valuable in dynamic markets, where innovation is important and/or where consumer preferences change regularly. In other words: inefficient rules will be replaced by efficient ones.

The third argument advanced by Miller is that, as a result of self-regulation, the profession itself fully bears the costs of the regulation, instead of the government. Because regulation governed by public authorities depends on tax income, self-regulation saves costs to taxpayers who do not consume the regulated service or product. Miller also claims that, because professionals regulate themselves, they have incentives to minimise the costs of enforcement and compliance, while government agencies may act to minimise only the enforcement costs of regulation. De Bijl and Van Damme (1996) add to this that generally self-regulation will enlarge the chances of acceptance and observance of conduct rules, because suppliers themselves have been involved in the actual formation of these rules. ${ }^{117}$

\subsubsection{Private interest arguments against self-regulation}

The arguments put forward by Miller are not convincing according to the private interest approach to regulation. Namely, because professionals seem to fit the criteria of special interest groups (after all, they are relatively small, single issue oriented and well organised), they lack the appropriate incentives to enforce and control quality standards. Taking this into account, one may cast doubts on the advantages derlying assumption that self-regulating agencies do not abuse the monopoly position they obtain when they become regulator (see $\$ 2.5 .3$ ).

117 De Bijl and Van Damme (1996, p. 24). 
of self-regulation discussed in the previous section. For professionals it is beneficial if competition is excluded as much as possible. Self-regulation in the form of excessively high quality standards, fixed prices, entry restrictions and stringent professional ethics may be used to achieve this goal. For example, a prohibition to advertise individual specialities will make consumers believe that all profession members are alike, which enables professionals to earn extra revenues because they can provide their services without having to worry about competition from colleagues. The result will be a decrease in the social welfare level and a redistribution of wealth from consumers to suppliers.

More specifically, the Miller-argument on relative flexibility of self-regulating agencies can be questioned along the lines of the private interest approach: if professions are able to limit competition by means of the prevailing self-regulation, they will resist any changes in the regulation that generate more opportunities for competition. The same argument applies to all changes in self-regulation that may have a negative effect on the scope of the monopoly rights of professions. The third argument of Miller has also been questioned by the private interest approach. That is, the fact that members of a profession both make the rules and bear the costs of enforcing and monitoring those rules, does in practice not imply that the regulatory costs are split in an efficient fashion between the sellers and the buyers. The profession can easily pass on most of these costs in higher prices for their services, so that in the end consumers still pay a large part of them. This leaves only the first argument of Miller, that of the specific knowledge of professionals, intact. ${ }^{118}$

The counter-arguments presented here can be summarised along the lines of the rent-seeking hypothesis by the statement that self-regulating agencies are not independent and will therefore always try to seek rents. Indeed, if one takes this assumption as a starting point the analysis is straightforward. One could for example argue that, since self-regulating agencies have special interests and at the same time carry out the enforcement of the regulation themselves, problems like information asymmetry and negative externalities will not be solved by self-regulation. After all, self-regulating agencies will then maximise their own (producer) surplus instead of that of the whole economy. Although this observation may have prima facie plausibility, it is obvious that it should preferably be supported by empirical evidence in order to have scientific value. Both the public and the private interest approach seem to contain plausible arguments regarding self-regulation. The appropriateness of the rent-seeking argument will of course also depend on the specific market that is analysed.

\subsubsection{Self-regulation: a summary of the literature}

Although many articles and books have been written that (sometimes among other issues) deal with the issue of self-regulation, it is not easy to find contributions to 
the economic literature that use a formal approach (i.e. which are based on a mathematic model) to analyse the behaviour of self-regulating agencies. ${ }^{119}$ The leading publications in this area are the articles by Shaked and Sutton (1981) and Gehrig and Jost (1995). Furthermore, Shapiro (1986), Von der Schulenburg (1986) and Donabedian (1995) have provided models that analyse the regulation of professions. Other interesting formal-economic papers, among which some of those discussed in section 4 above, mostly deal with the issues of self-regulation and rent seeking in a more general way. ${ }^{120}$

In subsection 2.4.2 I already presented Leland's conclusion that professional groups are likely to set quality standards too high from a social welfare point of view. Shaked and Sutton (1981) take this conclusion one step further. They argue by means of an economic model that the granting of monopoly rights to the selfregulating professions is likely to be welfare reducing. The intuition behind their result is that, if a profession attempts to maximise either the relative or the absolute incomes of its members, it will shrink to a size which is socially sub-optimal. ${ }^{121}$ However, they add to this rather strong statement another point, namely that it is welfare improving to permit the entry of a so-called para-profession. Such a paraprofession can supply a 'possibly inferior service at a lower price'. ${ }^{122}$ Gehrig and Jost (1995) conclude in their paper that even with asymmetric information on a market, ${ }^{123}$ self-regulation is socially desirable only if the profits of the supplier are given a sufficiently high weight in the social welfare function. ${ }^{124}$

Von der Schulenburg (1986) analyses some mechanisms that could lead to quality enforcement for professional services, in a situation where there are only high quality and low quality services and where all consumers prefer high quality. ${ }^{125}$ How-

Scarpa (1999, p. 253) states that 'the contribution that economic theory can give so far to the analysis of self-regulation is still preliminary'.

120 E.g. Stigler (1971), Krueger (1974), Peltzman (1976), Leland (1979), Becker (1983) and Shapiro (1983). See also Scarpa (1999) for an overview of some of the models discussed in this chapter. Shaked and Sutton (1981, p. 225). Shaked and Sutton (1981, p. 217).

123 The authors argue that any analysis of self-regulation has to start from information asymmetries between market participants and the social planner, because otherwise statutory regulation could implement the self-regulatory outcomes just as well. See Gehrig and Jost (1995, p. 311).

124 In their paper, Gehrig and Jost focus on the conditions and implications of self-regulation in markets in which professionals cannot credibly signal a higher quality of services individually, but may use self-regulation to enforce a (credible) minimum quality standard for the profession as a whole. The authors show that under these conditions self-regulation is more likely as monitoring costs are low, the proportion of migrants is high (in their model there is a chance that consumers may have to migrate to other local markets) or the number of local markets is small, ceteris paribus. sumers buy products for their features and that usually products have more than one feature. Of course, consumers may weigh some product features differently because their preferences 
ever, because it concerns experience goods some suppliers may try to benefit from the consumer's lack of full information by providing low quality services. His model is based on a dynamic market process in which consumers can build up long-term relationships with high quality suppliers. The author concludes - contrary to the common opinion - that administrated prices can be used to motivate new professionals to provide high quality. Entry barriers to the market should not be used according to Von der Schulenburg, because they hinder and increase the costs of such a quality-enforcing price policy. ${ }^{126} \mathrm{His}$ conclusions, however, are based on the assumptions that a supplier's marginal costs are constant (with high-quality production causing higher costs than low-quality production) and that the choice of a specific quality (high or low) is irreversible.

Also Shapiro (1986) stresses the importance of long-term reputations in his model. He analyses the effects of licensing and certification in a context where problems of professional quality are solely incentive problems, i.e. are the result of moral hazard. He concludes that licensing may improve social welfare because it alters the incentives of professionals by reducing their marginal cost of quality provision. Licensing is most effective when most consumers value quality highly, while certification is most effective when training and quality are strongly connected, according to Shapiro. However, his model also shows that licensing and certification cannot lead to Pareto improvements if consumer preferences for quality differ. ${ }^{127}$

Donabedian (1995) focuses on the creation of trust in professional services. Trust, the author states, is basic to the provision of professional services. ${ }^{128}$ Therefore he compares professional self-regulation, which is considered to be an input for the creation of such trust, with other inputs that society has at its disposal, like civil and criminal codes. The main result of his theoretical analysis is the prediction that reliance on self-regulation will increase with the specificity of investments made in human capital. In other words: professions where investments in human capital are low should be subject to other forms of enforcement than self-regulation, e.g. courts. A second prediction of the analysis, which has to do with the enforcement of regulation, is that in professions where returns are high and mobility is low, ${ }^{129}$ the commitment to the profession of individual professionals will be high.

differ. Therefore Von der Schulenburg had to make the assumption that whenever all information on the product features is available (which is not the case in a market characterised by information asymmetry), the products offered on the market can be clearly categorised according to quality.

Von der Schulenburg (1986, pp. 144-145).

Shapiro (1986, p. 856). See also the section on licensing and certification in this chapter (\$2.4.3).

Donabedian (1995, p. 107).

Donabedian defines a factor 'exit costs'. See Donabedian (1995, pp. 109-111). 


\subsection{An evaluation of the economic theory}

Having discussed the public and private interest approach to regulation, as well as a number of regulatory instruments and the issue of self-regulation versus public regulation, what does all this economic theory tell us about the regulation of liberal professions? The public interest approach teaches us that in markets for professional services (such as the market for pharmacists) there are often information problems between professionals and consumers because many professional services are experience goods or trust goods. These information problems may hence provide an argument in favour of regulation. Another public interest argument for regulation that seems to be relevant here is the presence of externalities, e.g. in the case of (too) low quality services provided by a professional. In addition, public interest theory tells us that a well-functioning competition policy is important. Competition policy should guarantee that welfare losses due to price fixing and other anti-competitive practices are avoided.

The private interest approach on the other hand warns for rent-seeking behaviour by interest groups (e.g. a professional organisation). Special interest groups may try to influence the level and the content of public regulation to their benefit. The danger of rent-seeking behaviour is of course even more present when self-regulation is involved, as has also been proven in the articles from Shaked and Sutton (1981) and Gehrig and Jost (1995). However, according to the public interest approach selfregulation also has some advantages over public regulation (specific knowledge, more flexible, less costly), although of these advantages only one argument appears to be undisputed in the literature: that of the better knowledge on quality and risks by self-regulating authorities as opposed to public authorities. Hence there is a trade-off: self-regulation seems superior to public regulation because of the superior information of the professional, but the disadvantage is that self-regulation entails a higher risk of rent seeking by the professionals. The question arises whether it is possible to enjoy the benefits of self-regulation (superior quality through better information) without the welfare losses caused by rent seeking. This is largely an empirical question which can only be answered by looking more carefully at a few specific forms of self-regulation. That is what I will do - for the case of pharmacists - in the empirical research presented in chapters 6 and 7. For these specific regulations the question will always arise whether it is an appropriate remedy for a market failure or whether the regulation in fact goes much further. It is precisely this disproportionate character of some (self-)regulations that may qualify them as instruments of rent seeking.

Welfare economics tells us that the effects of regulation on social welfare can be shown by the changes in consumer surplus, producer surplus and deadweight welfare loss. Since I have argued that (some) regulation of service quality can indeed enhance social welfare in cases of information asymmetry or externalities (by increasing the consumer surplus or decreasing the deadweight loss), the next question of course is what form this regulation should take. Therefore, I analysed some regulatory instruments, in increasing order of intervention into the market. If a certain 
profession needs to be regulated, one should take the most efficient regulatory form, i.e. the one that solves the information or externality problems at hand while keeping the restrictions to competition at a minimum. In other words, regulation should not go further than is necessary to cure the prevailing market failure.

In that respect I showed that licenses restrict market entry more than quality standards do, while in turn quality standards restrict competition more than information regulation (in the form of supervision of advertising, mandatory information provision or certification). However, in certain cases licenses work better than other forms of regulation, especially if one wants to exclude 'quacks' from the market. In the case of physicians or notaries, for example, social welfare might decrease if untrained professionals are allowed to be active on the market and simple information regulation would probably not be enough to protect consumers. What type of regulation is to be used depends therefore very much on the specific circumstances of the market. Again, one has to take care that the use of too restrictive regulations should be avoided. Price fixing is obviously the most restrictive regulatory instrument, especially when the government implements it or when it is backed by a declaration of 'generally binding'. Even though Von der Schulenburg (1986) claims that price fixing is the best way to enforce high quality production by professionals, he had to base his analysis on very specific assumptions. Namely, he assumed that on a market there are only high and (too) low quality services and homogeneous consumer preferences, whereas in reality one sees within a certain profession a wide spectrum of different qualities, while consumer preferences are often heterogeneous.

Hence, I cannot draw very firm conclusions that go into one clear-cut direction. There seems to be room for (self-)regulation in the professions, but of course one would like to see a guarantee of an improvement in social welfare. In this context the general conditions for exemption of a restrictive agreement under EC competition law, as defined in Article 81(3) of the EC Treaty, seem to provide a useful scheme. ${ }^{130}$ Application of these conditions may indicate the social welfare effects of a particular (self-)regulation. The four conditions are: (1) the agreement, decision or concerted practice must improve the production or distribution of goods or promote technical or economic progress; (2) it must allow consumers a fair share of the resulting benefit; (3) it must not impose restrictions on the undertakings that are not indispensable to the attainment of the objectives; and (4) it must not afford the undertakings the possibility of eliminating competition in respect of a substantial part of the products. If one substitutes the word 'regulation' for the phrase 'agreement, decision or concerted practice' it becomes clear that there is a link with the main themes discussed in this chapter. Indeed, condition (1) states that we only need regulation if social welfare is improved by this regulation, just as public interest

130 For a legal analysis of the conditions for exemption in Article 81(3) of the EC Treaty - former Article 85(3) - and the application thereof in individual cases, see e.g. Goyder (1998, Ch. 8) and Van den Bergh and Camesasca (2001, Ch. 4). 
theory suggests by its focus on market failure. Condition (2) adds to this that the consumer surplus must be given sufficient weight. Conditions (3) and (4) require that competition should not be restricted more than necessary (also because of the danger of rent seeking), which is just the point I stressed before. That is, one has to choose the optimal form of regulation.

Therefore, I conclude this chapter by advancing the proposition that regulation of a profession should preferably be measured against this scheme. Hence, if a group of professionals formulates a regulatory scheme, it should be checked that the proposal meets all the above-mentioned requirements.

\subsection{Summary}

In this chapter I first presented an overview of economic theories with respect to regulation in the liberal professions. The public interest approach of regulation considers regulation as a remedy for market failure, directed towards an improvement in social welfare. Four types of market failure in particular have been discerned in the literature: a lack of competition, information problems (adverse selection, moral hazard, bounded rationality), externalities and public goods. In the professions the information asymmetry argument seems to be most important. Because many professional services can be considered to be 'experience goods' or 'trust goods', regulation may be needed to prevent quality deterioration as predicted by Akerlof (1970). In addition, in some professions the moral hazard problem of demand generation (which occurs when a professional provides services to a consumer that he might not have wanted if he would have had perfect information) and the presence of externalities may provide arguments in favour of regulation. Public interest theory assumes that regulation will be formulated by government agencies to serve the public interest, but does not specify how or when a new regulation originates. Market failure always has to be compared with (possible) regulatory failure.

The danger of regulatory failure brought us to the private interest approach of regulation. This approach, as it is described in this chapter, has actually originated from three different theories: the capture theory, (parts of) public choice theory and the economic theory of regulation. Adherents of this private interest approach claim that interest groups are continually influencing political decisions in order to seek rents for themselves. This is unproductive from a social welfare point of view, since resources are devoted to capturing a wealth transfer from consumers to producers. Rent seeking is predicted to be most successful if interest groups are small, singleissue oriented and well organised. Self-regulating professional groups seem to satisfy these criteria.

Next, some regulatory instruments were investigated. In increasing order of intervention into the market, they are: information regulation, quality standards and prior approval (licensing and certification). Information regulation can be in the form of regulation of advertising or in the form of mandatory disclosure of information. 
To disclose information on the quality of professional services is a complicated matter when it concerns experience goods. In the long term the repeat buying mechanism may incite professionals to provide services of a proper quality and to voluntarily disclose information, but supervision over short-term profit seeking and false and misleading information remains a prerequisite. Standards constitute a heavier interference with the market, because they exclude certain products or services from the market. Because the computation of the optimal standard is not an easy task and because standards may exclude certain products from the market that some consumers might have still wanted to buy, it is important to investigate first whether a standard really is the best answer to an information or externality problem. When the damage resulting from a low quality service or product can be high, a more far-reaching instrument like standards or licensing may indeed be necessary. The latter instrument, licensing, prevents professionals who do not fulfil certain criteria from entering the market. The danger exists that licensing may be used by interest groups to create entry barriers. Moreover, licensing might incite some consumers to substitute licensed services by (low quality) alternative services. Certification, on the other hand, is only used as an instrument to provide information on certain specialities and/or training levels of individuals. However, training level and quality may not always be positively related, the overall effect of licensing and certification depends on the heterogeneity of consumer preferences for quality. Of course, which regulatory instrument should be used, depends very much on the specific circumstances of the market.

In section $5 \mathrm{I}$ looked at the topic of self-regulation. Many forms of self-regulation exist in the professions, often in addition to public regulation. The main arguments in favour of self-regulation can be found in Miller's article (1985). His arguments refer to respectively the specific knowledge of professionals, the flexibility of self-regulating agencies compared to public bodies and the lower costs of self-regulation. The private interest approach of regulation has brought forward some counterarguments. Namely, just because professionals seem to fit the criteria of special interest groups they lack the appropriate incentives to enforce and control quality regulation, according to this point of view. Only the argument of specific knowledge remains undisputed. However, it seems that both approaches contain plausible arguments regarding self-regulation. The formal-economic papers on the topic of self-regulation, which I discussed in subsection 5.4, do not seem to give clear-cut conclusions either. Some are critical of self-regulation, whereas others provide arguments in favour of self-regulation, but all are (necessarily) based on quite firm assumptions.

I concluded the chapter by repeating that in some professional markets there may indeed be room for (self-)regulation of quality, but one would like to see a guarantee of an improvement in social welfare. The general conditions for exemption of a restrictive agreement under EC competition law, as defined in Article 81(3) of the EC Treaty, provides a useful scheme in that respect. Therefore, regulation of a profession should preferably be measured against this scheme. 

In this chapter an overview of the market for drugs (i.e. medicines) and a brief history of the pharmaceutical profession are presented. First, the production, the distribution and the consumption of drugs are discussed (\$ 3.1). I do not aim to give an in-depth analysis of every aspect of the drug market. On the contrary, I will merely point out its basic structure, e.g. different players, categories of drugs and relevant regulation. After that the focus will be on the 'evolution' of the pharmacists' profession (\$3.2). I show that the role and functions of a modern pharmacist are different from those which he or she had some decades ago. Again, instead of an extensive historical analysis on the regulation of pharmacists, I prefer to describe only the most important changes that have occurred in the profession itself.

The reason to address the pharmaceutical market within the scope of this research should be clear: when analysing the regulation of pharmacists one should first describe what function it is that pharmacists actually exercise. Do they provide a service or are they (predominantly) sellers of pharmaceutical products? The contents of this particular function of the pharmacist may well explain the desirability of a particular type of regulation. Moreover, changes of this function over the years might also explain the changes of regulatory approaches.

\subsection{Production, distribution and consumption of drugs}

The market for drugs, on which pharmacists are active, has a number of characteristics that clearly distinguish it from other markets, and also make it a very difficult one to analyse. For one thing, many different players are active on this market besides pharmacists: the pharmaceutical industry, wholesalers, physicians (general practitioners and specialists), consumers (patients), the government, and health insurers. Furthermore, a distinction exists both between the prescribers (general practitioners and specialists) and the sellers (pharmacists) of a medicine, and between the consumers (patients) and those who pay (health insurers). Add to this the observation that the government intervenes heavily in the market by imposing all kinds of regulation, and it becomes obvious that the drug market is nothing like the 
standard economic model of supply and demand that we find in teaching books dealing with economic market structures. Therefore, one must first take a closer look at the production, the distribution and the consumption (including insurance) of drugs before one can investigate the specific regulation of pharmacists.

Figure 3.1: The drug market

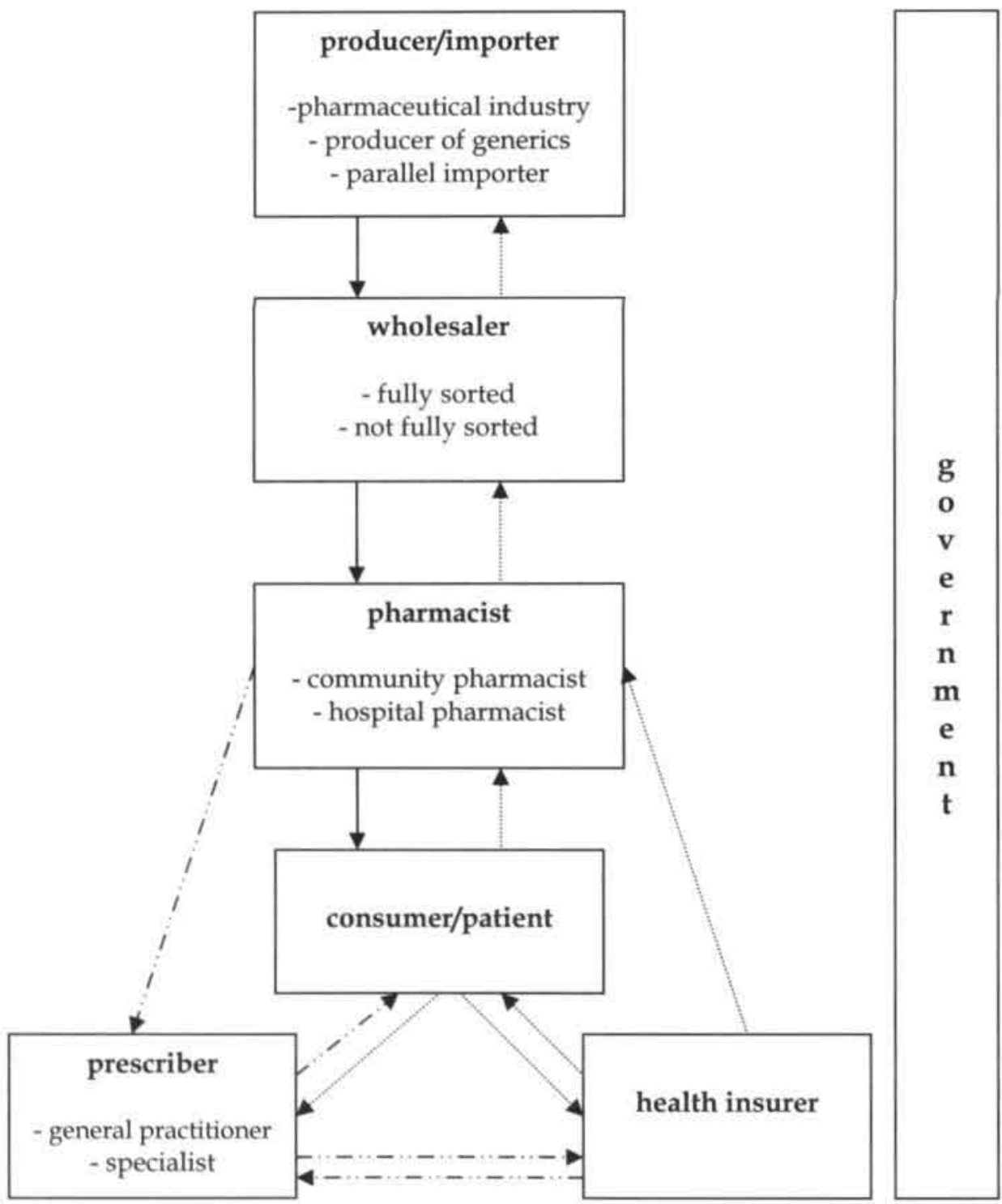


Figure 3.1 shows how complicated the drug market is. The arrows represent connections between the market participants, with the normal arrows representing flows of medicines, the dotted arrows representing flows of money, and the remaining arrows (with the dot-stripe-dot-pattern) symbolising 'other' relationships between market participants. Using this logic, one can for example read from the figure that medicines generally are distributed through wholesalers and pharmacists to the final consumer and that the financing goes via health insurers. The government, who as a regulator is involved in every stage of the drug market, is in principle connected to all market players, but for easy reference the corresponding arrows have been left out. ${ }^{131}$ In this chapter I will discuss the most important relationships between the participants on the drug market.

\subsubsection{Production}

\subsubsection{Categories of drugs}

Drugs can be divided into four different categories: pharmaceutical specialites, parallel-imported drugs, generic drugs and own preparates. Pharmaceutical specialites (or: proprietary medicinal products) are 'new' and branded drugs, which are developed by the pharmaceutical industry and protected by a patent. ${ }^{132}$ If such branded drugs are imported from other countries of the EU, outside the official distribution channel of the manufacturer, they are called parallel imports. This may occur when there are price differences between EU countries. The third category of drugs concerns the so-called generic drugs (or: generics). Generics do not always have a brand

The same argument can be made for some other relationships that are not explicitly represented in the figure, such as the direct delivery of medicines from the pharmaceutical industry to pharmacists and the supply of information from producers to physicians (which occurs regularly by means of advertisements or visits to the practices of general practitioners). Because these relationships are only of minor importance for my research topic (pharmacists) the corresponding arrows have been left out, again for easy reference.

A patent encourages drug producers to invest in research and development for new medicines (e.g. more cost-effective drugs, drugs with less negative side effects or new active ingredients). If such an invention would not be protected by a patent, other drug producers could easily copy it and bring the drug onto the market at a lower price, as they do not have to recover any investment costs (in other words: there are information externalities). This would, of course, reduce incentives to invest considerably. If, however, the inventor is granted a monopoly on the use of the new drug for a certain period of time, its incentives to invest would be restored. On the other hand: because a market that is protected by a patent is not subject to competition (see also chapter 2) and because diffusion of the innovation is prevented by the patent, the duration of the patent protection should not be infinite either. The question of the 'optimal patent life' is of course a very important one, but I will not deal with it within the context of this research. See for a discussion, e.g., Tirole (1992, pp. 394-401), Carlton and Perloff (2000, Ch. 16), and Sykes (2002). For an introduction to this topic in the law and economics literature see Cooter and Ulen (2000, pp. 128-138) and Van Velthoven and Van Wijck (2001, pp. 107-116). 
name. Instead, they are given the name of the active ingredient of the drug. ${ }^{133}$ It concerns imitations of pharmaceutical specialites, which enter into the market after the patent of the original has expired. Because producers of generic drugs do not have to recover any investments in research and development, generic drugs are cheaper than the original branded drugs. Finally, there is the category of own preparates: medicines prepared in the community pharmacy. Compared to the other categories, the number of own preparates is now very low both in the Netherlands and in Belgium, as will be explained in section 3.2 .

Furthermore, drugs are distinguished into prescription drugs and OTC (over-thecounter) drugs. ${ }^{134}$ The former must be prescribed by a general practitioner or a specialist before they can be obtained, and only pharmacists and dispensing physicians are allowed to deliver them. The latter can be obtained without a prescription, and may be sold either in the pharmacy or (in some countries) also at the chemist's or at a special counter in a supermarket. In Belgium OTC drugs may only be sold in pharmacies, whereas in the Netherlands there are more than 3000 chemist stores licensed to sell (among other products) OTC drugs, as well as over 800 chemist departments in supermarkets. ${ }^{135}$ The fact that in Belgium only pharmacies are allowed to sell OTC drugs might explain to some extent why the number of pharmacies there exceeds the number of pharmacies in the Netherlands by a considerable mar$\operatorname{gin}^{136}$

133 However, the name of the producer may be linked to the generic name of the drug. See SFK (1999, p. 21).

134 In some countries there is a third category of drugs that can only be obtained in a pharmacy or in the presence of a pharmacist: the so-called 'pharmacy-only medicines'. However, this specific category does not exist (anymore) in the Netherlands nor in Belgium, and will therefore not be considered separately here. In countries where pharmacy-only medicines do exist, such as the UK and Ireland, they are considered to be a special kind of OTC drug. See OFT (2003, volume 1, p. 13) and OFT (2003, volume 2, annexe C, p. 24).

135 Het Financieele Dagblad, Drogisterijketen koestert haar adviseursrol, 23 April 2001. In the Netherlands about $75 \%$ of all OTC drugs is sold at the chemist's, $20 \%$ is sold in the pharmacy and $5 \%$ in supermarkets, according to Het Financieele Dagblad, Drogisten ijveren voor medicijn zonder recept, 11 March 2000. Neprofarm, the Dutch association of OTC drug producers, provides more precise numbers on its website for the year 2001: in that year $78 \%$ of all OTC drugs was sold at the chemist's, $16.2 \%$ in the pharmacy and $5.8 \%$ in supermarkets. There were 3251 chemist stores and 847 chemist departments in supermarkets. Out of these 4098 OTC outlets, 3700 were licensed to sell all OTC drugs, while 398 had a limited license only (in particular at locations where there is no pharmacy or chemist store in the area). See <http://www.neprofarm.nl>.

Roughly, there are about 5300 community pharmacies in Belgium, as opposed to some 1600 community pharmacies and over 600 dispensing general practitioners in the Netherlands. The exact numbers and the developments during the last decades will be discussed in chapter 7 . 
Figure 3.2: Classification of drugs

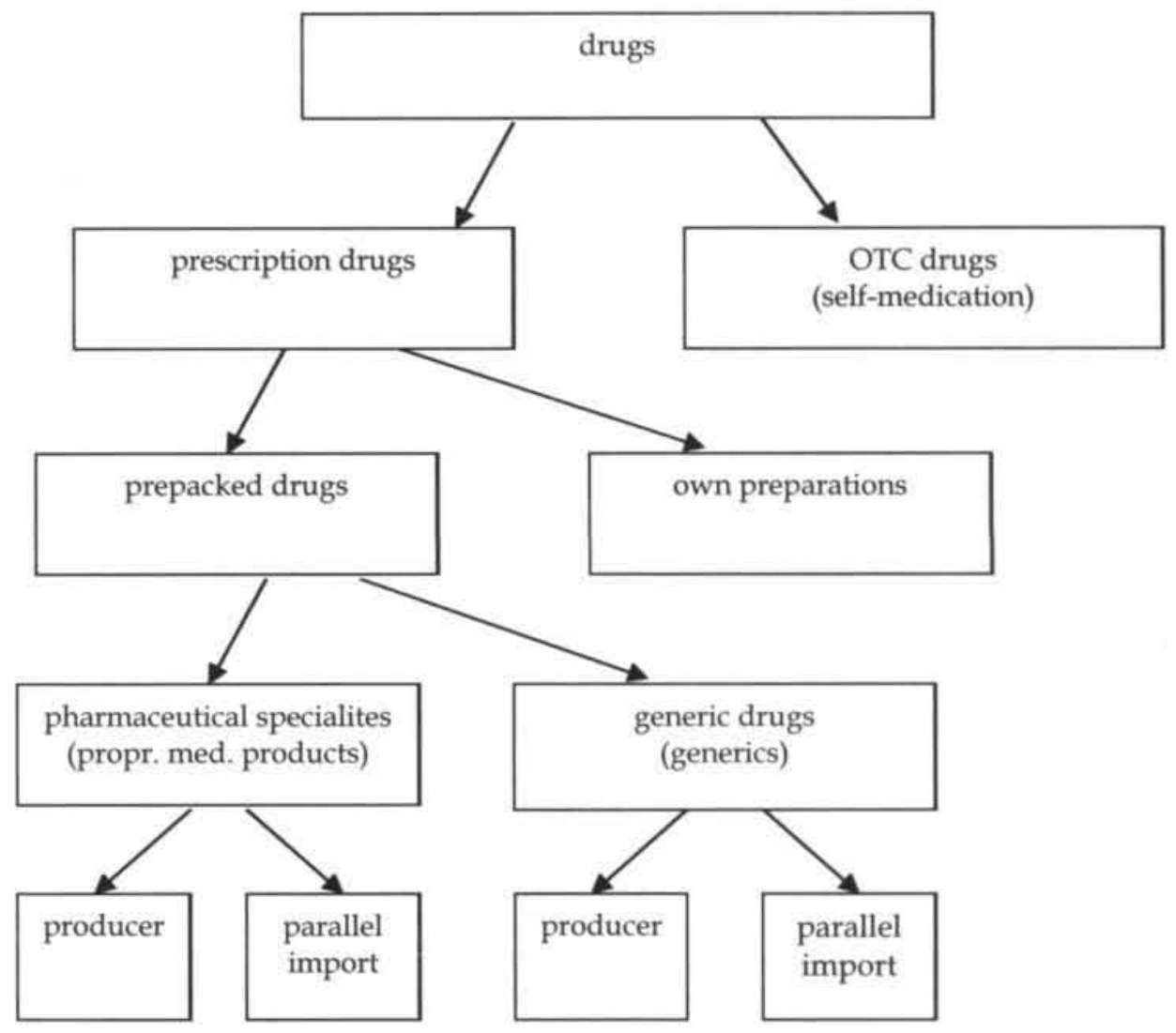

In figure 3.2 the classification of drugs described above is expressed once more by means of a diagram. For the sake of completeness I should add to the information presented in the figure, that OTC drugs can also be prescribed by a general practitioner or a specialist. However, when I talk about 'prescription drugs' I specifically refer to those drugs that can only be obtained on prescription, as shown in figure 3.2.

The share of generic drugs in the total number of prescriptions has been increasing for years in the Netherlands, at the expense of the share of parallel imports and pharmaceutical specialites. In 1995, $27.8 \%$ of all prescribed drugs were generics; in 1998 this number had increased to $37.4 \%$, while in 2001 it was $42.0 \%$. The share of parallel imports decreased from $12.1 \%$ in 1995 to $7.1 \%$ in 2001 , predominantly as an effect of price regulation by the Dutch government, as a result of which in the Neth- 
erlands price differences between different categories of drugs have decreased. ${ }^{137}$ The market share of specialites in the total number of prescriptions was $53.5 \%$ in 1995 and had decreased to $42.8 \%$ in 2001 , which is only slightly larger than the share of generic drugs. However, if one looks at the share of specialites in the total drug costs of prescribed medicines, one will find a larger number. As a percentage of total drug costs the following numbers can be found for the year 2001: specialites $66.6 \%$, parallel imports $13.8 \%$ and generics $16.3 \%$. Although here as well the share of specialites has slowly decreased over recent years (in 1999 it was still $67.1 \%$, leaving $14.5 \%$ for parallel imports and $15.1 \%$ for generics), it remains relatively high because new and often more expensive drugs come onto the market every day. ${ }^{138}$

In the Netherlands the share of generic drugs in the total consumption of prescribed drugs has always been very large compared to Belgium. In Belgium generics are hardly used. ${ }^{139}$ The explanation for this is simple: in Belgium the law still prohibits pharmacists to substitute pharmaceutical specialites (which have been prescribed by physicians) by generic drugs, although quite recently proposals have been made both by the government and by pharmacists to encourage the use of generics. I will discuss this in more detail in $\$ 3.2 .1$ and in $\$ 5.7$, where the recent developments in the Belgian regulation are central.

\subsubsection{Drug prices}

Contrary to what one might expect, drug prices are only to a small extent based on economic factors such as production costs and intensity of competition. Of course, these economic factors will have an influence on the price level, but manufacturers do not determine the prices solely by themselves. ${ }^{140}$ On the contrary, drug prices are heavily regulated by the government, both in the Netherlands and in Belgium. There are, for example, regulations that set maximum prices for drugs, and regulations that determine the fees of pharmacists. These will be discussed in $\$ 4.6$, for the Netherlands, and in $\S 5.6$, for Belgium. Furthermore, rules exist that regulate the

SFK (2001, p. 27). I will discuss the regulation of the price of drugs by the Dutch government at length in \$4.6.1.

Data source: SFK (Foundation for Pharmaceutical Statistics).

SFK (2002, p. 48). The SFK (Foundation for Pharmaceutical Statistics) also writes on the same page that in Germany and England generic medicines are used widely, while in Italy the share of generic drugs is low, like in Belgium.

The drug production market (the pharmaceutical industry) is not examined in this thesis, because it is only indirectly related to the retail market on which pharmacists are active. The drug industry in Belgium is described in AVGI (1998). Information on the Belgian and Dutch pharmaceutical industry can also be found on the websites of AVGI (<http://www.agimavgi.be >) and Nefarma (<http://www nefarma.nl>). 
maximum amounts that are to be reimbursed by health insurers. These are described in the appendix to this chapter. ${ }^{141}$

\subsubsection{Distribution}

I stated above that the 'normal' arrows in figure 3.1 represent the flow of drugs (i.e. the distribution) from the producer/importer to the final consumer/patient. A central role in the distribution is reserved for the pharmaceutical wholesaler, who constitutes the intermediary between producer and pharmacist. In this section I will look more closely at the position of the pharmaceutical wholesaler, as well as at the distribution function of pharmacists, the 'retailers' of the drug distribution channel.

\subsubsection{The wholesale channel}

The pharmaceutical wholesaler forms the link between manufacturers and dispensers of drugs, ensuring a safe and continuous supply (sometimes even several times a day) of medicines. Medicinal products often need special storage and secure handling. Obviously, dispensers (such as hospital and community pharmacists, dispensing physicians, and - in case of OTC drugs in the Netherlands - also chemists) cannot keep every medicine in stock; not only because of lack of storage room but also because this would be extremely costly. However, direct delivery from manufacturers to dispensers would be even more expensive. ${ }^{142}$ In the Netherlands, 90 to $95 \%$ of all medicinal products are purchased via wholesalers, according to an investigation by the Dutch Competition authority NMa. ${ }^{143}$ That leaves a share of 5 to $10 \%$ for direct deliveries from producers and importers to dispensers.

In the Netherlands BG Pharma, a trade organisation consisting of only four members (OPG, ${ }^{144}$ Brocacef, Interpharm and Euromedica) represents $80 \%$ of the total

141 For a brief overview of price and reimbursement regulations in Canada, France, Germany, Italy, Japan, the United Kingdom and the United States, see Danzon and Chao (2000, pp. 316$321)$. OFT (2003, volume 1) analyses some aspects of drug pricing in the United Kingdom. In OFT (2003, volume 2, annexe C) the regulation of drug prices in Canada, France, Germany, Norway, the Unites States and the Netherlands is presented briefly. See with respect to drug pricing also IHS (2003, Chs. 11-14) for case studies of the pharmaceutical profession in Ireland, Germany, Portugal and Sweden, and OECD (2002, pp. 193-197) for tables on price controls, profit controls, and price freezes and cut measures in selected OECD countries.

See the website of the European Association of Pharmaceutical Wholesalers, GIRP: <http://www.girp.org>.

NMa, Decision nr. 2451/2001 (Mediveen Groep B.V. en TTP Participaties Rotterdam B.V/Coriopharma C.V.), p. 7.

144 Within this trade organisation the OPG group is dominant with a share of over $40 \%$. The OPG is a very interesting case in itself, as this wholesale company has bought up many pharmacies in recent years. The OPG even has a background in retail pharmacy: it was established years ago by pharmacists. In a case study in chapter 7 I will discuss OPG in more detail (see $\$ 7.6$ infra). 
wholesale market. ${ }^{145}$ BG Pharma organises all so-called fully sorted wholesalers (volgesorteerde groothandels), which means that its members supply every medicine that is available in the Netherlands. In addition to these fully sorted wholesalers, there are a number of smaller wholesale dealers that supply only the most frequently prescribed medicines (niet-volgesorteerde groothandel). Wholesalers have been engaged a lot in backward and forward vertical integration. ${ }^{146}$ Backward integration by wholesalers takes place particularly by the taking-over of generic drug producers. For some wholesalers the production of generic drugs has become an important additional activity. Forward integration takes place, e.g. when a wholesaler buys up pharmacies in order to set up a franchise (i.e. a chain of pharmacies working under the same formula). In this way the wholesale industry provides itself with the opportunity to deliver drugs directly to patients. ${ }^{147}$ In the Netherlands the OPG group is very active in this field. ${ }^{148}$

The wholesale market in Belgium is less concentrated than the Dutch market. There are many relatively small companies, most of which are regionally oriented. Since 1 January 2002, the biggest wholesaler has been Febelco, with a market share of around $29 \% .{ }^{149}$ The German pharmaceutical chain GEHE is in second place: when the market shares of its three members are combined, GEHE's market share in the Belgian wholesale market in 2001 was $17 \% .{ }^{150}$ Furthermore, Les CERP ${ }^{151}$ had a mar-

Estimates of the exact market shares as published in the media differ slightly, depending on the consulted sources. For the year 2001 the market share of OPG in the Dutch wholesale market was estimated to be between $30 \%$ and $35 \%$ (most probably closer to $35 \%$ ), while that of its closest competitors Brocacef and Interpharm was calculated to be approximately $21 \%$ and 18\%, respectively. See, e.g., NMa, Decision nr. 2451/2001 (Mediveen Groep B.V. en TTP Participaties Rotterdam B.V./Coriopharma C.V.), p. 7. More information can be found on the websites of the wholesale companies: 〈http://www.opggroep.nl>, <http://www.brocacef.nl>, and <http://www.interpharm.nl>

146 Vertical integration means integration between parties that are active in different channels of the supply chain, e.g. integration between a producer and a wholesaler, or between a wholesaler and a retailer. Horizontal integration, on the other hand, stands for integration between suppliers within the same supply channel, such as integration between producers, integration between wholesalers and integration between retailers.

147 Nefarma (2000, pp. 23 and 57).

148 MDW (1999, pp. 22-23). With respect to OPG: supra, note 144.

149 Febelco came about through a merger of three formerly independent wholesale companies: ASMA (the biggest wholesaler in 2001 with a market share of $17 \%$ ), Inter Nos and LIFAK. See <http://www.febelco.be>.

150 The pharmaceutical wholesale business of GEHE in Belgium consists of PCB (11\% market share in 2001), SAMBRIA (4\%) and Ostend Pharma (2\%). GEHE A.G. is the European market leader in the field of pharmaceutical distribution, with activities in 10 European countries in 2001. In the Netherlands GEHE was not involved in wholesale activities in 2001, although in that year it started to buy up Dutch pharmacies (in Belgium it entered the retail market as well: Lloydspharmay Belgium S.A.). This information about GEHE and about the market shares of pharmaceutical wholesalers in Belgium was found on the internet: <http://www.gehe.de> and <http://www.febelco.be>. In April 2003 GEHE A.G. was renamed Celesio A.G.: <http://www.celesio.com>. 
ket share of $16 \%$ and Alpha Repartition a market share of $10 \%$ in 2001 , while the remainder of the market was served by smaller wholesalers.

\subsubsection{The retail channel}

There are two channels for the delivery of prescribed pharmaceuticals to the final consumer (patient): via community pharmacies (and sometimes dispensing general practitioners) and via hospital pharmacies. The former is called the extramural drug market, the latter the intramural drug market. In Belgium the extramural market is by far the biggest as it generates about $76 \%$ of the total ex-factory turnover; the hospital market generates the remaining 24\%.152 Somewhat comparable numbers for the Netherlands state that $14 \%$ of the total turnover of drugs in the Netherlands is gained by hospital pharmacies, which leaves $86 \%$ for dispensers in the extramural market. ${ }^{153}$ In this thesis I focus in particular on the extramural drug market, i.e. on community pharmacists.

The sale of drugs via internet and the amount of drug information that consumers can obtain through the internet have increased considerably over the last years. It seems that a new distribution channel for drugs has opened up: the internet pharmacy. Drugs that are distributed in this fashion still require a prescription from a general practitioner or specialist and the distribution must be done from a community pharmacy, ${ }^{154}$ but there is no direct supervision by the pharmacist. ${ }^{155}$ In order to

Les CERP consists of the Flemish wholesaler Aprophar (market share in Belgium: $9.20 \%$ ) and the Walloon wholesaler Cerp Phardip (6.53\%). See <http://www.aprophar.be> or <http:// www.phardib.be $>$ and for the market shares: $\langle$ http://www.febelco.be $>$ and $\langle$ http://www. gehe.de>. AVGI (2002, p. 21).

153 NMa, Decision nr. 2451/2001 (Mediveen Groep B.V. en TTP Participaties Rotterdam B.V /Coriopharma C.V.), p. 6. These numbers include OTC drugs.

In April 2000 a Dutch internet pharmacist (Rijkeboer) had to stop his activities because - according to the Inspection for Public Health - he did not comply with these legally determined conditions. See Het Financieele Dagblad, Internetapotheker stopt met activiteiten, 4 May 2000. Another - although very different - case concerns the Dutch internet pharmacy DocMorris (website: <http://www.0800DocMorris.com>), which had to appear before the European Court of Justice. The DocMorris pharmacy was selling drugs via internet to Dutch and German consumers. In Germany the prices of drugs are sometimes 15 to $20 \%$ higher than the drug prices in the Netherlands. However, according to German law a pharmacy is not allowed to send drugs by mail because of a prohibition on long distance sales. This was confirmed by the German court of Frankfurt in November 2000 in a case against DocMorris, but DocMorris appealed to this decision. In July 2001 the Court of Frankfurt referred the case to the European Court of Justice, which then had to consider the question whether European citizens should be allowed to order medicines registered within Europe by mail. In other words: do the German rules contradict the European rules with respect to the free movement of goods? Advocate General Stix-Hackl of the European Court of Justice was of the opinion that DocMorris should be allowed to deliver medicines to German clients, but that the distribution should be restricted to non-prescription drugs and to drugs that are authorised on the German market (Opinion, 11 March 2003). The judgements of the Landgericht Frankfurt am 
obtain prescription drugs from an internet pharmacy, consumers have to fill out an order form and send it, together with the original prescription, to the internet pharmacy by regular mail. Within a few days the drugs will be delivered to the consumer at the address of his/her choice. The consumer has to sign for receipt. The advantages of an internet pharmacy over a regular community pharmacy can be threefold: (1) internet pharmacies are sometimes cheaper: some non-prescribed OTC drugs are offered with an 'internet discount' of up to $5 \%$; (2) privacy-sensitive medicinal products such as contraceptives, incontinence products, and AIDS inhibitors, can be ordered through the internet; and (3) chronic drug users may profit from the internet channel as they do not have to go to a pharmacy every time for their repeat prescriptions. ${ }^{156}$ This already suggests that the main activities of internet pharmacies do not concern prescription drugs, but rather the products just mentioned, i.e. OTC drugs, privacy-sensitive medicinal products and some repeat prescriptions. In the Netherlands the number of internet pharmacies in 2000 was about $40 .{ }^{157}$ In Belgium the concept of internet pharmacies is still practically unknown, although in 2003 the American company Drugstore.com announced plans to start the sale of non-prescription drugs through the internet in 28 countries, among them Belgium. Belgian pharmacists doubt whether this is allowed, because Belgian laws prohibit long distance sales. ${ }^{158}$

Main can be found on its webpage: <http://www.landgericht.frankfurt-main.de>, under $A k$ tenzeichen 2-03 O 365/00, Aktenzeichen 2-03 O 366/00, and Aktenzeichen 3/11 O 64/01. See also Zorgkrant, Internetapotheek gaat naar Europees Hof, 18 August 2001. The judgement of the European Court of Justice can be found on the official website <htttp://curia.eu.int>, under Case C-322/01 Deutscher Apothekerverband.

Nefarma (2000, pp. 23 and 57).

See, for example, the website of eFarma, one of the biggest internet pharmacies in the Netherlands in 2003: <http://www.efarma.nl>. H.Tjiook, initiator and owner of eFarma, suggested the same advantages of an internet pharmacy over a community pharmacy again in various interviews: Reformatorisch Dagblad, Medicijnen bestellen bij internetapotheek, 6 June 2000; Emerce, Miljoenenboete voor internetapotheek, 6 October 2002. Furthermore, in the former article $\mathrm{H}$. Wieringa of Digitale Apotheek Nederland, another Dutch internet pharmacy, confirms that his internet pharmacy concentrates predominantly on selling privacy sensitive products such as contraceptive devices. For more information see also the website of Dé Virtuele Apotheek: <http://www.apotheek.org>. In early 2003 no less than 44 pharmacies were linked to this website, which next to providing a drug delivery service, also disseminates information about drugs and health care.

De Volkskrant, Apotheker krijgt nieuwe concurrentie, 9 August 2000. In the same year, online pharmacies in the United States had already reached a market share of $1 \%$. In the Netherlands internet pharmacies have not yet reached that market share, but initiator-owner $\mathrm{H}$. Tjiook of eFarma expects that it will be reached in 2006: Emerce, Online apothekers verwachten langzame groei, 21 July 2000; Emerce, Beter worden, 6 October 2000.

Het Laatste Nieuus, De internetfarmacie, kan dat wel?, 10 January 2003. I mentioned before that also in Germany the long distance sale of drugs is prohibited (supra, note 154). The decision of the European Court of Justice in the DocMorris case will therefore be of importance to Belgium as well. This decision, which at the time of writing was not yet available, can be 
Another development in the distribution of drugs is mail order pharmacy. Although the first two initiatives to introduce this kind of pharmacy in the Netherlands (by the health insurer Geové in 1992 and by health insurer Zilveren Kruis and Caremark in the mid-1990s) ${ }^{159}$ have failed, they had some success at first. The failure of these mail order 'experiments' was to a large extent caused by counter-campaigns from the side of the Dutch pharmacists and the big wholesale companies. ${ }^{160}$ Nowadays, however, many pharmacies have their own home delivery service, which might be considered a (late) reaction to the failed attempts at mail order pharmacy in the 1990s.

\subsubsection{Regulation of distribution margins}

In Belgium both the margin of a pharmaceutical wholesaler and the margin of a pharmacist are subject to strict regulation. The wholesaler is allowed to take a margin of $13.1 \%$ of his sales price, exclusive of VAT, with a maximum of $€ 2.18 .{ }^{161}$ In the Netherlands there is no such regulation of the wholesale margin, although, like in Belgium, the prices of drugs are heavily regulated, which of course has a large effect on competition and the margins of the players on the pharmaceutical market. ${ }^{162}$ The regulation of the drug prices and the pharmacist's fee in the Netherlands and Belgium will be presented in $\$ 4.6$ and $\$ 5.6$ respectively.

\subsubsection{Consumption}

Figure 3.1 showed that the consumption of prescription drugs is different from the consumption of most other products. First, consumers (patients) need a prescription from a general practitioner or specialist in order to obtain prescription drugs. Second, consumers often do not have to pay the full price of these drugs themselves, because - at least to a certain extent - their health insurers take care of this. ${ }^{163}$

In the Netherlands, if a patient consults a general practitioner, in $60 \%$ of the cases this leads to a prescription of a certain medicine. This is a low percentage compared

found on the official website of the European Court of Justice <http:www.curia.eu.int>, under Case C-322/01 Deutscher Apothekerverband.

$159 \operatorname{MDW}(1999$, p. 24); PriceWaterhouseCoopers (1999, p. 21).

160 See, for the case of Geové, a detailed analysis by Horsten (1996-1997).

161 AVGI, 2002, p. 24. See also PriceWaterhouseCoopers (1999, p. 15). With respect to the pharmacists' margin, I refer to $\$ 5.6 .2$, where that topic will be discussed at length.

162 PriceWaterhouseCoopers $(1999$, p. 21$)$ presents a table with information on the average price structure of medicines in a number of countries, among them the Netherlands and Belgium. The price structure, divided into manufacturer margin, wholesaler margin, pharmacy margin and VAT $\%$ was computed to be, for the Netherlands: $67.2 \%, 11.4 \%, 21.4 \%$ and $6 \%$ respectively. For Belgium the numbers are: $64.7 \%, 8.3 \%, 27 \%$, and $6 \%$ respectively. These computations were based on data from 1997. See also KNMP (2002b, p. 16) and AVGI (2002, p. 24).

163 In the appendix to this chapter I will outline the health insurance with respect to pharmaceuticals in the Netherlands and in Belgium. 
to the European average and in particular compared to southern European countries such as Spain and Italy, where the prescription percentage can increase to more than $90 \% .{ }^{164}$ However, in its last annual reports the Foundation for Pharmaceutical Statistics (SFK) has been noticing a slight change in the prescription pattern and the drug consumption pattern in the Netherlands towards the European average. ${ }^{165}$ Moreover, and this does not apply to the Dutch situation only, consumers nowadays take more individual responsibility than they did some decades ago, for example by asking the general practitioner for a prescription (or even by asking for a specific medicine) based on information found on the internet.

In Belgium the prescription percentage of physicians is much higher than it is in the Netherlands. In the annual report 2001 of Nefarma (the Dutch Association of the Research-based Pharmaceutical Industry) the 'percentage diagnosis with prescription' was shown for seven European countries, among them Belgium and the Netherlands. Belgium had the second highest percentage diagnosis with prescription, namely $87 \%$, before France, Spain, the United Kingdom and Germany. Only in Italy the percentage was higher (95\%). The Netherlands had - with $61 \%$ - the lowest percentage of all seven countries that were investigated. ${ }^{166}$

While patients generally do not have sufficient knowledge about drugs in order to be able to co-decide on the kind of therapy they need, an exception to this might be patients with chronic diseases. Nowadays there are many patients' associations both in the Netherlands and in Belgium. In the Netherlands there is also an umbrella organisation called the NP/CF, the Dutch Federation of Consumers/Patients. The main objective of the NP/CF is to form a countervailing power on the demand side of the health care market vis-à-vis health insurers, health care suppliers and the government. Furthermore, the NP/CF seeks to improve the knowledge of health care consumers by making information available to them and to function as a consultation platform for all patients' associations and health care consumers. ${ }^{167}$

The price sensitivity of consumers with respect to prescription drugs is different from their price sensitivity towards 'normal' consumption goods such as foods and electrics, because there is no direct relation between the price of a prescription drug (which is after all paid by health insurers) and the health insurance premium (paid

SFK (2002, p. 22). See also MDW (1999, p. 57) and Nefarma (2001, p. 42).

See also Ministerie van Volksgezondheid, Welzijn en Sport (1999, p. 30) and PriceWaterhouseCoopers (1999, pp. 17-18).

Nefarma, 2001, p. 42. In PriceWaterhouseCoopers (1999, p. 17) numbers for the year 1996 are presented for the same countries with the exception of Italy and based on the same source (IMS Health). When these numbers are compared with the numbers provided in Nefarma (2001), there is just one difference: in 1996 the 'percentage diagnosis with prescription' in the Netherlands was only $56 \%$.

Website: <http://www.npcf.nl>. 
by consumers), unless consumers have to pay a deductible. ${ }^{168}$ Furthermore, when general practitioners have to decide which particular drug they prescribe in a certain situation, they will not only take price as a criterion but also other factors such as possible side effects of a drug and familiarity with a particular (brand of medicine. Of course the latter makes it interesting for drug producers to pay a visit to the practices of general practitioners and specialists in order to make them 'familiar' with their products.

\subsection{The profession of pharmacist in the Netherlands and Belgium}

The pharmaceutical profession has been subject to many changes since the middle of the last century. While in the 1950 s the tasks of a pharmacist consisted merely of the preparation (i.e., compounding) and dispensing of medicines, nowadays pharmacists are especially considered to be the 'experts' in the field of pharmacotherapy. Modern pharmacists not only have a role in the drug distribution process, but also together with physicians - in the provision of health care (the term 'pharmaceutical care' is often used in this respect). ${ }^{169}$

In § 3.2.1 the developments that have taken place in the pharmaceutical profession during the last decades will be described. These changes have occurred gradually in many countries, ${ }^{170}$ largely under the influence of the rise of the pharmaceutical industry and the constantly increasing complexity of pharmacotherapy. Therefore, I will discuss the changes in the pharmaceutical profession in general terms: the discussion below applies not only to Dutch and Belgian pharmacists, but also to pharmacists in other countries such as, e.g., Germany, France and the United Kingdom. ${ }^{171}$ In $\$ 3.2 .2$ I will give a definition of the 'service' of a pharmacist. I need to define the main tasks of a pharmacist in order to be able to analyse the regulation of the profession in subsequent chapters.

\subsubsection{Developments}

Until the 1950s the main tasks of a pharmacist consisted of the preparation (compounding) and the dispensing of drugs to patients, on the basis of a prescription by a general practitioner or a medical specialist. The Dutch and Belgian regulation of the pharmaceutical profession protected these operations with a professional monopoly (which they still do now, as will be shown in chapters 4 and 5). However, under the influence of the introduction of the industrially prepared medicine - especially after the second World War - the preparing role of the pharmacist has

MDW (1999, p. 21).

Mullan (2000, pp. 38-43). Ten Hoopen (2001, p. 379) also uses the term 'pharmaceutical patient care'.

Ten Hoopen (2001, pp. 221-223) gives some examples.

The regulation of the profession in the Netherlands and in Belgium will be discussed below in chapter 4 and chapter 5 respectively. 
largely disappeared. In the Netherlands, between 1970 and 1990 the share of own preparations by pharmacists had stabilised around $5 \%$ of the turnover of a community pharmacy. ${ }^{172}$ For the year 2000 the Dutch Foundation for Pharmaceutical Statistics calculated the market share of own preparations in a community pharmacy to be just over $5 \%$, relative to the total number of prescriptions. ${ }^{173}$ With respect to Belgium, the Belgian Institute of Health Economics (BIGE) wrote in its 1999 report that between 1972 and 1992 the relative share of magistral preparations in the total expenditure for reimbursable drugs had decreased from $21 \%$ to $6.5 \% .{ }^{174}$ Modern pharmacists seem to be charged with different tasks and responsibilities instead. Here I will sketch the development of the pharmaceutical profession, which is still going on today. ${ }^{175}$

Van der Mijn (1989) describes three developments that have had a big influence on the pharmaceutical profession during the last century. While his analysis is primarily directed towards the Dutch situation, most of his findings apply to the profession in general. First, he mentions the rise of industrially prepared medicine at the expense of magisterially prepared medicine. As a result of this rise the emphasis in the pharmaceutical profession has shifted considerably from preparation of drugs towards distribution of industrially prepared products. ${ }^{176}$

Second, and related to the first point, is his observation that the medicine market has become more complex, because of the constantly growing number of new medicines and active substances that are brought onto the market each year. The complexity of the market makes it difficult for physicians to decide on which drug to prescribe, especially if they would not receive help from pharmacists. Compared to pharmacists, physicians generally know little about the chemical structure of drugs. Within the scope of their education it is impossible for physicians to acquaint themselves sufficiently with pharmacology and pharmacotherapy. Pharmacists, on the other hand, are educated less in medical-biological aspects, i.e. the human body. ${ }^{177}$ Hence, an important part of the surplus value of a modern pharmacist consists (or

TK 1998-1999, 26344 , nr. 1, p. 6.

SFK (2001, p. 28). In $2000,43.2 \%$ of all prescribed drugs and bandages were specialites; $41.5 \%$ were generics; $7.1 \%$ parallel imports; $2.9 \%$ bandages; and $5.3 \%$ own preparations and others. The share of own preparations and others as a percentage of total drug costs for the year 2000 was $1.4 \%$.

BIGE (1999, p. 113).

For a more elaborate discussion of the history of the pharmaceutical profession (also before the second half of the 20th century) see, in particular, Van der Mijn (1989, Chs. 2 and 5) for the Netherlands, and Mullan (2000, Chs. 2 and 3) for the UK.

Van der Mijn (1989, p. 107). Patients who need own preparations are now exceptional cases, e.g. a particular registered drug may be too strong for young children. Also, some patients may not be able to swallow a particular registered drug and administration by means of a cathether or infusion is required then. Pharmaceutisch Weekblad, Apotheekbereidingen, vol. 134, nr. 25, 25 June 1999.

Van der Mijn (1989, p. 108). 
should consist) of the transfer of his or her knowledge of drugs to prescribing physicians. Thus a kind of transfer of information between the pharmacist and the physicians has to be organised. In the Netherlands the cooperation between pharmacists and physicians does not only take place on an individual basis. On the contrary, the so-called pharmacotherapeutic consultations (structural consultations between groups of general practitioners and pharmacists) and pharmacotherapeutic transmural consultations (including hospital pharmacists and specialists as well) have been growing in importance rapidly. ${ }^{178}$ These consultations are stimulated and supported by the Dutch Ministry of Public Health, because the government hopes to reduce total health care costs by encouraging physicians to prescribe more cost-consciously. ${ }^{179}$ In many cases the pharmacotherapeutic (transmural) consultations lead to the setting up of local formularies ${ }^{180}$ and protocols. ${ }^{181}$ Belgian pharmacists and physicians, however, are not familiar with the concept of pharmacotherapeutic consultations.

The third development described by Van der Mijn is the differentiation in the practice of the profession. Nowadays one can distinguish between three types of pharmacists: community pharmacists, hospital pharmacists and industry pharmacists. ${ }^{182}$ Of course this increased specialisation has had an influence on the specific tasks of each type of pharmacist. In this thesis I focus primarily on community pharmacists.

In Ten Hoopen (2002) the Dutch pharmaceutical market is studied from a legal point of view. Like Van der Mijn, the author observes that the current role of pharmacists is very different from the one they had some decades ago. However, Ten Hoopen suggests that this change resulted not only from an increase in industrially prepared medicines, but also from the introduction of the computer in the pharmacy. She mentions some of the 'new tasks' of a modern Dutch pharmacist, which are recognised both by pharmacists and by the government: medication control (i.e.,

In Dutch: 'FarmacoTherapeutisch (Transmuraal) Overleg', hereafter FTO. At the end of the 1970s, FTO between pharmacists and general practitioners was introduced in the Netherlands on a local level. The goal of FTO is to improve the quality and effectiveness of medication use. See Blijleven (1998, p. 45). For a brief description of FTO and FTTO (pharmacotherapeutic transmural consultations) in the Netherlands, see, e.g., MDW (1999, p. 33) and Ministerie van Volksgezondheid, Welzijn en Sport (1999, pp. 55-56). The Boston Consulting Group (1999) is critical about the results of these consultations insofar as cost savings are concerned. TK 2000-2001, 24124 and 24 036, nr. 111, pp. 4, 17-19.

According to Venema (1998, p. 16) a formulary 'incorporates the preparations that should preferably be prescribed and delivered'. This means that a formulary always concerns a selection from the total range of medical preparations. See also OECD (2002, pp. 143-144).

See Moss (1998, p. 13) and supra, note 179. In the context of pharmaceutical patient care (for an introduction to this concept: supra, note 169) a protocol can be defined as 'a document in which the operations regarding pharmaceutical patient care for a group of existing or new users of a certain medicine, who are taking the medicine for the same purpose, are defined'. See Schüsler-van Hees, Essink and De Smet (1998, p. 34). 
checking for possible interactions with other drugs used by the patient), monitoring of therapy (primarily checking the prescription from the general practitioner or specialist), advising consumers on medicinal products and drugs, ${ }^{183}$ and providing pharmacotherapeutic information and advice to physicians. ${ }^{184}$ Indeed, in a letter of December 1998 to the Second Chamber (i.e., the Lower Chamber), the Dutch Minister of Public Health explicitly listed some of the new tasks and responsibilities of pharmacists: medication control, giving advice, information and documentation to patients, cooperation with physicians and detection of side effects of new drugs that are brought onto the market. ${ }^{185}$ However, the regulation of the profession has not yet been adapted much to the new role and functions of the pharmacist, as will be shown in chapter $4 .{ }^{186}$

If one looks at recent issues of some of the professional journals in pharmacy ${ }^{187}$ and at the national newspapers, ${ }^{188}$ one will note that pharmacists as well tend to emphasise the 'care' aspect of their profession as opposed to the distribution aspect. For example, many articles in the professional journals deal with the relationship between (community) pharmacists and patients, or are about the above-mentioned pharmacotherapeutic consultations with general practitioners and hospital pharmacists. Furthermore, health insurers in the Netherlands increasingly include the protocols, formularies and agreements resulting from pharmacotherapeutic consultations in their contracts with pharmacists and physicians. This, however, requires adequate information on the prescription behaviour of physicians and the

Examples are: providing information and advice related to travelling and health, to incontinence products (including samples) and to diabetes (including instructions of test strips and blood sugar meters), giving inhaler instructions, supplying needle-containers, etc. See Pharmaceutisch Weekblad, Meetbare zorg, vol. 137, nr. 25, 2002. Details about the information provided in pharmacies can also be found on various websites of pharmacies. Sometimes the information given by the pharmacist is a repetition of the information that was given by the physician, especially in case of the first distribution of medicinal products related to incontinence, asthma, diabetes, high blood pressure and menopause. The reason is that a patient in such cases often still has to process the diagnosis of the physician and wants to hear it again from the pharmacist, according to De Volkskrant, Apotheker nieuwe stijl houdt spreekuur, 17 January 2002.

Ten Hoopen (2001, pp. 30-31); further on in the book (pp. 216-223) she sketches the transformation process of the Dutch pharmacist as from the mid-1970s: from medication control (medicatiebewaking) to medication guidance (medicatiebegeleiding) and pharmaceutical patient care (farmaceutische patiëntenzorg). TK 1998-1999, 26 344, nr. 1, p. 6.

And 1 will show in chapter 5 that also in Belgium the regulation is still considerably lagging behind the development of the profession. See, for the Netherlands, Pharmaceutisch Weekblad, and for Belgium, in particular Antwerps Farmaceutisch Tijdschrift.

E.g. De Standaard, Mensen helpen geeft apotheker kick, 14 February 2000; De Volkskrant, Apotheker nieuwe stijl houdt spreekuur, 17 January 2002; Het Financieile Dagblad, Apothekers eisen $40 \%$ meer salaris, 26 March 2002. 
dispensing behaviour of pharmacists; otherwise health insurers will not be able to supervise the compliance with these provisions. ${ }^{189}$

Contrary to their Belgian colleagues, Dutch pharmacists are already allowed - and encouraged - to substitute branded drugs by generics, be it of course under certain conditions, among which the consent of the prescribing physician and the consent of the patient. The (legal) possibility of substitution in itself indicates yet another function of a modern pharmacist: to substitute, whenever possible, relatively expensive drugs by cheaper drugs (which have the same active ingredient and which do not have any negative side effects on the health of the patient in question) in order to decrease the costs of pharmaceutical care. Recently, a debate has started in Belgium about the question whether a physician should be encouraged to prescribe on the chemical substance name of a drug instead of prescribing a specific named drug. ${ }^{190}$ Proponents of prescription on substance name, such as the government and pharmacists, ${ }^{191}$ argue that the level of pharmaceutical care will increase if pharmacists have a larger say in the drug choice and that total health care costs will go down as a result. However, Belgian physicians, who have always been unfavourably disposed towards substitution of drugs by pharmacists, ${ }^{192}$ might also consider prescription on substance name to be an 'erosion of their competences'. In the Netherlands general practitioners are already encouraged (not only by the government but also by health insurers) to prescribe drugs on chemical substance name. ${ }^{193}$ The Dutch government went even further: in 2001 it proposed to oblige physicians to write down the diagnosis on every prescription. ${ }^{194}$

In this respect it is interesting to refer to a research published by the Dutch pharmacists' association KNMP in 2001. That research concluded that in an average Dutch community pharmacy, a pharmacist intervenes in 9 to $10 \%$ of the prescriptions from the physician. This intervention means that the pharmacist proposes to change the prescription of the physician. Intervention by the pharmacist is required if the prescribed drug does not go together well with earlier prescribed drugs, if something is wrong with the measurement of the dose and if a patient is intolerant of a certain medicine. Pharmacists may also take action if they do not trust a certain prescrip-

TK 2000-2001, 24124 and 24 036, nr. 111, p. 8.

De Standaard, Vandenbroucke baant weg voor stofnaam, 27 May 2002.

De Morgen, Apothekers willen generische geneesmiddelen promoten, 8 January 2003; De Financieel Economische Tijd, Apothekers promoten generische medicijnen, 9 January 2003.

De Standaard, Artsen tegen substitutierecht, 7 February 2002; Hombroeckx (2000, p. 188).

Het Financieele Dagblad, Proef prikkelt huisarts tot besparing medicijnen, 5 March 2002. According to NIVEL (the Dutch research institute for health care) general practitioners in the Netherlands prescribe more than half of all medicines on the basis of substance name. See Het Financieele Dagblad, Artsen schrijven minder merkmedicijnen voor, 21 May 1999.

TK 2000-2001, 24124 and 24 036, nr. 111, pp. 8-9. The professional association of physicians (KNMG), the professional association of general practitioners (LHV) and the Order of Physicians objected to this proposal. For positive comments on the proposal see Porsius (2002, p. 298-299); for criticism see Leenen (2002, pp. 786-787). 
tion, e.g. by contacting the general practitioner in attendance or by consulting the patient. Thus, the pointing out of mistakes in the prescribing behaviour of general practitioners and specialists seems to be an important task of a modern pharmacist. According to the researchers in question, the fact that 93 to $95 \%$ of the Dutch patients visit the same pharmacy every time is an advantage, because pharmacists are then in a better position to carry out this 'signalling function', ${ }^{195}$

I stated already that the developments observed by Van der Mijn and Ten Hoopen do not apply to the Netherlands and Belgium only. To end this section I will therefore look briefly at the pharmaceutical market in the UK, which has been analysed in detail by Mullan (2000). As recently as thirty years ago, compounding was still one of the main functions of a pharmacist in the UK. However, Mullan defines the primary role of the modern British pharmacist as follows:

to use his or her technical expertise to interpret the details of the prescription, to ensure that the prescription is valid, to dispense the drug product which has been prescribed or, in certain circumstances, an equivalent drug, [and] to give instructions to the patient on the use of the drug, including possible side-effects'.

As a secondary role Mullan mentions the provision of advice to patients who have a self-formulated, or doctor-assisted therapeutic plan involving the use of drug therapy. ${ }^{196}$ Obviously, in the UK as well, the relationship between pharmacist and patient has become more important over the last decades. ${ }^{197}$

\subsubsection{The service of a pharmacist today}

In this section I recapitulate the information from the previous section (\$ 3.2.1). There I showed that modern community pharmacists have tasks that are quite different from those they had some decades ago. Their main responsibility, that of being the retailers of the drug channel (distributing/selling medicines to final consumers) has remained the same, but apart from that the tasks of pharmacists have changed a lot. The preparation of medicines in the pharmacy (magistral preparation), which was a key activity of pharmacists in the 1950s, now makes up only a very small part of their job responsibilities. This can be explained to a large extent by the rise of industrially prepared medicine. On the other hand, because of the constantly increasing complexity of pharmacotherapy and specialisation of the profession, the provision of pharmaceutical care has become an important task of modern

Pharmaceutisch Weekblad, Apotheek ageert bij 1 op de 10 recepten, vol. 136, nr. 28, 2001, pp. 1018-1022. A summary of the results can be found in De Volkskrant, Apotheek grijpt in bij 9 procent recepten, 13 July 2001; and in NRC Handelsbiad, Apotheker haalt veel fouten uit recepten, 12 July 2001. Specialists and general practitioners doubt the results, according to De Volkskrant, Fout recept vaak door zelf schrijven arts, 31 July 2001.

Mullan (2000, p. 39).

OFT (2003) investigates the control of entry regulations in the community pharmacy sector in the UK. The report does, however, not explicitly deal with the new tasks of pharmacists. 
community pharmacists. The contents of this particular task of the pharmacist may call for a particular type of regulation. Therefore one needs to define exactly what this 'provision of pharmaceutical care' incorporates; in other words: what is the service of a pharmacist today next to the mere selling of drugs (and a little magistral preparation)?

The following 'new tasks' in the field of pharmaceutical care were presented in the previous section: medication control, monitoring of therapy, advising consumers and providing pharmacotherapeutic information and advice to physicians. If one considers the medication control (checking for possible interactions with other drugs used by the patient) and the monitoring of therapy (double-checking the prescription from the general practitioner or specialist), the added value of the pharmacist seems to be in the additional check-up, often by means of a computer system. These tasks can to a large extent be executed by pharmacists' assistants, be it under the supervision of a pharmacist. ${ }^{198}$ This is also the case if one considers the advice to consumers in the pharmacy (several examples of this kind of advice are given in the previous section). The last of the 'new tasks' mentioned above, providing information and advice to physicians, has been growing in importance rapidly in recent years. Especially in the Netherlands, pharmacotherapeutic (transmural) consultations between physicians and pharmacists take place on a regular basis nowadays. Finally, Dutch pharmacists are also encouraged to help decreasing the total drug costs in the Netherlands by substituting more expensive drugs by cheaper alternatives. This is, however, not specifically a task in the field of pharmaceutical care.

\subsection{Summary}

In the first section of this chapter the production, the distribution and the consumption of drugs were outlined. Figure 3.1 shows the connections between the many players in the pharmaceutical market: the pharmaceutical industry, wholesalers, physicians (general practitioners and specialists), pharmacists, consumers (patients), the government and health insurers. With regard to the production I first introduced the main categories of drugs: pharmaceutical specialites, parallel imports, generic drugs and own preparates (magistral preparates). Then I showed that drugs can be distinguished into prescription drugs (prescribed by a general practitioner or specialist and obtainable only from a pharmacist or dispensing physician) and OTC (over-the-counter) drugs. In Belgium OTC drugs are available in the pharmacy only, while in the Netherlands they can also be obtained in chemist stores and chemist departments in supermarkets licensed to sell them. Figure 3.2 depicts the classification of drugs graphically. Furthermore, I noted that the price and reimbursement of drugs are heavily regulated, both in the Netherlands and in Belgium. The regulation of the drug price will be discussed in more detail in $\$ 4.6$ and $\$ 5.6$; an overview of the regulation with respect to the reimbursement of drugs is presented in the appendix to this chapter. 
As far as the distribution of drugs is concerned, a distinction must be made between the wholesale channel and the retail channel. The pharmaceutical wholesaler is the link between the drug producers and the retailers. This wholesale channel is very important in the pharmaceutical market because medicinal products often need special storage and secure handling, while pharmacists and dispensing physicians obviously cannot keep every medicine in stock because of cost reasons. I examined the structure of the Dutch and Belgian wholesale market for drugs by introducing the undertakings active in these national markets. With respect to the retail channel I made a distinction between the intramural market (via hospital pharmacies) and the extramural market (via community pharmacies and dispensing physicians) and I looked at the extramural market by briefly discussing two quite recent pharmacy concepts: the internet pharmacy and mail order pharmacy.

The consumption of prescription drugs is different from the consumption of 'normal' goods. The price sensitivity is relatively low because consumers do not have to pay the full price of the drug themselves (because of reimbursement by health insurers), and patients generally do not choose their medicines themselves, because they have insufficient knowledge about drugs in order to be able to co-decide on the kind of therapy they need. I briefly discussed the prescription behaviour of physicians and the pattern of consumption in the Netherlands and in Belgium. In the Netherlands the 'percentage diagnosis with prescription' is lower than it is in Belgium. Furthermore, I stated that consumers nowadays take more individual responsibility than they did some decades ago, while also the number of patients' associations has grown in recent years.

Section 2 dealt with the 'evolution' of the pharmacists' profession. Three developments have had a big influence on the pharmaceutical profession since the first half of the last century, according to Van der Mijn (1989): the rise of industrially prepared medicine at the expense of magisterially prepared medicine, the increasing complexity of the medicine market, and the differentiation in the practice of the profession. As a result of this the role of the community pharmacist has changed. The modern community pharmacist appears to have a number of 'new tasks' in the field of pharmaceutical care, while his/her tasks involved in preparation of drugs have decreased considerably. In addition, the distribution, i.e. selling, of drugs still makes up an important part of the pharmacists' job responsibilities.

The 'new tasks' of pharmacists in the field of pharmaceutical care, which have been discussed in this chapter, incorporate medication control, monitoring of drug therapy, advising consumers and providing pharmacotherapeutic information and advice to physicians. Especially the last task has become very important, the first three tasks can also - at least to some extent - be performed by pharmacists' assistants under the supervision of a pharmacist. In the following chapters I will examine whether the new tasks of the community pharmacist have already been acknowledged by the legislator, i.e. whether they have been included somehow in public regulation. 


\section{APPENDIX CHAPTER 3: HEALTH INSURANCE}

In chapter 3 I stated that consumers (patients) do not pay the full price of prescription drugs themselves because either they are reimbursed by their health insurers or their health insurers pay (part of) the price directly to the pharmacist or dispensing physician. In this appendix I address the health insurance for pharmaceuticals in the Netherlands ${ }^{199}$ (\$ A.3.1 and $\S$ A.3.2) and Belgium ( $\$$ A.3.3 and $\S$ A.3.4). For both countries, an overview of the health insurance system is presented first, after which the financing and benefits under the health care system are examined.

\section{A.3.1 Health insurance for pharmaceuticals in the Netherlands: an overview}

In general, the Dutch health insurance system is divided into three categories that correspond to a classification system of health care. ${ }^{200}$ The first category concerns medical expenses associated with long-term care and high-cost treatment, such as hospital treatment and home care. For these costs there is a mandatory public insurance scheme in the Netherlands called the Exceptional Medical Expenses Act, ${ }^{201}$ which is financed by income-dependent contributions and government funds. The second category is that of normal and necessary medical care, e.g. visits to a general practitioner, hospital nursing and pharmaceutical services. For the medical costs of this category patients can be publicly or privately insured, as will be described below. The third category consists of medical expenses associated with forms of care regarded as being less essential, which are therefore predominantly covered by (voluntary) private insurance (e.g. most forms of dental care). The amount of medical care provided that is not funded by one of these insurance schemes is negligible..$^{202}$

In the Netherlands health insurance with respect to normal and necessary medical care is provided both by public health insurance funds and by private insurers. ${ }^{203}$ According to the Health Insurance Act, ${ }^{204}$ hereafter HIA, public insurance is compul-

199

200

In an earlier paper, Philipsen and Faure (2002b) investigate whether this Dutch system of insurance and compensation for pharmaceuticals is efficient.

Recently the Dutch government has proposed a number of changes in the health insurance system. See e.g. Ministerie van Volksgezondheid, Welzijn en Sport (2002, pp. 12-13). Here I will discuss the system as it was in 2002.

Wet van 14 december 1967 (Algemene Wet Bijzondere Ziektekosten), Stb. 655, 1967.

Ministerie van Volksgezondheid, Welzijn en Sport (1998, pp. 5-6).

There is a special (mandatory) insurance scheme for public servants other than central government officials and teaching staff, which constitutes only about $5 \%$ of the market. For details see Ministerie van Volksgezondheid, Welzijn en Sport (2002, Ch. 3).

Wet van 15 oktober 1964 (Ziekenfondswet), Stb. 392, 1964. 
sory for individuals meeting the criteria set by the legislation. Everyone meeting the criteria is automatically insured and must pay the statutory contributions, whether or not they wish to make use of the benefits offered. These contributions are to a large extent income dependent. The most important criterion is the income ceiling (in 2002 everyone with an income of up to $€ 30,700$ fell under the HIA; in 2003 the income ceiling was $€ 31,750$ ), but also people who receive unemployment benefits fall under the HIA. ${ }^{205}$ Insurance cover is extended to the partner and children of the insured party, subject to some conditions. This co-insurance is free of charge. Almost two thirds of the Dutch population is covered by the HIA: the number is over $64 \%$, while the privately insured account for $\pm 31 \%, 206$

Despite the statutory character of the HIA, individuals have to register with a health insurance fund in order to obtain benefits. This is purely an administrative procedure and does not imply entering into an insurance contract, since insurance cover already follows from legislation. Individuals can choose from a wide variety of health insurance funds; since 1992 health insurers have no longer been limited to certain regions and all health insurance funds work nationally now.207 Moreover, health insurance funds have a duty of acceptance. ${ }^{208}$ In order to obtain medical services individuals must apply to a practitioner (e.g. a pharmacist) with whom, or institution with which, their health insurance fund has concluded a contract. People have a free choice of practitioner or institution within the group contracted by the health insurance fund. ${ }^{209}$

The system just described accounts for $64 \%$ of the market; $31 \%$ of the Dutch population is insured with a private insurer. ${ }^{210}$ Although the contents of the services to be provided by the health care insurer are also the subject of regulation, there is much more scope and freedom to negotiate the scope of the coverage and the corresponding premiums. In private insurance the premium is in principle risk related (through the extent of coverage and the deductible). In practice, the higher income groups (individuals who cannot enter the HIA) take out private health insurance. heid, Welzijn en Sport (2002, Chs. 2-3).

Ministerie van Volksgezondheid, Welzijn en Sport (2002, p. 9).

Ministerie van Volksgezondheid, Welzijn en Sport (2002, p. 43).

Private insurers do not have this obligation.

There is an exception for general practitioners: once individuals have chosen a doctor from among those who have contracts with their health insurance fund, they are registered with that specific doctor.

Certain categories of people, like seamen and certain individuals entitled to cover who live outside the country, are required to register with specific funds (Ministerie van Volksgezondheid, Welzijn en Sport, 2002, p. 32). $5 \%$ is covered by the health insurance scheme for various categories of public servants. Supra, note 203. 


\section{A.3.2 Financing and benefits under the Dutch health care system}

\section{A.3.2.1 Financing}

The contribution for cover under the HIA consists of two parts: an income-related part that is collected by the government (a percentage deducted from the wage, profit, benefit or retirement pay) and a nominal (flat-rate) part, which is fixed and collected by the health insurance fund itself. Thus, the Dutch public health insurance is not only characterised by risk solidarity, but also by income solidarity. In addition, the income-related contribution is partly paid by the employer. ${ }^{211}$ Apart from these contributions, the public health insurance is financed by two other sources: an annually determined government grant and special transfer payments in respect of the elderly, paid by privately insured individuals via a statutory yearly contribution on top of their nominal (insurance) contribution. With the exception of the flat-rate contribution, all these fundings are channelled into a General Fund for health insurance, which is administered by the government.

The private health insurance is financed differently. Because private insurers do not benefit from government-collected contributions, they are completely dependent on the nominal contributions: the - in principle - risk related premiums. The premiums for private insurance differ - though not to a large extent yet - between insurance companies and are of course influenced by the size of the cover and the amount of the deductible chosen by the individual. There is no income solidarity in the private health insurance, only risk solidarity. ${ }^{212}$ However, next to its 'normal' health insurance policies, every private health insurer in the Netherlands is obliged to provide a so-called standard insurance as well. This standard insurance guarantees insurance cover to certain groups of people that do not fall under the HIA and therefore have to be insured privately. The premium for this standard policy is determined by the government. ${ }^{213}$ Also, private insurers are obliged to charge - in addition to the premium - two statutory contributions, which are fixed by the government. The first concerns a transfer that goes to the General Fund for public insurance (because older people are over-represented in this category). The second concerns a contribution that is used to fund the standard insurance. These statutory contributions are the same for every insurer. This shows that regulation seriously limits the scope for charging truly risk-related premiums in private health insurance.

On average, the flat-rate contribution was NLG $216(€ 98)$ per person in 1998. See Ministerie van Volksgezondheid, Welzijn en Sport (1998, p. 28).

212 And even there the term 'solidarity' is somewhat misleading. All this means is that risks are spread between various members of a risk group. This is the solidarity which simply amounts to the risk-spreading inherent in any insurance system. Solidarity does not, however, imply that good risks should subsidise bad risks. On the contrary, risks should as much as possible be differentiated. The 'solidarity' is thus limited to insured posing a similar risk. Sport (2002, Ch. 3). 


\section{A.3.2.2 Benefits}

Cover under the HIA gives entitlement to benefits in kind in the form of medical treatment and care. This is different from the private medical insurance, where individuals are reimbursed for medical expenses incurred by them. With respect to pharmaceutical services, it is important to mention here that the Drug Reimbursement System (infra, § A.3.2.3) applies. This means that the patient only gets a fixed amount reimbursed, as determined by the Drug Reimbursement System. If he chooses a more expensive drug he will have to cover the additional costs.

In 1997 individuals insured under the HIA were also obliged to pay charges towards the cost of treatment and services. This system of charges provided for a charge amounting to $20 \%$ of the cost of treatment and services provided under the HIA, whereby account was taken of a maximum of $€ 90$ per calendar year for the insured party and persons co-insured. ${ }^{214}$ Such a charge effectively functioned as a deductible, being an amount of the costs that is not reimbursed and which is borne by the patient. Today, however, this charge no longer exists.

As far as private health care insurance is concerned, the benefits are to a large extent dependent on what has been agreed between the insurer and the insured. However, as stated above, a standard insurance benefit, of which the content is fixed in regulation, has to be offered anyway. The amount and applicability of the deductible can, to a large extent, be freely negotiated in private health insurance; the size of the deductible will obviously have an influence on the premium charged.

\section{A.3.2.3 Drug Reimbursement System (GVS)}

Let us, given the scope of this research, turn once more to the Drug Reimbursement System (Geneesmiddelenvergoedingssysteem), or GVS, already indicated above. This regulation fixes the amounts the insurer is supposed to reimburse for pharmaceuticals and hence determines the scope of the benefits. The GVS contains reimbursement limits determined by the government. These reimbursement limits are the maximum amounts that will be reimbursed to consumers by (public) health insurers for clusters of therapeutically equal drugs. New pharmaceuticals (for which there is no substitute) will only be included in the GVS if they have a clear added value $^{215}$ to the drug package. In practice, new drugs are therefore often placed on a waiting list for some time before they are included in the GVS. ${ }^{216}$ The GVS was introduced in 1991 with the object of lowering the costs of health care in the Nether-

See Ministerie van Volksgezondheid, Welzijn en Sport (1998, p. 23). Some exceptions apply, such as e.g. the cost of a visit to a general practitioner and costs related to childbirth.

On the European level the Committee of Proprietary Medicinal Products carries out the assessment of 'new' drugs. In the Netherlands the added value of new drugs is judged by the Drug Assessment Board (College Beoordeling Geneesmiddelen, CBG).

Ministerie van Volksgezondheid, Welzijn en Sport, 1999 (pp. 25; 40-41). 
lands. However, the GVS also limits competition, because it has a big influence on the price-setting behaviour of the drug industry, while in addition the bargaining position of insurers decreases as a result of their duty to reimburse (up until the statutory limit) every prescription drug included in the GVS. Moreover, the GVS often delays the entry of new drugs into the market, as noted above. Since private insurers have always followed the national health services (public insurance) as far as reimbursement of drugs is concerned, in practice the GVS limits apply for both the public and the private health insurance sector.

\section{A.3.3 Health insurance for pharmaceuticals in Belgium: an overview}

The health care system in Belgium differs from the Dutch system in the fact that in Belgium the public health insurance is part of the social security system. There are various social security agencies and among them is a special agency for the health insurance called the RIZIV (National Institute for Health Care and Invalidity Insurance), which is funded by compulsory contributions. 217

The RIZIV does not pay suppliers of health care, such as physicians and dentists, directly, nor does it refund individuals for costs incurred.218 For the payment of health suppliers there are a number of health insurance funds called mutualiteiten, or 'mutuals'. ${ }^{219}$ Some of these health insurance funds have a religious or political connection due to historical reasons, but basically they all offer the same coverage and premium; hence they can only attract new members by offering supplementary services, by their geographical convenience and by their speed of settling claims. Everyone who is employed by a Belgian company is obliged to join or register with one of these funds. The contributions are deducted from the salary. 200

In contrast with patients in the Netherlands, patients in Belgium have a free choice of physician. Physicians are paid according to the fee-for-service system, which means that they are paid for each treatment on the basis of individual fees set by the federal government. The Belgian health insurance law states that individuals are entitled to the payment of the cost of medical care, which in practice implies that they have to pay the health care supplier directly. In order to receive reimbursement

217 For an extensive description of the Belgian social security system, see Federal Public Service Social Security (2001). For an overview of the history of the Belgian health insurance from 1945 to 1995 , see BIGE (1998, pp. 31-49).

218 Paulus et al (1999, p. 13).

219 These mutuals have united in five national confederations: the christian, socialist, neutral, liberal and independent confederation. There is also a government institution (for government officials) and an institution of the NMBS (the Belgian national railway company). See the website of RIZIV: <http:/ / inami.fgov.be> and BIGE (1998, pp. 38-39; 188). 
they have to present the receipt to the health insurance fund, i.e. the mutual. ${ }^{221}$ Only health services that received an official registration (nomenclatuur) are - partly or completely - reimbursed. ${ }^{22}$ In case a drug is prescribed by the physician, the subsequent procedure is slightly different. Then a third payer's scheme applies: consumers/patients do not have to pay the full price of the drug in the pharmacy, they only have to pay the difference between the full price of the drug and the amount that will be reimbursed by the health insurance. ${ }^{223}$ The pharmacist will be refunded by the health insurance funds.

\section{A.3.4 Financing and benefits under the Belgian health care system}

\section{A.3.4.1 Financing}

The RIZIV is financed by compulsory contributions and is - like the Dutch systemcharacterised by income solidarity. Employees, employers and self-employed people have to pay a contribution proportional to their revenues; ${ }^{24}$ there is no reference to the health risk. In addition, the federal government contributes to the financing of the RIZIV by means of direct subsidies. 225 The RIZIV divides these funds among the health insurance funds (the mutuals). The amount of the premium that individuals have to pay in order to join a health insurance fund is determined by the government and is therefore equal for every mutual. 226

\section{A.3.4.2 Benefits}

As was stated above, the mutuals take care of the payment of health care suppliers. The reimbursements are equal for every individual, but there are exceptions for especially vulnerable social groups such as widows, disabled, pensioners and orphans. Many individuals in Belgium choose to have a supplementary (public or private) medical insurance, ${ }^{227}$ because generally the mandatory insurance does not reimburse $100 \%$ of the medical bill. In 1999 , some $15 \%$ of total health care costs con-

Van der Mei (2001, p. 261).

Evers et al (2001, p. 4). According to Article 34 of the Act of 14-7-1994 concerning the mandatory insurance for medical care and payments (B.S. 27-8-1994), medical care in Belgium is divided in 23 different categories of medical dispensations.

Infra, $\$$ A.3.4.2.

For contribution percentages and other specific contributions, see Federal Public Service Social Security (2001, pp. 11-13).

Paulus et al (1999, p. 12).

NIVEL (1996, p. 22).

According to NIVEL (1996, p. 21 ) approximately $14 \%$ of the Belgian population had a supplementary insurance with a prioate insurer in 1996. 
sisted of co-payments by patients. 228 This supplementary medical insurance is directly provided by the mutuals.

With respect to the reimbursement of pharmaceuticals in Belgium, I mentioned earlier that individuals have to pay the difference between the full price of the drug and a certain amount that is reimbursed by the health insurance. Before a drug qualifies for reimbursement by the Belgian health insurance, it has to comply with a number of criteria stated in the Royal Decree of 21-12-2001 determining the procedures, terms and conditions regarding the compensation of the mandatory insurance for medical care and payments in the costs of pharmaceutical specialites. ${ }^{22}$ They include pharmacotherapeutical criteria, the society's interest in the drug and price criteria. ${ }^{200}$ Depending on a number of criteria, drugs will be assigned by the RIZIV to one out of five groups that correspond to different reimbursement rules.

This classification of pharmaceuticals is performed by the Commissie Tegemoetkoming Geneesmiddelen (CTG), which is associated with the RIZIV. Life-saving drugs, the socalled indispensable drugs (noodzakelijke geneesmiddelen), are placed in category A, which means that they will be fully reimbursed. Category B holds the medicines for treatment of non life-threatening diseases, which will be reimbursed for $75 \%$ if it concerns pharmaceutical specialites for which there are no generic alternatives and for $80 \%$ if it concerns drugs with generic status. Drugs that are assigned to category C will be reimbursed for either $50 \%, 40 \%$ (category Cs) or $20 \%$ (category Cx). Finally there is a category with those drugs that will not be reimbursed at all. ${ }^{231}$ For example, all over-the-counter (OTC) products, which are freely obtainable, belong in this category. After all, Article 2 of the Royal Decree of 21-12-2001 provides that drugs only qualify for reimbursement if they are prescribed and delivered by persons legally authorised to do this, and if these drugs are intended for entitled persons whether or not they are admitted to a hospital. The lists of all reimbursed pharmaceutical specialites and products and the category to which they belong are included

Paulus et al (1999, p. 13).

Koninklijk Besluit van 21 december 2001 tot vaststelling van de procedures, termijnen en voorwaarden inzake de tegemoetkoming van de verplichte verzekering voor geneeskundige verzorging en uitkeringen in de kosten van pharmaceutische specialiteiten, B.S. 29-12-2001. This Royal Decree entered into force at 1 January 2002 and replaced the Royal Decree of 2-9. 1980 determining the conditions under which the mandatory health care- and invalidity insurance will be prepared to bear the costs of the pharmaceutical specialites and of equal products.

See Article 4 of the Royal Decree of 21-12-2001.

See Article 2 of the Royal Decree of 7-5-1991 determining the personal share of the persons entitled in the costs of the in the framework of the mandatory insurance for medical care and payments reimbursable pharmaceutical products (Koninklijk Besluit van 7 mei 1991 tot vaststelling van het persoonlijk aandeel van de rechthebbenden in de kosten van de in het raam van de verplichte verzekering voor geneeskundige verzorging en uitkeringen vergoedbare farmaceutische verstrekkingen), B.S. 10-7-1991. 
in an appendix to the decree. The Minister of Social Affairs is charged with the enforcement of the decree.

For all drugs, except for those belonging to category A, patients thus have to pay an own contribution, a deductible. In Belgium this deductible is called remgeld. The amount of this remgeld is limited to a maximum of $€ 9.90$ for all drugs in category B, irrespective of the price. However, with respect to drugs in large packagings (i.e. containing more than 60 units) the remgeld is higher: $€ 14.80$. The maximum remgeld for drugs belonging to category $\mathrm{C}$ is $€ 16.50$; for the categories $\mathrm{Cs}$ and $\mathrm{Cx}$ there is no maximum. 232

The fact that there is a maximum for certain categories of drugs might cause problems for the health insurers. As a result of the continuous rise in the drug price level, the average remgeld percentage decreased in 1999 to $21 \%$, while before it had been fluctuating around $25 \%$ for some years. Because the prices of reimbursed drugs have increased enormously since 1987 and because the number of prescribed drugs increased with $10 \%$ in the period 1987-1996, it has become more and more difficult for the health insurers in Belgium to reimburse also new and expensive drugs. ${ }^{233}$ This still is a topical subject.

232 Amounts as from 1 January 2003: see Article 2 of the Royal Decree of 7-5-1991. The maximum remgeld is lower for widows, disabled, pensioners and orphans (the so-called WIGW's): $€ 6.60$ for category $B$ drugs ( $€ 9.90$ in case of large packagings) and $€ 9.90$ for category $C$ drugs. 


\section{THE REGULATION OF PHARMACISTS IN THE NETHERLANDS}

In this chapter an answer will be formulated to the second question posed in the introduction: what national regulations and self-regulatory measures issued by professional bodies exist in the Netherlands with respect to the pharmaceutical profession? In the discussion of the regulatory framework, emphasis will be laid on regulations that restrict competition. Where necessary, some case law will be discussed as well.

In $\$ 4.1$ the Dutch professional organisation of pharmacists, the KNMP, is introduced. The content of the self-regulation issued by this organisation is discussed in the sections after that, jointly with the content of the public regulations. These sections are arranged by topic. The topic of $\$ 4.2$ is education (training) of pharmacists. Section 4.3 discusses registration and title protection; this discussion also includes the scope of the professional monopoly of the pharmacist. The section after that $(\$ 4.4)$ presents an overview of regulation and case law concerning the establishment of pharmacies. Applying the terminology used in chapter 2: regulation of training, registration and establishment are examples of entry regulation. ${ }^{234}$ Subsequently regulation of advertising and design of the pharmacy $(\$ 4.5)$ is examined; this is a form of conduct regulation. The final topic is the regulation of prices and fees (\$ 4.6). Section 4.7 gives an overview of some recent developments. I already noted in chapter 3 that the pharmaceutical market is very dynamic and in this chapter it will be shown that this has affected the regulation of the pharmaceutical profession as well. Moreover, the introduction in 1998 of a strict national competition law, enforced by the Dutch Competition Authority (NMa), has strongly influenced the pharmaceutical market since then. 


\subsection{Professional code and rules of conduct}

The professional organisation of pharmacists in the Netherlands is called the KNMP, which stands for the Royal Dutch Association for the Advancement of Pharmacy (Koninklijke Nederlandse Maatschappij ter bevordering der Pharmacie). The KNMP issued its Professional Code and Rules of Conduct for Pharmacists in 1993. With this the old rules, which had been established in the early 1950s, were withdrawn. In general rules of conduct apply both internally, i.e. within a profession, and towards the society, although externally they have no binding force. External effect arises if the rules are actually accepted by third parties. ${ }^{235}$ Over $90 \%$ of all Dutch pharmacists are member of the KNMP, so the range of self-regulation is very wide. ${ }^{236}$

Apart from the Professional Code and Rules of Conduct, the KNMP also enacted the so-called Dutch Pharmacy Standards (Nederlandse Apotheek Norm) in 1996. The Dutch Pharmacy Standards have been enacted to work out the concept of 'proper care' (verantwoorde zorg) from the Care Institutions Quality Act $t^{237}$ and contain provisions on e.g. the design of a pharmacy. Just like the rules of conduct, the Dutch Pharmacy Standards have no binding external force (they bind, in other words, only the members). However, these provisions can play a role in the medical disciplinary rules. Moreover, the Dutch Pharmacy Standards have often been included to a large extent in the individual contracts between pharmacists and health insurance companies.

As a result of a number of decisions by the Dutch Competition Authority (NMa) in competition and health care cases in 2000 and 2001,238 the KNMP had to alter the content of the rules of conduct and the Dutch Pharmacy Standards. In 2002 a new version of the Dutch Pharmacy Standards was issued, in which some provisions of the old version have been removed. Moreover, the KNMP has now withdrawn its rules of conduct. The prevailing self-regulation consists therefore of the Dutch Pharmacy Standards of 2002, the Professional Code of 2001, and the so-called Professional Statute of 2000. The most important provisions of the old rules of conduct and of the (old and new) Dutch Pharmacy Standards will be discussed below, together

Leenen (1991, pp. 43-44).

Van Heest (1998, p. 6). The reasons to become a member of the KNMP have been summed up by Mr. F. Moss, Head of Legal Affairs of the KNMP, in a letter dated 8 April 2003: (1) to share in the costs of developing and facilitating the profession and the exercise of the profession of pharmacist; (2) to keep oneself informed of these developments; (3) to profit from certain products and services provided by the KNMP; (4) to profit from continuing education, advancement of expertise, conferences and other events organised by the KNMP; and (5) to maintain contact with colleagues and their way of exercising the profession. The list is nonexhaustive.

Wet van 18 januari 1996 betreffende de kwaliteit van zorginstellingen (Kwaliteitswet Zorginstellingen), Stb, 80, 1996.

See $\$ 4.7 .2$ infra. 
with the legislation and the case law. Provisions that (may) restrict competition between pharmacists will be emphasised. ${ }^{239}$

\subsection{Education}

The entry into a profession is made more difficult if students have to satisfy extraordinary high demands during their education, or if the entry into the education is attached to special conditions. This seems not to be the case in the Netherlands as far as the pharmacists' profession is concerned. Also, there are no special demands with respect to obligatory internships.

The quality of the content and structure of the pharmacists' education at the Dutch universities are supervised by the Dutch government. With regard to the content of the education a number of requirements are laid down in the Educational Requirements Decree for Pharmacists (Besluit opleidingseisen apotheker, 1997). The organisational structure of the education is regulated by the Higher Education and Scientific and Scholarly Research Act (Wet op het Hoger onderwijs en Wetenschappelijk onderzoek, 1993). ${ }^{240}$

The education lasts quite long, namely six years. This is longer than in any of the other EU Member States, where the duration is generally only four or five years. ${ }^{241}$ Until 1984 a selection committee regulated the intake of first-year students; after that this committee has been abolished. ${ }^{242}$ From 1984 to 1988 the number of firstyear students decreased temporarily and since then the number has increased almost every year until the mid-1990s. However, since then the number of first year students has decreased drastically: while in 1995 the number of first-year pharmacy students was still 373 , in 2001 it had been reduced to only $182 .{ }^{243}$ To a large extent this decrease is caused by the widening of the numerus fixus for the study of medicine, which came about as a result of a shortage of general practitioners in the Netherlands, ${ }^{244}$

The Professional Statute (KNMP, 2000a) does not contain specific restrictions to competition. It is a document that more generally describes the duties and responsibilities of a pharmacist. The pharmaceutical education is also regulated on a European level. The Directive $85 / 432$ /EEC of 16 September 1985, regarding the co-ordination of the legal and administrative rules of certain activities in the pharmaceutical field, fixes the minimum duration of the education at 5 years, whereof at least 4 years consisting of theoretical study and 6 months during practice in a public pharmacy or a hospital pharmacy. See Hombroeckx (2000, p. 181).

However, in some of those EU Member States an additional practical training of six months or one year is compulsory (in Italy two years). See IHS (2003, p. 75).

NIVEL (1994, pp. 68-69).

Source: Foundation for Pharmaceutical Statistics (SFK), in Pharmaceutisch Weekblad, vol. 137, nr. 20, 2002. See also Het Financieele Dagblad, Tekort aan apothekers loopt op, 17 May 2002.

Many students who are turned down for the study of medicine decide to register for the study of pharmacy instead, some of them hoping to draw a place in medicine in a later year. 
The number of graduates had grown between 1993 and 2000, but with a few fluctuations. On average around 125 students graduated every year in the period 19931997 , of which $60 \%$ were females. ${ }^{245}$ While in 2001 this number was even higher (155 graduates), for the first time a huge decrease was detected compared to the previous year (192 pharmacists graduated in 2000). ${ }^{246}$

\subsection{Registration and title protection}

\subsubsection{The professional monopoly of a pharmacist}

The professional monopoly of pharmacists is determined by the Drug Supply Act of $1958^{247}$ and by the Pharmaceutical Practice Decree of 1963.248 Article 1 of the Drug Supply Act defines pharmaceutical practice as the compounding (meaning the production in pharmaceutical form, as well as the labelling and packaging thereof) and the dispensing of medicines. Pharmaceutical practice is according to Article 2.1 reserved for pharmacists; and under specific conditions also for dispensing physicians, pharmacist's assistants, and the pharmaceutical industry and wholesalers. With respect to physicians who want to open a practice with a pharmacy, Article 6 provides that they may only practice pharmacy if a pharmacist has not been established either in the municipality concerned or in the adjoining municipalities. Moreover, dispensing physicians are not allowed to prepare drugs themselves or to dispense drugs to patients other than those living in their work area. Limited competence to practice pharmacy is given to chemists (i.e. druggists) and food companies, which means that they are permitted to sell self-care drugs (OTC drugs) at special counters. Thus, they are not qualified to deliver drugs on prescription. The fact that in the Netherlands self-care drugs can also be sold outside of the pharmacy at special counters, provided that such counters are supervised by chemists, is not unique in Europe, although in most EU countries this is not allowed. Belgium, for example, is not familiar with the concept of chemists selling OTC drugs. ${ }^{249}$

Next, Article 2.3 of the Drug Supply Act states that it is forbidden for persons who are not qualified in the pharmaceutical practice to compound or to dispense medicines. Given that only pharmacists may deliver drugs on prescription, they therefore have a professional monopoly in the extramural supply of prescribed drugs.

Own calculations, Source: NIVEL/NZI/OSA, 1998, p. 42.

Supra, note 243.

Wet van 28 juli 1958, houdende nieuwe regelen nopens de geneesmiddelenvoorziening en de uitoefening der arsenijbereidkunst (Wet op de Geneesmiddelenvoorziening), Stb. 408, 1958.

Besluit Uitoefening Artsenijbereidkunst, Stb. 75, 1963.

Sources: Neprofarm website: <http://www.neprofarm.nl/zelfzorg_algemeen.html>; Omega Pharma, Annual Report 2001, p. 49. The IHS research report $(2003$, p. 80) gives a nice overview of the pharmacists monopoly in the 15 EU Member States of 2002. Apart from the Netherlands, it is only allowed to sell OTC drugs in retail shops in Austria, Denmark, Germany, Ireland and the United Kingdom. 
In 1999 the professional monopoly of pharmacists was curtailed somewhat, by the removal of Article 15 from the Pharmaceutical Practice Decree. That (now repealed) article prohibited the employment of pharmacists by non-pharmacists. 250 Furthermore, a provision from Article 13 of the Drug Supply Act, which prohibited hospital pharmacists to dispense drugs outside of the hospital, was repealed on 1 April $2000 .^{251}$ The objective of this amendment was to make some competition possible between hospital pharmacies and community pharmacies in the extramural supply of drugs. 252

\subsubsection{Registration}

Before a pharmacist is allowed to practice pharmacy in the Netherlands, he or she must be registered with the regional Health Inspectorate (regionale Inspectie voor de Gezondheidszorg), in accordance with Article 14 of the Drug Supply Act. Until 2002 there were five different registers: for established pharmacists, for dispensing physicians, for observing pharmacists, for second pharmacists, and for pharmacist's assistants. As of October 2002 the registration for observing pharmacists and for pharmacist's assistants was no longer required. ${ }^{253}$

A number of requirements for registration as established (community) pharmacist are laid down in the Pharmaceutical Practice Decree, among which the requirements for the applicant to submit a pharmacy diploma and a statement of the property (Article 2). Once registered, a pharmacist or dispensing physician may only practice pharmacy in one pharmacy, according to Article 19 of the Drug Supply Act. An exemption is made for substitution during absence (e.g. in weekends) or illness of colleagues. These so-called observation rules are specified in Article 21 of the Drug Supply Act. However, according to a proposed amendment of the law, presented to the Second Chamber already on 26 July 2002, the government intends to repeal Article 19 of the Drug Supply Act. ${ }^{254}$

The Pharmaceutical Practice Decree contains a prohibition for the pharmacist to enter into any kind of agreement with respect to the public dispensing of medicines with physicians, dentists or midwives (Article 18). In 1999 a provision that restricted

Stb. 20, 1999. For health insurance funds, the ban on running pharmacies themselves was lifted in the same year: as from 1 January 1999, they have been granted a general exemption from Article 42.5 of the Health Insurance Act (provided that a qualified pharmacist is working behind the counter).

251

252

Stb. $97,2000$.

See also $\$ 4.7$.

See circular no 2002-10-IGZ. The argumentation given by the Health Inspectorate is that the old, detailed system of registration is no longer appropriate in the current climate and that its abolition would involve a decrease in the administrative burden of both pharmacists and of the Health Inspectorate.

TK 2001-2002, 28 494. See also \$4.7.1 infra. 
the entry of pharmacists to the market was repealed from this decree, namely Article 15 , already briefly mentioned above. This article provided that pharmacists were not allowed to be employed by non-pharmacists. Since the repeal of Article 15, it has become possible for qualified pharmacists to work in e.g. a chemist's chain.

\subsubsection{Title protection}

Although the Drug Supply Act and the Pharmaceutical Practice Decree still contain the most important rules with respect to the compounding and dispensing of medicines, they do not regulate the title protection of pharmacists. This task has been reserved to the Individual Health Care Professions Act, ${ }^{255}$ hereafter Professions Act, since an amendment in November 1997.256 For a number of health care professions the ban on the unqualified practice of the profession, which existed in the past, has been substituted by a system of registration combined with title protection and partial protection of the profession through a number of so-called reserved operations (voorbehouden handelingen). In principle everybody is allowed to enter the area of health care, except if by doing so they cause harm. However, the practice of a reserved operation defined in the Professions Act is punishable by law, if performed by an unqualified person on a professional basis. ${ }^{257}$ For pharmacists no reserved operations have been defined in the Professions Act. For them the protection of the professional monopoly supplied by the Drug Supply Act still applies.

Hence, in practice pharmacists will have noticed little change since the coming into force of the Professions Act in 1997. New is that the title 'pharmacist' (apotheker) is now reserved to those who are registered in the BIG-register. ${ }^{258}$ This register is managed by the Minister of Public Health, Welfare and Sports. Article 22 states how the title 'pharmacist' (and thus the entry into the register of the Professions Act) can be obtained. Required is the possession of a legally obtained certificate. The unqualified use of the title 'pharmacist' or a similar title is subject to punishment. 259

In Article 23 of the Professions Act the area of expertise of pharmacists is defined to be 'the performing of acts in the area of pharmaceutical practice'. To be able to actually practice their profession, pharmacists registered with the Professions Act still

Wet op de Beroepen in de Individuele Gezondheidszorg (Wet BIG), Stb. 655, 1993. This act also contains the disciplinary rules. The old Act of Medical Disciplinary Rules (Medische Tuchtwet) of 1928 was abolished in December 1997, when the Wet BIG came into force. Now the so-called disciplinary rules for health care ('tuchtrecht voor de gezondheidszorg'), defined in $\$ 7$ of the Wet BIG, watch over the quality of medical practice and the professionality of health care.

This can be punished by a fine not exceeding $€ 2,250$ or imprisonment of up to three months (Article 97 in conjunction with Article 23.4 of the criminal code).

This is the official name of this register. BIG stands for 'Individual Health Care Professions'.

Illegal use of a title protected by this Act can be punished with a fine of not more than $€ 2,250$.

See Article 100 in conjunction with Article 23.4 of the criminal code. 
have to apply to the regional Health Inspectorate, as described earlier in this chapter. In accordance with Article 15 of the Drug Supply Act, amended by the Professions Act, registration with the Health Inspectorate will be refused if the applicant does not have the title 'pharmacist'.

\subsubsection{Registration with the KNMP}

In addition to the statutory regulations the pharmacists' association KNMP has its own register: the register for community pharmacists. To maintain the subscription in this private register, community pharmacists have to meet certain demands made by the KNMP, like taking part in refresher courses or attending pharmaceutical conferences organised by the KNMP. Formerly, Article 2.12 of the (now repealed) Professional Code and Rules of Conduct stated that members of the KNMP must be registered there.

\subsubsection{Summary}

To become a pharmacist first the pharmacy diploma must be obtained, then a pharmacist has to enrol in two registers, namely that of the Health Inspectorate and the BIG-register. The title is protected by the Professions Act, while the operations of compounding and dispensing drugs are protected by the Drug Supply Act. Given that only pharmacists may dispense drugs on prescription, they therefore have a professional monopoly in the extramural supply of prescribed drugs. The amendment of 1997, which introduced the BIG-register, did not really change this. Practically, only a number of provisions from the Drug Supply Act have moved to the Professions Act.

\subsection{Establishment of pharmacies}

\subsubsection{The establishment policy of the KNMP}

In the period between 1975 and 1987 the pharmacists' association's private establishment policy applied: the KNMP Establishment Policy Decree (Besluit Vestigingsbeleid KNMP). Members had to receive the permission from the executive board of the KNMP if they wanted to establish or relocate a pharmacy. These rules were based on the idea that a proper quality of pharmaceutical aid can only be obtained if the financial foundation of a pharmacy is sound; and that for this a market of at least 8000 patients per pharmacy is required. ${ }^{260}$ But the KNMP has never been able

260 This norm was not based on financial foundations. It was based on the then applying subscription system (abonnementssysteem) with respect to pharmaceutical care for patients of national health services. According to that system, which remained in force until January 1988, pharmacists received a fixed amount per registered patient irrespective of the actual drug use. The earnings from this subscription system accounted for a substantial part of a 
to prevent non-members from establishing themselves. Suspension and the disqualification from practice can never be private law disciplinary rules; these are after all matters pertaining to public law. However, the KNMP can punish with e.g. a warning, a fine, a suspension from the membership of the KNMP or the deprivation of the right of being member of a KNMP board or committee. ${ }^{261}$

Although in theory it has always been possible for pharmacists to establish themselves without being a member of the KNMP, in practice this often was very difficult, for reasons I will explain below and in $\$ 4.4 .2$. In the case law of the early 1980s, the court repeatedly determined in civil law cases that non-members are not bound by a private law establishment policy. ${ }^{262}$ The objection put forward by the KNMP, that the establishment policy was a generally acknowledged code of conduct, might have been somewhat true, but this still cannot make a private rule legally binding. When the number of 'black establishments' increased in the 1980 s, the KNMP therefore changed its establishment policy. From 1987 onwards an advisory establishment policy without sanctions applies, called the Guidelines concerning the KNMP advisory establishment policy (Richtlijnen betreffende het vestigingsadviesbeleid KNMP), ${ }^{263}$

According to these guidelines, the KNMP gives advice about the establishment, relocation and closure of pharmacies, at every member's request. Also non-members and interested third parties may ask the KNMP for advice. Besides, the Guidelines allow the KNMP to advise on certain issues without being asked. Article 4 of the Guidelines provides the criterion for positive advice as to establishment or relocation:

Within an acceptable time the new or relocated pharmacy must be able to grow to a size that guarantees the foundation for a qualitatively good practice of the profession by the pharmacist(s). In addition, the conditions for good practice by the adjacent pharmacies have to be maintained. As a basis the Minimum Establishment Standard for Pharmacies (Minimum KNMP-Vestigingsnorm voor Apotheken) shall apply'.

In a commentary to this article, it is stated that the above includes that pharmacies have to be reasonably far apart and that newcomers may only inflict damage upon established pharmacists as long as this damage is not 'unreasonable'. The KNMP strives for the realisation of viable pharmacies. The above-mentioned Minimum Es-

pharmacist's gross profit. Since 1 January 1988 pharmacists have received a fee per prescription: the fixed fee (receptregelvergoeding). See KNMP (1997, p. 6), Leenen (1991, pp. 261-262).

See e.g. Rb. Maastricht, 15 July 1981, Tijdschrift voor Gezondheidsrecht, 1982, p. 88 and Rb. 'sGravenhage, 12 June 1985, Tijdschrift voor Gezondheidsrecht, 1986, p. 232.

1 will show in $\$ 4.4 .2$ and $\$ 4.7$ that nowadays the KNMP advisory establishment policy has become a dead letter because of the growing power of health insurers. However, it strongly influenced the establishment of pharmacies throughout the 1990 s and, moreover, it may still be a source of inspiration for new contracts between health insurers and pharmacists. 
tablishment Standard for Pharmacies serves as a guideline for assessing the financial feasibility (bedrijfseconomische haalbaarheid) - or the viability - of a pharmacy.

In this assessment, inter alia the following factors are considered: the expected number of prescriptions, the number of patients, the turnover, the number of physicians in the area and infrastructural characteristics. To determine the financial feasibility, the KNMP first calculates the gross profit at the expected number of prescriptions. From this gross profit the costs of practice (among them personnel and housing costs) and the investment and financing costs are subtracted, while the writing-offs are being considered as well. Because the gross profit has been related to the prescription volume since January $1988,{ }^{264}$ the establishment standard of the KNMP is also defined in the number of prescriptions. The standard for financial feasibility of a pharmacy lies at a structural (minimum) number of prescriptions of 40,000 per year. No difference is made between prescribed and non-prescribed drugs and medical devices. ${ }^{265}$ The estimate is flexible: the required minimum for financial feasibility is brought up to date by the KNMP if the Health Charges Board (CTG) makes an adjustment in the tariffs. If important market developments are observed by the Foundation for Pharmaceutical Statistics (Stichting Farmaceutische Kengetallen, SFK), those will also be included in the estimate. Dependent on the geographical position of the newcomer, additional preconditions apply in the judgement of financial feasibility, because a distinction is made between establishment in a rural area with a dispensing general practitioner, establishment in an urbanised area and establishment in a demarcated new housing estate.

\subsubsection{Contracts between pharmacists and health insurers}

Although the advices of the KNMP are not compulsory, the advisory establishment rules of the KNMP have often been included in some way in the contracts between health insurers and pharmacists. It appears from the case law in the 1990s that these contracts often contained roughly the same requirements as the old KNMP Establishment Policy Decree. In one of the cases from the rather extensive case law in the field of health insurance funds, the contracting policy of the health insurance fund in question was that each pharmacist's sphere of activity ought to be larger than 7,500 patients and that in principle contracts would only be made with a pharmacist-owner-administrator (apotheker-eigenaar-bestuurder). ${ }^{266}$ This is a clear example of market division, yet the Court decided in this case that there were plausible grounds for this: a well-considered distribution of care, to be provided by financially viable pharmacies that are managed rightly. The condition that contracts will only be made with a pharmacist-owner-administrator is also included in the Dutch

\section{Supra, note 260.}

These are numbers for the year 1997. The starting point of the calculations is a disposable income of 40,000 NLG (about $€ 18,151$ ) per year, excluding net living expenses of 12,000 NLG (about $€ 5,445)$. The complete calculation can be found in KNMP (1997).

Gerechtshof 's-Hertogenbosch, 14 May 1996, Tijdschrift voor Gezondheidsrecht, 1997, p. 66. 
Pharmacy Standards of the KNMP: Article 8.1 .0 holds that a pharmacy needs to be governed by a registered community pharmacist. In the above-mentioned case law, similar cases concerning contracts between health insurers (i.e. health insurance funds and private health insurers) and pharmacists can be found.

However, the Dutch Competition Authority (Nederlandse Mededingingsautoriteit, hereafter NMa), which was founded in January 1998 to enforce the new Dutch Competition Act of the same year, appears to be much stricter with respect to violations of the market division prohibition. In a number of decisions the NMa made clear that certain provisions in the contracts between health insurers and pharmacists are prohibited by the Competition Act. In addition, the NMa decided that the so-called collective negotiations between the representatives of health care providers (such as pharmacists and general practitioners) and health insurance funds can not be reconciled with the Competition Act. I will come back to the involvement of the NMa in section 7, where I discuss some recent developments in the Dutch pharmaceutical market.

In the individual agreements between health insurers and pharmacists, the contracting parties always have to take into account the so-called Outcomes of Consultation (Uitkomsten van Overleg) of the KNMP and the Dutch Association of Health Insurers (Zorgverzekeraars Nederland). ${ }^{267}$ These Outcomes of Consultation have been legally approved by the Board for Health Insurance (College voor Zorgverzekeringen, formerly called Ziekenfondsraad) and are therefore exempted from assessment under the Competition Act. They are partly based on the Dutch Pharmacy Standards issued by the KNMP. In the Outcomes of Consultation a number of conditions that must be included in every individual agreement between a health insurer and a pharmacist are written down. Although the subsequent interpretation of the individual agreements is left to the contracting parties, this system obviously prevents that the content of the individual agreements between pharmacists and health insurers is determined on a decentralised level. ${ }^{268}$

\subsubsection{Taking over of a pharmacy}

Pharmacists who want to set up their own practice by taking over an existing pharmacy have to overcome a different obstacle. That is, it will cost them a fortune to take over another pharmacy. The take-over costs consist of housing, stock and an amount for goodwill. The amount for goodwill is often very high (at least one times the annual turnover, but often much more) and the trend in recent years has shown a considerable increase in this amount. This implies that for recently graduated pharmacists it will be very difficult to set up their own practice after graduation. For

Article 44.4 of the Health Insurance Act. See also NMa, Decision nr, 912/2001 (CZ - Apotheker), p. 3 .

The government has recently proposed to abolish this system, in order to give health insurers more contracting freedom: TK 2000-2001, 24124 and 24 036, nr. 111, p. 13. 
large chains, such as OPG (see § 7.6), Alliance Unichem, GEHE/Celesio, and previously Boots (see § 7.5), which have substantial financial means, these problems are smaller. In $\$ 7.4$ I will discuss the goodwill problem in more detail.

\subsubsection{Summary}

It can be concluded that, although pharmacists in the Netherlands now have freedom of establishment, in practice it is still very difficult for them to start a new pharmacy. It is difficult for a recently established pharmacist to make contracts with health insurers in an area that does not meet the standards enacted by the KNMP, because these standards have been adopted to a large extent by the health insurers. Unless pharmacists succeed in concluding contracts with these health insurers, they effectively have no chance of entry into the market for the simple reason that their medicines will not be reimbursed (which is obviously disadvantageous for customers). For pharmacists who are members of the KNMP it has long been practically impossible to withdraw from the advisory establishment policy anyhow: until 2001 Article 2.13 of the (now repealed) rules of conduct provided that advice by an authorised KNMP-body had to be considered as important. Moreover, the take-over purchase of existing pharmacies is hampered by the high amounts for goodwill that need to be paid.

\subsection{Exercise of the profession}

\subsubsection{Advertising for drugs}

As regards advertising for drugs the Medication Advertising Decree (Reclamebesluit Geneesmiddelen) of 1994 is important. ${ }^{269}$ The public advertising of prescriptiononly drugs and pharmacy made medication is prohibited, while the advertising of other medication should promote the rational use thereof, by 'objectively presenting these products without exaggerating their qualities'. The special favours offered by the pharmaceutical industry to pharmacists are restrained in Article 15 of the Medication Advertising Decree, albeit very generally:

'the hospitality has to remain within reasonable bounds and must be subordinate to the main goal of the meeting'.

While advertising for drugs might benefit a pharmacist, for example if he or she would advertise more for drugs than other pharmacists, supplying drug information primarily seems to be a concern of the pharmaceutical industry. Anyhow, advertising branded drugs should never be a job of pharmacists, just because they are stimulated by the Dutch government to supply generic and parallel-imported drugs 
instead of equivalent proprietary medicinal products that are generally more expensive. ${ }^{270}$

\subsubsection{Advertising for pharmacies}

Advertising by pharmacists is not regulated by law, as opposed to the advertising of drugs. The old Professional Code and Rules of Conduct of the KNMP, which applied until late 2001, contained two articles on this subject. Article 2.16 provided the following:

'A community pharmacist is not allowed to approach patients directly and individually, if these patients are not his own clients. In addition, he is not allowed to compare himself with colleagues who are mentioned by name or who are distinctly indicated':271

The other restriction was mentioned in Article 2.23:

'Improper competition is prohibited. As such are always considered: (a) taking over patients/clients during duty or observation; (b) actively attracting staff from a neighbouring colleague; $(\mathrm{c})$ in any way affecting the patients' free choice of pharmacy. ${ }^{\prime 2 \pi 2}$

By the end of 1997 the Economic Competition Committee (Commissie Economische Mededinging) had already advised the Minister of Economic Affairs not to give an exemption from Article 2.16, but the committee had approved of Article 2.23a because of the importance of a well-functioning evening/weekend observance regulation..$^{273}$ Nevertheless, it took a long time - and additional investigations and decisions by the Dutch Competition Authority NMa - for the KNMP rules of conduct to be adapted accordingly.

It can be concluded that until late 2001 pharmacists faced many difficulties if they wanted to show their qualities to patients. This is a result of the combination of the restrictions to advertising mentioned above and the prevailing information asymmetry on the pharmaceutical market between the demand side and the supply side

This so-called incentive measure has been operative since 1988. Drugs have been clustered on the basis of their generic name, pharmaceutical form, method of administration and strength. More information on the incentive measure can be found in the next section ( $\$ 4.6$ ). See also SFK (1999, pp. 37-38).

'Een openbare apotheker mag niet rechtstreeks en individueel patiënten, niet zijnde eigen cliënten, benaderen. Ook mag hij zich niet vergelijken met met name genoemde of onmiskenbaar aangeduide collegae'.

'Tedere ongepaste concurrentie is verboden. Als zodanig worden in elk geval beschouwd: (a) het tijdens dienst of waarneming overnemen van patiënten/cliënten; (b) het actief aantrekken van personeel van een naburige collega; (c) het op enigerlei wijze beĭnvloeden van de vrije apotheekkeuze der patiënten." verdelingsregelingen, brief aan de Minister van Economische Zaken, 23 October 1997. 
of the pharmaceutical market. Competition in the quality of supplied services seems then only to be possible by providing extra services to customers, such as home delivery of medicines, or by offering a broad range of medical supplies and other products that can be obtained without prescription. However, as a result of the intervention of the NMa in the pharmaceutical market, there are - on paper - currently no more restrictions to advertising.

\subsubsection{Design of the pharmacy}

The original Articles 32 and 34-36 of the Pharmaceutical Practice Decree contained some requirements that pharmacies had to comply with regarding design and accessibility of the building. These articles were repealed in January 1996, because they were considered to have 'an adverse effect on the efficiency of the functioning of pharmacies'. ${ }^{274}$ However, shortly afterwards most of these provisions were included in the Dutch Pharmacy Standards. Most important were the following three: a pharmacist must be able to deliver every sensible prescription (Article 5.1), a pharmacy must have a separate room for magistral preparation of medicines (Article 9.2.5) and the pharmacy must be open for at least 9 hours a day between $8 \mathrm{AM}$ and $6 \mathrm{PM}$ and for at least 45 hours a week (Article 9.1.1). Combining the Articles 5.1 and 9.2.5, it followed that every pharmacist should be capable of magistral preparation of medicines. In addition to this, the Dutch Pharmacy Standards obliged pharmacists to either join a Regional Pharmacy Laboratory or to dispose of adequate laboratory facilities themselves (Article 9.2.7).

The Dutch Competition Authority NMa did not agree with these provisions, as it considers them as being restrictive of competition. ${ }^{275}$ In the new Dutch Pharmacy Standards, issued in September 2002, the above-mentioned provisions (and a few other articles) have been changed therefore by the KNMP. The new Article 5.1 prescribes that pharmacists stick to such opening hours that clients have sufficient opportunities to acquire medicines. With respect to the Articles 9.2 .5 and 9.2 .7 a phrase has been added to the original text in order to make clear that these provisions apply only if medicines are prepared in a pharmacy.

\subsection{Prices and fees}

This section describes how prices for drugs are fixed in the Netherlands. Obviously these prices depend to a certain extent on the production price and the market situation. As this is a law and economics research with respect to pharmacists, I will not go into these aspects of price-setting, but focus on how the law (more specifically: regulation) affects the price of drugs in a public pharmacy. In that respect two regulatory aspects need to be considered, namely: how regulatory action affects the price 
of drugs (\$ 4.6.1) and how regulation concerning the fees for the pharmacists themselves impact on the price of drugs $(\$ 4.6 .2)$.

\subsubsection{The price of drugs}

In the Netherlands drugs are divided into two categories: WTG and non-WTG. WTG drugs are drugs that may only be sold by pharmacists and dispensing physicians and which therefore fall under the Health Care Charges Act (Wet Tarieven Gezondheidszorg), hereafter WTG. In order to obtain these drugs, patients always need a prescription from a general practitioner or specialist. Non-WTG drugs may also be supplied in outlets other than pharmacies, such as chemists or sometimes even a special counter in a supermarket, provided that a chemist or a pharmacist plays a supervisory role at such a counter. ${ }^{276}$ If supplied on prescription at the pharmacy, non-WTG drugs may still be covered by the health insurance, but only under very specific conditions. ${ }^{27}$ Of all drugs supplied by community pharmacies on prescription, $80.5 \%$ were WTG drugs in $2001 .{ }^{278}$

The fee pharmacists receive for supplying WTG drugs, called the fixed fee, 279 is not related to the cost of the product. On the contrary, the fee is fixed per prescription and does not depend on whether the medicine costs $€ 5$ or $€ 50$. The fee also does not depend on the prescribed amount. The result is that in the Netherlands tariffs for WTG drugs do not or just barely differ between pharmacies. The purchase fee, the refund paid by insurers to pharmacists for the dispensing of drugs in the pharmacy, is determined by a reimbursement list in the so-called taxe of Z-index. Zindex is a company that is connected to the pharmacists' association KNMP. ${ }^{280}$ The taxe is a list of all drugs registered in the Netherlands and is published every month on the basis of the CTG ${ }^{281}$ tariff orders. The CTG tariff orders determine, inter alia, the fixed fee per prescription and the amounts that pharmacists are allowed to charge patients to compensate for their purchase costs. In practice, the CTG tariff

One can compare this with the general classification of drugs presented in Figure 3.2 in chapter 3: non-WTG drugs are the over-the-counter (OTC) drugs as presented in that figure.

Since 1 September 1999, only prescribed non-WTG drugs that are intended for chronic use (that is, which are used for a period exceeding 3 months a year) are reimbursed. In cases where it concerns a new medicine for the patient in question, he or she always has to pay the first prescription (the first 15 days) him/herself. See: CVZ, De vergoeding van zelfzorggeneesmiddelen met ingang van 1 september 1999, augustus 1999, pp. 2-4, and SFK (2001, p. 37).

SFK (2002, p. 45). In 2001 this percentage was $86.1 \%$ (SFK, 2001, p. 37); in 2000 it was $85.3 \%$ (SFK, 2000, p. 35).

Infra, $\$ 4.6 .2$.

More specifically: Z-index is a subsidiary of the KNMP Holding Ltd. See NMa, Decision nr. 912/2001 (CZ - Apotheker), pp. 3-4, and the website of Z-index: <http://www.z-index.nl>

Health Charges Board (College Tarieven Gezondheidszorg). Among the tasks of this government watchdog body are the supervision and registration of all drugs (proprietary, parallel-imported and generic) that have been put into circulation. 
orders allow the purchase costs of drugs to be recovered fully by the pharmacist. ${ }^{282}$ The taxe of Z-index is the only reimbursement list that satisfies the tariff orders of the CTG.

In the taxe the prices as set by the producers are entered. Only the prices reported by drug producers and importers are entered in the taxe and not the prices of those who actually deliver and charge the drugs to pharmacists in the vast majority of cases: the wholesalers. This of course leads to resale price maintenance. Moreover, because pharmacists operate on the basis of a 'pharmacy purchase price $=$ pharmacy retail price' principle, the producer or importer (indirectly) determines the final retail price of the drug. ${ }^{283}$ Once a drug has been included in the taxe, the only room left for the drug producer to compete by means of the price level is by using the margin between the cost price (i.e. the actual costs of the production of the drug) and the pharmacy purchase price as fixed in the taxe. This margin is used by producers to provide bonuses and discounts to pharmacists in order to persuade them to provide their drugs instead of those of competitors. ${ }^{284}$ Thus, in practice the taxe price is not the price that is actually paid by the pharmacist to the drug producer or wholesaler. However, patients and insurers do not derive any benefits from these practices, because the regulated taxe price is the price that pharmacists charge patients.

In the Netherlands the pharmaceutical products prescribed by a physician and dispensed through a pharmacy are usually either paid directly or reimbursed (entirely or for the largest part) via the system of health care insurance. ${ }^{285}$ Hence, it is in the interest of insurers to keep consumption of pharmaceutical products within a reasonable limit. As far as the reimbursement to pharmacists is concerned the taxe prices are maximum prices: that is, the health insurers are in principle allowed to deviate from these prices when reimbursing pharmacists. Nevertheless, although the insurers are allowed to deviate from the taxe prices, they rarely do this because of the administrative complexity of diversifying prices. In the current situation they only have to deal with one price per drug. By the end of the 1990s the government gave the fight against bonuses and discounts a prominent place in its drug policy. Since then, pharmacists have been obliged by the government to pass on some of their rebates by a decrease in the reimbursement prices of drugs that they may charge. ${ }^{286}$ This legally determined deduction of the reimbursement price is called 'claw back.'

MDW (1999, p. 67).

When drug producers make price decisions they have to take into account the provisions in the Drug Prices Act and the Drug Reimbursement System. This will be explained below. Ministerie van Volksgezondheid, Welzijn en Sport (1999, p. 28).

See the appendix to chapter 3 .

Ministerie van Volksgezondheid, Welzijn en Sport (1999, p. 49). The debate concerning bonuses and discounts is still very much alive. In the next section I will come back to this. 
I just explained that the pharmaceutical industry's scope for competing on the basis of price is limited once prices have been set in the taxe, and that drug producers therefore resort to bonuses and discounts. In principle the industry sets prices taking into account obvious elements such as the cost of production and the cost of research and development. Assuming that the drug enjoys intellectual property right protection, the producer will be able to set his price in such a way as to include a profit to compensate for development costs. However, prices can obviously not be set at random. On the one hand there may be competition from other pharmaceutical products with the same or similar effects. On the other hand prices are controlled by government regulation. Government regulation is necessary given that the (largely publicly financed) ${ }^{287}$ health care system in the Netherlands covers pharmaceutical products. To control the public budget it is hence in the interest of the government to control drug prices. This occurs in various ways. Firstly, the Drug Prices Act of $1996^{288}$ grants the Minister of Public Health the right to fix a maximum price for registered drugs of which the availability has to be guaranteed to every citizen. This price, which has already been fixed for a great number of drugs, is determined by the average price level in the neighbouring countries Belgium, Germany, France and Great Britain. It has to be reviewed at least twice a year. 289 Secondly, the Drug Reimbursement System (Geneesmiddelenvergoedingssysteem), or GVS, the statutory insured drug package introduced in 1991, strongly influences the price of drugs. Under the GVS, therapeutically mutually interchangeable drugs are clustered by the Ministry of Public Health. For every cluster the Ministry defines a reimbursement limit. If the price of a certain drug is higher than this limit, the price difference must be born by the patients who take the drug instead of by the health insurer. As a result, drug producers do rather not set prices above the reimbursement limit. On the contrary, many producers fix their prices exactly at or just below the GVS limit. 290

\subsubsection{The pharmacist's fee}

What is now the fee a pharmacist receives for his or her services of dispensing drugs, customer advice and looking after medication surveillance? Regulations in the Netherlands are as follows: for every dispensed drug on prescription the pharmacist receives a fixed fee (receptregelvergoeding), which in 2001 was $€ 5.65$, irrespective of the price or the quantity of the drug. ${ }^{291}$ The fixed fee is updated each year by the Health Charges Board. Hereby the Health Charges Board looks especially at developments in the number of dispensed WTG drugs per year. There is also a substitution measure that makes up part of the pharmacist's fee, albeit a relatively small part compared to the fixed fee. The substitution measure fits in with the

This is explained in the appendix to chapter 3.

Wet van 25 januari 1996 (Wet Geneesmiddelenprijzen), Stb. 90, 1996.

See Article 3 of the Drug Prices Act.

1 already discussed the GVS in the appendix to chapter 3 . See $\$$ A.3.2.2 and $\$$ A.3.3.

CTG, Tariefbeschikking 5200-1900-01-2. 
idea that a prescriber (e.g. a general practitioner or specialist) in principle has to prescribe under the substance name and not under the brand name. This so-called incentive measure (stimulansregeling) entails that a pharmacist is allowed to keep one-third of the price difference between a proprietary drug and an equivalent parallel-imported or generic drug. ${ }^{292}$ The final saving for the insurer is then twice as high as the incentive revenue of the pharmacist. However, the price differences between branded and generic drugs are becoming smaller and smaller due to the oppressive effect the Drug Prices Act and the Drug Reimbursement System exert on the price level. 293 The possibilities for parallel-import therefore have also decreased drastically. Revenue earned by pharmacists through the incentive measure is often lower than the amount they could earn by accepting rebates for branded drugs, so the incentive measure loses its appeal relative to the bonuses and discounts offered by drug producers and wholesalers. ${ }^{294}$ In 1999 it became clear that the government intended to incorporate the average incentive revenue per prescribed WTG-drug of 0.40 NLG $(€ 0.18)$ in the fixed fee. ${ }^{295}$ Pharmacists are then more or less obliged to obtain a minimum amount of substitution. The fixed fee and the incentive measure came into force on 1 January 1988.296

The KNMP claims that the fixed fee has not been adapted sufficiently to the rising pharmacy practice and staff costs, ${ }^{297}$ while in addition the revenues from the incentive measure have decreased as a result of the levelling of prices of pharmaceutical specialites and generic drugs. The deficits in the pharmacy budget, which according to many pharmacists have arisen, have been counterbalanced by bonuses and discounts from industry and wholesalers. After all, price competition has already been made virtually impossible as a result of all the government interference.

For years the government had openly tolerated the bonuses and discounts, until the Minister of Public Health suddenly brought the issue up again at the end of the 1990s. Dr. E. Borst, at the time Minister of Public Health, was of the opinion that bonuses and discounts must go to the health care sector, but the politicians in The Hague disagreed on the way to deal with this problem. And pharmacists claimed

CTG, Tariefbeschikking 5200-1900-02-1, Article 3.4 .

See, e.g., Pharmaceutisch Weekblad, De apotheekcijfers van 2001, vol. 137, nr. 17, 2002 (<http://www.sfk.nl>), and Pharmaceutisch Weekblad, Waar blijft de stimulans, vol. 135, nr. 22,2000, p. 771.

Bogin (1999, p. 11).

With this a saving of 39 million NLG ( $€ 17.7$ million) was intended. The underlying idea is that it is an elementary duty of a pharmacist to dispense efficiently and that therefore the incomes from the incentive measure should be involved in the calculations of the fixed fee (Ministerie van Volksgezondheid, Welzijn en Sport, Aanwijzing stimulansopbrengst in de tarieven farmaceutische zorg, 29 June 1999).

RVZ (1998, p. 96).

The fixed fee was $€ 4.54$ in 1994 and had gradually increased to $€ 5.08$ in 1999 and - under certain conditions (see $\$ 4.7 .1$ ) - to $€ 6$ in 2002. Source: SFK. Pharmaceutisch Weekblad, Receptregelvergoeding 2003, vol. 138, nr. 3, 17 January 2003. 
that, if the bonuses and discounts would be taken away from them, they should receive a higher fixed fee in accordance with the increased costs of practice and staff. Under pressure of summary proceedings by the KNMP and criticism from the Health Charges Board, the Minister of Public Health decided to do an investigation into the practice costs of pharmacists first. After long-lasting negotiations, the Ministry of Public Health, the Health Charges Board and the KNMP eventually concluded an agreement on the main lines in October 1999. The bonuses and discounts would be taken away in phases, while also the adjustment of the practice costs reimbursement would be taking place in phases. ${ }^{298}$ The reason behind this planning in phases was that a generic approach might have had disproportionate and disastrous consequences for individual pharmacists, given that the claw-back ${ }^{299}$ percentage on the purchase fee is an average percentage. The phasing creates room for a gradual development towards a new situation. In coming to this agreement the KNMP had to reconcile to a decrease in the income of pharmacists, but the pharmacists' association has been able to restrict this decrease somewhat, compared to the original plans of the Minister of Public Health, that did not take account of a fee for the increased pharmacy practice costs at all.

In 2001 the claw-back was on average $6.82 \%$. This brought in $€ 190 \mathrm{mln}$ for the government. However, the bonuses and discounts actually received by pharmacists are much higher than this amount. Moreover, pharmacists have reacted to the ever increasing claw-back by demanding more bonuses and discounts from wholesalers and the pharmaceutical industry. The estimations of the total amount of bonuses and discounts received by pharmacists vary quite a lot: for the year 2001 the Boston Consulting Group calculated the bonuses and discounts at $€ 520 \mathrm{mln}$, while Deloitte and Touche came to an even higher (maximum) amount of $€ 644 \mathrm{mln}$. $^{300}$ These estimations include the legally obliged claw-back of $€ 190 \mathrm{mln}$. Per pharmacy this would imply (on average) $€ 300.000$ per year. ${ }^{301}$ By the end of 2002, the acting Minister of Public Health, Mr. De Geus, submitted a proposal to bring in an additional $€ 280 \mathrm{mln}$ in 2003 (that is, on top of the $€ 190 \mathrm{mln}$ mentioned above) via another increase in the claw-back. ${ }^{302}$ The cabinet, pursuing to curtail the expenditure on health care and in particular the costs of medicines, accepted this proposal in November 2002. Naturally, the pharmacists were furious over these plans, while the SFK predicted that, if these plans were to be enforced, many pharmacies will run into serious financial problems and many pharmacists and pharmacists' assistants will lose

Ministerie van Volksgezondheid, Welzijn en Sport/KNMP, Minister en apothekers sluiten akkoord, press report Ministry of Public Health, 8 October 1999.

The legally determined deduction of the reimbursement price of a drug to pharmacists; see $\$ 4.6 .1$.

Ministerie van Volksgezondheid, Welzijn en Sport, Conclusies rond bonussen bevesigd, press report Ministry of Public Health, 17 December 2002.

De Volkskrant, De Geus dreigt apothekers met inzet van ECD, 10 January 2003.

To be precise, the proposal is to increase the claw-back to $9 \%$ for pharmaceutical specialites and to $40 \%$ for generic medicines. 
their jobs. The pharmacists' association KNMP and the wholesaler OPG started legal proceedings against these plans and succeeded: the judge suspended the government plans. Obviously the debate concerning bonuses and discounts is still very relevant. ${ }^{303}$

To the preceding discussion must be added, for the sake of completeness, that pharmacists also receive revenues from the sale of non-WTG drugs and medical devices (such products may be sold by chemists as well). The average profit margin on these products lies between 20 and $30 \% 3^{304}$ Just like the taxe for WTG drugs, the retail and purchase prices of these products are included in a list that is issued monthly by Z-index. Contrary to the case of WTG drugs there is some price competition between pharmacies in this field. However, since the sale of WTG drugs makes up (by far) the largest part of the turnover in pharmacies, it concerns relatively small amounts of money. ${ }^{305}$ Moreover, in calculating the fixed fee the Health Charges Board takes the average revenues pharmacists obtain from trade activities, other than the sale of WTG drugs, into account as well.

\subsubsection{Summary}

The price of drugs is regulated by the government via the Drug Prices Act and the Drug Reimbursement system. The prices of WTG drugs are laid down in a price list called the taxe. The reimbursement for the pharmacist consists of three components: the purchase fee (the refund paid by insurers to pharmacists based on the taxe prices), the fixed fee and the incentive measure (both determined by the government via the Health Care Charges Act).

Looking at these regulations, the conclusion from this section can be kept short. It appears that the possibilities for pharmacists to compete do not lie in their price policies. Quite to the contrary, the government regulates the whole market, with the exception of the relatively much lower revenues of pharmacists from other trade activities than the sale of WTG drugs.

This paragraph is based on a number of short articles: Elsevier, Pijn in portemonnee, 7 December 2002; Het Financieele Dagblad, Aanpak bonus apothekers vertraagd, 20 December 2002; De Volkskrant, Apothekers: 2050 banen weg door afromen bonussen, 2 January 2003; De Volkskrant, De Geus dreigt apothekers met inzet van ECD, 10 January 2003; Pharmaceutisch Weekblad, 2000 banen op de tocht, vol. 138, nr. 1, 2003; OPG Groep N.V., Preliminary relief judge grants OPG's request for suspension of clawback, press release OPG, 29 April 2003; Dagblad De Limburger, Apotheker voorziet zware tijden, 30 April 2003; Het Financieele Dagblad, Rechter stopt extra afromen van apothekers, 30 April 2003. Tinke (1998, p. 41).

305 Split up per product category, $83 \%$ of the turnover of an average pharmacy in 2001 was determined by WTG drugs, against $12 \%$ by non-WTG drugs and OTC and $5 \%$ by medical devices. See SFK (2002, p. 54). 


\subsection{Recent developments}

Since the end of the 1990s, the regulation of the Dutch pharmaceutical market has been subject to many changes, both in the law and in the self-regulation. In this section I will have a closer look at these recent changes. Naturally, the introduction of the new Dutch Competition Act in 1998 and the strict enforcement of this act by the Dutch competition authority (NMa) has had a huge impact on the regulatory framework of the pharmaceutical market, especially where it concerns selfregulation. Therefore I will also summarise the most important decisions of the $\mathrm{NMa}$ in recent cases relating to pharmacists. The effects of these changes in the regulatory framework - if any - will not be discussed here. As far as the changes in the law and in the self-regulation have already had an impact on e.g. the number of pharmacies, tariffs, prices and other indicators, this will be discussed in chapter 7 .

\subsubsection{Measures taken by the government}

As already described in $\S 4.3 .1$, the Ministry of Public Health took a number of measures in the late $1990 \mathrm{~s}$ with the objective of intensifying competition between pharmacists in the market for extramural drug provision. Firstly, the professional monopoly of pharmacists was restricted to some extent in 1999 by the removal of Article 15 from the Pharmaceutical Practice Decree. This enabled pharmacists to be employed by non-pharmacists. The British chemistry chain Boots Health and Beauty immediately tried to make use of this change in the regulation. The Boots case will be analysed in more detail in chapter 7 . Secondly, for health insurance funds (the public health insurers) ${ }^{306}$ the ban on running pharmacies themselves has been lifted as from 1 January 1999, by granting them a general exemption from Article 42.5 of the Health Insurance Act. Of course, this exemption applies only under the condition that a qualified pharmacist is working behind the counter. The third amendment was adopted in the year 2000, although an earlier proposal had already been made in 1998. A provision that prohibited hospital pharmacies to dispense drugs outside of the hospital was repealed on 1 April 2000. This provision was formerly part of Article 13 of the Drug Supply Act. The aim of this amendment was to enable hospital pharmacies to compete with public pharmacies by giving hospital pharmacies the possibility of also supplying patients who have not been hospitalised with medicines, through polyclinic pharmacies in or near the hospital. Consumers are then given greater freedom of choice in obtaining medicines, whereas public pharmacies are encouraged to improve their efficiency and quality.

Furthermore, from a proposed amendment of the law, which was sent to the Second Chamber of the Dutch Parliament in July 2002, it becomes clear that (a) the Dutch government is planning to repeal Article 19 of the Drug Supply Act and (b) that it intends to include pharmacists in the WGBO (Wet op de Geneeskundige Behan- 
delingsovereenkomst): the Medical Treatment Contracts Act. ${ }^{307}$ The former implies that pharmacists would be allowed to practice pharmacy in more than one pharmacy. This would provide opportunities for health insurers to become more proactive in the provision of pharmaceutical care. ${ }^{308}$ The latter implies that the new tasks of pharmacists, as providers of pharmaceutical services (instead of them being considered as mere sellers of medicines), would be recognised by law. ${ }^{309}$

These new tasks of pharmacists were also emphasised in another way in 2002. In that year the fixed fee was increased from $€ 5.65$ (see $\$ 4.6 .2$ ) to $€ 6$ by the Health Charges Board, but for the first time a condition was attached to this: the full amount of $€ 6$ would only be reimbursed if pharmacists had drawn up a plan with respect to the innovation of pharmaceutical care within their pharmacy in the year 2002. ${ }^{310}$ Pharmacists who did not participate would be cut down by $€ 0.18$. This condition, formulated by the Health Charges Board in accordance with $\mathrm{ZN}$ (the national association of health insurers) and the pharmacists' association KNMP, was another signal of a slowly changing pharmaceutical market. In this respect it is of course important that the performance of pharmacies in the field of pharmaceutical care can be measured somehow. In 2002 more and more pharmacies in the Netherlands started to make use of so-called 'care records' to register their activities. WINAp, the Scientific Institute of Dutch Pharmacists (affiliated with the KNMP), has appointed a number of activities for registration in a 'care record', such as distributing drug passports, samples of incontinence products and needle containers, giving inhaler instructions to customers, consulting with physicians by telephone, etc. ${ }^{311}$

\subsubsection{The impact of the Competition Act on the pharmaceutical market}

Since the introduction of the Dutch Competition Act in 1998, many requests for exemption from the cartel prohibition have reached the Dutch Competition Authority (hereafter NMa), as regards individual agreements between health insurers and pharmacists. In principle such agreements fall under the cartel prohibition because they are matters of market division. In reaction to the many requests for exemption by the health insurers, the director-general of the NMa publicly replied (as early as September 1999) that the NMa is of the opinion that health insurers generally try to settle too many issues through informal consultations with physicians, pharmacists

TK 2001-2002, 28 494, nr. 2.

TK 2001-2002, $28494, \mathrm{nr} .3, \mathrm{p}$. 1. The new role for health insurers as 'directors' in the provision of pharmaceutical care is the core of many proposals for reform of the Dutch health care system. See e.g. MDW (1999), Ministerie van Volksgezondheid, Welzijn en Sport (1999), Boston Consulting Group (1999), TK 2000-2001, 24124 en 24 036, nr. 111, and TK 2001-2002, 24 124 en 28 008, nr. 112.

For a discussion of these 'new tasks' of pharmacists: supra, $\$ 3.2$. For more information on the WGBO in relation to pharmacists, see Ten Hoopen (2001, Ch. 5).

CTG, Tariefbeschikking 5200-1900-02-01.

Pharmaceutisch Weekblad, Meetbare zorg, vol. 137, nr. 25, 2002 
and hospitals, instead of letting competition prevail on the health care market. The director-general referred not only to contracts dealing with market division, but also to agreements on tariffs. He warned the parties involved that the NMa was about to do a targeted research of the individual and collective agreements in this sector. ${ }^{312}$

In 2001, the NMa took a decision on the policy with regard to the establishment of practices and collective negotiations by the Dutch association of general practitioners, the LHV. ${ }^{313}$ The NMa decided that agreements with regard to collective negotiations, e.g. in relation to tariffs and agreements on the division of the market, contravened the Competition Act. Naturally, this decision has had a strong influence on the self-regulation in other liberal professions (among them pharmacists), by making explicit that agreements regarding tariffs and market division are prohibited. ${ }^{314}$

Also in 2001 a decision was taken regarding collective standard agreements between a health insurance fund $(\mathrm{CZ})$ and the regional representatives of pharmacists established in the respective region. ${ }^{315}$ This standard contract contained agreements on tariffs and agreements with regard to the setting up and distribution of practices, which were not allowed following the line of reasoning of the LHV case described above. Only agreements on quality and administrative procedures are allowed by the NMa. $\mathrm{CZ}$ now pursues a unilateral establishment policy and a unilateral tariff policy, which is not prohibited by the Competition Act. Obviously the bargaining power is shifting more and more from the pharmacists to the health insurers.

I noted in $\$ 4.7 .1$ that in 2001 a provision prohibiting hospital pharmacies to dispense drugs outside of the hospital was repealed from the Drug Supply Act. In the AstraZeneca case, the NMa supported the legislator's aim of enabling hospitals to compete with pharmacies (thereby encouraging pharmacies to improve their efficiency and quality and giving consumers greater freedom of choice). ${ }^{316}$ AstraZeneca is a company active in the research and development, the production, and the marketing of pharmaceutical products. The company gave very large discounts to hospitals purchasing its medicines, on the condition that these hospitals only use the medicines in the intramural market (i.e. for patients admitted to the hospital). By imposing a prohibition on the resale to public pharmacies or individual patients,

De Volkskrant, NMa roept verzekeraars in de zorg tot de orde, 28 September 1999. $\mathrm{NMa}$, Decision nr. 537/2001 (Landelijke Huisartsen Vereniging).

314 The fact that professional bodies are subject to the supervision of the NMa had already been determined before. In August 1998 the NMa decided that the KNMvD, the association for veterinary surgeons, is an entrepreneurial association falling under the Dutch Competition Act (Decision $n$ r. 397/1998, pp. 9-10). The exemption applied for by the KNMvD, with respect to its professional code and rules of conduct, was not granted by the NMa for parts of the rules of conduct. 
AstraZeneca was able to keep up an artificial price difference between the intramural and the extramural drug market. The NMa made clear in its decision that such contract provisions are not only contrary to the legislator's aim of creating more competition in the pharmaceutical market but also contrary to the Competition Act.

On the basis of its decisions in a number of health care cases, ${ }^{317}$ among which those described above, a consultation document was published by the NMa in 2002.318 This document, the so-called Guidelines for the Health Care Sector (Richtsnoeren voor de Gezondheidszorg) provides clarity on what is and what is not permitted in accordance with the Competition Act. The traditional method of (mostly collective) contracting between health care providers and health insurers is in conflict with the cartel prohibition of the Competition Act, while it is also in conflict with the legislator's aim of changing from a supply-driven to a demand-driven system of health care. After all, collective contracting between representatives of health care providers and health insurers prevents individual health care providers from differentiating their services in relation to each other. Only collective agreements that are limited to the actual advancement of the quality of care or to administrative procedures are allowed. ${ }^{319}$

\subsection{Summary}

The regulation of pharmacists in the Netherlands consists of public regulation (notably, the Drug Supply Act, the Pharmaceutical Practice Decree, the Professions Act and various provisions regarding drug prices and fees) and self-regulation enacted by the Dutch pharmacists' association KNMP. Currently the self-regulation comprises the new Dutch Pharmacy Standards of 2002, the Professional Code and the Professional Statute. Furthermore, there is a KNMP advisory establishment policy, but in practice this document has become a dead letter. Most pharmacists are member of the KNMP, so the range of the remaining self-regulation is wide.

There are no extraordinary restrictions with respect to the education (training) of pharmacists. The entry into the profession is regulated by a double registration system. A pharmacist with the proper diploma has to enrol in the register of the Health Inspectorate and in the title register of the Professions Act. The compounding and dispensing of drugs are protected. Only pharmacists - and under specific conditions dispensing physicians - are allowed to dispense prescription drugs. Hence, phar-

Notably: NMa, Decision nr. 537/2001 (Landelijke Huisartsen Vereniging), NMa, Decision nr. 2451/2001 (Mediveen Groep B.V. en TPP Participaties Rotterdam B.V./Coriopharma C.V.), NMa, Decision nr. 912/2001 (CZ - Apotheker), NMa, Decision nr. 1915/2001 (Zilveren Kruis - Geneesmiddelenformularium Kennemerland), and NMa, Decision nr. 1994/2002 (AstraZeneca). NMa (2002b).

319 NMa, (2002a, p. 32). However, small groups or joint ventures of health care providers, such as general practitioners and pharmacists, are allowed to enter into joint negotiations with health insurers, but subject to certain conditions. See NMa (2002b). 
macists have a professional monopoly in the extramural supply of these drugs. For every dispensed prescription drug pharmacists receive a fixed fee: the so-called receptregelvergoeding. Until the end of the 1990s community pharmacists were also protected from competition by health insurers, hospital pharmacies and chains of wholesalers and chemists. However, a number of restrictions to competition, e.g. a prohibition on employment of pharmacists by non-pharmacists, have been lifted by the Dutch government. OTC drugs may in the Netherlands also be sold by licensed chemists (druggists).

The establishment of pharmacies has long been regulated by the KNMP: between 1975 and 1987 in the form of a private establishment policy and from 1987 onwards in the form of an advisory establishment policy. According to the advisory establishment policy a pharmacy must have a minimum number of prescriptions (formerly a minimum number of patients) in order to be 'financially sound'. Although, from a strictly legal perspective, the KNMP has never been able to prevent nonmembers from establishing themselves, in practice the establishment rules have always had a strong influence on the Dutch market. Naturally, KNMP members were bound by these rules. Just as important, however, is the fact that the contracts with health insurers, which are a necessary condition for surviving in the Dutch pharmacy market, were based on the KNMP advisory policy. Even though collective negotiations have explicitly been prohibited by the Dutch Competition Authority $\mathrm{NMa}$, many contracts nowadays still contain provisions that are based on similar provisions regarding the financial feasibility of a pharmacy.

Next to the establishment of pharmacies, the self-regulation of the KNMP has until recently also restricted the advertising for pharmacies and the competition between pharmacists. The provisions concerned ceased to exist in 2001, when the KNMP rules of conduct were withdrawn. Hence, on paper there are no more restrictions to advertising. In addition, three provisions of the Dutch Pharmacy Standards, which contained strict requirements regarding the design and accessibility of a pharmacy, have been changed. These changes in the self-regulation can to a large extent be attributed to the intervention in the pharmaceutical market by the NMa, on the basis of the Competition Act of 1998.

There are almost no possibilities for pharmacists to compete by price in the Netherlands. Drug prices are regulated by the government: both the Drug Prices Act and the Drug Reimbursement System have a large influence on the drug price. The prices are laid down in a price list, the so-called taxe. As a result the only price competition that takes place in the drug market is competition in the form of bonuses and discounts from the pharmaceutical industry and wholesalers to pharmacists. The government wants these bonuses and discounts to flow back to the health care sector and introduced the 'claw back' system in the 1990s. That is, the refund paid by health insurers to pharmacists for a dispensed drug, which is based on the taxe prices, is not the full price: a percentage (the 'claw back') is deducted from the taxe price. The debate concerning bonuses and discounts is still very relevant. 


\section{THE REGULATION OF PHARMACISTS IN BELGIUM}

After the discussion of the regulatory framework with respect to pharmacists in the Netherlands, I now turn to Belgium. The structure of this chapter is similar to that of chapter 4. That is, $\S 5.1$ discusses the most important professional associations in Belgium, being the Order of Pharmacists and the Belgian Pharmacists Association (APB). Subsequently, $\$ 5.2$ deals with regulation of the education of pharmacists and $\$ 5.3$ deals with registration and the professional monopoly of the pharmacist. In $\$ 5.4 \mathrm{I}$ consider regulation of establishment. In addition to a Royal Decree that looks after the establishment of pharmacies, a Royal Decree exists that regulates the takeover price. The topic of section 5 is the exercise of the profession: I examine, successively, the advertising for drugs, the advertising for pharmacies and the design of the pharmacy. The price of drugs and the reimbursement for the pharmacist, which are determined by law, are central in $\S 5.6 .1$ and $\S 5.6 .2$ respectively. Finally, some recent developments in the Belgian regulation of pharmacists are presented in $\S 5.7$.

\subsection{Professional code and rules of conduct}

In Belgium pharmacists are organised in the Order of Pharmacists (Orde der Apothekers), which was called into being by an Act from 1949. This Act was replaced in 1967 by the Royal Decree no 80 concerning the Order of Pharmacists (Koninklijk Besluit nr. 80 van 10 november 1967 betreffende de Orde der Apothekers), which since then has contained the most important provisions related to this Order. ${ }^{320}$ Three years later a Royal Decree was formulated that specifies the organisation and the functioning of the boards of the order. ${ }^{321}$ Next to the national board of the Order of Pharmacists there are ten provincial boards, as well as a Dutch-speaking and a

B.S. 14-11-1967. Since this is a numbered Royal Decree, it can also change a law. A numbered Royal Decree works like a formal act.

321 Koninklijk Besluit van 29 mei 1970 tot regeling van de organisatie en de werking der raden van de Orde der apothekers, B.S. 4-7-1970. 
French-speaking Board of Appeal. In a case from 1993 the tasks and competences of the Order were described as follows:

\begin{abstract}
'the Order of Physicians and the Order of Pharmacists are public institutions that have been founded by law and who have competences, which are enforced under the supervision imposed by that law. They have as their duty to watch over the respect of the ethical rules, as well as the compliance with the honour, the discretion, the decency and the dignity of the Order members. They group in a compulsory way all those that practice the profession of physician or pharmacist'. 122
\end{abstract}

The so-called professional deontology, issued by the Order of Pharmacists, provides the ethical rules about the practice of the pharmacist's profession. Formally, these professional rules have no legal binding force, no more than the professional code and rules of conduct issued by the KNMP in the Netherlands. The King of Belgium does have the possibility to grant binding force to these rules, but until now this has never happened. The professional deontology was formulated some decades ago by the national board of the Order and has barely changed in the course of time. In spite of the clear need for an update or revision of some rules, so far no concrete steps have been taken for this. ${ }^{323}$ The national board of the Order of Pharmacists can also give advice about matters that are of interest to pharmacists. Again, this kind of advice has no legally binding force and therefore cannot contain obligations. Should such an advice still carry obligations or prohibitions, than it may be subjected to an annulment by the Council of State (Raad van State). ${ }^{324}$ The most important duties of the provincial boards are approving, postponing or refusing entries into the register of pharmacists (which is kept up to date on the provincial level), 325 watching over the compliance with the deontological rules in the province and taking disciplinary measures. The provincial boards in Belgium can be compared with the administration of the disciplinary rules in the Netherlands, because the provincial boards also have the authority to impose - rather heavy - punishments. Both (fellow) pharmacists and patients can file complaints with the Order of Pharmacists. Complaints are dealt with on the provincial level. Possible sanctions that can be imposed by the provincial boards of the Order are the following: warning, censure, reprimand, the suspension of professional practice for at most two years and elimination from the register of the Order. ${ }^{326}$

Arbitragehof nr. 68/93, 29 September, 1993, B.S. 28-10-1993, 23.557.

The first deontological rule goes all the way back to 1951, the most recent one is the tenth deontological rule issued in 1992. However, in a newsletter dated 4-5-2002 the Order of Pharmacists announced that it is currently reworking the deontological rules; see <http://www. ordederapothekers,be>.

Balthazar (1994, p. 114).

If the entry into this register is refused or postponed, the reasons for this must be clearly stated, according to Article 6 of the Royal Decree no 80 concerning the Order of Pharmacists. Royal Decree no 80 concerning the Order of Pharmacists, Article 16. 
Next to the Order of Pharmacists there is another federation that groups all pharmacists on a national level: the Belgian Pharmacists Association (Algemene Pharmaceutische Bond), hereafter APB. The APB asserts the interests of all pharmacists and is the interlocutor of all official bodies on both the international, national and regional level. The APB offers pharmacists and the pharmaceutical sector many services, such as a drugs data base and a Documentation office, and publishes several magazines. Because the APB is the national federation of all acknowledged pharmacists' associations in Belgium it has been empowered since 22 December 1975 to use the title 'Royal Association' (Koninklijke Maatschappij). ${ }^{327}$

In the following sections the effects of the Belgian self-regulation and public regulation on the functioning of the market for pharmaceutical services will be described. Similar to the survey of the Dutch restrictions on competition in the previous chapter, this will be done for every category - and simultaneously with the legal provisions.

\subsection{Education}

Regarding the education there are no notable rules restrictive of competition on the market for pharmacists in Belgium. However, like in the Netherlands, the structure of the pharmaceutical study is regulated. Students first have to obtain a certificate of 'candidate in the pharmaceutical studies', which takes (at least) 2 years. Then, in order to obtain the title 'pharmacist', another 3 years of education are needed. No additional practical experience is required. ${ }^{328}$ There has never been a numerus clausus for the admission to the study. Nevertheless, the number of final-year students remained roughly constant from the end of the 1980 s until the mid-1990s: between 400 and $450 . .^{329}$ A reason for this could be that the career opportunities after graduation are limited by the strict establishment rules and the high takeover prices in the case of a pharmacy transfer (to be discussed in § 5.4). However, since no reduction in the number of students could be detected at the time; it seemed mainly to be a matter of a natural stabilisation in the supply of pharmacy students. After all, there are also career opportunities outside of the community pharmacy for the graduated, e.g. in the industry. Nevertheless, in the late 1990s the number of students decreased again: in 2000 the number of new students was only 250.330 Of the recently graduated pharmacists three out of four are females. Already since 1988 there have been more female than male qualified pharmacists in Belgium.

APB Statuten, 1994, Articles 1-2.

Furthermore, there is also an EC Directive that regulates the pharmaceutical education: see Hombroeckx (2000, p. 181) and supra, note 240.

$\operatorname{BIGE}(1999$, p. 60).

De Morgen, Dreigend tekort aan apothekers door te weinig studenten, 1 September 2000. 


\subsection{Registration and title protection}

\subsubsection{The professional monopoly of the pharmacist}

The protection of the professional monopoly of community pharmacists (officinaapothekers) is laid down in the Royal Decree no 78 from 1967 concerning the practice of the health care professions. ${ }^{331}$ Article $4 \$ 1$ of this decree holds the following:

'No one is allowed to practice pharmacy who does not have the legal pharmacist's diploma, obtained according to the legislation on the assignation of academic degrees and the programme of the university exams, unless that person is exempted from this by law'.132

Dispensing drugs, even if this happens free of charge, is not allowed if this is done 'on a common basis' by someone who does not meet this criterion. It is also prohibited for non-qualified persons to prepare drugs, to offer drugs for sale, or to sell them in the retail trade. The operations reserved for pharmacists are thus listed indirectly here. ${ }^{333}$ According to Article $4 \S 2$, under specified conditions physicians, dentists and veterinary surgeons have a limited competence to dispense drugs too. It follows that in Belgium - contrary to the Netherlands - it is not allowed for retailers such as chemists (druggists) to sell OTC drugs. ${ }^{334}$ The provisions regarding manufacturers and industry pharmacists can be found elsewhere, namely in the

331 Koninklijk Besluit nr. 78 van 10 november 1967 betreffende de uitoefening van de gezondheidszorgberoepen, B. S. 14-11-1967. Formerly - until 1 September 2001 - called Royal Decree concerning the practice of medicine, nursing, the paramedical professions and the medical committees (Koninklijk Besluit betreffende de uitoefening van de geneeskunst, de verpleegkunde, de paramedische beroepen en de geneeskundige commissies). The title has been changed by Article 27 of the Wet van 10 augustus 2001 houdende maatregelen inzake gezondheidszorg, B.S. 1-9-2001.

'Niemand mag de artsenijbereidkunde uitoefenen die niet het wettelijk diploma van apotheker bezit, dat werd behaald overeenkomstig de wetgeving op het toekennen van de academische graden en het programma van de universitaire examens, of die niet wettelijk ervan vrijgesteld is'.

313 The penalty for the practice of a reserved operation is an eight day's to six month's imprisonment and/or a fine of between $500 \mathrm{BEF}$ and $5000 \mathrm{BEF}$. See Royal Decree no 78, Article 38 $\$ 1$. These fines will be raised by a multiplier (the so-called opdeciemen) to correct for currency depreciation, Currently the multiplier is 200. The disappearance of the Belgian Franc as of 1 January 2002 has led to an adaptation of all the existing fines to the euro. This has been regulated in Articles 2, 3 and 4 of the Act of 26 June 2000 concerning the introduction of the euro (B.S. 29-7-2000). As a result of Article 2 of this Act, all existing fines in the acts are now considered to be euros. Thus a fine of $500 \mathrm{BEF}$ has to be multiplied with 200 and divided by $40.3399=€ 2,478.94$. See on this rather complicated system Amo (2001-2002, pp. 996-999) and the reaction by Wailliez (2001-2002, p. 1514).

See also IHS (2003, pp. 76, 80) 
Royal Decree concerning the manufacture, large scale distribution and delivery of drugs from $1960.3^{335}$

In Belgium, for the dispensing of registered drugs a doctor's prescription is required, like in the Netherlands. ${ }^{336}$ However, substitution of branded drugs by generic drugs, like this takes place in the Netherlands is not allowed for pharmacists in Belgium (see $\$ 5.6 .1$ and supra, $\$ 3.2 .1$ ).

\subsubsection{Registration}

A pharmacist who has obtained a diploma is not immediately permitted to practice pharmacy. He first has to have his title formally approved by the Medical Commission (Geneeskundige Commissie) ${ }^{337}$ of the province where he is planning to establish himself and he has to register with the Order of Pharmacists. The visa is a procedure that gives the Medical Commission the possibility to prohibit individuals, who are no longer physically or mentally capable, to exercise their profession. ${ }^{338}$ Article $7 \S 1$ of the Royal Decree no 78 holds that the pharmacist has to pay a certain amount - determined by the King - to the provincial Medical Committee for having received the approval (visa). The registration with the Order has been specified in Article 2 of the Royal Decree no 80 concerning the Order of Pharmacists, which states that pharmacists must be enrolled in that register in order to be allowed to practice pharmacy in Belgium. There is a similar register for physicians, on the basis of the Royal Decree no 79 concerning the Order of Physicians. It is not allowed to practice medicine and pharmacy at the same time, not even for holders of both diplomas. Exceptions have been made for dispensing physicians. The criterion is comparable to the Dutch one: in a region, a dispensing physician can only establish himself if the geographical distribution of pharmacies makes it impossible to meet the requirements of public health. Moreover, physicians who are allowed to dispense drugs are not allowed to have a public (community) pharmacy. If a pharmacy is to be established in a region with a dispensing physician, the physician in question has a two year term to do away with his drug depot. Account is taken of possible mitigating circumstances. ${ }^{339}$ However, in practice these rules are not relevant anymore; there are almost no dispensing physicians left in Belgium because of the great number of community pharmacies.

Koninklijk Besluit van 6 juni 1960 betreffende de fabricage, de distributie in het groot en de terhandstelling van geneesmiddelen, B.S. 22-6-1960.

A Medical Commission consists of a chairman and a vice-chairman, who are proposed by the national board of the Order of Physicians and appointed by the King; and in addition two members for every medical profession, plus one member for every paramedical profession (if recognised by the King).

338 Hombroeckx (2000, p. 182).

339 Wet van 12 april 1958 betreffende de medisch-pharmaceutische cumulatie, B.S. 20-6-1958, Articles 1-4 and 9bis. 


\subsubsection{Summary}

One can conclude that in Belgium the professional monopoly of the pharmacist is protected by legislation. The practice of pharmacy is subject to a double registration procedure and the tasks of a pharmacist are clearly, be it indirectly, enumerated. The King, viz. the government, has a large say in the practice of the pharmacists' profession.

\subsection{Establishment of pharmacies}

The rules for the establishment of pharmacies are formally prescribed in Belgium. Already in 1967 the basis of these rules was formulated in the Royal Decree no 78. Article $4 \S 3$ of this decree states:

'For opening, transferring or merging of community pharmacies a prior permit is required, granted to one natural or one legal person making the application. [...] The King determines [...] the criteria intended to organise a distribution of the pharmacies'. 30

These criteria have been worked out in two important decrees: the Royal Decree of 25-9-1974 concerning the opening, transfer and merger of pharmacies open to the public, ${ }^{341}$ and the Royal Decree of 13-4-1977 settling the rules that permit to fix the value of the transfer of pharmacies and to supervise this transfer. ${ }^{342}$

\subsubsection{Supervision over the establishment of pharmacies}

The Belgian establishment law can be characterised as an administrative-legal system of permissions supported by a system of criminal injunction and sanctions..$^{343}$ Permissions are given by the Minister of Public Health and advice is given by an establishment committee. Such a permission is personal and is granted to one natural or one legal person. ${ }^{34}$ The objective of the establishment policy is stimulating public health by 'restricting the number of pharmacies to a maximum for every municipality' in order to realise a good distribution of pharmacies, according to Article $1 \S 1$ of the Royal Decree of 1974 . The establishment of new pharmacies is made very diffi-

'Voor de opening, de overbrenging of de fusie van voor het publiek opengestelde apotheken is een voorafgaande vergunning vereist, toegestaan aan éen natuurlijk of één rechtspersoon die de aanvraag doet. [...] De Koning bepaalt [...] de criteria die erop zijn gericht een spreiding van de apotheken te organiseren'.

Koninklijk Besluit van 25 september 1974 betreffende de opening, de overbrenging en de fusie van voor het publiek opengestelde apotheken, B.S. 5-10-1974.

Koninklijk besluit van 13 april 1977 tot vaststelling van de regels die toelaten de waarde van de overdracht der apotheken vast te stellen en toezicht uit te oefenen op deze overdracht, B.S. 28-5-1977.

Nys (1981-1982, p. 2576).

See also Hombroeckx (2000, p. 186). 
cult by the strict criteria that are employed. The maximum number of pharmacies in every municipality depends on the population figure of the municipality concerned (Article $1 \S 2$ ). Depending on whether the population of the municipality is at least 30,000 , between 7,500 and 30,000 , or less than 7,500 , the number of pharmacies may not be higher than the quotient that is the result from the number of inhabitants divided by $3,000,2,500$ and 2,000 respectively. Next to that, $\$ 3$ contains a series of distance criteria, which allow a deviation from the population criteria. That is, the establishment of a pharmacy will also be permitted if the pharmacy that lies closest to the planned pharmacy is located 1, 3 or 5 kilometres away and covers the needs of 2,500, 2,000 and 1,500 inhabitants respectively. In practice, the criterion 5 kilometres $-1,500$ inhabitants is no longer relevant. ${ }^{345}$

The pharmacy density in Belgium is very high compared to that of other European countries - and certainly compared to the Netherlands. The operational and transportation costs of the distribution of drugs are high too, because there is a large network of pharmacies and wholesalers, and often deliveries are made several times a day to the same pharmacy. Belgium thus opts for quick and small-scaled deliveries and an individual approach to patients, but it has to pay a price for that in the form of higher costs. ${ }^{346}$

The Belgian government feared that the 'oversupply' of pharmacies would lead to too much competition and less service to patients. That is why in 1994 the government supplemented the establishment rules from the Royal Decree of 1974 with a moratorium. ${ }^{347}$ For a period of five years, lasting until 8 December 1999, it was not allowed to open new pharmacies; only a better distribution of pharmacies in certain areas was still permitted. This moratorium was renewed in 1999 for a period of as much as ten years. At the same time a registration procedure for all existing pharmacies was adopted, in order to supervise the moratorium more effectively. ${ }^{348}$

\subsubsection{Supervision over the takeover price of pharmacies}

The Royal Decree of 13-4-1977 imposes restraints on the takeover price of a pharmacy. The implementation of this decree is in the hands of the Minister of Public Health. Article $1 \S 1$ dictates that the value of the transfer of a community pharmacy may not be higher than the sum of three elements:

' $1^{\circ}$ the furniture and the equipment, estimated by a registered expert; $2^{\circ}$ the stock of products belonging to the pharmacist's profession, estimated by a registered expert; $3^{\circ}$

345 Demeester (1990, p. 118).

346 Antwerps Farmaceutisch Tijdschrift, 12, 1998, pp. 26-27.

347 B.S 18-10-1994.

348 Koninklijk Besluit van 8 december 1999 tot wijziging van het KB van 25 september 1974, B.S. 14-12-1999. 
$150 \mathrm{pc}$ of the average of the gross profits which have been gained in the course of at most the five taxable periods preceding that of the transfer'.

Yet the limits of the takeover prices are quite easy to circumvent because the price of the building is free. After all, in the Royal Decree of 13-4-1977 no account has been taken of the price of real estate. Just like in the Netherlands very high amounts have to be paid sometimes in order to be able to take over a pharmacy in Belgium, despite the regulated takeover prices. ${ }^{349}$ Due to the high prices that have to be paid many pharmacies to be taken over are now bought by commercial chains or private individuals who are not pharmacists. ${ }^{350} \mathrm{I}$ will deal with the issue of takeover prices more extensively in chapter 7 .

\subsubsection{Summary}

Concluding, the same problem exists in Belgium as in the Netherlands, namely that it is extremely difficult for beginning pharmacists to capture a place in the market. This is not only a result of high takeover prices, but also of the tightening of the establishment act in the form of the moratorium that has been included into the Royal decree of 25-9-1974.

\subsection{Exercise of the profession}

\subsubsection{Advertising for drugs}

Advertising for drugs in Belgium is restricted by law, as it is in the Netherlands. ${ }^{351}$ Article 9 of the Drug Act (Wet op de Geneesmiddelen) of $1964^{352}$ states that every advertising concerning a drug that is not registered or on which a suspension or a ban is placed, is prohibited. Moreover, the same article prohibits all kinds of advertising intended for the public if it concerns drugs that may only be dispensed on submission of a medical prescription. The Drug Act deals with bonuses and discounts as well. Article 10 holds the following:

'When providing drugs, it is prohibited to offer - directly or indirectly - premiums or advantages. It is prohibited for the producers, importers and wholesalers of drugs to offer or grant directly or indirectly premiums or advantages to persons authorised to prescribe drugs. It is prohibited to require or accept premiums or advantages' 155

Het Nieuwsblad, Apothekers willen minder apotheken, 4 November 1998. Antuerps Farmaceutisch Tijdschrift, 4, 1999, p. 17.

In fact the advertising for prescription drugs was restricted in some way in all the $15 \mathrm{EU}$ Member States in 2002, according to the IHS research report (2003).

Supra, note 336 .

Het is verboden bij de levering van geneesmiddelen rechtstreeks of zijdelings premies of voordelen aan te bieden. Het is aan de fabrikanten, invoerders en groothandelaars van geneesmiddelen verboden, rechtstreeks of zijdelings premies of voordelen aan te bieden of te 
The rules about advertising for drugs were first specified in a Decree from 1972, but today again another Decree applies: the Royal Decree of 7-4-1995 concerning the information and advertising with respect to drugs for human use. ${ }^{354}$

\title{
5.5.2 Advertising for pharmacies
}

In Belgium, the advertising by individual pharmacists for their practices is supervised by the Order of Pharmacists on the basis of their professional rules. The second deontological (i.e. professional) rule of the Order of Pharmacists, formulated in 1951, warns against excessive commercialisation of the profession. It states that, for pharmacists, it is 'not deontological' to provide, encourage or tolerate any kind of publicity for the benefit of their practice. The Order wants to prevent that the honour and dignity of the pharmacist's profession is harmed by advertising. The third professional rule, which was formulated in 1955 and which contains provisions with regard to unfair competition between pharmacists, gives a more detailed explanation of this. Article 3.4 of this rule reads as follows:

\begin{abstract}
'A pharmacist is not allowed to advertise in any form, directly or indirectly, for the benefit of his practice. For instance by prospectuses, circular letters, by a special typographical style or special announcements in the phone books, press, radio, cinema, gifts, travellers, the promise of all sorts of benefits like refunds, discounts, bonuses etc...'.355
\end{abstract}

Finally, Article 1c of the same professional rule, prohibits a pharmacist to

'make mention of the soundness of his products and of the value of his preparations, with the view of making it seem as if his colleagues make no claim to this quality', 156

However, in early 1999 a very important decision was taken by the Court of Cassation, which considerably weakened this supervisory function of the Order. ${ }^{357}$ In the decision in question, the Court of Cassation nullified a decision of the Board of Appeal of the Order of Pharmacists, which imposed a disciplinary punishment on a pharmacist who distributed carrier bags with the logo of her pharmacy on them.

verlenen aan personen die geneesmiddelen mogen voorschrijven. Het is verboden om premies of voordelen te verzoeken of ze te aanvaarden.'

Koninklijk Besluit van 7 april 1995 betreffende de voorlichting en de reclame inzake geneesmiddelen voor menselijk gebruik, B.S. 12-5-1995.

'Het is aan de apotheker verboden, direct of indirect onder om het even welke vorm publiciteit te maken in het voordeel van zijn officina. Bij voorbeeld door prospectussen, rondzendbrieven, door een speciale typografische manier of buitengewone mededelingen in de telefoongidsen, pers, radio, bioscoop, geschenken, reizigers, de belofte van allerhande voordelen van welke aard ook, zoals restorno's, rabat, premies, enz...'

'gewag te maken van de degelijkheid van zijn producten en van de waarde van zijn bereidingen met het inzicht te doen uitschijnen dat zijn collega's op deze hoedanigheid geen aanspraak kunnen maken.'

Hof van Cassatie, 7 May 1999, R.W., 1999-2000, p. 112. 
The Court of Cassation decided that the Order of Pharmacists is an entrepreneurial association and as such falls under competition legislation. ${ }^{358}$ Being an entrepreneurial association, the Order is not allowed to impose obligations that significantly prevent, restrain or distort competition in the Belgian market concerned or in a substantial part of it, according to Article $2 \S 1$ of the Act on the Protection of Economic Competition ${ }^{359}$ It is allowed to examine whether the advertising used is reconcilable with the professional rules of the pharmacist. Only if by advertising the honour or dignity of the profession is seriously endangered, such advertising may be prohibited. Thus, in principle pharmacists are allowed to advertise their stores. ${ }^{360}$ With this decision the Belgian Court of Cassation follows the European trend, ensuing from the European competition rules. In an earlier case the European Commission already decided that the European competition rules with respect to advertising are applicable to the professions as well. ${ }^{361}$ Moreover, this decision not only brings the Belgian disciplinary procedures in line with the provisions in European law, but also with the state of affairs in other European countries, among them the Netherlands. ${ }^{362}$ In the Netherlands, incidentally, a similar case occurred already in 1998, with respect to the professional association for veterinary surgeons ${ }^{363}$

\subsubsection{Design of the pharmacy}

The 1964 Drug Act contains provisions with respect to the drugs that have to be kept in stock by pharmacists. Before drugs can be entered into trade they have to be registered with the Ministry ${ }^{364}$ of Public Health ${ }^{365}$ and satisfy the requirements of the farmacopee, which is published and kept up to date by the government (Article 2). The King is allowed to compel pharmacists - and others who are entitled to dis-

Formally the Court of Appeal of the Order of Pharmacists can take a new decision after a cassation decision. If then a second decision of the Court of Cassation follows, that one is final.

Wet van 5 augustus 1991 tot bescherming van de economische mededinging, B.S. 11-10-1991. A coordinated version of this act, including several changes in the text, was published at 1 September 1999 (Wet van 1 juli 1999 tot bescherming van de economische mededinging, B.S. 1-9-1999).

Het Belang van Limburg, Vrije beroepen moeten vrij kunnen concurreren, 24 August 1999.

For an overview of the most important cases in this field see Andrews (2002) and European Commission: Competition DG, Invitation to Comment: Regulation in Liberal Professions and its Effects, Commission Services Working Document, 27 March 2003, pp. 4-6.

De Juristenkrant, Na de advocaten, nu de apothekers, September 1999.

NMa, Decision nr. 397/1998. Supra, note 314. See also $\$ 4.7 .2$ for a brief discussion of some competition cases in the Netherlands with respect to the liberal professions.

In the framework of the so-called Copernicus reform of the federal government, in Belgium the designation 'Ministry' has been replaced by 'Federal Public Service'. However, I will use the old designation 'Ministry' for the sake of clarity. For details about the Copernicus reform see e.g. the official website: <http://www/copernic-us.be>.

See Article 1 of the Royal Decree concerning the registration of drugs (Koninklijk Besluit van 3 juli 1969 betreffende de registratie van geneesmiddelen), B.S. 10-7-1969. 
pense drugs - to keep certain drugs from this farmacopee in their pharmacy or depot. The same goes for specific equipment, appliances, instruments and reagents (Article 3). ${ }^{366}$

In 1965 the Order of Pharmacists issued a professional rule that has an effect on the design of pharmacies. In its sixth deontological rule concerning the publicity in the pharmacy, some instructions regarding the design of the pharmacy and the shopwindow (it is for instance prohibited to 'display therapeutic instructions or recommendations in any way on behalf of the public') and a ban on provocative neon signs have been formulated.

\subsection{Prices and fees}

\subsubsection{The price of drugs}

In Belgium the price structure and the distribution margins on the market for drugs are determined by law, just as in the Netherlands. The drug prices have to be approved by the Ministry of Economic Affairs. ${ }^{367}$ Whenever an agreement about the price is reached with the drug producer, this price is laid down legally. Moreover, the Minister of Economic Affairs first has to consider a recommendation for the prices by the Drug Board (Geneesmiddelencommissie). This Drug Board, which is under the supervision of the Ministry of Public Health, also has responsibility for the assessment of registration requests for drugs. ${ }^{368}$ If it concerns drugs that are eligible for reimbursement by the mutuals (Belgian health insurance funds; see the appendix to chapter 3), the price is assessed as well by the Commissie Tegemoetkoming Geneesmiddelen of the RIZIV, the National Institute for Health Care and Invalidity Insurance. To qualify for reimbursement by the mutuals, a drug producer has to file an application for acceptance with the RIZIV, simultaneously with an application for recognition of the price at the Ministry of Economic Affairs. If drugs qualify for reimbursement by the mutuals, they will be assigned by the RIZIV - more specifically, the Commissie Tegemoetkoming Geneesmiddelen - to one out of five groups that correspond to different reimbursement rules. The criteria for this classification are laid down in the Royal Decree of 21-12-2001 determining the procedures, terms and conditions regarding the compensation of the mandatory insurance for medical care and

Under penalty of an eight day's to one month imprisonment and/or a fine of between 100 $B E F$ and 1000 BEF ( $€ 495.79$ and $€ 4,957.87$; supra note 333 ). See Wet van 25 maart 1964 op de geneesmiddelen, B.S. 17-4-1964, Article $16 \$ 2$.

See Article 314 of the Act of 22-12-1989; the Ministerial Decree concerning the prices of reimbursable drugs (Ministerieel Besluit van 29 december 1989 betreffende de prijzen van de terugbetaalbare geneesmiddelen), B.S. 6-1-1990; and the Ministerial Decree concerning the prices of nonreimbursable drugs (Ministerieel Besluit van 29 december 1989 betreffende de prijzen van de niet-terugbetaalbare geneesmiddelen), B.S, 6-1-1990.

According to the Royal Decree of 3-7-1969. Supra, note 365. 
payments in the costs of pharmaceutical specialites. ${ }^{369} \mathrm{I}$ already discussed the criteria for classification and the different categories of drugs (A, B, C, Cs and Cx) in detail in the appendix to chapter 3 .

With the exception of the so-called indispensable drugs (noodzakelijke geneesmiddelen) placed in category A, consumers in Belgium always have to pay an own contribution called remgeld for every drug they buy. The amount of the own contribution is limited - by the government - to a maximum for the drugs belonging to category B and category C. ${ }^{370}$ Because of the fact that the own contribution is limited, health insurers might run into difficulties, since the prices of reimbursed drugs have been increasing for years and years already. In particular, it has become very difficult for the health insurance to reimburse new - and often more expensive medicines.

Indeed, despite the fact that the budget for drugs was twice as high in 1999 as it was ten years earlier, the budget was still too low if one considers how much money is actually needed to pay for the medical progress. For some new and very expensive drugs patients had to pay out of their own pockets. The prices of category A drugs increased from on average $641 \mathrm{BEF}(€ 15.89)$ to $1327 \mathrm{BEF}(€ 32.90)$ in the period 19871996: more than a doubling. In the same period the prices of reimbursed drugs increased from on average $419 \mathrm{BEF}(€ 10.39)$ to $724 \mathrm{BEF}(€ 17.95){ }^{371}$

Moreover, because the drug prices are laid down by law, the same problem of bonuses and discounts exists as in the Netherlands (see \$ 4.6.1), although in Belgium the receivers are predominantly hospitals instead of pharmacies. That is, pharmaceutical companies often give discounts on drugs to hospitals. These discounts are not reported to the mutuals.

Unlike the situation in the Netherlands, substitution of generic drugs for (more expensive) proprietary drugs occurs very rarely in Belgium. At the end of the $1990 \mathrm{~s}$ the percentage of generic drugs in Belgium was still only $1 \%$ of all reimbursed drugs. ${ }^{3 / 2}$ Part of this can be explained by examining the stringent rules with regard to substitution of proprietary drugs in Belgium. ${ }^{373}$ Article 11 of the Royal Decree no 78 , which was added to the text of the decree in 1993 but still has not come into force for political reasons (including resistance from the physicians and the pharmaceutical industry), provides:

Supra, note 229.

See the appendix to chapter 3.

Het Nieuzsblad, Pillen pijlsnel duurder, 10 February 1999.

Het Belang van Limburg, Eén Limburger op vijf kent generische geneesmiddelen, 22 October 1999; Het Belang van Limburg, De ene pil is de andere niet, 6 March 2001. In SFK (2002, p. 48) it is stated that generic drugs are hardly used in Belgium, while in the Netherlands the percentage of generics in the total number of prescriptions in 2001 was $42 \%$. See also $\$ 3.1 .1 .1$.

See, for these rules, also Hombroeckx (2000, pp. 187-188). 


\begin{abstract}
'The King determines, by a decree consulted in the Council of Ministers, the provisos and the implementing measures according to which the pharmacist is allowed to substitute a prescribed pharmaceutical speciality by another, under the conditions that the active components of the substitute are the same and that the prescriber does not explicitly resist against such a substitution and that the price for the patient is cheaper'.
\end{abstract}

Today Belgian physicians still prescribe many branded drugs and they generally are not so favourably disposed towards substitution by pharmacists. Moreover, the pharmacists' association APB admits that pharmacists do not have an incentive to substitute, as long as they will earn less on selling a generic medicine than on selling a branded drug.

Some conditions for substitution of pharmaceutical specialites by generic drugs can be gathered from the aforementioned Article 11 of the Royal Decree no 78. First, a generic drug must have the same active components and it must be 'bio-equivalent'. Second, there should not be explicit resistance from a physician. A similar provision could already be found in the ninth deontological rule of the Order of Pharmacists from 1991, which emphasises that 'a pharmacist has to consider how the approval of the physician can be obtained'. However, as stated earlier, Belgian physicians still prescribe very little generic drugs compared to specialites, while generally they are not favourably disposed towards substitution by the pharmacist. Third, the price of the substituted drug must be lower for the patient. Here the remgeld is meant and not the costs of the health insurance, as a result of which drugs in category A are precluded from substitution in any case. Moreover, the price difference between a generic drug and an original pharmaceutical speciality has to be at least $26 \%$ if a generic drug wants to qualify for reimbursement by the RIZIV (as of 1 January 2003; in 2002 this was $20 \%)^{374}$

Since 1 June 2001 the reference reimbursement system (referentieterugbetaling) has been effective. With this system the government wants to encourage the prescription of cheaper drugs. The reimbursement base of original specialities for which also a cheaper generic alternative is available has been lowered, which implies that patients have to pay a higher remgeld if a more expensive drug is prescribed and dispensed. ${ }^{375}$

\title{
5.6.2 Reimbursement for the pharmacist
}

Besides the fact that a pharmacist has few possibilities to substitute drugs and the fact that there is no incentive measure like there is in the Netherlands, the margins on drug sale have been fixed, both for wholesalers and for pharmacists. ${ }^{376}$ Pharma-

Ministerie van Sociale Zaken en Pensioenen, Op 1 januari 2003 belangrijke prijsevoluties in de geneesmiddelensector, press report Ministry of Social Affairs, 17 December 2002.

See e.g. the website of RIZIV: <http://www.riziv.be>, At 1 January 2003 this lower reimbursement base was $26 \%$.

PriceWaterhouseCoopers (1999), p. 15. 
cists receive a margin of 31 percent on the sale of drugs, up to a ceiling of $€ 7.44$ for every packaging. ${ }^{37}$ Because more and more expensive drugs and drugs in large packagings are coming onto the market, margin erosion occurs: already in 1998 the pharmacists' association APB claimed that the real profit margin was only $26.5 \%$ per prescription instead of $31 \%$. The explanation for this was that as much as $40 \%$ of the sale of drugs was sold at the ceiling price (or above) because of the ever increasing drug prices. The APB feared that it would become more and more difficult for pharmacists to keep expensive drugs in stock. ${ }^{378}$ Indeed, in 2002 the real profit margin had decreased further to $18 \%$, according to new computations made under the authority of the APB. ${ }^{379}$

However, if the price structure of medicines in different countries - divided into the margin for the producer, wholesaler, pharmacist and government (VAT) - is compared, then it seems that the margin for pharmacists in Belgium was at an average level in the late $1990 \mathrm{~s} .{ }^{380} \mathrm{I}$ will come back to this issue in the next section with respect to the recent developments in the Belgian market.

\subsubsection{Summary}

Summarising, it may be stated that competition between pharmacists or between wholesalers in Belgium has no influence at all on the tariffs, given that prices and margins are determined by law. The pharmacists' associations, like the umbrella association APB and the Order of Pharmacists, only function as bargaining partners and advisory bodies here.

\subsection{Recent developments}

Whereas in the Netherlands recent measures taken by the government with respect to the pharmaceutical market were directed in particular at breaking the professional monopoly of the community pharmacist (see §4.6.1), in Belgium this was not the case. Pharmacists in Belgium have always been allowed to own more than one pharmacy, and there has never been a prohibition on the possession of pharmacies by non-pharmacists (although of course the establishment must be run by a pharmacist). Recent measures of the Belgian government concentrated mainly on the difficult task of keeping the health insurance affordable, e.g. by encouraging the prescription of cheaper generic drugs (by means of the reference reimbursement

377

378

379

380

AVGI (2002, p. 24).

De Standaard, Apothekers vragen opslag, 24 October 1998.

Het Belang van Limburg, Sommige apothekers nu al tegen de armoedegrens, 6 November 2002; Het Nieuwsblad, Boze apothekers op vrijdagmarkt, 23 November 2002; Gazet van Antwerpen, Generica niet duurder, 20 December 2002.

For Belgium the margin on drugs was subdivided as follows by PriceWaterhouseCoopers (1999, p. 21) for the year 1997: $64.7 \%$ for the producers, $8.3 \%$ for the wholesalers, and $27 \%$ for the pharmacists. Supra, note 162. 
system introduced in June 2001 and a proposal to introduce prescription on substance name), increasing the remgeld on large packagings of drugs ${ }^{381}$ and reducing the prices for old and often prescribed drugs. In addition, the government proposed an improved check on the cheating with prescriptions by pharmacists. Such cheating occurs when pharmacists substitute prescribed drugs with more expensive variants, which is obviously forbidden by law..$^{382}$

Furthermore, no changes took place with respect to the self-regulation by pharmacists, again contrary to the Dutch case. Pharmacists in Belgium have recently been more concerned about their incomes: at the end of 2002 heated discussions between the Belgian Minister of Social Affairs Frank Vandenbroucke and the associations of pharmacists - leading eventually to strikes by the pharmacists - were enlarged upon in the media. ${ }^{383}$ Just like previous discussions between pharmacists and the government, both in the Netherlands and in Belgium, the main argument made by the pharmacists was that their incomes had been decreasing for years because of rising drug prices coupled with unchanged profit margins (i.e. tariffs). ${ }^{384}$ In chapter $7 \mathrm{I}$ will look at the income of pharmacists in more detail.

\subsection{Summary}

Pharmacists in Belgium are regulated both by the government and by self-regulation. The former includes the Royal Decree no 78 concerning the practice of the health care professions, the Royal Decree no 80 concerning the Order of Pharmacists and the Royal Decrees with respect to the supervision over the establishment of pharmacies and the takeover price of pharmacies. There are also various price and fee regulations. The self-regulation consists predominantly of the deontological (i.e. professional) rules issued by the Order of Pharmacists, In addition to the Order of Pharmacists there is a second national pharmacists' association in Belgium, the APB, mainly involved in lobbying and in the provision of information.

With respect to the education (training) of pharmacists there are no notable rules restricting competition. However, the professional monopoly of the pharmacist in the preparation and dispensing of drugs is protected by legislation. This monopoly

See the appendix to chapter 3.

De Standaard, Dokters dreigen met opzeggen tariefafspraken, 5 October 1999.

See many newspaper articles as well as information published on the websites of the professional pharmacists' associations. E.g. Gazet van Antuerpen, Apotheker staakt vandaag, 22 October 2002; Het Belang van Limburg, Dinsdag weer uur lang actie van apothekers, 31 October 2002; De Financieel-Economische Tijd, Apothekers sluiten hun deur uit protest tegen besparingen, 6 November 2002; Het Belang van Limburg, Sommige apothekers nu al tegen armoedegrens, 6 November 2002; De Standaard, Apothekersberoep smaakt zuur, 23 November 2002; De Financieel-Economische Tijd, Ruim 5000 zorgverstrekkers betogen zaterdag in Brussel, 11 December 2002; <http://www.kava.be>; <http://www.apb.be>.

Also mentioned by pharmacists was dissatisfaction with the amount of administrative tasks, such as the monitoring of physicians' prescriptions. 
includes the sale of OTC drugs. The practice of pharmacy is subject to registration with the Medical Commission of the province where a pharmacist wants to establish himself and to registration with the Order of Pharmacists. It is very difficult for beginning pharmacists to capture a place in the market. This is not only a result of high takeover prices (despite regulation of this takeover price by the Royal Decree of 13-4-1977), but also of the tightening of the establishment act in the form of the moratorium that has been included into the Royal decree of 25-9-1974. The establishment act itself already contained strict criteria regarding population and distance to other pharmacies.

The deontological rules of the Order of Pharmacists contain provisions that restrict the advertising by individual pharmacists for their practice, and they also include instructions regarding the design of the pharmacy building and the shop-window. According to the Belgian Court of Cassation advertising may only be prohibited if it seriously endangers the honour or dignity of the profession. However, even though most of the deontological rules were formulated decades ago, they have - until 2003 - barely changed in the course of time.

Furthermore, drug prices, wholesale margins and pharmacy margins are almost completely determined by the government in the form of several Ministerial and Royal Decrees. Pharmacists have little possibilities to compete by price, because drug prices are laid down legally. The reimbursement by the mutualiteiten (health insurers) is regulated by the National Institute for Health Care and Invalidity Insurance, RIZIV. Constant increases in drug prices are causing problems with the financing of the health insurance in Belgium (as in many European countries, including the Netherlands). An additional problem for the RIZIV is that the amount of the own contribution, the remgeld, is fixed, which means that the constant increases in drug prices put extra pressure on its drug budget. 


\section{AN ECONOMIC ANALYSIS OF THE REGULATION IN THE NETHERLANDS AND BELGIUM}

From the extensive regulatory frameworks sketched out in chapter 4 and 5 respectively it follows immediately that the regulation of the pharmaceutical market, both in the Netherlands and in Belgium, is quite complex. For the analysis of these different and complex institutions one could choose various approaches. First of all it seems interesting to highlight a few similarities and differences concerning the regulation of pharmacists in the two countries (\$ 6.1). After that I will analyse to what extent these complex regulations can be considered as serving a public interest goal ( $\$ 6.2)$ or a private interest goal $(\$ 6.3){ }^{385}$ That is, the economic theory presented in chapter 2 will be applied to the different regulations outlined in the previous chapters. I will show that the public interest analysis and the private interest analysis come to a joint conclusion, namely that the regulation of pharmacists in the Netherlands and Belgium is - at least to some extent - outdated and hence also inefficient from an economic point of view. In the next chapter some quantitative data will be presented to illustrate the extent to which pharmacists in both countries can be considered as successful rent seekers.

\subsection{Differences and similarities in regulation}

Table 6.1 summarises the most important regulations that (may) restrict competition in the Dutch and Belgian pharmaceutical markets. A brief look at the regulation of the pharmaceutical profession in the Netherlands and Belgium shows that there are some similarities. ${ }^{386}$ While neither of the countries has a numerus clausus for the admission to the study of pharmacy, both countries do regulate the entry into the profession by means of registration procedures based on minimum educational requirements. They also have in common that the government protects the professional monopoly of the pharmacist, the definition of which is about the same in both have been discussed at length in chapter 2 .

Supra, chapter 4 for the Netherlands and chapter 5 for Belgium. 
countries with the exception that in the Netherlands OTC drugs may also be sold by licensed chemists (druggists), whereas in Belgium this is not allowed. ${ }^{387}$ Moreover, in the Netherlands as well as in Belgium pharmacists have to be registered with a regional medical commission, although in Belgium pharmacists also have to be registered with the Order of Pharmacists. ${ }^{388}$ In the Netherlands the second register for pharmacists is the public register that protects the title of 'pharmacist'. This may constitute a relatively small difference in regulation. However, a major difference is that in Belgium the establishment policy with respect to new pharmacies - including the regulation of takeover prices - is completely regulated by Royal Decrees, as opposed to the Dutch advisory establishment policy of the pharmacists' association KNMP, which in practice is now of only little importance compared to the $1990 \mathrm{~s}^{389}$ In general it appears that the Order of Pharmacists in Belgium, which has been called into being by law, has tasks that differ from those of the Dutch KNMP, the duties of which are not legally prescribed. The KNMP is engaged also in lobbying, bargaining with health insurers and the government, and the provision of information about the profession and its development to KNMP members and third parties. In Belgium some of these activities are carried out by the APB, the second national professional association of pharmacists. In both countries the degree of self-regulation in the pharmaceutical profession has always been impressive, but in the Netherlands some competition restrictive provisions have recently been removed from the KNMP rules of conduct.

See also supra, note 249.

According to the IHS report (2003, p. 74) membership in the pharmacists' association is compulsory in several EU Member States. Next to Belgium the following countries are mentioned by the IHS: Austria, France, Germany, Italy, Portugal, Spain, United Kingdom, Greece and Luxembourg. The Pharmaceutical Group of the European Union (PGEU) argues that Ireland should be added to this list: 〈http://www.pgeu.org >.

Such legally determined maximum on the number of pharmacies as it exists in Belgium is not unique in Europe: according to IHS (2003, pp. 73-74) the number of pharmacists is restricted in 10 out of 15 EU Member States: Austria, Belgium, Finland, France, Italy, Portugal, Spain, Greece, Luxembourg and Sweden (which is a special case because there all pharmaceutical products are sold via a state-owned company). Only in Denmark, Germany, Ireland (since 2002), the Netherlands and the United Kingdom there is no formal 'economic needs test'. In some of these countries there may, however, be some kind of self-regulation in force, such as is the case in the Netherlands. According to OFT $(2003$, volume 2, pp. 30, 38, 71) the US and Canada belong to the group of countries without a legally determined 'economic needs test'. 
Table 6.1: Overview of most important regulations

\begin{tabular}{|c|c|c|}
\hline Category of regulation & Content of regulation & $\begin{array}{l}\text { Public/self- } \\
\text { regulation }\end{array}$ \\
\hline Entry requirements & $\begin{array}{l}\text { Netherlands: } \\
\text { educational requirements ( } 6 \text { yrs) } \\
\text { double registration } \\
\text { Belgium: } \\
\text { educational requirements ( } 5 \text { yrs) } \\
\text { double registration (incl. compulsory } \\
\text { membership Order of Pharmacists) }\end{array}$ & $\begin{array}{l}\text { public } \\
\text { public } \\
\text { public } \\
\text { public and s-r }\end{array}$ \\
\hline Other entry regulation & $\begin{array}{l}\text { Netherlands: } \\
\text { advisory establishment policy } \\
\text { pharmacist may only practice phar- } \\
\text { macy in one pharmacy } \\
\text { Belgium: } \\
\text { regulation of establishment and take- } \\
\text { over prices of pharmacies }\end{array}$ & $\begin{array}{l}\text { s-r } \\
\text { public } \\
\text { public }\end{array}$ \\
\hline Professional monopoly & $\begin{array}{l}\text { Netherlands: } \\
\text { compounding and dispensing of } \\
\text { medicines (excl OTC) } \\
\text { Belgium: } \\
\text { compounding and dispensing of } \\
\text { medicines (incl OTC) }\end{array}$ & public \\
\hline Conduct regulation & $\begin{array}{l}\text { Netherlands: } \\
\text { since } 2002 \text { only minor restrictions } \\
\text { regarding design of pharmacy } \\
\text { Belgium: } \\
\text { some restrictions to advertising } \\
\text { some restrictions on design of phar- } \\
\text { macy }\end{array}$ & $\begin{array}{l}\text { s-r } \\
\text { s-r } \\
\text { public and s-r }\end{array}$ \\
\hline Price regulation & $\begin{array}{l}\text { Netherlands: } \\
\text { regulation of drug price } \\
\text { incentive measure } \\
\text { fixed fee for pharmacist } \\
\text { Belgium: } \\
\text { regulation of drug price } \\
\text { fixed margin for pharmacist }\end{array}$ & $\begin{array}{l}\text { public } \\
\text { public } \\
\text { public } \\
\text { public } \\
\text { public }\end{array}$ \\
\hline
\end{tabular}

Until the end of 2001 the self-regulatory body of pharmacists in the Netherlands prohibited its members to make the pharmaceutical market transparent for consumers by means of advertising for the individual pharmacy, whereas in Belgium this is still the case. In addition, some strict rules concerning the design of the pharmacy and the exercise of the profession could be found in the self-regulation 
issued by the KNMP until 2002 and can still be found today in the deontological rules of the Belgian Order of Pharmacists. Of course there have always been slight differences in the content of these rules, but the overall tendency has - until 2002 at least - been the same in both countries. This kind of self-regulation is obviously restricting competition and inhibits a differentiation of services. The self-regulation of advertising and other restrictions on the exercise of the profession have come under attack quite recently in Dutch and Belgian case law. ${ }^{390}$ In the Netherlands some provisions of the rules of conduct and the Dutch Pharmacy Standards have been removed or changed as a result of investigations by the Dutch Competition Authority NMa.

In the field of drug pricing policy and tariffs there appear to be similarities too. Both in the Netherlands and in Belgium pharmacists do not have any influence on prices of drugs and on the tariffs they may ask for their services. ${ }^{391}$ However, there are differences in the pharmacist's fee: the receptregelvergoeding in the Netherlands is a fixed amount, while the pharmacist's margin in Belgium amounts to a percentage of the drug price. Furthermore, in Belgium there is no incentive measure directed at the dispensing of cheaper products. On the contrary, a Belgian pharmacist might sooner be tempted to substitute more expensive drugs for cheaper ones. Legal provisions prohibit this, but the supervision of this is not always easy.

Looking at the big picture, there seems to be an important difference between the function of pharmacists in the Netherlands and pharmacists in Belgium. Although in both countries pharmacists have become (specialised) distributors of medicinal products instead of producers of medicines, ${ }^{392}$ the interpretation of this distribution function has been different. A Dutch pharmacist is allowed under certain circumstances to substitute prescribed drugs by cheaper or better alternatives, contrary to a Belgian pharmacist. In addition, the Dutch pharmacist today seems to have a prominent role as an advisor to physicians, considering the importance of pharmacotherapeutic consultations in the Netherlands. On the other hand, a Belgian pharmacist is strictly bound by the prescription of the physician and is a mere seller of drugs. As opposed to their Dutch colleagues, Belgian pharmacists have a monopoly on the distribution of OTC drugs as well. In chapter 7 I will show that this may have had an effect on the number of pharmacies in both countries.

For the Netherlands, see $\$ 4.7 .2$, and for Belgium, see $\$$ 5.5.2.

According to IHS (2003, p. 78) in all 15 EU Member States there was a legally determined maximum price for prescription drugs in 2002. For details about price and fee regulation in other countries see Danzon and Chao (2000), OECD (2002) and OFT (2003). Supra, note 141.

I discussed this at length in chapter 3 , 


\subsection{A public interest analysis of the regulation on the pharmaceutical market}

In chapter $2 \mathrm{I}$ explained that information asymmetry between pharmacists and drug users (patients) and the possible occurrence of negative externalities may provide a public interest justification for regulatory intervention. That is, regulation may in these cases be needed to guarantee a reasonable level of the quality of pharmaceutical services. Also, I noted that regulatory intervention differs in the extent to which it intervenes in a market. In some markets a simple information regulation (in the form of certification, mandatory information disclosure, or a prohibition on misleading advertising) may be sufficient to solve market failure. In other markets a stronger regulation of quality may be needed, such as prescribed quality standards or licensing. However, the danger exists that a regulatory solution to market failure causes misallocations in other sections of the economy or generates costs that are bigger than the efficiency gains from the regulation. Therefore regulatory failure always has to be compared with market failure: is the cure (regulation) maybe worse than the disease (market failure)? To answer that question the Dutch and Belgian regulation of pharmacists will be submitted to a proportionality test, whereby the question is asked whether the regulation is an appropriate answer to market failure or whether it goes too far in the sense of creating more problems (raising costs) than it solves. In this section I will examine whether the tightly regulated Dutch and Belgian pharmaceutical markets really serve the public interest. First the restrictions on market entry will be discussed $(\$ 6.2 .1)$ and after that I take a look at the regulations that restrict the competition between pharmacists (\$6.2.2).

\subsubsection{Entry regulation}

Pharmacists in the Netherlands and Belgium have a professional monopoly in the dispensing of prescribed medicines to patients. ${ }^{393}$ In the Netherlands the title of pharmacist is protected by law, so that consumers can only hand in their prescriptions at a registered pharmacist who has a legally obtained diploma. In Belgium pharmacists have to have their title formally approved before entry into the market. Because pharmaceutical services are experience goods ${ }^{394}$ in a market characterised by information asymmetry between pharmacist and patient, some regulation of the services provided by pharmacists is necessary to prevent quality deterioration of the kind described by Akerlof. ${ }^{305}$ However, the question arises whether this regulation should take the form of title protection, as is the case in the Netherlands and in Belgium. There is a double registration procedure (regional and national) in both countries. The regional registration is said to be necessary to keep the administration of

For the Netherlands, see \$ 4.3.1, and for Belgium, see \$ 5.3.1.

This is true if one considers the services of a pharmacist like giving drug advice to customers and physicians, monitoring of therapy and medication control a specific service. The mere selling of prepacked drugs cannot be considered a 'service' in the strict sense of the word.

Akerlof (1970). 
the number of pharmacists (in all categories) up to date. The fundamental question that remains unanswered is whether a far-reaching regulatory instrument such as title protection coupled with a professional monopoly on the sale of prescription drugs is necessary to reach the public interest goal of protecting public health. Other instruments that already partially exist, such as ex ante control of the quality of pharmaceutical products, could also reach that goal to some extent, without the negative effects as far as the restriction of competition is concerned. Indeed, an additional problem is that the specific services of the pharmacist might warrant regulation, but this is less the case for the sale of prescribed drugs. In chapter 3 I explained that the main tasks of pharmacists have changed considerably over the last decades. For a modern pharmacist, providing a service (medication control, monitoring of therapy, customer advice, and providing information and advice to physicians in the form of pharmacotherapeutic consultations) has become more and more important compared to the preparation and sale of drugs. However, it appears that both in the Netherlands and in Belgium the regulation has not been adapted at all to these new tasks. ${ }^{396}$ On the contrary, the current regulation still protects the distribution function of the pharmacist, despite the fact that - because of the rise of industrially prepared medicine - most drugs sold are now prepacked drugs.

Considering the regulation of the establishment of pharmacies the public interest argument of correction for market failure is even weaker. Why regulate also the entry into the market for community pharmacists if there already is a double registration procedure in order to guarantee good service quality? With respect to the Netherlands, the KNMP advisory establishment policy must be examined more closely to provide an answer to this question. In $\$ 4.4 .1$ the justification used by the KNMP for its establishment policy has been presented:

'the financial exploitation of a pharmacy has to be financially sound, and therefore a minimum number of prescriptions is needed.'

One could ask whether the concept of financial feasibility, which is based on the desired number of prescriptions, has not been defined too narrowly by the KNMP, but to determine this would be very difficult. With respect to Belgium it is obvious

Until the year 2000 the professional monopoly of the community pharmacist was protected even more in the Netherlands. However, the measures taken by the Dutch government in the late 1990s, i.e. enabling pharmacists to be employed by non-pharmacists, enabling health insurance funds to run pharmacies themselves and encouraging the competition between community pharmacies and hospital pharmacies (see $\$ 4.7 .1$ ), hint at a new approach of the pharmaceutical profession, towards a more liberal regime. The ownership of more than one pharmacy is still prohibited, although a proposal to lift this provision has already been written (supra, note 307). In Belgium the incorporation of pharmacies has never been restricted. According to IHS (2003, p. 78) incorporation was in 2002 prohibited in most of the other EU Member States: Austria, Denmark, Finland, France, Germany, Italy, Spain, Sweden, Greece and Luxembourg. Apart from the Netherlands and Belgium, only in the United Kingdom and Ireland (since 2002) the regulations with respect to incorporation and ownership of pharmacies are less rigid. 
that with the Royal Decrees from 1974 and 1977 and the recently prolonged moratorium the entry of new pharmacies into the market is regulated in a very restrictive manner. ${ }^{397}$ This strict establishment policy was the result of fear for an 'oversupply' of pharmacies by the Belgian government. Indeed, the pharmacy density in Belgium has always been very high relative to most other European countries, and also compared to e.g. the United States and Canada. ${ }^{398}$ However, the question remains whether it is really in the public interest to have guidelines or rules about the financial feasibility of a pharmacy: is it after all not up to the pharmacist to determine whether he or she thinks it is feasible to enter the market? Again one has the impression that the tool used goes much too far in order to cure the information asymmetry, and again the tool is directed at a protection of the distribution function of pharmacists instead of the quality level of services. Because market competition is likely to be severely restricted, in the end the cure may be worse than the disease. It is highly unlikely that a moratorium on the establishment of pharmacists would pass the test of Article 81(3) of the EC Treaty, regarding the general conditions for exemption of a restrictive agreement under EC competition law. I discussed the four conditions of Article 81(3) in § 2.6 .

\subsubsection{Conduct regulation}

As far as the public regulation of fees is concerned, one can be brief. Although there are differences of form between the Netherlands and Belgium, the bottom line is that both prices of prescription drugs and fees of the pharmacist are regulated and that price competition is almost totally excluded. Even if there might be a public interest argument to give a monopolistic right to pharmacists to sell some drugs albeit that the question still arises whether the same goal could not be reached via less interventionist means than the ones observed in the Netherlands and Belgium it should at any rate be possible for them to compete with respect to prices and quality. However, I have shown in previous chapters that there are no possibilities at all for pharmacists to compete by prices. In the Netherlands pharmacists receive a fixed amount per prescription, in Belgium they receive a fixed margin on the sale of drugs. Such tight price regulation is hardly to the benefit of the consumer: there is no possibility to choose between good service/higher price and little service ${ }^{399} /$ lower price. This absence of choice constitutes the most important problem from a consumer perspective. According to the present tariff structure, Dutch and Belgian

397

The Belgian regulations with respect to the establishment of pharmacies are presented in \$5.4.

Infra, \$ 7.2. See also OFT (2003, volume 1, p. 10) and Antwerps Farmaceutisch Tijdschrift, 12, 1998, pp. 26-27.

One could object to this that we do not want consumers to choose for little service because negative externalities might occur as a result of the absence of certain pharmaceutical services, such as information about the side effects of a drug or the interaction between different drugs. Even if this would be true, e.g. in cases of a first distribution of a strong medicine, this still leaves our argument intact. Regulation of fees is not a solution to this externality problem. 
pharmacists are even inclined to sell as many prescribed drugs as possible while giving little or no advice, because they do not get extra money for these timeconsuming services ${ }^{400}$ Hence, the current structure of price regulation in the Netherlands and Belgium even has adverse effects on the incentives of pharmacists to increase the quality of their services.

Without price competition as an option, the only way left for pharmacists to compete with others would be in the quality of services. But also that kind of competition has long been seriously restricted as a result of (self-)regulation, both in the Netherlands and in Belgium. ${ }^{401}$ Until recently, there has been an almost complete prohibition of advertising for pharmacies in both countries. This prohibition can hardly be said to serve a public interest goal. It was therefore under serious attack from judges and competition authorities. In the Netherlands advertising was prohibited until late 2001, whereas in Belgium the professional rules still contain such provisions. The fact that in the Netherlands the restrictions on advertising were not approved by the Dutch Competition Authority NMa already indicates that such provisions will in all probability not be exempted by the criteria of Article 81(3) of the EC competition law.

The same conclusion can obviously be reached as far as the highly restrictive regulations concerning the exercise of the profession in both countries are concerned. Because in the Netherlands pharmacies until 2002 had to satisfy the requirements included in the old Dutch Pharmacy Standards of the KNMP, a differentiation in the provision of services was almost impossible. Every pharmacist had to abide by the opening hours, the requirement to have a separate room for magistral preparation of medicines, and the requirement to deliver every sensible prescription. In Belgium, the sixth professional rule defined by the Order of Pharmacists contains requirements that are very similar to these. It goes without saying that for pharmacists the possibilities to compete in quality decrease largely for these reasons. ${ }^{402}$ Hence, these regulations do not seem to serve a public interest goal either, as was again made clear by the Dutch Competition Authority NMa, which based its analysis - indirectly - on the criteria provided in Article 81(3) of the EC Treaty. In the new Dutch Pharmacy Standards of the KNMP the aforementioned provisions have been changed. ${ }^{403}$

See, for the Netherlands, $\$ 4.6$, and for Belgium $\$ 5.6$.

For an overview of this regulation, see $\$ 4.5$ and $\$ 5.5$ respectively.

This is not to say that the possibilities of non-price competition are totally excluded. It is theoretically still possible to compete with better services or the offer of a wider range of nonprescription goods. However, it remains difficult to convey these competitive advantages to the consumer, given the prohibition of advertising and other restrictions on the exercise of the profession.

Because of these recent developments, and the fact that the regulation in this area is 'only' self-regulation, the IHS report (2003, p. 80) concludes that, compared to other EU Member 


\subsubsection{Conclusion}

In sum, although there seem to be valid reasons for some kind of regulation of the services provided by pharmacists, notably the information asymmetry argument and the possible occurrence of externalities as a result of low quality services, the profession appears to have 'abused' the public interest justification by introducing all kinds of restrictive regulations, which go much further in limiting competition than the public interest goal would justify. ${ }^{404}$ Moreover, the current regulation of the pharmaceutical profession protects the distribution function of pharmacists, whereas actually only some regulation of the quality of services provided by a pharmacist (i.e. in the field of pharmaceutical care) seems needed. In other words, the contents of the regulation are to an important extent disproportionate to the market failure to be solved. In addition, the definition of the professional monopoly in the Dutch and Belgian law and the corresponding protection of the distribution function of the pharmacist is outdated in the sense that it is not related at all to the new tasks of a pharmacist in the field of pharmaceutical care. Moreover, because of the rise of industrially prepared medicine nearly all drugs sold today are prepacked drugs.

\subsection{A private interest analysis of the regulation on the pharmaceutical market}

In the previous section I concluded that the Dutch and Belgian regulation of pharmacists is disproportionate to the market failure to be solved. Hence, the private interest approach (the capture theory, public choice and the Chicago theory of regulation) might to some extent explain the intensity of the regulations examined. In this section the rent-seeking hypothesis, which has been defined in $\$ 2.3$, will therefore be tested by means of an analysis of the regulation of the pharmaceutical market in the Netherlands and in Belgium. Similar to the analysis above, I first deal with entry regulation ( $\$ 6.3 .1$ ) and subsequently with conduct regulation ( $\$ 6.3 .2)$.

\subsubsection{Entry regulation}

Some of the Dutch and Belgian regulations concerning pharmacies provide a strong case backing up Stigler's hypothesis that regulation is merely used as a barrier to entry with the aim of providing rents to the pharmacies ${ }^{405}$ Especially the regulation concerning the establishment of pharmacies seems to constitute evidence of this 'barriers to entry' hypothesis. Although there are considerable differences of form between the Netherlands and Belgium, in both countries the self-regulatory bodies can somehow influence the establishment of pharmacies. In the Netherlands the establishment (and limitation) of pharmacies has for a long time been based on an

States, the conduct regulation index of pharmacists is low both in the Netherlands and in Belgium.

404 I will explain this in more detail in $\$ 6.3$.

405 Stigler (1971). For a discussion see also $\$ 2.3$. 
advisory policy of the KNMP. The advisory establishment policy is still relevant today, albeit in practice only via the contracts between pharmacists and health insurers. Even if these contracts are no longer based on the guidelines of the KNMP and no longer result directly from collective negotiations (because this is prohibited by the Dutch Competition Authority NMa), at least they include similar provisions regarding the viability of a pharmacy. It is effectively impossible for pharmacists in the Netherlands to enter the market without consent of the health insurer. Hence, it is not only the (self-)regulation of the pharmaceutical profession that constitutes the source for rent seeking in the Netherlands, but also the behaviour of the health insurers. Belgium introduced a formal moratorium on pharmacies in 1994, in addition to the two Royal Decrees that supervise the establishment and takeover prices of pharmacies. The argument that a pharmacy should be 'financially sound' (used in the Netherlands) and the distance and population criteria (in Belgium) only serve to limit the number of market participants, but do not provide any guarantee for an increased quality of the services provided. In both cases one can ask whether it is in the public interest to have guidelines about the financial feasibility of the pharmacy or the distance of a pharmacy to other pharmacies. It is moreover obvious that, by regulating the entry of newcomers to the market, the 'insiders' benefit, because there will be less competition in the market.

Next, I have to consider again the regulation of the professional monopoly of the pharmacist. I noted in the previous section that, while actually the services provided by a pharmacist should be protected, in the current regulation the distribution function is protected. Moreover, the professional monopoly is linked to the reimbursement for the pharmacist: in the Netherlands by means of the fixed fee and in Belgium by means of the fixed margin. ${ }^{406} \mathrm{It}$ is not clear which group benefits from this regulation, if any. Definitely not the consumers, since pharmacists are not encouraged to offer high quality services. It is also unclear to what extent pharmacists themselves benefit from the current definition of the professional monopoly. Of course, the legal protection of the sale of prescribed drugs - which in Belgium even extends to the sale of OTC drugs - does protect them from competition by e.g. chemists (druggists) and supermarkets. In addition, because of the fixed drug prices, pharmacists have a strong bargaining position in the market vis-à-vis the pharmaceutical industry. They have a key position in the distribution of drugs because they can demand high bonuses and discounts in exchange for placing certain medicines on the shelves. This argument applies in particular to the Dutch market, where pharmacists have possibilities to substitute drugs and where prescription on substance name occurs relatively often compared to Belgium (see $\$ 3.2 .1$ and $\$ 4.6 .2)$. However, the system of the fixed fee/fixed margin, which emphasises the sale of drugs, does not relate at all to the changed function of the pharmacist. In chapter 3 I showed that the main tasks of the pharmacist have changed considerably 
over the last decades: for modern pharmacists, providing a service (in particular customer advice and pharmacotherapeutic consultation) has become more important than the preparation (compounding) of drugs, which in the late 1950s was still their main task. The drugs they sell bday are predominantly prepacked drugs. Pharmacists who are indeed willing to concentrate on these new tasks are under the current regulation discouraged to do so. Some pharmacists therefore argue that they would rather be reimbursed differently, i.e. they claim to prefer a higher fixed fee to the present untransparent system of bonuses and discounts.

One could also suggest that the regulation of the professional monopoly of the pharmacist is beneficial to the pharmaceutical industry, because direct price competition is excluded and pharmacists are paid for every prescribed drug they sell, which may encourage them to sell more drugs (or smaller packagings). However, a pharmacists is only allowed to dispense such drugs on submission of a prescription from a general practitioner or specialist. The pharmaceutical industry may try to circumvent this 'problem' by sending medical representatives to the practices of general practitioners and specialists in order to promote its products. Furthermore, one could suggest that health insurers might benefit from the current system of price and fee regulation, since it decreases price and quality competition in pharmaceutical products and services considerably. It is however unclear if this is really an advantage or rather a disadvantage, because health insurance funds and 'mutuals' that would like to attract new members by offering lower prescription drug prices (or good pharmaceutical services) are to some extent prevented from doing this in the current system. This is especially a problem in the Netherlands, where recent attempts by health insurers, the government and generic drug producers to either bring very cheap drugs on the market or to decrease the costs of public health care by increasing the claw back on certain categories of drugs were sabotaged by pharmacists, wholesalers and the pharmaceutical industry.407 Summing up, the outdated and untransparent regulation of the professional monopoly of pharmacists (both in Belgium and in the Netherlands) is likely to generate rents for different interest groups, but it is even more likely that none of the interest groups benefit from it anymore. In the latter case it constitutes a good example of regulatory failure from the side of the government.

\subsubsection{Conduct regulation}

Leaving aside the price regulation discussed above, other aspects of the (self-) regulation of conduct in the Netherlands and Belgium seem to aim at a limitation of competition only. This is e.g. the case with the prohibition of advertising. A prohibi- 
tion of advertising will make the market less transparent. Hence, it will become more difficult for patients to compare service quality between pharmacists. This seems only to serve a private interest goal. ${ }^{408}$ The same can be said for the regulation of the exercise of the profession (notably the mandatory design of the pharmacy and related aspects). Of course one could argue that it may be in the public interest that a pharmacy is well-designed, but again such regulations seem to go much further than the public interest goal would require. In the Netherlands it was prohibited by the old Dutch Pharmacy Standards (i.e. until 2002) to have opening hours only in the evening, or to just provide medicines for specific groups of patients. Differentiation of pharmaceutical services is made very difficult by such prohibitions

It is, however, not always clear who are precisely the 'winning' pharmacists in this private interest game. The interests of pharmacists may indeed well be heterogeneous. Some may wish to compete against others in order to gain a larger share of the market, whereas others may wish to be protected from that competition. It is hence not a priori clear that all pharmacists gain from, e.g., a ban on advertising. However, the fact remains that many of these professional rules limit competition and therefore consumer choice. But there again I should repeat that - as far as prescription drugs are concerned - the opportunities for consumer choice among the drugs they purchase is often non-existent or at least limited to the services that are offered during and after the sale of the drug.

\subsubsection{Conclusion}

Indeed, parts of the regulation of Dutch and Belgian pharmacists seem to be predominantly a result of rent-seeking behaviour by 'insiders' who want to eliminate competition as much as possible. In particular the regulation of establishment and the restrictions on advertising and exercise of the profession seem to belong to this category, as they do not guarantee any increase in service quality, whereas they do guarantee a relatively 'quiet life' for pharmacists already in the market. However, other regulations such as the price/fee regulation, do not seem to provide any specific benefits for pharmacists (or at least, not anymore), especially considering the recent attempts from the Dutch government to take back some of the 'unofficial' income that pharmacists receive in the form of bonuses and discounts.

Some regulations may benefit other interest groups. Indeed, the influence of health insurers in the establishment of pharmacies in the Netherlands points at the fact that this establishment policy might be in the interest not only of the pharmacists, 
but also of the health insurers. Another element that illustrates the influence of health insurers is the regulation of drug prices. It is clear that health insurers have an influence on the drug delivery system, as they clearly have an interest in keeping the price of pharmaceuticals (and the pharmacist's fee) within a reasonable limit. ${ }^{409}$ Moreover, the current system of regulated prices decreases the competition between health insurers. With respect to price regulation one also has to take into account the interests of the pharmaceutical industry. As a result of the current system of price regulation in the Netherlands and Belgium, drug producers can only compete by providing bonuses and discounts to pharmacies and hospitals. However, given that these drug producers still appear to be able to give huge discounts, it is difficult to say whether they benefit from the current pricing system or not. Pharmacists and wholesalers have a strong bargaining position vis-à-vis the pharmaceutical industry. Anyway, the influence of health insurers, wholesalers and the pharmaceutical industry in addition to pharmacists provides support for the hypothesis of Becker that regulation is the result of a competition for political influence among interest groups, ${ }^{410}$ but the results, in terms of rents for the different groups, are not always clear. With respect to the professional monopoly of the pharmacist in the distribution of drugs and the accompanying tariff regulation, in particular, it is difficult to draw firm conclusions. Obviously the professional monopoly protects pharmacists from competition by chemists and other possible retailers, but pharmacists who would indeed be willing to concentrate more on providing services are discouraged to do so. In $\S 6.3 .1 \mathrm{I}$ showed that it is doubtful whether the combination of a professional monopoly and a fixed fee/margin, which is based on tasks that pharmacists had decades ago, serves any group at all. Here the private interest analysis appears to reach the same conclusion as the public interest analysis.

\subsection{Summary}

On the basis of a qualitative analysis of the Dutch and Belgian regulation of pharmacists, one can conclude that although there certainly is a public interest argument in favour of some regulation of the quality of pharmaceutical services, parts of the regulation are not in the public interest. The tariff regulation, prohibition of advertising, restrictions to the design of the pharmacy and the establishment policy seem to go further than what would be warranted to cure a market failure. This corresponds with the prediction in the literature that a profession will seek to obtain monopoly profits by using regulation to grant them monopoly rights.411

However, although the regulation clearly is to some extent promulgated in the interest of the pharmacist, it is also likely that, for example, the price regulation is the

410 Becker, 1983. Physicians, as well, may have some influence on the regulation of the pharmaceutical market, e.g. regarding their succesful opposition against a substitution regulation for drugs in Belgium. 
result of competition for regulation among different interest groups. Price regulation probably promotes the interests of health insurers and the pharmaceutical industry as well. That is, although one could argue that normal price competition between drug producers would be more beneficial for health insurers, in the current system with regulated prices they hardly have to worry about competition with other health insurers. In addition, the pharmaceutical industry is, despite regulated maximum prices, able to provide large amounts of bonuses and discounts to pharmacists and hospitals. It is very difficult to state who exactly benefits from such regulation.

Furthermore, it is likely that none of the involved parties (pharmacists, health insurers, the government, drug producers and consumers) benefit from the current regulation that links the professional monopoly of the pharmacist to the fixed fee/margin. This combination only encourages the mere selling of prescription drugs, while giving no incentives at all to provide services, despite the often asumed new tasks of pharmacists in the field of 'pharmaceutical care', and despite the fact that nowadays most drugs sold are prepacked drugs. Both the public interest analysis and the private interest analysis come to this conclusion, because neither the public nor the regulated parties seem to benefit anymore from this oldfashioned regulation. ${ }^{412}$ A solution might be found in a new remuneration system for pharmacists that strictly separates between distribution tasks and tasks in the field of pharmaceutical care. I will come back to this proposal in chapter 8. First, I will provide a number of empirical data to investigate the extent to which Dutch and Belgian pharmacists can be considered as successful rent seekers. 


\section{AN EMPIRICAL AND COMPARATIVE ANALYSIS}

It is obviously another question whether the pharmacists in the Netherlands and Belgium are successful rent seekers. That is largely an empirical question. As far as the contents of the regulation are concerned, pharmacists in both countries appear to have been quite successful, at least in limiting competition. I will now examine whether the regulation was also effective in limiting the entry into the profession. Therefore I will look at the number of pharmacies and the number of pharmacists (and the development thereof) in the Netherlands and Belgium. In that respect it will be interesting to relate these developments to differences in regulation between both countries. In addition I will examine whether these barriers to entry also lead to rents for pharmacists, although answering this question has proven to be very difficult. In $\$ 7.1 \mathrm{I}$ first explain why it is so difficult to conduct empirical research into the actual rents obtained by pharmacists - if there are any - and also introduce the methods I used to try to tackle this problem. The analysis of the number of pharmacies and the number of pharmacists is the subject of $\S 7.2$. In order to find some empirical evidence of the existence or non-existence of rents obtained by pharmacist, I will present some data on the (relative) income of pharmacists (\$ 7.3) and some indications of high takeover prices $(\$ 7.4)$.

The sections after that focus on two case studies with respect to the Dutch pharmaceutical market: a case study of Boots (\$ 7.5), which discusses the failed attempt of this British chemist's chain to open pharmacy departments in the Netherlands, and a case study of OPG ( $\$ 7.6)$, a company that was established over a decade ago by pharmacists and which is now (still) the biggest pharmaceutical wholesaler in the Netherlands. The section on Boots gives some insights into how the different parties on the pharmaceutical market reacted to this new market entrant and analyses why the Boots experiment failed. The section on OPG deals with the increasing market power of this wholesale chain in the Netherlands, and also briefly discusses the development of chain retailing in the Dutch pharmaceutical market. 


\subsection{How to measure rent seeking on the pharmaceutical market}

Because the pharmaceutical market is very different from other markets I have to use some rather unusual techniques to measure the effects of rent seeking by pharmacists. In previous chapters I noted that tariffs on the pharmaceutical market are (very tightly) regulated. The income of pharmacists depends largely upon the fixed fee/fixed margin, which they receive for every sold prescription drug, whereas drug prices are jointly set by the industry and the government. Because fees are determined by regulation and individual pharmacists do not have any influence on the prices they are allowed to charge for their services, a price comparison does not seem to be a meaningful way to start the empirical analysis. That is, a comparison of prices of pharmaceuticals between the Netherlands and Belgium - or a comparison with other countries - would not be a useful proxy for the rent seeking by pharmacists, since pharmacists hardly influence these prices.

The same goes for an analysis of the income of pharmacists. Although it might be useful to look at the development of pharmacy incomes, this does not completely represent the amount of rents gathered by pharmacists. As long as it remains impossible for pharmacists to compete in prices, their income is not an optimal criterion for an analysis of rent-seeking behaviour. However, the 'unofficial' income received in the form of bonuses and discounts from the pharmaceutical industry would be a better indicator of the success of rent seeking by pharmacists. Unfortunately, estimates of the amount of bonuses and discounts received by pharmacists differed largely between the comprehensive researches carried out in the Netherlands, i.e. by the Dutch Tax Department and PriceWaterhouseCoopers with respect to the year 1997 and by the Boston Consulting Group and Deloitte and Touche for the year 2001.413 Some information could be provided by examining the aggregate income of the pharmaceutical profession. However, even if one would find, e.g. that the income of pharmacists is high relative to the income of other liberal professions, that would not necessarily be any proof of successful rent seeking. High incomes do not necessarily correspond with high rents; it is necessary to distinguish between supra-competitive profits and high incomes. A high income may also be - at least to some extent - an effect of investments in long training (education) or a compensation for greater responsibilities. ${ }^{414}$ Moreover, exact data on the earnings of pharmacists are hard to obtain, partly because of non-disclosure policies and partly because these data are in some cases just not available. This is a well-known problem: in many papers and research reports that analyse the regulation of the liberal profes-

For 1997, the Dutch Tax Deparment calculated an amount of $577 \mathrm{mln}$ NLG $£ 262 \mathrm{mln}$ ), whereas PriceWaterhouseCoopers calculated the bonuses and discounts to be NLG $360 \mathrm{mln}$ ( $€ 136 \mathrm{mln}$ ). See Ministerie van Volksgezondheid, Welzijn en Sport, GMV 992292, 23 March 1999. With respect to the year 2001, the Boston Consulting Group came to an amount of $€ 520$ $\mathrm{mln}$ and Deloitte and Touche to $€ 644 \mathrm{mln}$ (see also $\$ 4.6 .2$ ). Obviously the differences are considerable. 
sions from a quantitative point of view, lack of data (especially on earnings, but also on prices and costs as a time-series) often excludes the proper use of statistical and econometric models to assess the effects of restrictive regulation. ${ }^{415}$ In the (probably even more complex) pharmaceutical market the situation is no different.

A more appropriate method to measure the rents obtained by pharmacists seems to be to analyse the take-over prices of pharmacies. Rents might be incorporated in the goodwill and the take-over price of the pharmacy. There are all kinds of indications that the prices of pharmacy buildings in the Netherlands and in Belgium are indeed significantly higher than those of other buildings in the same area. Hence it is not only the building that is paid for, but the business as well. Unfortunately it is extremely difficult to obtain exact data on the amounts of goodwill paid for the takeover of a pharmacy, again predominantly because of non-disclosure policies. I did however find some information about take-over prices paid for pharmacies, which will be presented in $\$ 7.4$ infra.

Furthermore, I use the case studies of Boots and OPG to analyse the behaviour of different parties in the Dutch pharmaceutical market, such as pharmacists, health insurers and wholesalers. From these case studies one can therefore also gather some (circumstantial) evidence of rent-seeking behaviour by these different interest groups. In addition, the case studies give an overview of recent developments in the rapidly changing Dutch pharmaceutical market.

Hereafter I will first measure the rent-seeking behaviour of pharmacists in another way, namely by looking at the effectiveness of the establishment policy in limiting entry into the profession. Such regulation decreases competition between pharmacists by limiting the number of competitors on the already regulated market. With respect to the establishment policy of the KNMP in the Netherlands it is especially interesting to indicate its effects during the 1980s and 1990s. In Belgium the establishment of pharmacies is regulated by the government in the form of a moratorium, the effects of which can be shown easily.

\subsection{The number of pharmacists}

The evolution over time of the number of pharmacies (community pharmacies, dispensing physicians, and hospital pharmacies together) in the Netherlands is shown in Figure 7.1 for the period 1970-1998. ${ }^{416}$ The effects of the KNMP establishment policy are visible in this figure. During the period in which the policy was obligatory

415

416

HIS (2003, pp. 126-127).

Data sources for Figures 7.1-7.3: Dutch Bureau of Statistics (CBS), Eurostat and own calculations. Although some more recent data exist regarding the number of pharmacies and the number of pharmacists, these data are not always compatible with the numbers presented in Figures 7.1-7.3. In some cases determinants are not available as a time-series after 1998, whereas in other cases sources contradict each other. 
for KNMP members (1975-1987) the number of pharmacies decreased. After 1987 the number eventually increased again, but it is obvious that also the advisory establishment policy - enacted in 1987 - was able to prevent the number of pharmacies to reach the 1970 level of 2,298. The initial increase was therefore temporary. In 1998 the number of pharmacies was only 2,244 (divided into 1,547 community pharmacies, 605 dispensing physicians and 92 hospital pharmacies). 
Figure 7.1: Pharmacies in the Netherlands (inc. dispensing physicians)

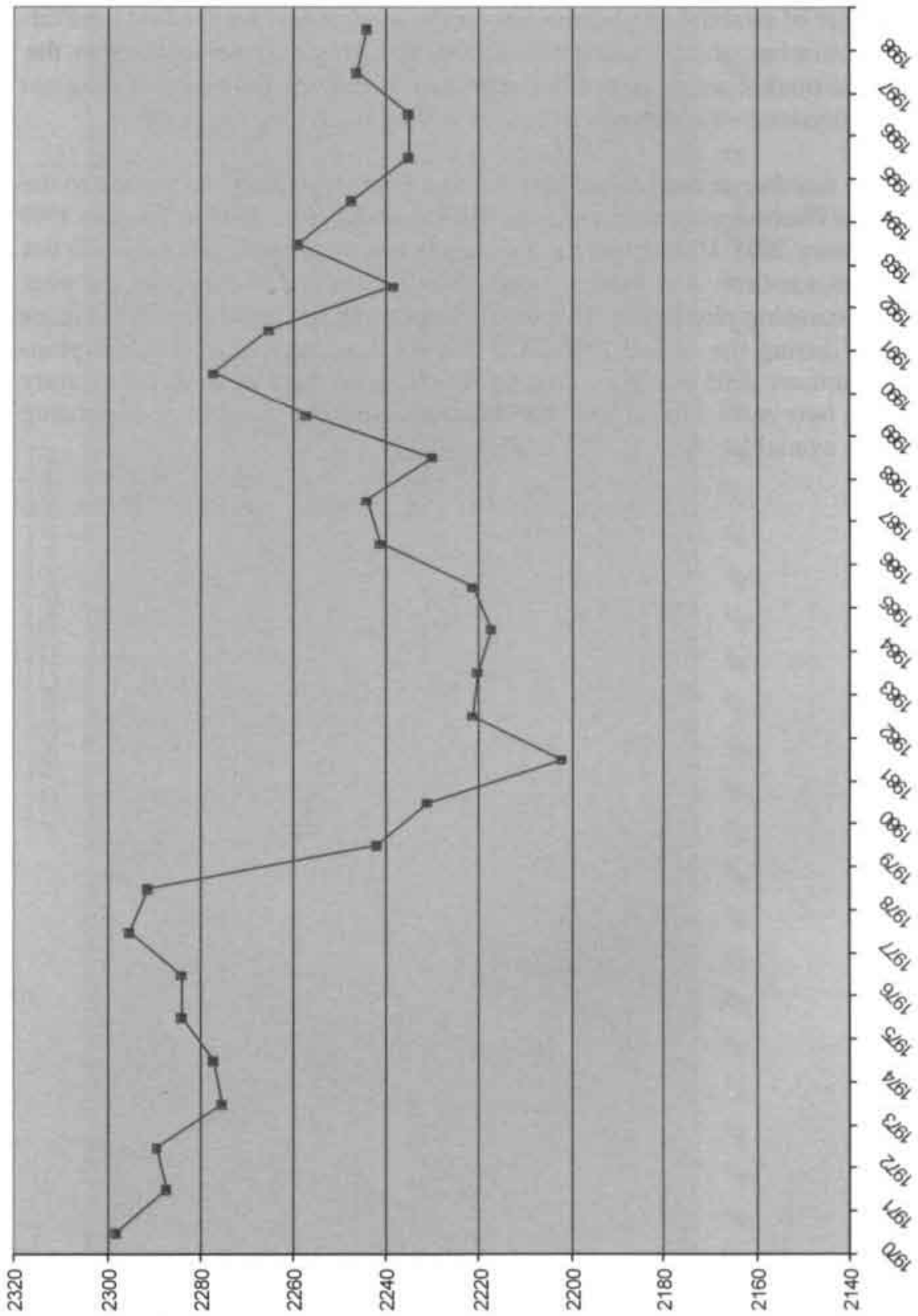


Looking at Figure 7.2, which indicates the relationship between the number of community pharmacies and dispensing physicians, it appears that for almost every new community pharmacy a dispensing physician gave up his drug depot. ${ }^{417}$ In 1982 the number of established pharmacists on the market was for the first time larger than the number of dispensing physicians. It seems that newcomers to the pharmaceutical market are more or less dependent on the possibilities of buying out a dispensing physician or a pharmacist who is willing to give up his practice.

After 1998 the number of established pharmacists kept increasing. According to the Foundation for Pharmaceutical Statistics SFK it increased from 1547 in January 1998 to 1602 in January 2001. Unfortunately, the number of dispensing physicians is not provided by this source. A different source, NIVEL, states a number for the year 2001 of 578 dispensing physicians. This would imply that the trend shown in Figure 7.2 continued during the period 1998-2001. The total number of established pharmacists on 1 January 2003 was according to SFK 1654: an increase of 52 community pharmacies in two years. No comparable data regarding the number of dispensing physicians are available. established in areas where no pharmacist is established. 


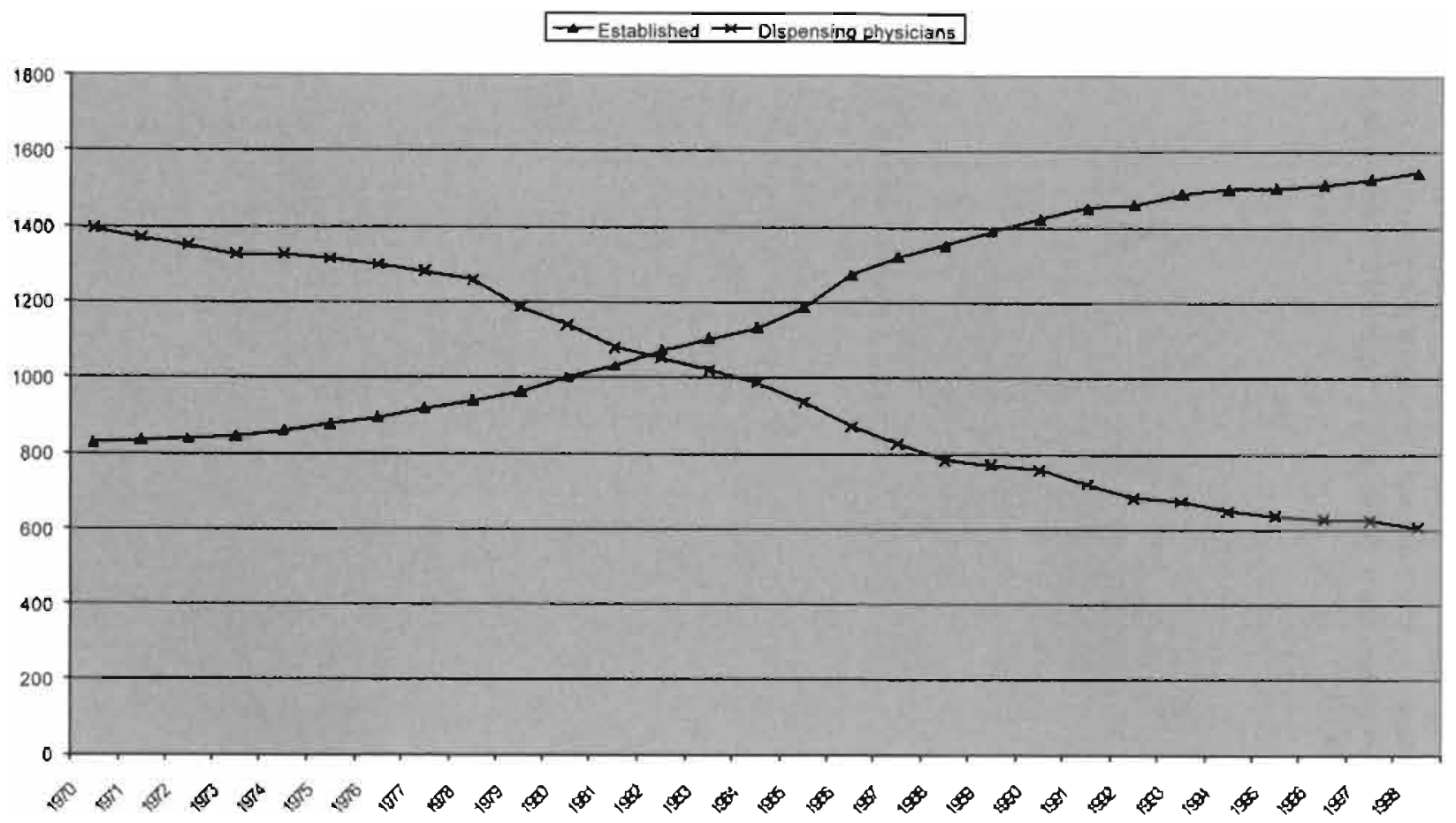

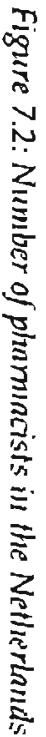

岕 
In a market without population growth the fact that newcomers are dependent on buying out dispensing physicians or pharmacists might be nothing to really worry about (that is, if the initial number of pharmacies would have been optimal at the outset), but in the Netherlands, like in all of Europe, the population has increased enormously during the last decades. The number of patients per pharmacy (including dispensing physicians) increased from 5,934 in the year 1970 until 7,274 in the year 1998, as shown in Figure 7.3. 
Figure 7.3: Patients per pharmacy in the Netherlands

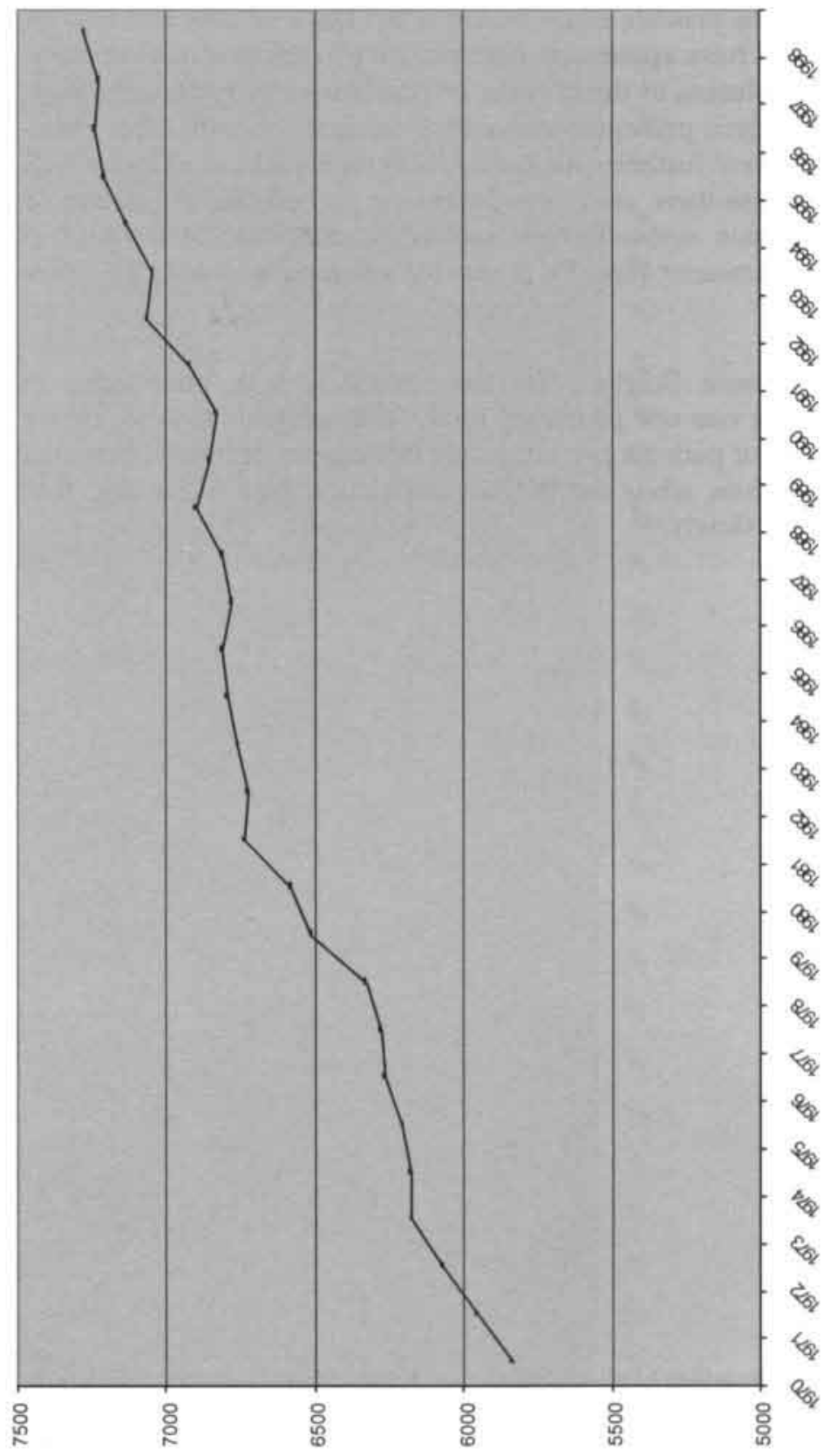


While, of course, this presentation of the number of pharmacies in the Netherlands cannot be explained by the KNMP establishment policy alone (also the drug policy enforced by the Dutch government and the development of the profession itself may be responsible), it does provide some tentative evidence of rent seeking. $\mathrm{h}$ deed, the Dutch regulations have apparently been effective in limiting market entry. Thus these data on the evolution of the number of pharmacies provide some support for the qualitative analysis presented above. ${ }^{418} \mathrm{~A}$ comparison with other countries seems necessary to draw further conclusions, although such an analysis will certainly not be easy because there are many differences in both the regulation of the pharmaceutical profession across Europe and in the definition of the professional monopoly of the pharmacist. Here I will provide a comparison with the situation in Belgium.

With the exception of Greece, Belgium has the tightest web of pharmacies in Europe. ${ }^{419}$ On average there was one pharmacy for 1,935 inhabitants in 1998. Figure 7.4 shows that the number of patients per pharmacy in Belgium decreased between 1961 and 1986, but since then, while the Belgian population kept increasing, this number has increased very slowly. ${ }^{420}$ tisch Tijdschrift, 12, 1998, pp. 26-27; OFT, 2003, volume 1, p. 10. the Belgian pharmaceutical market because of the high pharmacy density. 
Figure 7.4: Patients per pharmacy in Belgium

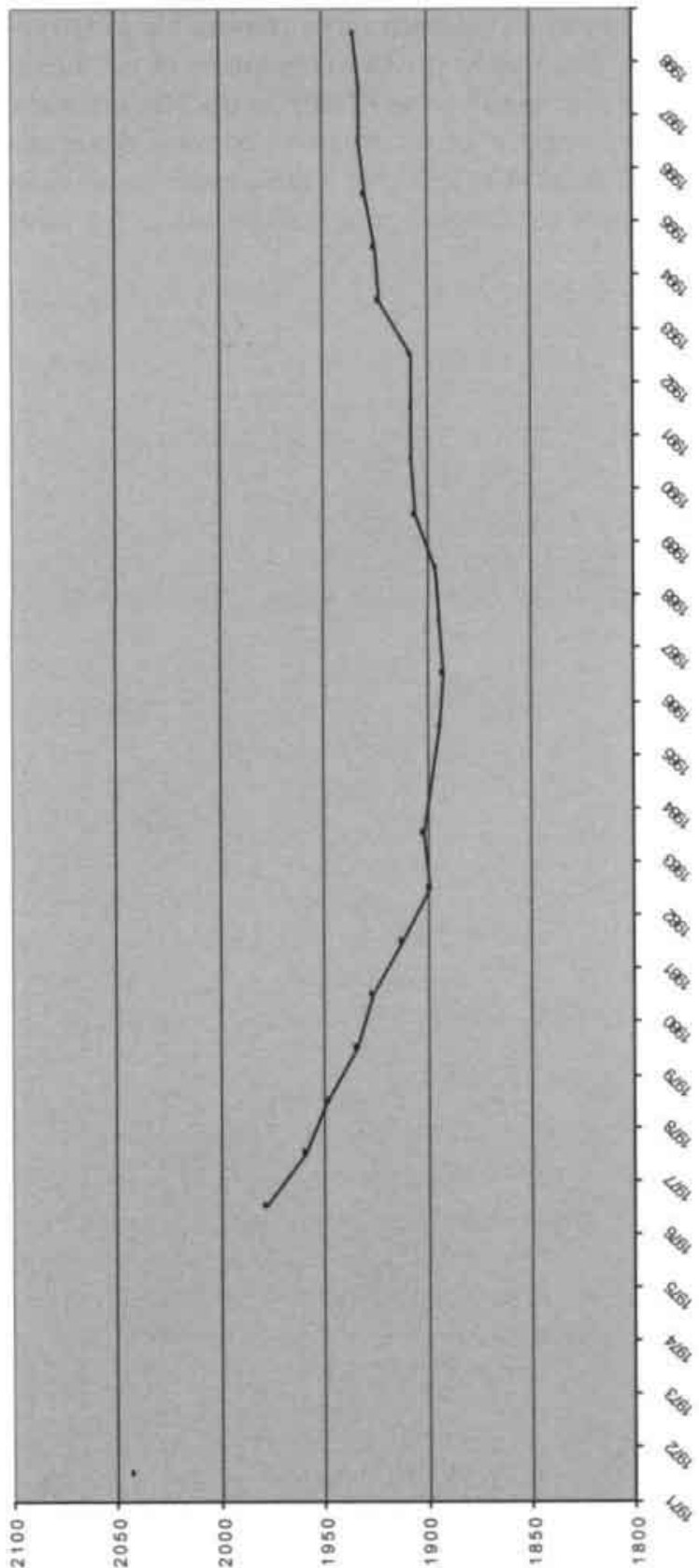


Figure 7.5 presents the number of community (established) pharmacies in Belgium. As opposed to the Netherlands, one sees an increase in this number, although since the mid-1980s the number of community pharmacies has remained almost constant. It seems therefore that the public regulations in Belgium did a reasonable job in reducing the number of new pharmacies. The reason for this regulation of establishment of pharmacies is different from the one used by the KNMP in the Netherlands: in Belgium the government fears an 'oversupply' of pharmacies. Because the number of pharmacists active on the Belgian market is still very high (much larger than the Dutch number), it will remain difficult for Belgian pharmacists to open a new pharmacy. 
Figure 7.5: Number of community pharmacies in Belgium

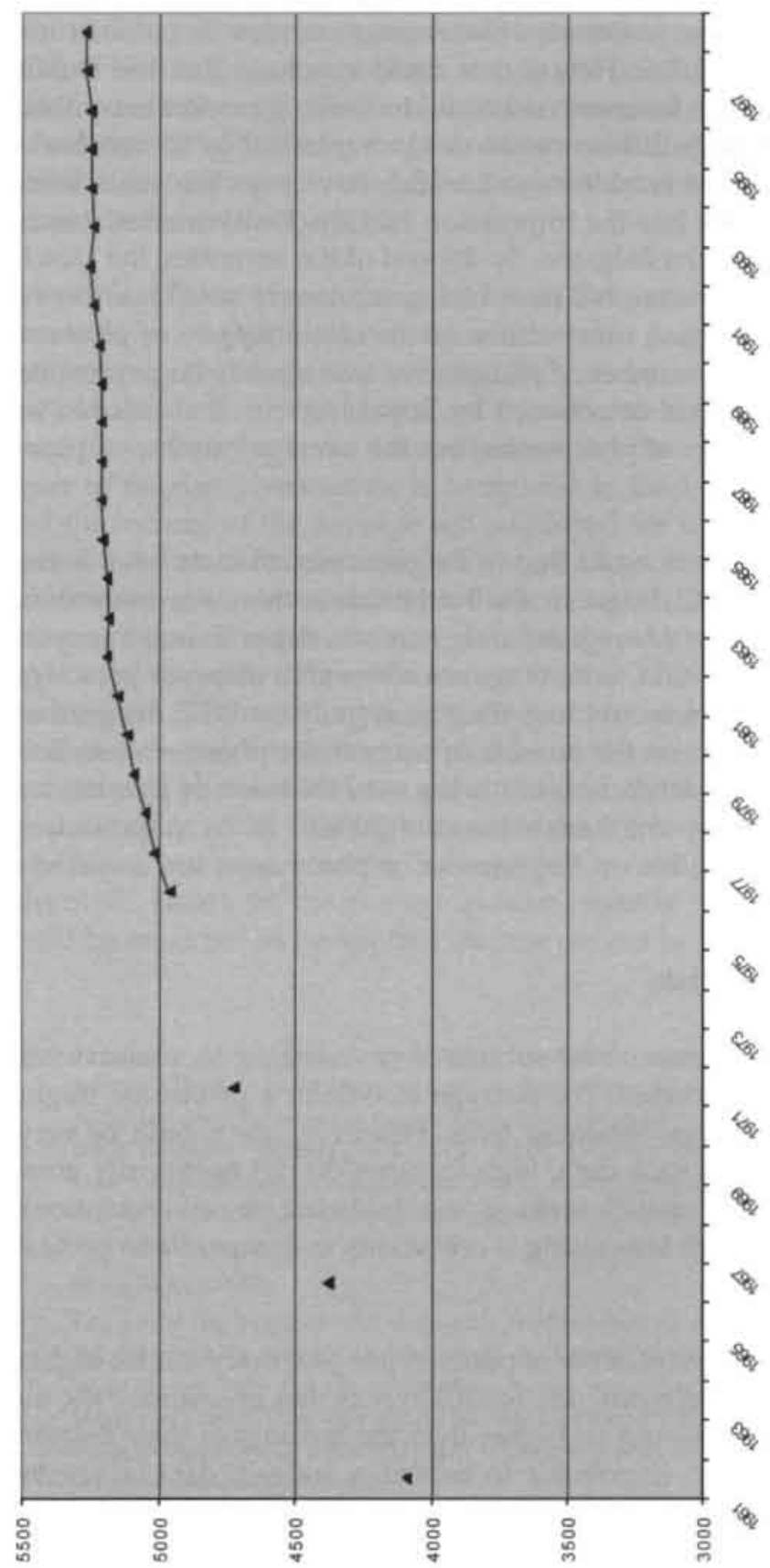


Although I noticed that both Belgium and the Netherlands have been quite successful in restricting the entry of pharmacies into their respective markets, there are considerable differences between the two countries. Whereas in the Netherlands in 1998 there were 7,274 patients per pharmacy, the average number of patients for one pharmacy in Belgium was 1,935. Hence, one could conclude that the Dutch pharmacists have apparently been far more successful in limiting market entry than their Belgian colleagues. That large difference can not be explained by merely looking at the contents of the rules of establishment, which have over the years been very strict in both countries. One has the impression that the Dutch started much earlier to limit market entry than the Belgians. By the end of the seventies, the Dutch (private) regulations apparently succeeded in reducing an already small number of pharmacies even further. The Belgian moratorium on the establishment of pharmacies came only in 1994, when the number of pharmacies was already large (despite the population and distance criteria determined by Royal Decree). It succeeded in limiting the growth of the number of pharmacies, but the average number of pharmacies remained high.

Finally, one of course has to bear in mind that in Belgium pharmacists have a monopoly in the distribution of OTC drugs. In the Netherlands there are more than 4000 OTC outlets such as chemists (druggists) and chemist's departments in supermarkets. ${ }^{421}$ However, these 'other' OTC outlets are not allowed to dispense prescription drugs. If Belgian pharmacists would lose their monopoly on OTC drugs, this would probably have a large effect on the number of community pharmacies in Belgium. Furthermore, in the Netherlands nowadays the establishment of pharmacies is more and more determined by the health insurers instead of by pharmacists themselves. The consequences of this on the number of pharmacies are as yet unclear.

\subsection{The income of pharmacists}

Another way of getting an indication of the success of rent seeking by pharmacists is by examining data on their incomes. The average income of a profession might give some estimate of its success in obtaining rents. However, one should be very careful with the interpretation of such data; high incomes do not necessarily emanate from high rents as a result of rent seeking (e.g. lobbying or self-regulation). Nevertheless, income data are still interesting if one wants to compare one profession with others.

Since I just noticed that the average number of patients per pharmacy is a lot higher in the Netherlands than it is in Belgium, one would expect that on average the incomes of the Dutch pharmacists would be higher than the incomes of their Belgian colleagues. That is, unfortunately, impossible to ascertain. Indeed, data on the in- 
come of Dutch pharmacists are extremely difficult to find, ${ }^{42}$ not least because a large part of their income depends on the bonuses and discounts received from the pharmaceutical industry. The average turnover of a Dutch pharmacy in 1999 was $€ 1,810,583 .{ }^{423}$ The gross profit at this turnover would be $€ 376,638$ (according to the SFK), which implies a gross profit margin per pharmacy of almost $21 \%$. However, if I add the bonuses and discounts and then compute the gross profit margin, it would be almost $25 \% .{ }^{424}$ The average bonuses and discounts per pharmacy are about $€ 90.756$ (according to own calculations based on numbers given by the SFK and PriceWaterhouseCoopers) ${ }^{425}$

It is difficult to compare these data with Belgian data, since the Dutch data represent turnover, which is obviously not the same as income. However, some comparison between Dutch gross profit and Belgian incomes may be possible. I will come back to that below. First it seems interesting to look at the Belgian data separately, since they allow for some comparison with other professions. In Figure 7.6 the income of Belgian pharmacists is compared to the income of three other professions and the income of the average self-employed for the period 1982-1999.426 The numbers show that in Belgium the income of all professions exceeds the income of the self-employed workers, although the architects' income is very close to that of the self-employed. The data also suggest that the relative income of pharmacists is quite high: until the early 1990s the average income of pharmacists was even higher than the average income of physicians. The pharmacists' income is significantly higher than the attorney's income as well. Hence, there is at least some tentative evidence that Belgian pharmacists as a group might be efficient rent seekers. However, one has to keep in mind that high incomes do not necessarily result from rent-seeking behaviour, but may also be, for example, a reward for investments in prolonged education. However, the average income seems to be substantially higher than what could be expected as postponed income caused by longer studies. A part of this re-

This information gathering problem has been discussed in $\$ 7.1$. With regard to incomes, several attempts have been made to acquire these data for the Netherlands, but this appeared to be impossible because most institutions claimed 'not to have this specific information at their disposal' (KNMP, SFK, CBS, CTG, Ministry of Health). The Dutch tax department, which has control of such income data, stated that it has a duty of confidentiality and decided not to grant an exemption in this case after a 'careful weighing of interests' (letter dated 3 April 2001).

SFK (2000, p. 54).

I.e., I add the bonuses and discounts to the nominator and denominator and again compute the gross profit margin (gross profit as a percentage of total turnover). If one would then want to compute the net profit margin, one would need to subtract a 'normal income' from the gross profit. Then one would be able to compare the net margin of a pharmacist to that of other professions (if available) and - probably even more interesting - to that of 'normal' retailers such as supermarkets.

I divide the total number of bonuses and discounts by the number of established pharmacies and dispensing physicians.

Data source: National Institute for Statistics (NIS). Conversion rate: $1,000,000 \mathrm{BEF}=€ 24,789$. 
ward can in that case be considered as rent. A similar conclusion concerning the relative success of pharmacists in rent-seeking was reached in an earlier Belgian paper by Faure and Van den Bergh, based on an examination of data from attorneys, architects, physicians and pharmacists between 1982 and 1988.427 
attomeys - phamnacies $*$ architects $*$ - physicians - gelfemployed

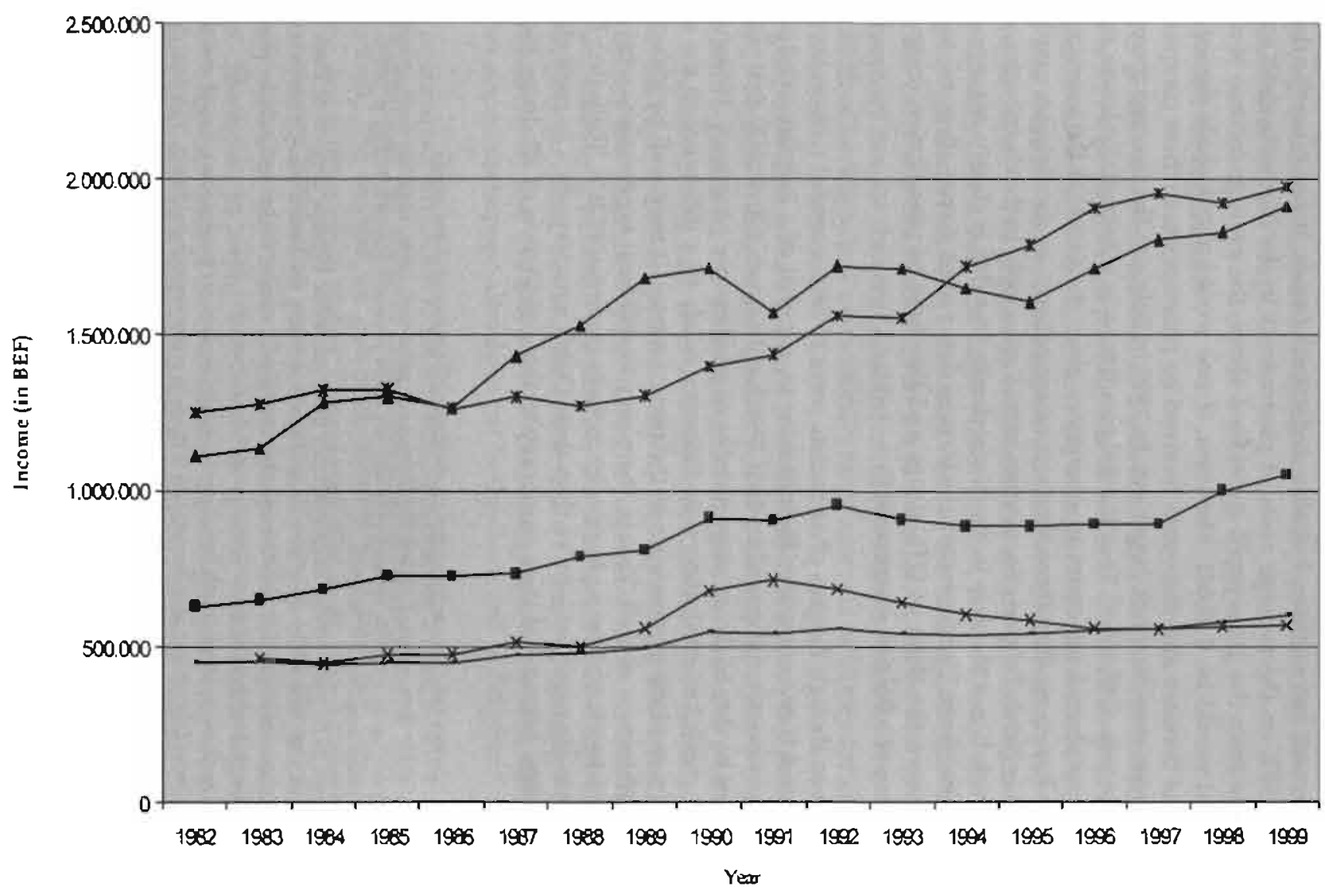


Unfortunately these nice Belgian data cannot be compared with Dutch data, since the latter are not available. However, I noticed above that the gross profit (before taxes, before deduction of costs) of an average pharmacy in the Netherlands in 1999 was $€ 376,638.428$ This can to some extent be compared to the Belgian data, which provide income before taxes, but after deduction of costs. If one takes the data provided by SFK on the average costs of pharmacists in the Netherlands ${ }^{429}$ and subtracts these from the gross profit mentioned above, the average income of a Dutch pharmacist would be $€ 69,641$. Moreover, if one would also include the estimated amounts of bonuses and discounts received by pharmacists in these computations, the difference may be much larger yet. In 1999 in Belgium the average income of a pharmacist was $€ 47,360.430$ That the Belgian figure is substantially lower than the Dutch figure should not come as a surprise, given the fact that the average Dutch pharmacy has more than three times as many patients as the Belgian counterpart. On the other hand, Belgian pharmacists have a monopoly in the distribution of OTC drugs, which is not the case in the Netherlands, but this is clearly not represented by our estimations. Unfortunately the income data I used do not allow me to distinguish between the share of OTC drugs and the share of prescription drugs in the total income of a Belgian pharmacist. ${ }^{431}$

In sum: even though Belgian pharmacists seem to be successful rent-seekers at the national level if one compares their income to, e.g. that of a Belgian architect, they do relatively poorly compared to their Dutch colleagues. Obviously that must to a large extent be due to the average number of patients per pharmacy. However, one should be careful in attributing this difference solely to a difference in the relative lobbying force of the pharmacists in the two countries. It may well be imbedded in cultural differences as well. That is, there may be different expectations with respect to the services offered by a pharmacist in both countries. ${ }^{432}$ It is likely that Belgian pharmacists are regarded - more than their Dutch counterparts - as mere distributors of drugs, because of their monopoly in the distribution of all drugs including

Here I do not take into account the crude data on bonuses and discounts.

To estimate these costs, I added the figures for personnel costs, housing costs, general costs, computer costs, interest, writing-offs and car costs presented in SFK $(2000$, p. 50) to arrive at an average amount of $€ 306,996$.

One has to be very careful in interpreting these numbers, because they come from different sources and, moreover, they are rather crude (especially the Dutch data). However, because the difference suggested here between the average income of Dutch and Belgian pharmacists is so huge, one can still draw some tentative conclusions.

One could try to distinguish between the profit margin on prescription drugs and the profit margin on OTC drugs and investigate if there is some cross-subsidising. The data do not allow this, however. Of course, the total profit margin could in theory still be computed, that is, if one knows the average turnover per pharmacy. Because of incompatibility of data sources, I was not able to do this either.

See chapter 3, which discusses the pharmaceutical market and the service of a pharmacist in the Netherlands and Belgium, and chapter 6, where some differences between these countries are presented. 
OTC. The fact that the Belgian public apparently expects quick service offered by a large body of pharmacists, will also have some influence on the 'optimal' number of pharmacists in a society. In the Netherlands, on the other hand, pharmacists seem to have a slightly more service-oriented function, because they are more and more taking part in pharmacotherapeutic consultations with physicians and they have more possibilities to substitute drugs.

\subsection{Takeover regulation}

Takeover prices can be considered as a powerful indicator of rent-seeking as well. The mere fact that goodwill is paid for the takeover of a pharmacy proves that the pharmacy itself has a value, other than the value of the real estate, the stocks etc. Hence, this confirms Moore's hypothesis that a license will confer property rights upon the licensees. ${ }^{433}$ The practice in both countries shows that the 'license' to operate a pharmacy has a real and high value. Indeed, it is obvious that the large amounts of goodwill that have to be paid both in the Netherlands and in Belgium restrict the entry into the market. Even if a pharmacist would be able to establish a new pharmacy despite the strict establishment rules discussed above he would face the problem of having to pay extraordinary large amounts of money for goodwill.

More specifically, the goodwill consists of the capitalised surplus profits gained from trade benefits (bonuses and discounts, see $\$ 4.6$ and $\$ 5.6$ above) and the expected future profits on the pharmaceutical market. Because the pharmaceutical market is protected by a high degree of regulation, both in the Netherlands and in Belgium, the expected future profits on the market are high. ${ }^{434}$ This situation creates opportunities for incumbent pharmacists to capitalise their undertaking, while young (i.e. recently graduated) pharmacists who cannot afford the high amounts of goodwill have no choice but to enter employment by the big wholesale chains, the only entrepreneurs that can still afford these sums of money. In fact, one even sees these developments happen already in the Netherlands and in Belgium.

Dutch pharmacists who want to set up their own practice by taking over an existing pharmacy have to pay takeover costs consisting of housing, stock and an amount for goodwill. The amount for goodwill amounts to at least one time the annual turnover, but is often much higher. Considering that as mentioned above the average pharmacy in 1999 had an annual turnover of about $€ 1,810,583$ (see $\S 7.3$ ), it immediately becomes clear that the average goodwill contributes a substantial amount. Moreover, in recent years one has seen a considerable increase in this amount. ${ }^{435}$ The estimates of the amounts that are actually paid vary widely. In 2002, C. Roozen, chairman of KNMP-department Limburg, stated in Dagblad De Limburger

433

434

435

Moore (1961).

Pharmaceutisch Weekblad, Big goodwill, bad results, vol. 135, nr. 38, 2000, pp. 1410-1411.

De Jong (1998, pp. 612-13); Het Financieele Dagblad, Zorg op de beurs, 20 February 2002; this was confirmed as well in an interview with an anonymous Dutch pharmacist (24 July 1999). 
that wholesale chains like OPG and GEHE pay goodwill amounts of up to 9 times the yearly profit or 1.6 times the annual turnover of a pharmacy, which implies that 'for a moderately big pharmacy between 2 and $3 \mathrm{mln}$ euro is laid down'. ${ }^{436} \mathrm{In}$ an interview in Het Financieele Dagblad with C. Oomen, director of the small Dutch health insurer DSW, an even higher estimate of the goodwill is put forward: 1.5 times the yearly turnover of a pharmacy, which entails that for relatively big pharmacies (more than 12,000 customers) a goodwill of between $€ 4$ and $€ 4.5$ million is paid out. ${ }^{437}$ If one considers an average pharmacy instead and takes the average turnover computed in $\S 7.3$, then the estimate would be about the same as the one suggested above by Oomen: $€ 2.7 \mathrm{mln}$. In any case, it is obvious that for independent Dutch pharmacists (not to mention recently graduated pharmacists) it is nearly impossible to set up an own practice, while for already established pharmacists the temptation to sell the building and capitalise the goodwill is strong. According to DSW-director Oomen the 'independent pharmacist' is disappearing gradually from the Dutch market while the market power of the big chains, i.e. the wholesalers, is growing rapidly: about $23 \%$ of all Dutch community pharmacies in 2002 was owned by wholesale chains. ${ }^{438}$

Also in Belgium very large sums have to be paid sometimes when taking over a pharmacy, this despite the regulated takeover prices. ${ }^{439}$ On the contrary, the regulation of entry into the market by means of the legally determined moratorium might even be the primary cause of the increase in takeover prices (i.e. the amounts paid for goodwill). After all, the moratorium enhances the economic value of the already existing pharmacies, which drives up the price. ${ }^{440}$ Due to the high prices that have to be paid many pharmacies taken over in Belgium are now bought by commercial chains or private individuals who are not pharmacists. In 1999 about $20 \%$ of the pharmacies in Belgium belonged to non-pharmacists. However, it also occurs that established pharmacists buy up pharmacies to form minichains. ${ }^{41}$

Dagblad De Limburger, Veel apothekers verkopen zaak, 26 March 2002.

Het Financieele Dagblad, Ziekenfonds DSW: apothekers eenmalig verkwanseld, 12 April 2002.

Ibid. See also Dagblad De Limburger (supra, note 280) and \$ 7.6 infra.

Het Nieuwsblad, Apothekers willen minder apotheken, 4 November 1998.

See also Peers (2000, p. 206).

Antwerps Farmaceutisch Tijdschrift, 4, 1999, p. 17. Furthermore, the Belgian market is characterised by the existence of a fairly large number of cooperations such as Multipharma, PPL+ and De Volksmacht. These cooperations are united in Ophaco: <http://www.ophaco.be>. 
Although I do not have data on the exact amounts ${ }^{442}$ of goodwill to be paid by aspiring pharmacists because of non-disclosure policies, already the fact in itself that in both countries large sums of money have to be paid for goodwill suggests that there are rents that can be captured by the already established pharmacists. Of course, as stated in $\$ 7.1$, one should distinguish between, on the one hand, supra-competitive profits, and, on the other hand, high incomes resulting from investments in training and compensations for greater responsibilities. However, the problem is that the amounts paid for goodwill in the Dutch and Belgian markets of pharmacists largely concern rents that result from protective regulation; they do not always concern reimbursements for real efforts. In this respect it is also interesting to refer to a recent report by the Office of Fair Trading (OFT) which investigates the entry regulations in retail pharmacy in the UK. In the UK, as in the USA, chain store retailing in pharmaceuticals (e.g. chemist's chains, pharmacy departments in supermarkets) has existed for a long time already. The OFT report includes an investigation by a valuer and transfer agent of pharmacy businesses. ${ }^{43}$ Apparently, British supermarket chains 'claim to have paid high prices to acquire independent pharmacy businesses'. These supermarket chains attributed that to the effects of entry regulations in the UK, which include the obligation to purchase a NHS dispensing contract, i.e. a license to sell prescription drugs. However, the OFT report also points to the fact that

\footnotetext{
'it is not possible to draw firm conclusions on profitability from the prices at which pharmacies close to supermarkets change hands. High values for some dispensing contracts may be driven by the supermarkets' desire to increase their footfall. ${ }^{44}$
}

The observation that the number of chain outlets in the Netherlands and in Belgium is increasing at the expense of the number of independent pharmacies, as in the UK, is in itself not a problem. After all, to practise as a pharmacist does not imply that one should also be a conventional storekeeper. Consumers are not deprived of the pharmaceutical services provided by a qualified pharmacist in a chain store. Still a prohibition on incorporation exists in many of the other EU countries. ${ }^{445}$ Reekie (1997) argues that this may well be a result of lobbying by pharmacists who are 'successfully participating in a cartel-like environment where those innovations are retarded'. ${ }^{46}$

On the website <http://www.beleggingsweb.nl>, which provides information on stocks and shares, some information is given about amounts of goodwill paid by OPG in the period 1999-2001 (see: Tip van de Week, Week 50-2001). From the information presented there on the total amounts of goodwill paid by OPG in each year, one can compute that in 1999 the company paid on average $€ 3.2 \mathrm{mln}$ goodwill for a pharmacy, in 2000 it paid $€ 3.4 \mathrm{mln}$, and in 2001 it paid $€ 2.1 \mathrm{mln}$. The huge differences in these amounts can partly be explained by differences in the size of the pharmacies in question.

The 'Orridge report': OFT, 2003, volume 2, annexe G, pp. 170-178.

OFT (2003, volume 1, p. 16).

445 IHS (2003, p. 78). Supra, note 396.

446 Reekie (1997, p. 279). In this article Reekie (p. 283) explicitly mentions the lobbying against corporate ownership in Denmark, Holland, Germany and South Africa. He further concludes 
In the next two sections (in particular \$ 7.6) I will look in some more detail at the development of pharmacy chains in the Netherlands.

\subsection{Case study 1: Boots}

In § 4.7.1 I described how, in the late 1990s, the Dutch Ministry of Public Health tried to stimulate competition in the extramural supply of drugs. The amendments of 1999, which lifted the ban on the exploitation of a public pharmacy by health insurers and the ban on employment of pharmacists by non-pharmacists respectively, did indeed promote the possibilities to compete in the Dutch market. While, initially, the health insurers adopted an attitude of expectation with respect to starting their own pharmacies, ${ }^{47}$ the British chemist's chain Boots Health and Beauty reacted almost immediately on the amendments. However, Boots' adventure in the Dutch pharmacy business did not last very long.

The establishments of Boots in England, where the company is one of the three market leaders in community pharmacies, ${ }^{448}$ are characterised by large chemist's and perfume departments combined with pharmacy departments, located in socalled A1 locations in big shopping centres. Since the amendment of 1999 that permitted the employment of pharmacists by non-pharmacists in the Netherlands, Boots started right away to open pharmacy departments in the Dutch stores as well. The company did not bother about the advisory establishment policy of the KNMP. After all, in principle there was free establishment of pharmacies in the Netherlands. And, contrary to independent individual pharmacists, Boots expected to be capable of entering the market relatively easy, because its chemist's department could compensate possible starting losses of its pharmacy department. As early as July 1999, Boots had 7 establishments in the Netherlands and big plans for expansion in the near future: the goal of the company was to have 50 Dutch establishments in 2003.

(p. 284) that '[pharmacy] retailers have influenced regulation and legislation in many [....] countries. Their success includes slowing down by legal process advances in distribution'.

An exception worth mentioning is the small health insurer DSW, which by 2003 owned 4 pharmacies (Het Financieele Dagblad, DSW overweegt claim De Geus, 23 April 2003). However, there is also some criticism on DSW: the Foundation for Pharmaceutical Statistics SFK argues that 'it is not clear how $€ 4 \mathrm{mln}$ worth of premiums spent on goodwill on behalf of an own pharmacy in Schiedam lead to hundreds of millions of euros flowing back to the public' (Pharmaceutisch Weekblad, De Geus uit de bocht, vol. 138, nr. 10, 2003).

The community pharmacy market in the UK is characterised by a high proportion of pharmacies belonging to a chain. In 2002 the three market leaders accounted for $27 \%$ of all NHS contractor pharmacies (i.e. pharmacies with a license to dispense prescription drugs). With 1268 outlets, Boots the Chemists had a share in the total number of outlets in the UK of $10.5 \%$; Lloydspharmacy, which is owned by the wholesaler GEHE A.G. (Celesio), had a share of $10.9 \%$ and Moss Pharmacy, which is owned by the wholesaler Alliance Unichem, had a share of $6.4 \%$. OFT (2003, volume 1, p. 11). 
Because of the entry of Boots into the Dutch pharmaceutical market, a differentiation in services came about. Calling their pharmacy departments 'B-pharmacies', the Boots establishments did not take care of magistral preparation (i.e. the production of pharmacy made drugs) or home delivery of drugs. Besides, a Boots pharmacy could not treat chronic patients, nor could it participate in any observation schedule. After all, the establishments of Boots do not have office windows and no arrangements could be made for night duty because the stores are bound by the opening hours of the shopping centre. ${ }^{49}$ The result obviously was that Boots merely became a supplier of prescribed drugs, which caused a differentiation in the Dutch market for pharmaceutical services. The pharmaceutical service offered by the Boots chain can be considered some kind of para-profession. 450

Boots soon found out that it was made very difficult for its pharmacy departments to make contracts with health insurers. The chemist's chain even had to go to court in order to receive the possibility to hand in prescriptions to two of the largest Dutch health insurers, CZ and VGZ. Only health insurer Zilveren Kruis, which had (some years before) also been one of the firsts to experiment with mail order pharmacy, entered into a contract with Boots voluntarily. Making contacts with general practitioners and community pharmacists also turned out to be very difficult for Boots establishments. This can be explained by the fact that the establishment of a Boots pharmacy in a certain area would cause an enormous decrease in the value of community pharmacies in its surroundings. General practitioners often showed solidarity with the incumbent pharmacists, probably because they meet each other on a regular basis during the meetings within the scope of pharmacotherapeutic consultations (see $\$ 3.2 .1$ ). ${ }^{451}$ The reaction mentioned above by health insurers such as VGZ and CZ can possibly be explained in the same way. They might fear to harm their relationships with the incumbent pharmacists if they would bargain with a chain like Boots. However, this view is not founded scientifically. ${ }^{452}$

In the meantime, however, the Dutch adventure of Boots has ended already. In August 2000 Boots terminated all its activities in the Netherlands due to disappointing results of its pharmacy departments. The company concluded a strategic alliance with Ahold-daughter Etos and sold all its establishments to this Dutch chemist's chain. ${ }^{453}$ The lack of success of the Boots pharmacy departments can partly be explained by the tense Dutch labour market at the time. There was a shortage of

Pharmaceutisch Weekblad, vol. 133, nr. 27, pp. 919-921.

Shaked and Sutton, 1981. Supra, \$2.5.4.

Supra, note 178.

Pharmaceutisch Weekblad, vol. 133, nr. 27, 1999, pp. 919-920; Dagblad de Limburger, Prozac naast parfum en poeders, 26 June 1999.

More specifically: Boots sold all its 17 establishments - of which 10 had a pharmacy department - with its 400 employees to Etos, which gained the exclusive right to distribute Boots products in the Netherlands. Het Financieele Dagblad, Nederlandse ketens lonken naar Europa, 23 April 2001. 
pharmacists and assistants willing to work in the Boots stores: while the company owned 17 shops in the Netherlands, for only 10 of these establishments it had been able to find enough pharmacists and assistants. ${ }^{454}$ Furthermore, the failure of Boots in the Netherlands resulted from the fact that the number of rendered prescription drugs appeared to fall short of expectations, especially compared to the number of OTC drugs sold. The combination of a chemist's and a pharmacy seemed not to work in the Netherlands. Perhaps part of the failure of Boots can be explained by the unfamiliarity of Dutch consumers (i.e. patients) with the pharmacy department of Boots. However, it is likely that also the opposition from other pharmacists, health insurers, and physicians had an influence on the course of events. For example, some physicians send their prescriptions electronically to a limited number of pharmacies only. And in \$3.1.2 I already mentioned the case of the mail order pharmacy initiated by the health insurer Geove that was pushed out of the market by opposition from pharmacists, wholesalers and health insurers. ${ }^{455}$ The failure of Boots shows once again how difficult it is to create some competition in the heavily regulated Dutch pharmaceutical market. It is evidently insufficient to break the professional monopoly of pharmacists only partially, as long as there is still much restrictive self-regulation elsewhere in the market. ${ }^{456}$ However, I will demonstrate in $\S 7.6$ that other companies, viz. the big national and international pharmaceutical wholesale chains, have been more successful in entering the Dutch retail market.

In April 2003, less than 3 years after the chemist's chain Etos bought the Boots establishments, Etos itself opened two pharmacy departments in its stores in the Dutch city Den Bosch. In addition, so-called Drug Service outlets (Medicijnservice punten) have been opened in three other Etos stores in Den Bosch. At these outlets prescriptions can be handed in. The medicines concerned can be collected some hours later or can be posted by Etos to the address chosen by the patient. Moreover, Etos cooperates with the supermarket Albert Heijn (which is also a Ahold-daughter), of which five branches have been equipped with a Drug Service outlet. Initially, it concerns a test, but if the results are satisfactory Etos hopes to attain national coverage in the long term. Etos expects to do better than Boots, because of the more strategic locations and the fact that the brand 'Etos' is already known in the Netherlands. The company expects that the Dutch drug market will remain lucrative in the near future because of a strong increase of the ageing population. Problems in finding employees, i.e. pharmacists and pharmacist's assistants, are not expected; Etos and Albert Heijn employ flexible timetables and therefore expect to find many part-time workers. The initiative of Etos is supported by the major health insurers in Den Bosch, $\mathrm{CZ}$ and VGZ, and by the organisations of patients and consumers. The pharmacists' association KNMP disapproves of the Drug Service outlets, arguing that the safety of the drug provision and the quality of pharmaceutical care provided at these counters will be lower than the safety and the quality provided in a

De Volkskrant, Apotheker krijgt nieuwe concurrentie, 9 August, 2000.

See also infra, \$ 7.6, and Horsten (1996/1997, pp. 93-115).

This conclusion was first presented in Maks, Philipsen and Faure (2001). 
regular pharmacy. According to Etos, however, the safety is guaranteed by an electronic system of medication guidance. The Drug Service outlets are supervised by a qualified pharmacist; the distribution takes place by a chemist or a pharmacist's assistant. ${ }^{457}$

Like Boots before them, Etos is providing some kind of para-profession. Consumers have a choice between a regular pharmacy and a drug counter. The emphasis at a drug counter lies on an accessible and fast distribution; if consumers want more advice or information, they can always choose to go to a regular pharmacy. Time will tell if the Etos 'experiment' is indeed more successful than the one carried out by Boots.

\subsection{Case study 2: OPG}

OPG, in full OPG Group N.V., is the largest pharmaceutical wholesaler in the Netherlands, with a market share of about $35 \%$. Established as a cooperative in 1899 by a group of pharmacists, with the aim of purchasing medicines as cheaply as possible for all of its members, ${ }^{458}$ the profile and mission of the company have expanded in recent years. That is, in addition to its wholesale activities, the company has also successfully entered the Dutch retail market, by buying up pharmacies. In fact, the financial performance of OPG now depends to a large extent on the company's position in the retail market. OPG became a public limited liability company in January 2001 and today has operations in Poland (Orfe group: wholesale and retail activities), Belgium (the relatively small pharmaceutical wholesaler Flandria N.V.) and Norway. ${ }^{459}$ In early 2003 OPG announced plans to take over a small number of pharmacies in Belgium. ${ }^{460}$

One may wonder whether OPG, with its very strong position in the Dutch pharmaceutical market and its background as a cooperative of pharmacists, has (had) a role in preventing unwanted newcomers from entering the retail market. On the other hand, the market power of OPG may (have) be(en) important vis-à-vis the market power of the pharmaceutical industry. For these reasons OPG is an interesting case to investigate within the context of this research. Furthermore, given that OPG is not the only pharmaceutical chain that has been engaged in entering the Dutch pharmaceutical market, I will below briefly consider the most significant other (in-

Sources: <http://www.etosapotheek.nl>; De Volkskrant, Medicijn op recept bij Etos en AH, 11 December 2002; Het Financieele Dagblad, Etos ziet nog rek op drogistenschap, 27 December 2002; De Volkskrant, Drogist bevordert zichzelf tot apotheker, 29 April 2003; Etos, Etos Apotheekservice opent deuren voor publiek in 's-Hertogenbosch, press report Etos, 29 April 2003. Het Financieele Dagblad, Apothekers willen tegenwoordig meer vrije tijd, 12 March 2001. Website OPG Group: <http://www.opggroep.nl>.

460 De Financieel Economische Tijd, OPG wil apotheken overnemen in Beigiè, 15 February 2003; Het Laatste Nieuws, OPG aast op Belgische apotheken, 18 February 2002. 
ternational) pharmacy chains as well, i.e. the German pharmaceutical chain GEHE (in April 2003 renamed Celesio) and the British-French company Alliance Unichem.

In early 2001 OPG had taken over 80 pharmacies already in the Netherlands. The procedure is simple: OPG pays a take-over price to the pharmacists in question and employs him/her within its so-called Mediveen Groep. I noted in chapter 4 that this became possible only in 1999, as a result of the lifting of a legal provision that prohibited the employment of pharmacists by non-pharmacists (the old Article 15 from the Pharmaceutical Practice Decree). Pharmacists who belong to the OPG chain - or another wholesale chain such as GEHE or Alliance Unichem - do not need to worry anymore about the management of the pharmacy. Apparently many formerly selfemployed pharmacists wanted more free time and did not mind being employed, although there are also many pharmacists who rather run their own business. OPG formulated as an objective to own 150 pharmacies by the end of the year 2002. This appeared not to be unfeasible: at the end of 2001 OPG owned 117 pharmacies and in June 2002 the number had risen to 137. Considering the large number of potential acquisition candidates still 'in the pipeline' at the time, the objective was therefore comfortably within OPG's reach. ${ }^{461}$ Indeed, the Annual Report of 2002 stated a number of 153 Mediveen pharmacies. Because of the plans of the Dutch government to cut the pharmacists' rates by increasing the clawback (see $\S 4.6 .2$ ), OPG decided to temporarily stop the acquisition activities to await further developments. ${ }^{462}$

But OPG did more than just awaiting further developments: it took legal action against the government plans, just as the pharmacists' association KNMP did. In an official press release OPG stated that it

\footnotetext{
'believes that there is insubstantial support for this measure and that it has been rashly implemented. Moreover, the government has not demonstrated that the interests of those directly affected by this measure were properly taken into account in the decision-making process' toi
}

On 29 April 2003 the judge of the Trade and Industry Appeals Board (College van Beroep voor het Bedrijfsleven) granted the request of OPG and the KNMP and suspended the government measures until, at least, 1 August 2003. Naturally, the health insurers and the government were disappointed with this result. ${ }^{464}$

OPG Groep NV, Annual Report 2001, p. 5; OPG Groep NV, Halfjaarbericht 2002, p. 3.

OPG Groep NV, Annual Report 2002, pp. 7-8.

OPG Groep N.V., Legal action against clawback of purchase reimbursement for pharmaceuticals, press release OPG, 18 April 2003.

Ministerie van Volksgezondheid, Welzijn en Sport, Aanpak kortingen apothekers blijft uitgangspunt, press report Ministry of Public Health, 29 April 2004; OPG Groep N.V., Preliminary relief judge grants OPG's request for suspension of clawback, press release OPG, 29 April 2003; Het Financieele Dagblad, Rechter stopt extra afromen van apotheker, 30 April 2003; Pharmaceutisch Weekblad, Markt in beroering, vol. 138, nr. 21, 23 May 2003. 
OPG was (probably) involved as well in a little price war that broke out in May 2003. After expiration of the patent of the cholesterol reducer Zocor, a pharmaceutical specialite, the generic drug producer Genthon started to offer its unbranded cholesterol reducer simvastatine at record low prices, but Genthon was boycotted immediately by pharmacists and wholesalers. Pharmacists of course were afraid to lose the high discounts (of up to $80 \%$ ) they used to receive for cholesterol reducers in the past. Again, the health insurers and the government seemed to be left emptyhanded, and the power block of pharmacists and wholesalers seemed to be effective. Although the health insurers CZ, Menzis and VGZ announced plans to reimburse only the cheap Genthon variant of simvastatine, ${ }^{465}$ some wholesalers already cancelled orders. Moreover, Genthon is a relatively small drug producer that will never be able to serve the whole Dutch market, and other producers of simvastatine were not taking part in the 'price war'. The branch association of health insurers $\mathrm{ZN}$ wanted the Dutch Competition Authority NMa to investigate the situation and therefore filed a complaint against the pharmacists and wholesalers that exclude Genthon from delivery. Apparently, Genthon and some health insurers keep a register of those pharmacies and wholesalers that take part in the boycot (which is, unfortunately, confidential). The NMa announced that it was going to investigate the price agreements in the whole drug branch, i.e. producers, wholesalers and pharmacists. ${ }^{466}$

In $\S 3.1 .1 .2 \mathrm{I}$ already mentioned that the pharmacists and the big wholesale companies were also mixed up somehow in the failure of the very first mail order pharmacy experiment in the Netherlands, initiated by the health insurer Geové in 1992. Horsten (1996/1997), who wrote an extensive case study on the Geové mail order pharmacy, makes mention of the fact that OPG was involved again, this time by refusing to deliver products any longer to a pharmacist who was participating in this mail order experiment. The other (of the very few) fully sorted wholesalers in the Netherlands were not willing to take over the delivery either. ${ }^{467}$ It seems that OPG, together with the other fully sorted wholesalers and the KNMP (which was against the idea of mail order pharmacy) was using its market power here to sabotage any 'non-cooperative' pharmacists. It is important to put in mind that the time (i.e. 1993) the Dutch Competition Act was not yet in force.

The discussion above does not alter my belief already discussed in \$ 7.4 that chain store retailing in itself is no threat to the quality of pharmaceutical care. However, in

That is, if the physician does not specifically prescribe the original speciale Zocor and holds to that decision. In that case a pharmacist is obliged to dispense Zocor.

Sources: <http://www.zn.nl>; Trouw, Boycot goedkope medicijnen, 8 May 2003; De Volkskrant, Medicijnenoorlog toont falen overheidsbeleid, 9 May 2003; Het Financieele Dagblad, Aanklacht bij NMa tegen apothekers, 9 May 2003. In June 2003 the NMa invaded the main office of the KNMP in order to look for evidence of price agreements and boycotting of cheap drug producers: see KNMP, NMa bezoekt KNMP, press report KNMP, 4 June 2003; De Volkskrant, NMa-overval in kantoor apothekers, 6 June 2003. 
situations where wholesale chains such as OPG have market power in the wholesale market combined with a large market share in the retail market, one should be aware of any possible abuse of this market power. The investigations initiated by the NMa in May 2003, which I mentioned above, will most probably have to deal with this issue as well.

As a final note to this section, it is interesting to have a look at the development of chain retailing in the Netherlands: after all, OPG may be the biggest pharmacy chain but it is not the only company involved in buying up pharmacies. Following the UK and the USA, and in line with the trend in several other countries, the relative number of independent pharmacies in the Netherlands is going down at the expense of the number of chain outlets. In the year 2001 the number of pharmacies belonging to a chain was 380 out of a total number of public pharmacies of 1630 , which is a percentage of $23 \%{ }^{468}$ Looking at the current developments, this percentage will only increase in the coming years. The most striking targets have been reported by the German pharmaceutical company GEHE and the British-French company Alliance Unichem. GEHE was at the end of 2001 the owner of 11 pharmacies (all obtained in that year) and reported to strive for 200 to 250 pharmacies within 3 to 5 years from then. Alliance Unichem has since 2000 been the owner of all pharmacies within the 'Vier Vijzels' group. This group comprised of 27 pharmacies at the end of 2001. The target of Alliance Unichem was to have 100 pharmacies in the Dutch market within 3 years from then. In early 2003 it owned 38 pharmacies. ${ }^{469}$

\subsection{Summary}

This chapter dealt with the question whether pharmacists in the Netherlands and Belgium are actually successful rent-seekers, by means of a presentation and analysis of a number of empirical data. Also, I tried to analyse whether differences in regulation between these countries might to some extent explain the effectiveness of pharmacists' rent seeking. I considered the evolution of the number of pharmacies and pharmacists, the (relative) average income of pharmacists, and the issue of goodwill. However, acquiring exact data for the last two categories appeared to be quite difficult for various reasons, which have been described in detail in $\S 7.1$. Some parts of the analysis therefore consisted of own computations on the basis of circumstantial evidence. In addition to the indicators mentioned above, I presented two case studies (Boots and OPG) in which the rent-seeking behaviour of different parties in the Dutch pharmaceutical market is analysed. 50). $\$ 3.1 .2 .1$ ), is also part of Alliance Unichem. For more information on GEHE and AllianceUnichem, see: <http://www.gehe.de>, <http:www.celesio.com>, 〈http://www.4v.nl>, <http://www.alliance-unichem.com>. 
With respect to the number of pharmacies, there are considerable differences between the Netherlands and Belgium. In Belgium the number of pharmacies is much higher than in the Netherlands, but the effect of the establishment policy is visible in both countries. The reasons behind the establishment policy differ between the countries, however. In the Netherlands the reason behind the KNMP policy is a restriction of entry by the incumbent pharmacists to guarantee 'financially sound' pharmacies, while in Belgium the government tries to regulate the 'oversupply' of pharmacies. It follows that the number of patients per pharmacy in the Netherlands is much higher than the Belgian one. Moreover, in Belgium this number has been more or less constant (slightly decreasing at first and now slightly increasing) during the last decades, while in the Netherlands the number of patients per pharmacy is high and has always been increasing. One has the impression that the Dutch started much earlier with limiting market entry than the Belgians and that they succeeded in reducing an already small number of pharmacies even further.

The data on the average incomes of pharmacists suggest that Dutch pharmacists have higher incomes than their Belgian counterparts, although Belgian pharmacists do relatively well compared to a number of other professionals in Belgium. Obviously this difference will to a large extent be due to the average number of patients per pharmacy. The fact that Belgian pharmacists have a monopoly in the distribution of OTC drugs, whereas in the Netherlands also licensed chemists are allowed to sell OTC drugs, seems to have a much smaller effect on our income data (probably because this influences the number of pharmacies as well). However, one has to be careful with interpreting income data, since high incomes do not necessarily emanate from higher rents as a result of rent-seeking behaviour. Also, it is difficult to obtain data on the average pharmacist's income (especially concerning the Netherlands) and the data I found could not be compared with one another without making some additional assumptions.

I also considered the 'goodwill-problem'. Both in the Netherlands and in Belgium pharmacists who want to take over a pharmacy have to pay large amounts of money for goodwill. This practice shows that the license to operate a pharmacy has a real and high value (over and above the value of real estate, stocks, and such). The fact that high amounts of money have to be paid for goodwill already suggests that there are rents that can be captured by pharmacists. Although one should obviously distinguish between supra-competitive profits and high incomes resulting from, e.g. investments in training or compensation for greater responsibilities, there seems to be a problem with the goodwill paid for pharmacies in the Netherlands and in Belgium. Namely, the amounts paid for goodwill largely relate to rents resulting from protective regulation (in particular the professional monopoly analysed in chapter 6) as opposed to reimbursements for real efforts.

Due to the high prices that have to be paid for a pharmacy nowadays, many pharmacies in the Netherlands and Belgium are now taken over by wholesale chains and chemist's chains. This is in itself not a problem, because consumers are not deprived of the pharmaceutical services provided by a qualified pharmacist in a chain store. 
However, the first experiment in the Netherlands, undertaken by the British chemist's chain Boots, failed. In 1999 Boots started opening pharmacy departments in its stores as a reaction to the amendments in the Dutch law that lifted the ban on employment of pharmacists by non-pharmacists. It offered a kind of para-profession in the sense that it merely became a supplier of prescribed drugs and was less concentrated on providing a service. The eventual failure of the Boots experiment can partly be explained by the tense Dutch labour market at the time and, perhaps, partly by the unfamiliarity of Dutch drug consumers with the pharmacy departments of Boots. However, probably also the opposition from other pharmacists (non-cooperation, provisions in the Dutch Pharmacy Standards), health insurers (contracting problems) and physicians (non-cooperation, electronic prescriptions) contributed to this. The chemist's chain Etos, which bought the Boots establishments in 2001, started a similar experiment in April 2003. Time will have to tell if this is going to be a more successful one.

I also studied OPG, the biggest wholesaler in the Dutch pharmaceutical market with a market share of about $35 \%$ and also active in buying up pharmacies: at the end of 2002 OPG owned 153 pharmacies. One may wonder whether OPG, with this strong market position and a background as a cooperative of pharmacists, has had a role in preventing unwanted newcomers from the market. Indeed, OPG played a part in the failure of the very first mail order experiment in the Netherlands, by refusing to deliver products to a pharmacist who was participating in this experiment. OPG was also, together with pharmacists, successfully involved in a legal action against government plans to increase the claw-back in 2003. In addition, it is possible that OPG (again, together with pharmacists) was one of the wholesalers involved in the boycotting of Genthon, a generic drug producer that started to offer its unbranded cholesterol reducer at record low prices. In any case, one should be aware of any possible abuse of market power in situations such as this where wholesalers have market power in the wholesale market combined with a large (and increasing) market share in the retail market. The Dutch Competition Authority NMa announced in May 2003 that it was going to investigate the price agreements in the whole drug branch, after a complaint filed by the health insurers' association $\mathrm{ZN}$ against pharmacists and wholesalers. In that respect it seems necessary that also the 'power block' between pharmacists and wholesalers is investigated. 


\section{CONCLUSIONS}

Having passed through every research stage described in the beginning of this thesis I am now able to provide an answer to the central problem statement: do there exist forms of (self-)regulation in the pharmaceutical profession that increase social welfare in the economy, or is this regulation merely a result of rent-seeking behaviour? In this journey I had to combine elements from economics, law, and - as far as the investigation into the activities of pharmacists is concerned - pharmacy, and I have looked at the situation in both the Netherlands and in Belgium (with occasional comparisons with other countries and other professions).

The first stage involved an investigation of the existing relevant economic literature, in order to answer the subquestion: what does economic theory tell us about (self-) regulation in the professions? It would lead us too far afield to give an extensive answer here (for that I refer to chapter 2), but a brief summary of the results seems called for. I distinguished between the public interest approach and the private interest approach to regulation. The former looks upon regulation as a remedy for market failure, directed towards an improvement in social welfare. Most important for the case of the liberal professions is the information asymmetry argument: because many professional services, e.g. the provision of pharmaceutical care by a pharmacist, are 'experience goods' or even 'trust goods', regulation may be needed to prevent quality deterioration resulting from adverse selection. In addition, the presence of externalities may provide an argument in favour of professional regulation, as well as the moral hazard problem of demand generation (although the latter does not seem to be relevant in the case of pharmacists). The private interest approach, which has originated from the capture theory, public choice theory, and the economic theory of regulation, stresses the influence of interest groups in the formation of regulation. The basic idea of this approach is that interest groups are continually influencing political decisions in order to seek rents for themselves, which is unproductive from a social welfare point of view. After all, resources are then devoted to capturing a wealth transfer from consumers to producers. Professional associations are often small (relative to the public at large), single-issue oriented and 
well organised. These are precisely the criteria that define an interest group according to the economic literature.

Regulation should not go further (in limiting market entry or restricting competition) than is necessary to cure the prevailing market failure. The most efficient regulatory instrument(s) should be chosen, taking into account the effects of regulation on consumer surplus, producer surplus and the deadweight welfare loss. I showed in that respect that licensing and quality standards constitute a heavier interference with the market than regulation of information (supervision of advertising, mandatory information provision, certification), but are more effective in keeping low quality services from the market. Naturally, the type of regulation to be used depends very much on the specific circumstances of a market. Price fixing, especially when backed by the government, is the kind of regulation that is most restrictive of competition.

The main arguments in favour of self-regulation (as opposed to public regulation) refer to the specific knowledge of professionals, the flexibility of self-regulating agencies compared to public bodies and the lower costs of self-regulation. However, of these arguments only one is left undisputed by the private interest approach, namely the 'specific knowledge' argument. Both approaches contain plausible arguments pro and contra self-regulation. Also the formal-economic papers 1 discussed do not seem to give clear-cut arguments pro or contra self-regulation. I concluded the economic overview by stating that there may indeed be room for (self-)regulation of quality in the professions based on the arguments mentioned above, but one would like to see a guarantee of an improvement in social welfare. Therefore, the regulation of a profession should preferably be measured against EC Competition law, as defined in Article 81(3) of the EC Treaty.

The second subquestion I had to answer is the following: what national regulations and self-regulatory measures issued by professional bodies exist in the Netherlands and in Belgium with respect to the pharmaceutical profession? Before I could deal with this question I first needed to give an overview of the pharmaceutical market (production, distribution and consumption of drugs) and to analyse the evolution of the pharmacists' profession and the role and functions of a pharmacist today (details in chapter 3). Of course, the dispensing of drugs still makes up an important part of a modern pharmacist's job responsibilities, as it did decades ago. However, he/she also appears to have a number of 'new tasks' in the field of pharmaceutical care, while the tasks involved in compounding of drugs have decreased considerably. The 'new tasks' include medication control, monitoring of drug therapy, advising consumers and providing pharmacotherapeutic information and advice to physicians. Especially the last task has become very important; the first three tasks can to some extent also be performed by pharmacists' assistants under the supervision of a pharmacist. 
It has become clear from the legal analysis that the complex regulation in the Netherlands (chapter 4) and Belgium (chapter 5) has not greatly adapted to meet these new tasks. For both countries I considered, successively, the regulations regarding education, registration and title protection, establishment and takeover prices, exercise of the profession (advertising, design of the pharmacy), and prices and fees. Both countries regulate the entry into the profession through registration procedures and protect the professional monopoly of the pharmacist in the dispensing of prescription drugs. In Belgium also the sale of OTC drugs is reserved for pharmacists. Moreover, in Belgium the establishment of pharmacies is completely regulated by Royal Decrees. This is not the case in the Netherlands, where the establishment policy of the pharmacists' association KNMP is now of little importance compared to the 1980s and 1990s. In general the self-regulatory power of the KNMP, which was impressive until the beginning of the 21st century, has been decreasing in recent years, predominantly as a result of the introduction of the Competition Act in the Netherlands and its enforcement by the NMa. Until the end of 2001 the KNMP prohibited its members (over $90 \%$ of all pharmacists) to advertise their pharmacy, while in Belgium in 2003 this was still the case. In addition, strict rules concerning the design of the pharmacy and the exercise of the profession could be found in the self-regulation of the KNMP up until 2002 and can still be found in the 'deontological rules' of the Order of Pharmacists in Belgium, which apply to all pharmacists. However, these rules have come under attack in Dutch and Belgian case law, which in the Netherlands has already led to some changes in the self-regulation.

In the Netherlands and in Belgium pharmacists do not have any influence on the price of drugs and on the tariffs they may ask for their services. As a matter of fact, this is the case - at least to some extent - in all EU Member States. In the Netherlands the 'receptregelvergoeding' is a fixed amount, while in Belgium the margin of a pharmacist amounts to a percentage of the drug price. In the Netherlands there is an incentive measure to encourage the dispensing of cheaper products: under certain circumstances a Dutch pharmacist is allowed to substitute prescribed drugs by cheaper or better alternatives. A Belgian pharmacist is strictly bound by the original prescription. Considering their professional monopoly that also includes OTC drugs, Belgian pharmacists seem to be (more than their Dutch counterparts) mere sellers of drugs, while Dutch pharmacists have a more prominent role also as an advisor to physicians considering the relative importance of pharmacotherapeutic consultations in the Netherlands.

On the basis of these economic and legal frameworks I was able to carry out the qualitative and quantitative analysis. The qualitative analysis is related to the third subquestion: does the (self-)regulation of the pharmaceutical profession promote social welfare, or should it (to a lesser or greater extent) be considered as a tool in the hands of private interest groups? The answer to the first part of this subquestion is that, although I just noted that there are some public interest arguments in favour of some regulation of the quality of pharmaceutical services, a considerable number of regulations found in the Netherlands and Belgium do not promote social welfare. I explained that the fee regulation, prohibition of advertising, restrictions on the design of the 
pharmacy and the establishment policy seem to go further than would be warranted to cure a market failure (see chapter 6). Moreover, these regulations generally concentrate more on the protection of the distribution task of pharmacists, while one would actually like to see only a regulation of the quality of services. Most drugs sold in a pharmacy today are prepacked drugs anyway, because of the rise of industrially prepared medicine at the expense of magisterially prepared medicine.

Should these regulations be considered tools in the hands of private interest groups then? With respect to pharmacists, in particular the establishment policy, the prohibition of advertising and the regulation of the design of the pharmacy seem to be promulgated in their interest, at least to some extent. These are exactly those regulations that have always been formulated and enforced by the professional associations themselves (with the exception of the establishment decree in Belgium). However, the price and fee regulation may be the result of competition for regulation among different interest groups, as it probably promotes the interests of health insurers and the pharmaceutical industry as well. That is, although one could argue that normal price competition between drug producers would be more beneficial for health insurers, in the current system with regulated prices they hardly have to worry about competition with other health insurers. The pharmaceutical industry itself is apparently still able to provide large amounts of bonuses and discounts to pharmacists and hospitals.

Furthermore, it is likely that none of the involved parties (pharmacists, health insurers, the government, drug producers and consumers) benefit from regulation that links the professional monopoly of the pharmacist to the fixed fee/margin. The professional monopoly in the distribution of drugs does of course protect pharmacists from competition from other retailers such as chemists. However, the combination of this monopoly with the fixed fee/margin only encourages the mere selling of (mostly prepacked) prescription drugs, while giving no incentives at all to provide services, despite the often assumed new tasks of pharmacists in the field of pharmaceutical care. Both the public interest and private interest analysis come to this conclusion (see, again, chapter 6). Hence, my findings based on the qualitative research support the position of European Commissioner Mario Monti referred to at the very beginning of this thesis. Indeed, as Monti stated, the pharmaceutical profession is one of the oldest and most regulated professions, and I showed that the regulations have not at all adapted to the new tasks that pharmacists have.

Although pharmacists in both countries appear to have been quite successful in as far as the contents of the regulation is concerned, it is another question whether they have been successful rent seekers. Hence the fourth subquestion: is there any empirical evidence of rent-seeking behaviour by pharmacists? Because the pharmaceutical market is very different from many other markets I had to use some rather unusual techniques to estimate the effects of rent seeking by pharmacists (see chapter 7). In addition, some empirical data appeared not to be obtainable because of non-disclosure policies or non-availability, e.g. with respect to the average pharmacist's income and the goodwill paid for the take-over of a pharmacy. Some parts of my 
qualitative analysis therefore consisted necessarily of own computations on the basis of circumstantial evidence.

I showed, by presenting a number of figures, that the establishment policies of the KNMP and the Belgian government have been quite effective. From a comparative point of view, I showed that the total number of pharmacies and pharmacists in Belgium is a lot higher than in the Netherlands, whereas in the Netherlands the number of patients per pharmacy is higher. This difference can partly be explained by the fact that Belgian pharmacists also have a monopoly on OTC drugs, but it may also be explained partly by the fact that Belgian patients - apparently - expect a quick service offered by a large body of pharmacists. The data on the average incomes of pharmacists I presented suggest that Dutch pharmacists have higher incomes than their Belgian counterparts, although Belgian pharmacists do relatively well compared to a number of other professionals in Belgium. One has the impression that the Dutch started much earlier with limiting market entry than the Belgians and that they succeeded in reducing an already small number of pharmacists even further. The effects of this on the average pharmacist's income appear to have been bigger (in my rather crude estimations) than the mere fact that Dutch pharmacists do not have a monopoly on OTC drugs. Unfortunately it was not possible to distinguish between the margin on OTC drugs and the margin on prescription drugs, because the Belgian data did not allow me do to that. With respect to the amounts paid for goodwill of pharmacies, finally, I found that these are high in both countries. The fact that high amounts of money have to be paid for goodwill already suggests that there are rents that can be captured by pharmacists. More specifically, the goodwill consists of the capitalised surplus profits gained from trade benefits (bonuses and discounts) and the expected future profits on the pharmaceutical market. However, one has to be careful in interpreting these data on incomes and goodwill amounts, since high incomes and goodwill amounts do not necessarily emanate from higher rents as a result of rent seeking behaviour. One should distinguish between supra-competitive profits and high incomes resulting from investments in training or compensation for greater responsibilities. But there seems to be a problem with the goodwill paid for pharmacies in the Netherlands and Belgium, exactly because the amounts paid for goodwill largely concern rents that result from protective regulation (notably, the professional monopoly) as opposed to reimbursements for real efforts.

In addition to this presentation of empirical data, I presented two Dutch case studies dealing with Boots and OPG, respectively. The failure of Boots and the way in which power blocks of wholesalers (such as market leader OPG) and pharmacists sabotage new distribution initiatives and attempts by the government, generic drug producers (Genthon) and health insurers to decrease the costs of health care, show how difficult it is to create some competition in the heavily regulated Dutch pharmaceutical market. It appeared in particular from the Boots case that it is insufficient to break the professional monopoly of pharmacists only partially, as long as there is still much restrictive self-regulation elsewhere in the market. However, the intervention by the Dutch Competition Authority NMa in the pharmaceutical mar- 
ket in recent years has already resulted in some drastic changes in the KNMP selfregulation. In addition, the health insurers seem to be more and more willing to let go of the collective agreements with pharmacists: while in the Boots and mail order pharmacy cases they were mostly on the side of the 'incumbent' pharmacists and wholesalers, in 2003 they seem to be more and more on the side of the government (as the Genthon and claw-back cases show).

Although I found qualitative and quantitative proof for the arguments put forward by the private interest approach to regulation, the empirical question of whether Dutch and Belgian pharmacists are successful rent-seekers remains a difficult one to answer, because additional (very difficult-to-obtain) data are needed to make stronger claims. Hence, this question remains an open one that is certainly worth further research, not only with respect to the countries dealt with in this thesis but also with respect to other countries - and other professions. The studies mentioned in the introduction (and throughout some of the other chapters) commissioned by the European Commission and by the Irish Competition Authority, as well as the market investigations carried out by the Office of Fair Trading in the UK show that a lot of research into the (over)regulation of professions is still being carried out today.

The conclusions to my positive (as opposed to a normative) law and economics analysis of the regulation of pharmacists have hereby been restated. Indeed, part of the regulation seems to be a result of rent-seeking behaviour by pharmacists, and it also seems that some of the self-regulatory rules which aim at a protection of the distribution tasks should preferably be abandoned, notably those regarding advertising and the design of the pharmacy. This applies in particular to Belgium, because in the Netherlands the self-regulation has undergone some changes already, as I noted above. Other regulations do not seem to serve a public nor a private interest goal. From a normative point of view, I already noted at the end of chapter 6 that a solution to one of the main problems I came across in this thesis, i.e. the inefficiency of the current definition of the professional monopoly and its connection to the reimbursement of pharmacists, might be found in a new remuneration system for pharmacists. One should think of a remuneration system that rewards pharmacists separately for tasks performed in the field of pharmaceutical care, such as advise to physicians, and for distributional tasks. In this respect the developments in the Netherlands, where - forced by the government - health insurers are more and more becoming the directors of the drug market, generate some interesting opportunities. Health insurers could be given more possibilities to reward pharmacists for specific tasks performed, e.g. by enabling them to hire or employ pharmacists for the sole purpose of purchasing drugs, or by rewarding them for certain pre-defined pharmaceutical services provided to patients. Eventually this may lead to a further differentiation within the pharmacist's profession: some pharmacists may choose to specialise more in service, while others may choose to specialise in distribution tasks, e.g. under the authority of health insurers. More differentiation between service-oriented pharmacies on the one hand and pharmacies such as those of Boots 
Chapter 8

and Etos specialised in the quick distribution (para-professions) on the other hand will most probably be the result. 



\section{SAMENVATTING}

\section{Hoofdstuk 1: Inleiding}

In dit proefschrift staan de zogenaamde 'vrije beroepen' centraal, waartoe bijvoorbeeld advocaten, architecten, accountants, artsen en apothekers behoren. Deze beroepen worden gekenmerkt door een hoge graad van regulering, die niet alleen door de overheid wordt opgesteld, maar ook door de beroepsgroepen zelf via zelfregulering. Gedurende de laatste jaren heeft de (publieke en zelf-) regulering van het vrije beroep steeds meer aandacht gekregen van de politiek, d.w.z. regulerende instanties en mededingingsautoriteiten en als gevolg daarvan ook van juristen en de media. Zo is de Europese Commissie in 2003 een onderzoek begonnen naar de regulering van het vrije beroep in de EU-lidstaten, terwijl ook in het Verenigd Koninkrijk en in Ierland uitgebreide rapporten zijn verschenen over het onderwerp, geschreven in opdracht van de respectievelijke mededingingsautoriteiten. In Nederland heeft het onderwerp veel aandacht gekregen in het kader van de zogenaamde MDWprojecten (Marktwerking, Deregulering en Wetgevingskwaliteit) en heeft de Nederlandse Mededingingsautoriteit NMa meerdere zaken behandeld betreffende concurrentiebeperkende zelfregulering in de vrije beroepen.

Enerzijds kan een hoge mate van regulering de toegang tot het beroep en de concurrentie tussen beroepsbeoefenaren beperken; anderzijds zou deze regulering nodig kunnen zijn om de kwaliteit van de dienstverlening te waarborgen of te verbeteren. Omdat beroepsgroepen in het algemeen niet onafhankelijk zijn van de belangen die zij reguleren, is het bovendien interessant om de effecten van zelfregulering op de sociale welvaart te analyseren. Daartoe is in dit proefschrift het apothekersberoep in Nederland en België bestudeerd. Echter, de conclusies gaan verder dan de regulering van Nederlandse en Belgische apothekers alleen, omdat zij tot op zekere hoogte ook van toepassing zijn op andere beroepen en op andere landen. De vraag die centraal staat in dit proefschrift is de volgende: zijn er vormen van (zelf)regulering in de apothekersmarkt die de maatschappelijke welvaart in de economie verhogen, of is deze regulering vooral een resultaat van 'rent seeking' gedrag? Om tot een antwoord op deze vraag te komen worden vier subvragen gedefinieerd. 


\section{Hoofdstuk 2: Een economische analyse van de regulering van de vrije beroepen}

De eerste van deze vier subvragen betreft een economische analyse van (zelf-) regulering, ofwel: wat kunnen we leren van de bestaande economische theorieën over regulering? Daarvoor moeten de public interest en private interest benadering van regulering onderzocht worden. De public interest benadering van regulering beschrijft hoe (zelf-) regulering zou kunnen dienen als een correctie voor marktfalen. Het reguleren van marktfalen beoogt te leiden tot verhoging van de maatschappelijke welvaart. Vier vormen van marktfalen worden benadrukt in de economische literatuur: een gebrek aan concurrentie, informatieproblemen (averechtse selectie, moreel risico, begrensde rationaliteit), externe effecten en publieke goederen. Voor de vrije beroepen lijkt vooral informatieassymetrie tussen dienstverlener en klant een belangrijk argument te zijn. Omdat de meeste professionele diensten 'ervaringsgoederen' of 'vertrouwensgoederen' zijn, zou regulering nodig kunnen zijn om achteruitgang van de kwaliteit (als gevolg van averechtse selectie) zoals voorspeld door Akerlof (1970) tegen te gaan. Ook het moreel risico probleem van vraagontwikkeling (hetgeen optreedt als een beroepsbeoefenaar diensten verleent die de consument niet gewild zou hebben als hij of zij volledige informatie had gehad) en de aanwezigheid van negatieve externe effecten zouden aanleidingen kunnen zijn om te interveniëren in de markt.

De private interest benadering is afgeleid van drie economische theorieen die alle de opvatting hebben dat de rol van belangengroepen in de formulering van regulering erg groot is. Deze theorieën zijn de capture theory, (elementen uit) public choice en de economic theory of regulation van Stigler (1971). Deze theorieën hebben als overeenkomst dat zij alle suggereren dat regulering niet alleen een antwoord is op marktfalen (of zelfs helemaal niet), maar ook een resultaat van rent-seeking gedrag door belangengroepen die in staat zijn om de regelmakers te beïnvloeden. Aanhangers van de private interest benadering beweren dat belangengroepen continu bezig zijn met het beïnvloeden van politieke besluiten, met het oogpunt om zelf winsten, ofwel rents, te behalen. Rent seeking is volgens Olson (1965) het meest succesvol als een groep relatief klein is, haar belangen zich toespitsen op een heel specifiek onderwerp en zij goed is georganiseerd. Organisaties van vrije beroepsbeoefenaren lijken in het algemeen aan deze criteria te voldoen.

Daarnaast wordt in hoofdstuk 2 een aantal vormen van kwaliteitsregulering geanalyseerd, in oplopende mate van ingrijpen in het marktproces. Achtereenvolgens worden de volgende instrumenten besproken: informatievoorziening en de regulering van reclame, kwaliteitsstandaarden en licenties (vergunningen) en certificaten. Uit de economische analyse van deze vormen van regulering wordt onder meer duidelijk dat, hoe verder een regulering ingrijpt in het marktproces, hoe groter de kans wordt dat regulerend ingrijpen naast algemene welvaartsdoeleinden ook private belangen zal dienen. Vervolgens staat het onderwerp zelfregulering centraal. De hoofdargumenten voor zelfregulering werden reeds gepresenteerd in een artikel van Miller (1985). Hij verwees naar de specifieke kennis waarover vrije beroepsbeoefenaren beschikken, de flexibiliteit van zelfregulerende autoriteiten ten opzichte 
van de overheid en de lagere kosten van zelfregulering. Echter, de private interest benadering geeft een aantal tegenargumenten. Immers, juist omdat beroepsbeoefenaren lijken te voldoen aan de criteria voor belangengroepen, ontberen zij prikkels om kwaliteitsregulering door te voeren en te controleren. Alleen het argument van specifieke kennis blift onbetwist. Beide benaderingen hebben plausibele argumenten ten opzichte van zelfregulering. Helaas is de mathematisch-economische literatuur die poogt zelfregulering te modelleren nog vrij summier. Deze literatuur geeft bovendien ook geen eenduidige argumenten voor of tegen zelfregulering. Empirische studies naar de voors en tegens van zelfregulering lijken daarom noodzakelijk.

Men kan dus concluderen dat in sommige markten van professionele dienstverlening er inderdaad enige ruimte zou kunnen zijn voor (zelf-) regulering van de kwaliteit, maar er dient een garantie te zijn van een welvaartsverbetering. In dat opzicht voorziet Artikel 81(3) van het EG-mededingingsrecht, waarin de voorwaarden voor vrijstelling van een mededingingsbeperkende overeenkomst opgesomd worden, in een bruikbaar schema. De regulering van een vrij beroep zou getoetst kunnen worden aan de hand van dit schema.

\section{Hoofdstuk 3: De farmaceutische markt}

De tweede subvraag, welke behandeld wordt in de hoofstukken $3 \mathrm{t} / \mathrm{m} 5$, is: hoe zijn de Nederlandse en Belgische apothekersmarkt gereguleerd? Om deze vraag te kunnen beantwoorden is het noodzakelijk eerst een inleiding te geven in de structuur van de farmaceutische markt, welke gekenmerkt wordt door een groot aantal marktdeelnemers die allemaal in meer of mindere mate met elkaar in contact staan: de farmaceutische industrie, groothandels, artsen (huisartsen en specialisten), apothekers, consumenten (patiënten), de overheid en zorgverkeraars. Figuur 3.1 geeft de onderlinge relaties weer. Daarna worden in hoofdstuk 3 achtereenvolgens de productie, distributie en consumptie van geneesmiddelen besproken. Wat betreft de productie van geneesmiddelen onderscheiden we verschillende soorten geneesmiddelen: merkgeneesmiddelen (specialités), parallelimport, generieke geneesmiddelen en apotheekbereidingen. Bovendien kunnen geneesmiddelen worden opgedeeld in receptgeneesmiddelen (voorgeschreven door een huisarts of specialist en alleen verkrijgbaar bij een apotheker of apotheekhoudend huisarts) en OTC, ofwel zelfzorggeneesmiddelen. In België zijn OTC geneesmiddelen alleen in de apotheek verkrijgbaar, terwijl deze in Nederland ook in (gelicenseerde) drogisterijen of drogisterij-afdelingen in supermarkten verkrijgbaar zijn. De onderverdeling in soorten geneesmiddelen is grafisch uitgebeeld in figuur 3.2. De prijs van receptgeneesmiddelen alsmede de vergoeding door zorgverzekeraars zijn zwaar gereguleerd, zowel in Nederland als in België.

Wat betreft de distributie van geneesmiddelen, dient een onderscheid te worden gemaakt tussen het groothandelskanaal en de detailhandel. De groothandels vormen de link tussen de farmaceutische industrie en de detailhandel. De detailhandel voor receptgeneesmiddelen bestaat uit de intramurale markt (via ziekenhuisapo- 
theken) en de extramurale markt (via openbare apotheken en apotheekhoudend huisartsen). Relatief nieuw zijn de internetapotheek en de postorderapotheek.

De consumptie van receptgeneesmiddelen verschilt van die van 'normale' goederen. De prijsgevoeligheid is relatief laag omdat consumenten niet de gehele prijs van het geneesmiddel hoeven te betalen (vanwege vergoeding door zorgverzekeraars). Bovendien kiezen patiënten over het algemeen hun medicijnen niet zelf, omdat zij onvoldoende kennis hebben over geneesmiddelen om mee te kunnen beslissen over de benodigde therapie. Echter, de invloed van de consument op het voorschrijfgedrag van de arts is in de afgelopen jaren enigszins toegenomen door de opkomst van patiëntenorganisaties en door de toename in informatie die verkrijgbaar is via internet. In Nederland is het percentage 'diagnose met prescriptie' lager dan in België.

In hoofdstuk 3 wordt ook de ontwikkeling van het apothekersberoep gepresenteerd. Volgens Van der Mijn (1989) hebben sinds de eerste helft van de vorige eeuw drie gebeurtenissen een grote invloed gehad op het apothekersberoep: de opkomst van het industrieel vervaardigde medicijn ten koste van de eigen bereidingen, de toenemende complexiteit van de geneesmiddelenmarkt en de differentiatie in de uitoefening van het beroep. De rol van de openbare apotheker is hierdoor behoorlijk veranderd. De moderne openbare apotheker heeft een aantal nieuwe taken gekregen op het gebied van farmaceutische zorg, terwijl zijn/haar taken in de bereiding van geneesmiddelen aanzienlijk zijn afgenomen. Distributie (verkoop) van geneesmiddelen vormt nog steeds een belangrijk onderdeel van het takenpakket van een apotheker.

De hiervoor bedoelde nieuwe taken op het gebied van farmaceutische zorg zijn medicatiebewaking, therapiebewaking, het geven van voorlichting aan de gebruiker en het verstrekken van farmacotherapeutische informatie en adviezen aan de arts. Vooral dit laatste is erg belangrijk geworden; de eerste drie taken kunnen tot op zekere hoogte ook uitgevoerd worden door apothekersassistenten onder toezicht van een apotheker.

\section{Hoofdstuk 4: De regulering van apothekers in Nederland}

Het regulerend kader van de Nederlandse apothekersmarkt bestaat uit publieke regulering (Wet op de Geneesmiddelenvoorziening, Besluit Uitoefening Artsenijbereidkunst, Wet op de Beroepen in de Individuele Gezondheidszorg en verschillende bepalingen met betrekking tot prijzen en vergoedingen) en zelfregulering opgesteld door de Nederlandse apothekersvereniging KNMP. De zelfregulering anno 2003 bestaat uit de (nieuwe) Nederlandse Apotheek Norm van 2002, de Beroepscode en het Professioneel Statuut. Ook is er een KNMP vestigingsadviesbeleid, maar in de praktijk is deze tekst nauwelijks relevant meer. Een zeer groot gedeelte van de apothekers is lid van de KNMP, dus het bereik van de zelfregulering is erg groot.

Er zijn geen buitensporige restricties betreffende de opleiding tot apotheker in $\mathrm{Ne}-$ derland. De toegang tot het beroep wordt geregeld door een dubbel registratiesys- 
teem. Een apotheker met het juiste diploma moet zich inschrijven in het register van de regionale Inspectie voor de Gezondheidszorg en in het titelregister van de Wet op de Beroepen in de Individuele Gezondheidszorg. Het bereiden en afleveren van geneesmiddelen wordt beschermd door de Wet op de Geneesmiddelenvoorziening. Alleen apothekers - en onder bepaalde voorwaarden apotheekhoudende huisartsen - mogen receptgeneesmiddelen afleveren. Zij hebben derhalve een domeinmonopolie in de extramurale levering van geneesmiddelen op recept. OTC geneesmiddelen mogen in Nederland ook verkocht worden door gelicenseerde drogisten. Voor elk afgeleverd receptgeneesmiddel ontvangen apothekers een vast bedrag: de zogenaamde receptregelvergoeding. Tot het einde van de jaren negentig waren openbare apothekers geheel beschermd tegen concurrentie van zorgverzekeraars, ziekenhuisapothekers en ketens van groothandels en drogisten. Echter, een aantal concurrentiebeperkingen, dat bij wet bepaald was, zoals een verbod op loondienst en een verbod op extramurale levering door ziekenhuisapothekers, is inmiddels opgeheven door de overheid.

De vestiging van apotheken wordt al lang gereguleerd door de KNMP: tussen 1975 en 1987 in de vorm van een privaat vestigingsbeleid en vanaf 1987 in de vorm van een vestigingsadviesbeleid. Volgens dit vestigingsadviesbeleid moet een apotheek een minimum aantal prescripties hebben (vroeger was dit nog een minimum aantal patiënten) om 'bedrijfseconomisch haalbaar', ofwel levensvatbaar, te zijn. Hoewel strikt juridisch bekeken de KNMP nooit heeft kunnen verhinderen dat niet-leden zich vestigen, hebben de vestigingsregels in de praktijk een grote invloed gehad op de Nederlandse markt. Ten eerste natuurlijk omdat KNMP-leden gebonden waren aan deze regels. Net zo belangijk is echter het feit dat de medewerkersovereenkomsten tussen zorgverzekeraars en apothekers, die een essentiële voorwaarde vormen voor overleven in de Nederlandse apothekersmarkt, gebaseerd waren op het KNMP vestigingsadviesbeleid. Hoewel collectieve onderhandelingen expliciet verboden zijn door de Nederlandse Mededingingsautoriteit $\mathrm{NMa}$, bevatten veel medewerkersovereenkomsten tegenwoordig nog steeds bepalingen die zijn gebaseerd op de KNMP-bepalingen aangaande de bedrijfseconomische haalbaarheid van een apotheek.

Naast de vestiging van apotheken, legde de zelfregulering van de KNMP tot voor kort ook restricties op met betrekking tot het adverteren voor de eigen praktijk en de concurrentie tussen apothekers. Deze restricties werden opgeheven in 2001, toen de KNMP gedragsregels werden ingetrokken. Op papier zijn er nu geen advertentiebeperkingen meer. Daarnaast werden drie bepalingen van de Nederlandse Apotheek Norm gewijzigd, die eisen stelden ten aanzien van de inrichting en toegankelijkheid van een apotheek. Deze veranderingen in de zelfregulering zijn in hoge mate een resultaat van het ingrijpen in de farmaceutische markt door de NMa op basis van de Mededingingswet van 1998.

Er zijn bijna geen mogelijkheden voor apothekers in Nederland om te concurreren in prijs. Geneesmiddelenprijzen worden gereguleerd door de overheid, met name via de Wet Geneesmiddelenprijzen en het Geneesmiddelenvergoedingssysteem. De 
prijzen worden vastgelegd in een prijslijst, genaamd de taxe. Het gevolg is dat de enige prijsconcurrentie die zich voordoet in de geneesmiddelenmarkt, concurrentie is in de vorm van kortingen en bonussen verstrekt door de farmaceutische industrie en groothandels aan apothekers. De overheid wil dat deze bonussen en kortingen terugvloeien naar de gezondheidszorg en introduceerde daarom het zogenaamde 'claw back' systeem in de jaren negentig. Dit houdt in dat de vergoeding die betaald wordt door zorgverzekeraars aan apothekers voor een afgeleverd geneesmiddel, welke is gebaseerd op de taxeprijzen, niet de volledige prijs is: een percentage (de 'claw back') wordt van deze taxeprijs afgetrokken. Het debat rond bonussen en kortingen is vandaag de dag nog steeds gaande.

\section{Hoofdstuk 5: De regulering van apothekers in België}

Ook Belgische apothekers worden zowel door de overheid als door de beroepsgroep zelf gereguleerd. Eerstgenoemde categorie bestaat onder meer uit het Koninklijk Besluit nr. 78 betreffende de uitoefening van de gezondheidszorgberoepen, het Koninklijk Besluit nr. 80 betreffende de Orde der Apothekers en de Koninklijke Besluiten aangaande het toezicht op de vestiging van apotheken en de overnameprijs van apotheken. Ook zijn er verschillende regels betreffende prijzen en vergoedingen. De zelfregulering bestaat voornamelijk uit de deontologische regels van de Orde der Apothekers. Naast de Orde is er een tweede nationale apothekersvereniging in België, de APB, welke zich vooral bezighoudt met lobbyen en informatieverstrekking.

Wat betreft de opleiding tot apotheker zijn er geen concurrentiebeperkende regels. Echter, het domeinmonopolie van de apotheker in het bereiden en afleveren van geneesmiddelen, inclusief OTC geneesmiddelen, wordt beschermd door regulering. Om actief te kunnen zijn als apotheker dient men zich eerst te registreren bij de Geneeskundige Commissie van de provincie waar men zich wil vestigen en bij de Orde der Apothekers. Het is zeer moeilijk voor startende apothekers om een plaats in de markt te veroveren. Dit is niet alleen een gevolg van hoge overnameprijzen (ondanks regulering van de overnameprijs door het $\mathrm{KB}$ van 13-4-1977), maar ook van het moratorium dat is opgenomen in de vestigingswet. Deze vestigingswet, het $\mathrm{KB}$ van 25-9-1974, bevatte voorheen reeds strikte criteria betreffende bevolkingsgrootte en de minimum afstand tot andere apotheken.

De deontologische regels van de Orde der Apothekers bevatten bepalingen die het adverteren voor de eigen praktijk beperken en die instructies opleggen voor de inrichting van een apotheek en de etalage. Volgens het Belgische Hof van Cassatie mag adverteren alleen verboden worden als het de eer en waardigheid van het beroep in gevaar brengt. Echter, hoewel de meeste deontologische regels reeds tientallen jaren geleden geformuleerd werden, zijn deze tot 2003 nog nauwelijks veranderd.

Geneesmiddelenprijzen, alsmede de marges voor groothandels en apothekers, worden volledig door de overheid bepaald door middel van verschillende Ministeriële 
en Koninklijke Besluiten. Apothekers hebben weinig mogelijkheden om te concurreren in prijs, omdat geneesmiddelenprijzen wettelijk vastgelegd zijn. De vergoeding door de mutualiteiten (de Belgische zorgverzekeraars) wordt gereguleerd door het RIZIV, het Rijksinstituut voor Ziekte- en Invaliditeitsverzekering. De almaar stijgende geneesmiddelenprijzen leveren problemen op voor de verzekering van de gezondheidszorg in België (zoals in vele andere Europese landen, waaronder Nederland). Een bijkomend probleem voor het RIZIV is bovendien dat het bedrag van de eigen bijdragen, het zogenaamde 'remgeld', vast ligt, zodat de stijgingen in de geneesmiddelenprijzen het budget voor geneesmiddelen verder onder druk zetten.

\section{Hoofdstuk 6: Een economische analyse van de regulering in Nederland en België}

De derde subvraag heeft betrekking op een kwalitatieve analyse van de regulering: bevordert de (zelf-) regulering van de apothekersmarkt de mantschappelijke welvaart, of moet deze (in meer of mindere mate) beschouwd worden als een instrument in de handen van belangengroepen? Een public interest analyse van de Belgische en Nederlandse regulering laat zien dat, hoewel er argumenten zijn voor enige regulering van de kwaliteit van farmaceutische diensten, een gedeelte van de bestaande regulering zeker niet in het algemeen belang is. De regulering van de tarieven, het verbod op reclame, de voorschriften omtrent de inrichting van de apotheek en het vestigingsbeleid lijken alle verder te gaan dan nodig is om marktfalen te corrigeren. Dit komt overeen met de voorspelling in de literatuur dat een beroepsgroep zal proberen om monopoliewinsten te behalen via regulering die hen beschermd tegen concurrentie.

Hoewel de regulering tot op zekere hoogte in het belang van apothekers zelf is opgesteld, is het ook aannemelijk dat bepaalde regels, zoals de prijsregulering, het resultaat zijn van concurrentie tussen verschillende belangengroepen. Prijsregulering zal waarschijnlijk ook de belangen van zorgverzekeraars en de farmaceutische industrie dienen. D.w.z., hoewel men kan beweren dat normale prijsconcurrentie tussen producenten van geneesmiddelen gunstiger zou zijn voor zorgverzekeraars, zullen zij zich in het huidige systeem van gereguleerde prijzen nauwelijks zorgen hoeven te maken over concurrentie met andere zorgverzekeraars. Bovendien is de farmaceutische industrie ondanks de gereguleerde prijzen blijkbaar nog steeds in staat om hoge bedragen aan bonussen en kortingen te verlenen aan apothekers en ziekenhuizen. Het is zeer moeilijk vast te stellen wie nu eigenlijk profiteert van een dergelijke regulering.

Verder is het onwaarschijnlijk dat een van de betrokken partijen (apothekers, zorgverzekeraars, de overheid, de farmaceutische industrie en consumenten) profitereert van de huidige regulering die het domeinmonopolie van de apotheker koppelt aan de receptregelvergoeding (Nederland) en de apothekersmarge (België). Deze koppeling moedigt slechts de verkoop van receptgeneesmiddelen aan, terwijl het geen enkele prikkel geeft aan apothekers om diensten te verlenen, dit ondanks de veronderstelde nieuwe taken van apothekers op het gebied van 'farmaceutische zorg' en ondanks het feit dat de meeste geneesmiddelen op de markt tegenwoordig voorverpakt zijn. Zowel de public interest analyse als de private interest analyse in 
hoofdstuk 6 komen tot deze conclusie, omdat tegenwoordig noch het publiek (de consument), noch de gereguleerde partijen baat lijken te vinden bij deze ouderwetse regulering. Een oplossing zou gevonden kunnen worden in de introductie van een nieuw vergoedingssysteem voor apothekers dat strikt onderscheid maakt tussen distributietaken (inkooptaken) en zorgtaken.

\section{Hoofdstuk 7: Een empirische en vergelijkende analyse}

In dit hoofdstuk wordt de vierde en laatste subvraag behandeld: is er enig empirisch bewijs van rent-seeking gedrag door apothekers? Hierbij is het tevens zinvol om te bekijken of verschillen in regulering tussen Nederland en België leiden tot verschillen in de effectiviteit van rent seeking door apothekers. Hiervoor beschouw ik het aantal apotheken en apothekers, het (relatieve) gemiddelde inkomen van apothekers, en de goodwill betaald bij de overname van een apotheek. Echter, het verkrijgen van gegevens omtrent inkomens en overnameprijzen blijkt behoorlijk lastig te zijn: enerzijds worden sommige gegevens niet openbaar gemaakt of wordt geclaimd dat bepaalde cijfers niet beschikbaar zijn, terwijl anderzijds informatiebronnen elkaar behoorlijk kunnen tegenspreken (een voorbeeld hiervan zijn de enorme verschillen in de schattingen van de bonussen en kortingen in Nederland). De analyse bestaat daarom noodzakelijkerwijs gedeeltelijk uit indirect bewijs. In aanvulling op de bovengenoemde incidatoren worden daarom ook twee casestudies gepresenteerd, respectievelijk betreffende Boots en OPG.

Wat betreft het aantal apotheken zijn er aanzienlijke verschillen tussen Nederland en België. Hoewel in België het aantal apothekers veel hoger is dan in Nederland, zijn de effecten van het vestigingsbeleid door de jaren heen in beide landen zichtbaar. De redenen achter het vestigingsbeleid verschillen echter: in Nederland is de reden voor het KNMP-beleid een beperking van toetreders door zittende apothekers om financieel haalbare apotheken te garanderen, terwijl in België de overheid het 'overaanbod' van apotheken wil reguleren. Het aantal patiënten per apotheek is in Nederland veel hoger dan in België. Bovendien is dit aantal in België min of meer constant gebleven gedurende de laatste decennia, terwijl in Nederland dit aantal hoog is en steeds is blijven stijgen. Het lijkt erop dat de Nederlandse apothekers eerder begonnen zijn met het beperken van de markttoegang dan hun Belgische collegae en dat zij erin geslaagd zijn om een reeds klein aantal apotheken verder te beperken.

De gegevens over gemiddelde inkomens van apothekers die gepresenteerd worden in hoofdstuk 7 (welke gedeeltelijk zijn gebaseerd op eigen berekeningen) suggereren dat Nederlandse apothekers hogere inkomens genereren dan Belgische, hoewel in België apothekers het relatief goed doen qua inkomen ten opzichte van een aantal andere vrije beroepen. Dit verschil zal voor een groot deel verklaard kunnen worden door het gemiddeld aantal patiënten per apotheek. Het feit dat Belgische apothekers een monopolie op OTC geneesmiddelen hebben, terwijl in Nederland ook gelicenseerde drogisten deze producten mogen verkopen, lijkt een veel kleiner effect op de inkomensgegevens te hebben (waarschijnlijk omdat dit ook het aantal 
apotheken beïnvloedt). Men moet echter voorzichtig zijn met het interpreteren van inkomensgegevens, aangezien hoge inkomens niet noodzakelijkerwijs voortvloeien uit hoge winsten als gevolg van rent seeking gedrag, maar tot op zekere hoogte een gevolg kunnen zijn van investeringen in een lange opleiding of een compensatie voor grote verantwoordelijkheden.

In Nederland en België worden hoge bedragen voor goodwill betaald bij de overname van een apotheek. Dit laat zien dat de licentie om een apotheek te houden een reële en hoge waarde heeft (bovenop de waarde van het onroerend goed, de voorraden en dergelijke) en dat er sprake is van rents die kunnen worden bemachtigd door apothekers. Hoewel er natuurlijk onderscheid dient te worden gemaakt tussen bovenmatige winsten enerzijds en hoge inkomens die het resultaat zijn van investeringen in onderwijs of grote verantwoordelijkheden anderzijds, is er een probleem met de goodwill die betaald wordt voor Nederlandse en Belgische apotheken. Het betreft hier namelijk winsten die voortkomen uit beschermende regulering (met name het domeinmonopolie zoals geanalyseerd in hoofdstuk 6) in tegenstelling tot vergoedingen voor reële inspanningen.

Vanwege de hoge prijzen die betaald moeten worden voor een apotheek, worden veel apotheken in Nederland en België tegenwoordig overgenomen door groothandels- en drogisterijketens. Dat is op zich geen probleem, omdat consumenten hierdoor niet onthouden worden van farmaceutische dienstverlening door gekwalificeerde apothekers. Toch mislukte het eerste experiment, dat was opgezet door de Britse drogisterijketen Boots. In 1999 begon Boots met het openen van apotheekafdelingen in haar winkels als een reactie op de wijziging in de Nederlandse wet die het verbod op loondienst schrapte. De onderneming bood een soort 'para-professie' aan doordat zij zich specialiseerde in het aanbieden van receptgeneesmiddelen en niet of nauwelijks in het verlenen van diensten. De uiteindelijke mislukking van het experiment van Boots kan gedeeltelijk verklaard worden door de gespannen Nederlandse arbeidsmarkt toentertijd en wellicht ook door de onbekendheid van de apotheekafdelingen van Boots bij het Nederlandse publiek. Echter, de analyse in hoofdstuk 7 laat zien dat waarschijnlijk ook de tegenwerking door andere apothekers (het niet willen samenwerken, bepalingen in de Nederlandse Apotheek Norm), zorgverzekeraars (problemen met medewerkersovereenkomsten) en artsen (het niet willen samenwerken, elektronische voorschriften) hieraan bijdroeg. De drogisterijketen Etos, die de Boots-vestigingen in 2001 gekocht heeft, is een vergelijkbaar experiment begonnen in 2003. De tijd zal moeten uitwijzen of dit project meer succes heeft.

De tweede casestudy betreft OPG. Dit is de grootste Nederlandse groothandel in medicijnen met een marktaandeel van rond de $35 \%$, die bovendien actief is in het opkopen van apotheken. Eind 2002 beheerde OPG reeds 153 apotheken. Men kan zich afvragen of OPG met haar sterke marktpositie en een achtergrond als coöperatie van apothekers een rol heeft gespeeld in het weren van ongewenste nieuwkomers op de markt. Inderdaad heeft OPG een aandeel gehad in het mislukken van de eerste postorderapotheek in Nederland, doordat zij weigerde te leveren aan een 
apotheker die deelnam aan dit project. OPG was ook - samen met apothekers - betrokken bij juridische stappen die werden ondernomen tegen de overheidsplannen om de 'claw back' te verhogen in 2003. Verder is het mogelijk dat OPG (opnieuw samen met apothekers) een van de anonieme groothandels was die betrokken waren bij de boycot van Genthon, een fabrikant van generische medicijnen die zijn cholesterolverlagers tegen zeer lage prijzen aanbood. Men moet zich tenminste bewust zijn van eventueel misbruik van marktmacht in situaties zoals deze, waarin groothandelaren marktmacht in de groothandelsmarkt combineren met een groot (en stijgend) marktaandeel in de detailhandel. De Nederlandse Mededingingsautoriteit NMa kondigde in mei 2003 aan dat zij de prijsafspraken in de gehele geneesmiddelensector onder de loep zou nemen, als gevolg van een klacht die werd ingediend tegen apothekers en groothandelaren door Zorgverzekeraars Nederland. Het lijkt hierbij noodzakelijk om ook het machtsblok van apothekers en groothandels nader te onderzoeken.

\section{Conclusies}

De centrale probleemstelling, zijn er vormen van (zelf)regulering in de apothekersmarkt die de maatschappelijke welvaart in de economie verhogen, of is deze regulering vooral een resultant van 'rent seeking' gedrag, is in het voorgaande uitgebreid beantwoord aan de hand van de vier subvragen. Hoewel er kwalitatief en kwantitatief bewijs voor de argumenten van de private interest benadering van regulering gevonden werd, blijft de empirische vraag of Nederlandse en Belgische apothekers succesvolle rent seekers zijn moeilijk te beantwoorden, aangezien additionele (en vaak moeilijk te verkrijgen) gegevens nodig zijn om hardere claims te maken. Deze vraag blijft dus gedeeltelijk onbeantwoord en is zeker verder onderzoek waard, niet alleen met betrekking tot de landen die in dit proefschrift behandeld zijn, maar ook met betrekking tot andere landen - en andere beroepen. De studie door de Europese Commissie en de rapporten in opdracht van de Ierse mededingingsautoriteit en de Britse OFT geven al aan dat er vandaag de dag nog veel onderzoek gedaan wordt naar de (over)regulering in het vrije beroep.

De conclusie van de positieve (in tegenstelling tot een normatieve) rechtseconomische analyse van de regulering van apothekers is derhalve dat een gedeelte van de regulering inderdaad een resultaat van rent-seeking gedrag door apothekers lijkt te zijn, terwijl het bovendien erop lijkt dat enkele bepalingen uit de zelfregulering beter geschrapt kunnen worden. Het betreft de bepalingen die zich richten op een bescherming van de distributietaken, met name de regels over reclame en inrichting van de apotheek, en dan vooral in België, aangezien in Nederland de zelfregulering recentelijk al onderhevig is geweest aan een aantal wijzigingen. Verder zijn er regels die noch een public interest noch een private interest doel lijken te dienen. Vanuit normatief oogpunt kan over de inefficiëntie van de huidige definitie van het domeinmonopolie van de apotheker en de koppeling hiervan aan de vergoeding voor de apotheker, gezegd worden dat een oplossing gevonden zou kunnen worden in een nieuw vergoedingssysteem. Hierbij moet gedacht worden aan een vergoedingssysteem dat apothekers apart beloont voor taken op het gebied van de farmaceuti- 
sche zorg - zoals advies aan artsen - en voor distributietaken. In dat opzicht bieden de huidige ontwikkelingen in Nederland, waar zorgverzekeraars meer en meer gedwongen worden door de overheid om de regisseurs van de zorg te worden, interessante mogelijkheden. Zorgverzekeraars zouden nog meer opties moeten hebben om apothekers gericht te belonen voor het uitvoeren van bepaalde taken, bijvoorbeeld door apothekers in te huren of in dienst te nemen voor de inkoop van medicijnen, of door hen specifiek te belonen voor bepaalde vooraf gedefinieerde farmaceutische diensten aan patiënten. Dit zal uiteindelijk (kunnen) leiden tot een verdere differentiatie binnen het apothekersberoep: sommige apothekers kunnen ervoor kiezen om zich te specialiseren in dienstverlening, terwijl anderen zich zouden kunnen specialiseren in distributietaken, bijvoorbeeld in opdracht van zorgverzekeraars. Meer differentiatie tussen zorggerichte apotheken enerzijds en apotheken zoals Boots en Etos, die gespecialiseerd zijn in een snelle distributie (para-professies), anderzijds, zal hoogstwaarschijnlijk het resultaat zijn. 



\title{
BIBLIOGRAPHY
}

\section{Aiginger e.a. 1998}

Aiginger, K., Mueller, D.C. and C. Weiss, 'Objectives, Topics and Methods in Industrial Organization During the Nineties: Results from a survey', International Journal of Industrial Organization, 16, 1998, 799-830

\author{
Akerlof 1970 \\ Akerlof, G., 'The Market for Lemons: Quality, Uncertainty and the Market Mecha- \\ nism', Quarterly Journal of Economics, 85, 1970, pp. 488-500.
}

Andrews 2002

Andrews, P., 'Self-Regulation by Professions - The Approach Under E.U. and U.S. Competition Rules', European Competition Law Review, 6, 2002, pp. 281-285.

\section{APB 1994}

APB (Algemene Pharmaceutische Bond), APB Statuten, Brussel, 1994.

Arno 2001-2002

Arno, P., 'Overgangsrecht van de aanpassing van de strafrechtelijke geldboeten aan de euro', Case note by correctionele rechtbank Brugge, 15 January 2002, Rechtskundig Weekblad, 2001-2002, pp. 996-999.

\section{Arrow 1963}

Arrow, K., 'Uncertainty and the Welfare Economics of Medical Care', American Economic Review, 1963, pp. 941-973.

\section{AVGI 1998}

AVGI (Algemene Vereniging van de Geneesmiddelenindustrie), De Geneesmiddelenindustrie in België: Economische bijdrage en relaties met de overheid, Brussel, 1998.

\section{AVGI 2002}

AVGI (Algemene Vereniging van de Geneesmiddelenindustrie), Key Figures 2002, Brussel, 2002. 


\section{Balthazar 1994}

Balthazar, T., 'Substitutie van Geneesmiddelen', Vlaams Tijdschrift voor Gezondheidsrecht, 2, Nov.-Dec. 1994, pp. 107-136.

\section{Becker 1983}

Becker, G.S., 'A Theory of Competition Among Pressure Groups for Political Influence', Quarterly Journal of Economics, 98, 1983, pp. 371-400.

\section{Benham and Benham 1975}

Benham, L. and A. Benham, 'Regulating Through the Professions: A perspective on information control', Journal of Law and Economics, 18, 1975, pp. 421-447.

\section{Bentley 1908}

Bentley, A.F., The Process of Government, Chicago, University of Chicago Press, 1908.

\section{BIGE 1996}

BIGE (Belgisch Instituut voor Gezondheidseconomie), Compendium Gezondheidsstatistiek 1996, Brussel, 1996.

\section{BIGE 1998}

BIGE (Belgisch Instituut voor Gezondheidseconomie), Economische en Sociale Aspecten van de Belgische Gezondheidszorg, Brussel, 1998.

\section{BIGE 1999}

BIGE (Belgisch Instituut voor Gezondheidseconomie), Compendium Gezondheidsstatistiek 1999, Brussel, 1999.

\section{Blijleven 1998}

Blijleven, W., 'Working Together on Effectiveness', in: KNMP (Koninklijke Nederlandse Maatschappij ter bevordering der Pharmacie), Pharmacy in the Netherlands: Special issue 1998, The Hague, 1998, p. 44-47.

\section{Boadway and Harris 1977}

Boadway, R. and R. Harris, R., 'A Characterisation of Piecemeal Second Best Policy', Journal of Public Economics, 8, 1977, pp. 169-190.

\section{BOGIN 1999}

Bogin (Bond van de Generieke Geneesmiddelen Nederland), Marktwerking, Deregulering en Wetskwaliteit: Eindelijk ook in de geneesmiddelensector?, Bogin Position Paper, 1999.

\section{Bortolotti and Fiorentini 1999}

Bortolotti, B. and G. Fiorentini, 'Barriers to Entry and the Self-Regulating Professions: Evidence from the market for Italian accountants', in: B. Bortolotti and G. Fiorentini (eds), Organized Interests and Self-Regulation: An economic approach, Oxford University Press, 1999, pp. 131-157. 


\section{Bos 1995}

Bos, D.I., Marktwerking en Regulering: Theoretische aspecten en ervaringen in Nederland en het buitenland, Onderzoeksreeks directie Marktwerking, Ministerie van Economische Zaken, 1995.

\section{Boston Consulting Group 1999}

Boston Consulting Group, Geneesmiddel Verzekerd: Een nieuwe Rol voor Zorgverzekeraars in het Inkoopproces van Geneesmiddelen, 1999.

\section{Buchanan, Tollison and Tullock 1980}

Buchanan, J.M., Tollison, R.D. and Tullock, G. (eds), Toward a Theory of the RentSeeking Society, College Station, Texas A\&M University Press, 1980.

\section{Buchanan and Tullock 1962}

Buchanan, J.M. and G. Tullock, The Calculus of Consent: Logical foundations of constitutional democracy, Ann Arbor, University of Michigan Press, 1962.

\section{Buchanan and Tullock 1975}

Buchanan, J.M. and G. Tullock, 'Polluter's Profits and Political Response: Direct controls versus taxes', American Economic Review, 65, 1975, pp. 139-147.

\section{Carlton and Perloff $\mathbf{2 0 0 0}$}

Carlton, D.W. and J.M. Perloff, Modern Industrial Organization, third edition, Addison-Wesley, 2000.

\section{Cave 1985}

Cave, M., 'Market Models and Consumer Protection', Journal of Consumer Policy, 8, 1985, pp. 335-351.

\section{Coase 1960}

Coase, R., 'The Problem of Social Cost', Journal of Law and Economics, 3, 1960, pp. 144.

\section{Cooter and Ulen 2000}

Cooter, R. and T. Ulen, Law \& Economics, third edition, Addison Wesley Longman, 2000.

\section{Cox and Foster 1990}

Cox, C. and S. Foster, The Costs and Benefits of Occupational Regulation, FTC nomic Issues, 1990.

\section{Cullis and Jones 1998}

Cullis, J. and P. Jones, Public Finance and Public Choice, 2nd. ed., Oxford, Oxford University Press, 1998. 


\section{Curran 1993}

Curran, C., 'The American Experience with Self-Regulation in the Medical and Legal Professions', in: M. Faure, J. Finsinger, J. Siegers and R. Van den Bergh (eds), Regulation of Professions: A law and economics approach to the regulation of attorneys and physicians in the U.S., Belgium, the Netherlands, Germany and the U.K., Antwerpen, MAKLU, 1993, pp. 47-87.

Dales 2002

Dales, J.H., Pollution, Property \& Prices: An essay in policy-making and economics, Edward Elgar, Cheltenham, 2002.

\section{Darby and Karni 1973}

Darby, M. and E. Karni, 'Free Competition and the Optimal Amount of Fraud', Journal of Law and Economics, 16, 1973, pp. 67-88.

\section{Danzon and Chao 2000}

Danzon, P.M. and L. Chao, 'Does Regulation Drive Out Competition in Pharmaceutical Markets?', Journal of Law and Economics, 43, 2000, pp. 311-357.

\section{De Bijl and Van Damme 1996}

De Bijl, P. and E. Van Damme, Regulering en Zelfregulering in Markten met Kwaliteitsonzekerheid, Center for Economic Research, Tilburg, 1996.

\section{De Jong 1998}

De Jong, J.G.A.M., 'Apothekers zijn Ondernemende Zorgverleners', De Accountant, 104, 1998, pp. 612-614.

\section{Demeester 1990}

Demeester, H., 'Twintig Jaar Vestigingswet voor Apotheken', Hospitalia, 1990, pp. 117-119.

\section{Den Hertog 2000}

Den Hertog, J., 'General Theories of Regulation', in: B. Bouckaert and G. De Geest (eds), Encyclopedia of Law and Economics, Volume III: The Regulation of Contracts, Edward Elgar, Cheltenham, 2000, pp. 223-270.

\section{Dingwall and Fenn 1987}

Dingwall, P. and P. Fenn, 'A Respectable Profession? Sociological and Economic Perspectives on the Regulation of Professional Services', International Review of Law and Economics, 7, 1987, pp. 51-64.

\section{Donebedian 1995}

Donabedian, B., 'Self-Regulation and the Enforcement of Professional Codes', Public Choice, 85, 1995, pp. 107-118. 


\section{Evers, Paulus and Boonen 2001}

Evers, S., Paulus, A. and A. Boonen, Integrated Care Across Borders: Possibilities and Complexities', International Journal of Integrated Care, 1, 2001.

\section{Faure and Van den Bergh 1991}

Faure, M. and R. Van den Bergh, 'Self-Regulation of the Professions in Belgium', International Review of Law and Economics, 11, 1991, pp. 165-182.

\section{Federal Public Service Social Security 2001}

Federal Public Service Social Security (http://socialsecurity.fgov.be), Everything You Have Always Wanted to Know about Social Security: 2001 edition, Brussels, 2001.

\section{Friedman and Kuznets 1945}

Friedman, M. and S. Kuznets, Income from Independent Professional Practice, National Bureau of Economic Research, New York, 1945.

\section{Gehrig and Jost 1995}

Gehrig, T. and P. Jost, 'Quaks, Lemons and Self-Regulation: A Welfare Analysis', Journal of Regulatory Economics, 7, 1995, pp. 309-325.

\section{Goyder 1998}

Goyder, D.G., EC Competition Law, third edition, Clarendon Press, Oxford, 1998.

\section{Green 1961}

Green, H. A. J., 'The Social Optimum in the Presence of Monopoly and Taxation', Review of Economic Studies, 29, 1961, pp. 66-77.

\section{Grossman 1981}

Grossman, S., "The Informational Role of Warranties and Private Disclosure about Product Quality', Journal of Law and Economics, 24, 1981, pp. 461-483.

\section{Hägg 1997}

Hägg, P.G.T., 'Theories on the Economics of Regulation: A survey of the literature from a European perspective', European Journal of Law and Economics, 4, 1997, pp. 337-370.

\section{Hahn 1989a}

Hahn, R.W., 'Economic Prescriptions for Environmental Problems: How the patient followed the doctor's orders', Journal of Economic Perspectives, 3, 1989, pp. 95-114.

\section{Hahn 1989}

Hahn, R.W., 'A New Approach to the Design of Regulation in the Presence of Multiple Objectives', Journal of Environmental Economics and Management, 17, 1989, pp. 195-211. 


\section{Hante-Domas 2003}

Hantke-Domas, M., 'The Public Interest Theory of Regulation: Non-Existence or Misinterpretation?', European Journal of Law and Economics, 15, 2003, pp. 165-194.

\section{Hatta 1977}

Hatta, T., 'A Theory of Piecemeal Policy Recommendations', Review of Economic Studies, 44, 1977, pp. 1-21.

\section{Hombroeckx 2000}

Hombroeckx, L., 'Legal Issues of the Exercise of Pharmacists', in: S. Callens (ed.), Chapters on Pharmaceutical Law, Intersentia, 2000, pp. 181-190.

\section{Horsten 1996-1997}

Horsten, M., Postorderfarmacie in Nederland 1993-1994: Een studie over fair competition, mimeo, 1996-1997.

\section{IHS 2003}

IHS (Institut für Höhere Studien), Economic Impact of Regulation in the Field of Liberal Professions in Different Member States: Regulation of Professional Services, Study for the European Commission, Vienna, 2003.

\section{Indecon - London Economics 2003}

Indecon - London Economics, Indecon's Assessment of Restrictions in the Supply of Professional Services, Prepared for the Competition Authority by Indecon International Economic Consultants - London Economics, Dublin - London, 2003.

\section{Keenan and Rubin 1988}

Keenan, D, and P. Rubin, 'Shadow Interest Groups and Safety Regulation', International Review of Law and Economics, 8, 1988, pp. 21-36.

\section{Kleiner and Kudrle 2000}

Kleiner, M.M. and R.T. Kudrle, 'Does Regulation Affect Economic Outcomes? The Case of Dentistry', Journal of Law and Economics, 43, 2000, pp. 547-582.

\section{Knieps 2001}

Knieps, G., Wettbewerbsökonomie, Springer-Verlag, Berlin, 2001.

\section{KNMP 1993}

KNMP (Koninklijke Nederlandse Maatschappij ter bevordering der Pharmacie), Beroepscode en Gedragsregels van de KNMP, Den Haag, 1993.

\section{KNMP 1996}

KNMP (Koninklijke Nederlandse Maatschappij ter bevordering der Pharmacie), Nederlandse Apotheeknorm: Norm voor de farmaceutische zorgverlening door de openbare apotheek, Den Haag, 1996. 


\section{KNMP 1997}

KNMP (Koninklijke Nederlandse Maatschappij ter bevordering der Pharmacie), Minimum Vestigingsnorm voor Apotheken, Den Haag, 1997.

\section{KNMP 2000a}

KNMP (Koninklijke Nederlandse Maatschappij ter bevordering der Pharmacie), Professioneel Statuut Openbaar Apotheker en Ziekenhuisapotheker, Den Haag, 2000.

\section{KNMP 2000b}

KNMP (Koninklijke Nederlandse Maatschappij ter bevordering der Pharmacie), Farmacie in Balans, Den Haag, 2000.

\section{KNMP 2001}

KNMP (Koninklijke Nederlandse Maatschappij ter bevordering der Pharmacie), Beroepscode, Den Haag, 2001.

\section{KNMP 2002}

KNMP (Koninklijke Nederlandse Maatschappij ter bevordering der Pharmacie), Nederlandse Apotheeknorm: Norm voor de farmaceutische zorgverlening door de openbare apotheek, Den Haag, 2002.

\section{Krueger 1974}

Krueger, A.O., 'The Political Economy of the Rent-Seeking Society', American Economic Review, 64, 1974, pp. 291-303.

\section{Lancaster 1966}

Lancaster, K., 'A New Approach to Consumer Theory', Journal of Political Economy, 74, 1966, pp. 132-157.

\section{Lazzarini 2001}

Lazzarini, S.G. and P. Carvalho de Mello, 'Governmental versus Self-Regulation of Derivative Markets: Examining the U.S. and Brazilian experience', Journal of Economics and Business, 53, 2001, pp. 185-207.

\section{Leenen 1991}

Leenen, H.J.J., Handboek Gezondheidsrecht: Gezondheidszorg en Recht, 2 druk, Samson, Amsterdam, 1991.

\section{Leenen 2002}

Leenen, H.J.J., 'Apotheker hoort niet in WGBO thuis', Pharmaceutisch Weekblad, 2002, vol. 137, nr. 22, 2002, pp. 786-787.

\section{Leland 1979}

Leland, H.E., 'Quaks, Lemons and Licensing: A Theory of Minimum Quality Standards', Journal of Political Economy, 87, 1979, pp. 1328-1346. 


\section{Lipsey and Lancaster 1957}

Lipsey, R.G. and K. Lancaster, 'The General Theory of Second Best', Review of Economic Studies, 24, 1957, pp. 11-32.

Maks, Philipsen and Faure 2001

Maks, J.A.H., Philipsen, N.J. and M.G. Faure, '(Zelf-) Regulering van de Apothekersmarkt in Nederland', Maandschrift Economie, 65, 2001, pp. 208-227.

\section{Maloney 1982}

Maloney, M.T. and R.E. McCormick, 'A Positive Theory of Environmental Quality Regulation, Journal of Law and Economics, 25, 1982, pp. 99-123.

\section{Mamuth 1992}

Mamuth, H.A., Markteconomie: analyse en evaluatie, derde editie, Universiteit Maastricht, Utrecht, 1992.

\section{Mattei 1994}

Mattei, U., 'Efficiency in Legal Transplants: An Essay in Comparative Law and Economics', International Review of Law and Economics, 14, 1994,pp. 3-19.

McNutt 2002

McNutt, P.A., The Economics of Public Choice, second edition, Edward Elgar, Cheltenham, 2002.

\section{MDW 1995}

MDW (Marktwerking Deregulering en Wetgevingskwaliteit), Domeinmonopolie Advocatuur: Rapport 27 juni 1995, Den Haag, 1995.

\section{MDW 1997}

MDW (Marktwerking Deregulering en Wetgevingskwaliteit), Concurrentie en Prijsvorming in de Gezondheidszorg: Rapport 23 mei 1997, Den Haag, 1997.

\section{MDW 1999}

MDW (Marktwerking Deregulering en Wetgevingskwaliteit), Geneesmiddelen: Rapport 1 december 1999, Den Haag, 1999.

\section{Milgrom and Roberts 1992}

Milgrom, P. and J. Roberts, Economics, Organization and Management, Englewood Cliffs, NJ: Prentice-Hall International, 1992.

\section{Miller 1985}

Miller, J.C., 'The FTC and Voluntary Standards: Maximizing the Net Benefits of SelfRegulation', The Cato Journal, 4, 1985, pp. 897-903. 
Ministerie van Sociale Zaken en Werkgelegenheid 1982

Ministerie van Sociale Zaken en Werkgelegenheid, Toetredingsreguleringen bij Vrije Beroepen: Een voorstudie bij zes beroepsgroepen; Literatuurstudie: vrije beroepen en professionalisering, IVA-Tilburg, Instituut voor Sociaal-Wetenschappelijk Onderzoek van de Katholieke Hogeschool te Tilburg, 1982.

Ministerie van Volksgezondheid 1998

Ministerie van Volksgezondheid, Welzijn en Sport, Health Insurance in the Netherlands, fourth edition, The Hague, 1998.

\section{Ministerie van Volksgezondheid, Welzijn en Sport 1999}

Ministerie van Volksgezondheid, Welzijn en Sport, Een Helder Recept: Bevindingen en adviezen van de Begeleidingscommissie Uitvoering Geneesmiddelenbeleid, Den Haag, 1999.

\section{Ministerie van Volksgezondheid 2002}

Ministerie van Volksgezondheid, Welzijn en Sport, Ziektekostenverzekeringen in Nederland: Stand van zaken per 1 januari 2002, Den Haag, 2002.

Ministerie van Volksgezondheid, Welzijn en Sport, Ministerie van Economische Zaken 1997

Ministerie van Volksgezondheid, Welzijn en Sport, Ministerie van Economische Zaken, Mededinging in de Gezondheidszorg: Rapport van de projectgroep mededinging gezondheidszorg, Den Haag, 1997.

\section{Moore 1961}

Moore, T.G., 'The Purpose of Licensing', Journal of Law and Economics, 4, 1961, pp. 93-117.

\section{Moss 1998}

Moss, F., 'Legislation on Medication in the Netherlands', in: KNMP (Koninklijke Nederlandse Maatschappij ter bevordering der Pharmacie), Pharmacy in the Netherlands: Special issue 1998, The Hague, 1998, pp. 11-13.

\section{Mullan 2000}

Mullan, K., Blackstone's Pharmacy Law \& Practice, Blackstone Press Limited, London, 2000 .

\section{Nefarma 2000}

Nefarma (Nederlandse Vereniging van de Research-georiënteerde Farmaceutische Industrie), Jaarverslag 2000/Annual Report 2000, Den Haag, 2000.

\section{Nefarma 2001}

Nefarma (Nederlandse Vereniging van de Research-georiënteerde Farmaceutische Industrie), Jaarverslag 2001/Annual Report 2001, Den Haag, 2001. 


\section{Nelson 1970}

Nelson, P., 'Information and Consumer Behavior', Journal of Political Economy, 78, 1970, pp. 311-329.

$\mathrm{Ng} 1977$

Ng, Y., 'Towards a Theory of Third Best', Public Finance, 32, 1977, pp. 1-15.

Ng 1983

Ng, Y., Welfare Economics, MacMillan, London, 1983.

\section{NIVEL 1994}

NIVEL, Beroepen in de Extramurale Gezondheidszorg 1994: Aanbod van beroepsbeoefenaren en samenwerkingsverbanden in de extramurale gezondheidszorg in de periode 19801993, De Tijdstroom, Utrecht, 1994.

\section{NIVEL 1996}

NIVEL, Literatuurstudie Ziektekostenverzekering in Europees Perspectief, Utrecht, 1996

\section{NIVEL 1998}

NIVEL, Arbeidsmarkt Farmakundigen, Utrecht, 1998.

NIVEL, NZi en OSA 1998

NIVEL, NZi en OSA, Rapportage Arbeidsmarkt Zorgsector, Ministerie van VWS, Den Haag, 1998.

NMa 2002a

NMa (Nederlandse Mededingingsautoriteit), Anmual Report of NMa and DTe for 2001, The Hague, 2002.

\section{NMa 2002b}

NMa (Nederlandse Mededingingsautoriteit), Richtsnoeren voor de Zorgsector, Den Haag, 2002.

\section{Nys 1981-82}

Nys, H., 'De Nieuwe Criteria voor de Vestiging van Apotheken', Rechtskundig Weekblad, 1981-82, pp. 2567-2576.

\section{OECD 2002}

OECD, 'Competition and Regulation Issues in the Pharmaceutical Industry', $O E C D$ Journal of Competition Law and Policy, 4, 2002, pp. 103-222.

\section{OFT 2001}

OFT (Office of Fair Trading), Competition in Professions: A report by the Director General of Fair Trading, London, 2001. 


\section{OFT 2003}

OFT (Office of Fair Trading), The Control of Entry Regulations and Retail Pharmacy Services in the UK: A report of an OFT market investigation, Volumes 1-3, London, 2003.

\section{Ogus 1994}

Ogus, A.I., Regulation: legal form and economic theory, Clarendon Press, Oxford, 1994.

\section{Ogus 2000}

Ogus, A., 'Self-Regulation', in: B. Bouckaert and G. De Geest (eds), Encyclopedia of Law and Economics, Volume V: The Economics of Crime and Litigation, Edward Elgar, Cheltenham, 2000, pp. 587-602.

\section{Olson 1965}

Olson, M., The Logic of Collective Action: Public goods and the theory of groups, Harvard University Press, Cambridge, 1965.

\section{Paulus, e.a. 1999}

Paulus, A., Fecher, F., Van der Made, J., Evers, S. and A. Boonen, Cross Border Care Between Belgium and the Netherlands: A health economics and law perspective, first draft version, paper for the Euregional Symposium: Law and Cross Border Economics (Maastricht, November 17 and 18, 1999), 1999.

\section{Peers 2000}

Peers, J. (Commissie Peers), Gezondheidszorg in België: Uitdagingen en Opportuniteiten, rapport Commissie Peers, Brussel, 2000.

\section{Peeters 2003}

Peeters, M., Emissions Trading as a New Dimension to European Environmental Law: The political agreement of the European Council on greenhouse gas allowance trading', European Environmental Law Review, 12, 2003, 82-92

\section{Peltzman 1976}

Peltzman, S., 'Toward a More General Theory of Regulation', Journal of Law and Economics, 19, 1976, pp. 211-240.

\section{Philipsen and Faure 2002a}

Philipsen, N.J. and M.G. Faure, 'The Regulation of Pharmacists in Belgium and the Netherlands: In the Public or Private Interest?', Journal of Consumer Policy, 25, 2002, pp. 155-201.

\section{Philipsen and Faure 2002b}

Philipsen, N.J. and M.G. Faure, 'Insurance of the Costs of Pharmaceuticals in the Netherlands: A Law and Economics Perspective', The Geneva Papers on Risk and Insurance, 27, 2002, pp. 609-625. 


\section{Porsius 2002}

Porsius, A.J., 'De arts en de indicatie op recept', Pharmaceutisch Weekblad, vol. 137, nr. 9, 2002, pp. 298-299.

\section{Posner 1974}

Posner, R.A., 'Theories of Economic Regulation', Bell Journal of Economics and Management Science, 5, 1974.

\section{Posner 1979}

Posner, R.A., 'The Chicago School of Antitrust Analysis', University of Pennsylvania Law Review, 127, 1979, pp. 925-948.

\section{Posner 1998}

Posner, R.A., Economic Analysis of Law, fifth edition, Aspen Law \& Business, 1998.

\section{PriceWaterhouseCoopers 1999}

PriceWaterhouseCoopers, The Dutch Drug Expenditure and Policy in a European Context: A quick scan comparison of the Dutch expenditure on drugs and the underlying policy in several European countries, The Hague, 1999.

\section{Reder 1982}

Reder, M.W., 'Chicago Economics: Permanance and Change', Journal of Economic Literature, 20, 1982, pp. 1-38.

\section{Reekie 1997}

Reekie, W.D., 'Cartels, Spontaneous Price Discrimination and International Pharmacy Retailing', International Journal of the Economics of Business, Vol. 4, No. 3, 1997, pp. 279-285.

\section{RVZ 1998}

RVZ (Raad voor de Volksgezondheid en Zorg), Farmaceutische Zorg door Arts en Apotheker, Zoetermeer, 1998.

\section{Sahner e.a. 1989}

Sahner, H., Herrmann, H., Rönnau, A. und H. Trautwein, Zur Lage der Freien Berufe 1989 (Teil II), Forschungsinstitut Freie Berufe, Universităt Lüneburg, Lüneburg, 1989

\section{Scarpa 1999}

Scarpa, C., "The Theory of Quality Regulation and Self-Regulation: Towards an application to financial markets', in: B. Bortolotti and G. Fiorentini (eds), Organized Interests and Self-Regulation: An economic approach, Oxford University Press, 1999, pp. 236-260.

\section{Scherer and Ross 1990}

Scherer, F.M. and D. Ross, Industrial Market Structure and Economic Performance, 2nd print, Houghton Mifflin, Boston, 1990. 


\section{Schüsler-Van Hees e.a. 1998}

Schüsler-Van Hees, M.T.I.W., Essink, R.T.G.M. and P.A.G.M. de Smet, 'Pharmaceutical Patient Care in the Netherlands', in: KNMP (Koninklijke Nederlandse Maatschappij ter bevordering der Pharmacie), Pharmacy in the Netherlands: Special issue 1998, The Hague, 1998, p. 33-35.

\section{SFK 1998}

SFK (Stichting Farmaceutische Kengetallen), Data en Feiten 1998: Kostenontwikkeling van de farmaceutische hulp, Den Haag, 1998.

\section{SFK 1999}

SFK (Stichting Farmaceutische Kengetallen), Data en Feiten 1999: Kostenontwikkeling van de farmaceutische hulp, Den Haag, 1999.

\section{SFK 2000}

SFK (Stichting Farmaceutische Kengetallen), Data en Feiten 2000, Den Haag, 2000.

\section{SFK 2001}

SFK (Stichting Farmaceutische Kengetallen), Data en Feiten 2001, Den Haag, 2001.

\section{SFK 2002}

SFK (Stichting Farmaceutische Kengetallen), Data en Feiten 2002, Den Haag, 2002.

\section{Shaked and Sutton 1981}

Shaked, A. and J. Sutton., 'The Self-Regulating Profession', Review of Economic Studies, 48, 1981, pp. 843-862.

\section{Shapiro 1983}

Shapiro, C., 'Premiums for High Quality Products as Rents to Reputation', Quarterly Journal of Economics, 1983, pp. 659-680.

\section{Shapiro 1986}

Shapiro, C., 'Investment, Moral Hazard and Occupational Licensing', Review of Economic Studies, 53, 1986, pp. 843-862.

\section{Shavell 1984}

Shavell, S., 'Liability for Harm versus Regulation of Safety', Journal of Legal Studies, 13,1984 , pp. 357-374.

\section{Shavell 1979}

Shavell, S., 'On Moral Hazard and Insurance', Quarterly Journal of Economics, 1979, pp. 541-562.

\section{Skaggs and Carlson 1996}

Skaggs, N.T. and J.L. Carlson, Microeconomics: Individual Choice and its consequences, second edition, Blackwell Publishers, 1996. 


\section{Stephen and Love $\mathbf{2 0 0 0}$}

Stephen, F.H. and J.H. Love, 'Regulation of the Legal Profession', in: B. Bouckaert and G. De Geest (eds), Encyclopedia of Law and Economics, Volume III: The Regulation of Contracts, Edward Elgar, Cheltenham, 2000, pp. 987-1017.

\section{Stigler 1971}

Stigler, G.J., 'The Theory of Economic Regulation', Bell Journal of Economics and Management Science, 2, 1971, pp. 3-21.

\section{Stiglitz 2002}

Stiglitz, J.E., 'Information and the Change in the Paradigm in Economics', American Economic Review, 92, 2002, pp. 460-501.

\section{Sykes 2002}

Sykes, A.O., 'TRIPS, Pharmaceuticals, Developing Countries and the Doha Solution', Chicago Working Papers in Law and Economics (Second Series), Chicago, 2002.

\section{Temple Lang 2000}

Temple Lang, J., The Principle of Essential Facilities in EC Competition Law - The Position since Bronner', Journal of Network Industries, 1, 2000, pp. 375-405.

\section{Ten Hoopen 2001}

Ten Hoopen, M.M., Zorg op Recept: De relatie apotheker-geneesmiddelengebruiker in veranderend maatschappelijk en juridisch perspectief, Boom Juridische uitgevers, Maastricht, 2001.

\section{Tinke 1998}

Tinke, J.L., 'How Does the Pharmacist Earn the Right Fee for the Job?', in: KNMP (Koninklijke Nederlandse Maatschappij ter bevordering der Pharmacie), Pharmacy in the Netherlands: Special issue 1998, The Hague, 1998, pp. 40-43.

\section{Tirole 1992}

Tirole, J., The Theory of Industrial Organization, Fifth printing, Cambridge Massachusetts, MIT Press, 1992.

\section{TNO 1998}

TNO Preventie en Gezondheid, Marktwerking en Mededinging in de Geneesmiddelensector, TNO-rapport 98.029, Leiden, 1998.

\section{Tollison 1982}

Tollison, R.D., 'Rent Seeking: A Survey', KYKLOS, 35, 1982, pp. 575-601.

\section{Tollison and Congleton 1995}

Tollison, R.D. and R.D. Congleton (eds.), The Economic Analysis of Rent Seeking, The International Library of Critical Writings in Economics 49, Edward Elgar Publishing Ltd., 1995. 


\section{Truman 1951}

Truman, D.B., The Government Process: Political interests and public opinion, New York: Knopf, 1951.

\section{Tullock 1967}

Tullock, G., 'The Welfare Costs of Tariffs, Monopolies, and Theft', Western Economic Journal, 5, 1967, pp. 224-232.

\section{Van Dalen 1998}

Van Dalen, 'The Training and Work of Pharmacists' Assistants', in: KNMP (Koninklijke Nederlandse Maatschappij ter bevordering der Pharmacie), Pharmacy in the Netherlands: Special issue 1998, The Hague, 1998, pp. 86-88.

\section{Van den Bergh 1993}

Van den Bergh, R., 'Self-Regulation in the Medical and Legal Professions and the European Internal Market in Progress', in: M. Faure, J. Finsinger, J. Siegers and R. Van den Bergh (eds), Regulation of Professions: A law and economics approach to the regulation of attorneys and physicians in the U.S., Belgium, the Netherlands, Germany and the U.K., Antwerpen, MAKLU, 1993, pp. 21-43.

\section{Van den Bergh 1997}

Van den Bergh, R., Economische Analyse van het Mededingingsrecht: Een terreinverkenning, tweede herziene druk, Gouda Quint, Deventer, 1997.

\section{Van den Bergh 1999}

Van den Bergh, R., 'Self-Regulation of the Medical and Legal Professions: Remaining Barriers to Competition and EC-Law', in: B. Bortolotti and G. Fiorentini (eds), Organized Interests and Self-Regulation: An economic approach, Oxford University Press, 1999, pp. 89-130.

\section{Van den Bergh and Camesasca 2001}

Van den Bergh, R.J. and P.D. Camesasca, European Competition Law and Economics: A comparative perspective, Erasmus University Rotterdam, Intersentia, 2001.

\section{Van der Mei 2001}

Van der Mei, A.P., Free Movement of Persons Within the European Community: Crossborder access to public benefits, Maastricht, 2001.

\section{Van der Mijn 1989}

Van der Mijn, W.B., Beroepenwetgeving in de Gezondheidszorg, derde druk, Kluwer, Deventer, 1989. 


\section{Van Heest 1998}

Van Heest, M., 'The Royal Dutch Association for the Advancement of Pharmacy: The Society for all Dutch Pharmacists', in: KNMP (Koninklijke Nederlandse Maatschappij ter bevordering der Pharmacie), Pharmacy in the Netherlands: Special issue 1998, The Hague, 1998, pp. 5-6.

\section{Van Velthoven and Van Wijck 2001}

Van Velthoven, B.C.J. and P.W. van Wijck, Recht en Efficiëntie: Een inleiding in de economische analyse van het recht, derde druk, Kluwer, Deventer, 2001.

\section{Varian 1984}

Varian, H.R., Microeconomic Analysis, second edition, Norton, New York, 1984

\section{Venema 1998}

Venema, F.J., 'Community Pharmacy in the Netherlands', in: KNMP (Koninklijke Nederlandse Maatschappij ter bevordering der Pharmacie), Pharmacy in the Netherlands: Special issue 1998, The Hague, 1998, pp. 14-17.

\section{Verbogt 1997}

Verbogt, S., Hoofdstukken over Gezondheidsrecht, zesde druk, Gouda Quint BV, Deventer, 1997.

\section{Viscusi e.a. 2000}

Viscusi, J.K., Vernon, J.M. and J.E. Harrington, Economics of Regulation and Antitrust, third edition., MIT press, Cambridge, 2000.

\section{Von der Schulenburg 1986}

Von der Schulenburg, J.M. Graf, 'Regulatory Measures to Enforce Quality Production of Self-Employed Professionals: A Theoretical Study of a Dynamic Market Process', in: Von der Schulenburg, J.M. Graf and G. Skogh (eds.), Law and Economics and the Economics of Legal Regulation, Dordrecht, Kluwer Academic Publishers, 1986, pp. 133-147.

\section{Wailliez 2001-2002}

Wailliez, G., 'Reactie. Antwoord op de annotatie "Overgangsrecht inzake de aanpassing van de strafrechtelijke geldboeten aan de euro"', Rechtskundig Weekblad, 2001-2002, p. 1514.

\section{Ziekenfondsraad 1996}

Ziekenfondsraad, Uitkomst van Overleg ZN/KNMP, 1996. 


\section{CURRICULUM VITAE}

Nicolaas Johannes (Niels) Philipsen was born on 24 September 1975 in Venray, the Netherlands. He obtained his gymnasium degree (secondary school) from the Katholieke Scholengemeenschap Jerusalem in Venray in 1993. In September 1993 he went to Maastricht to study Economics at the Faculty of Economics and Business Administration of Maastricht University, with specialisations in microeconomics and competition policy. He received his Master's degree in May 1998.

In July 1998 Niels Philipsen started his $\mathrm{PhD}$ research into the regulation of and by pharmacists at the Faculty of Law of Maastricht University. This research was part of the NWO program 'Competition and Regulation'. Since then he has been working as a researcher at METRO, the Maastricht European Institute for Transnational Legal Research. His research and teaching interests include law and economics, regulation of professions and competition policy. He is a member of the European Association of Law and Economics and the Ius Commune Research School. In June, July and August 2003 he worked in Brussels for the European Commission (DG Competition) on a project concerning the regulation of the liberal professions in the EU. 
A book series devoted to the common foundations of the European legal systems. The lus Commune Europaeum series includes comparative legal studies as well as studies on the effect of treaties within national legal systems. All areas of the law are covered. The books are published in various European languages under the auspices of MEIRO, the institute for Transnational Legal Research at Maastricht University.

This book examines the regulation of pharmacists in the Netherlands and Belgium from the perspective of law and economics. It starts with an extensive and accessible overview of the economic literature with respect to the regulation (induding selfregulation) of liberal professions. Subsequently, this book analyses the extent to which the current regulation of Dutch and Belgian pharmacists serves the public interest and the extert to which this regulation is a result of rent-seeking behavour by privateinte: rest groups: The author concludes that some regulation, notably with respect to advertising. design of the pharmacy, establishment of pharmacies and drug prices, does not seem to serve the public interest. Moreover, he criticises the regulation of reimbursement for the pharmacist, which in both countries is still linked to the pharmacist's monopoly in the distribution of drugs, despite new tasks of the pharmacist in the fieid of pharmaceutical care In addition to a theoretical analysis, the author carries out an empirical research of rent-seeking behaviour in the pharmaceutical market.

Although the book studies the situation in the Netherlands and in Belgium, its conclusions will certainly apply to other countries and other professions. The book will therefore be of interest to all economists, lawyers and practitioners interested in regulation of the liberal profersions as well as practitioners and academics working in the field of health care.

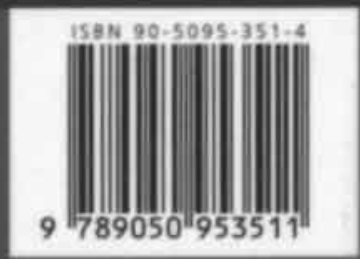

